\title{
Einfiührungsgejet5. *)
}

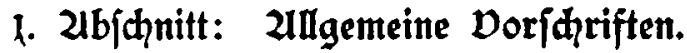

I. $\mathfrak{A r t .} 1$ (‥ 1). Laకి $\mathfrak{B H B S . ~ t r i t t ~ m i t ~ b e n t ~}$ in Iraft.

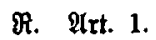

Das $\mathscr{B B B}$. tritt ant cinem burh Railerliđge Betorbnung mit Bujtimmung bes Bunbešrathes feitzulebenden Tage, pãteftens am gleidzettig mit eitem Befege, Getr. Ulenberungen bes Geriditsverfafiunggigefebes, ber (5)B. unb ber RontD., einem Beiese iber bie 8wartgäber|teige= rung unb bie Bmangsvertwaltung, einer \&rumbbituorbmung unb eitem Bejege ltber bie Angelegenbeitent ber freitwilligen Bseriditgbarteit in Strajt.

Motive 1, Protofolle 113, RomBeriat 309.

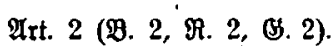

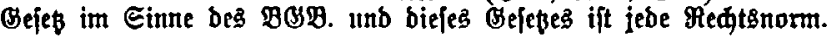

Motive 1, \$rotololle 113, 568 .

I $\mathfrak{A}$ rt. 3.

Soweit in bem $B \leftrightarrow B$. oder in biefem Gejege bie Megelung ben Lanbeşgejesen vorbehalten ober bejtimmt ift, bab bie Lanbesgejęe unberührt bleibelt

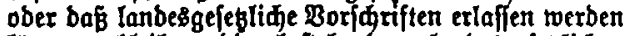
töntten, bleiben bie beftehenben Ianbesgefeblidien Boridriften in straft unb tonnen neue Intbesgejeß lidue Borfdriftert erlaffen twerben; cin nebert bem BGP. unb biejem dejege in Praft bleibenbes

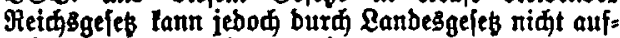
gehoben ober geănbert twerben.

\section{9}

I Int. 4.

Menn in Feidjegejegen ober in Ranbeşgefezen auf Borfdriften bertwiejen ift, welde burd bas BBP. ober biefes Befes auber fraft gefebt toerben,

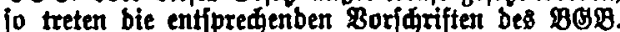
vber biejes Gefeges an bie Ctelle jener Borjuriften.
अ. Art. 1 .

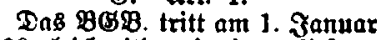
1900 gleidzeiti 8 mit eintem (s)ejese, betr. Aenderungen bes Bertidts: verjaffungsg gejeses, ber (EBD. und ber SontD., einent Befese aber bie Bwangsిberjteigerung uno bie Zroang goverwaltutg, einer Srunb= budjorbnung unb einen Befefe über bie $\mathfrak{A}$ ngelegenbeiten ber frei= willigen Bseridtabarteit it Straft.

Motive 1 f., Rrotololle 114.

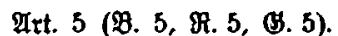

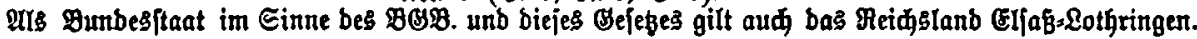
Plotive 2, Protololle -.

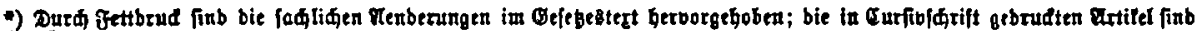
it Brotfat gelommet. 


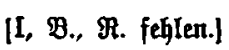

RomBorlage Art. 5a. (G. 6).

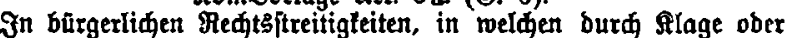

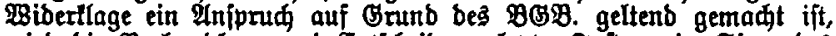
wirb bie Berhanblung unb Entfareibung lester ßnitand im Sinne bes

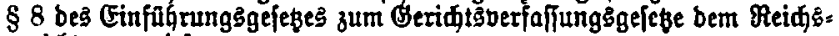
geridit zugerwiejen.

@ten:eridte 344.

Art. 6 (B. - , R. - , G. $\rightarrow$.

Eine Ehefrau theilt nicht den Wohnsitz des Ehemannes, iwenn auf beständige Trennung von Tisch und Bett erkannt ist.

Motive 2, Protololle 114 f.

Art. 7 (B. - R. 一, G. - ).

Die Vorschriften des BGB. über die Wirkungen eines gerichtlichen Veräusserungsverbotes finden auf ein Veräusserungsverbot, welches von einer anderen Behörde als einem Gerichte innerhalb der Grenzen der Zuständigkeit derselben erlassen ist, entsprechende Anwendung.

Motibe 2, Brototolle 115.

Art. 8 (B. - R. - , G. 一).

Die Vorschriften der $\$ \S 692-700$ des BGB. finden auf Aktien, welche auf Inhaber lauten, entsprechende Anwendung.

Plotibe 2, Brototolfe 115.

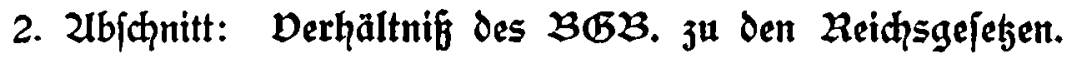

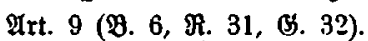

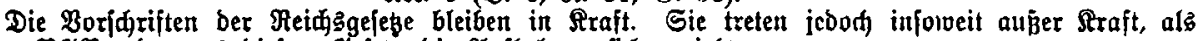

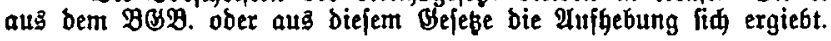

Mlotive 3 f., Frotololle 115 ff.

I Ort. 10

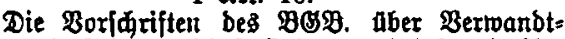

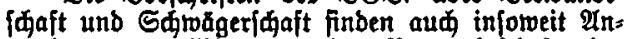
menbung, ats Birtungen ber Bertwanbtifaft ober

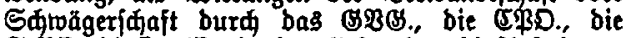
StPD., bie SiontD. ober bas (s) ejeß, betr. bie Anfedtung

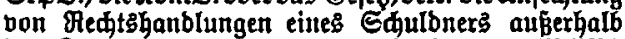
bes ९onfursberfahrens $\mathfrak{v}$. 21. Jufi 1879 (MGgl. 5. 277) beftimmt finb.

B. Ârt. 7 ( $\mathfrak{R} .32$, B. 33).

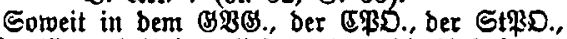
ber SontD. unb in bem Gejebe, betr. Die Anjedtung

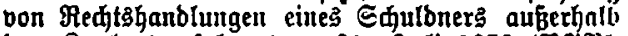

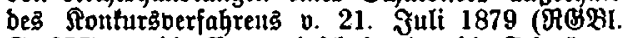
5. 277) an bie Bermantotjdaft ober bie Samăgcr: ifaft redjtlidje frolgen getnïpft futb, finben bie

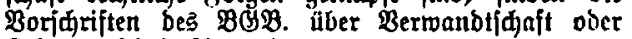

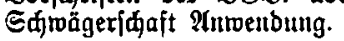

Motive 4, Prototolle 117.

1 Mirt. 11-15,

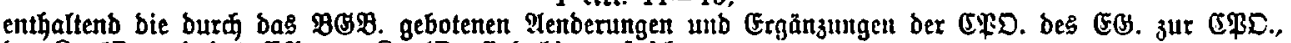
Der BoutD. und bes GO. zur RontD., find bier geftridient.

\section{I $\mathfrak{A}$ זt. 16.}

Die Boridriftent bes Stज̈g. werben burd bie nadjolgenben Borfariften naw Maß̈gabe ber ben leğteren gegebenen Bezeidinungen erję̧t und ergănzt:

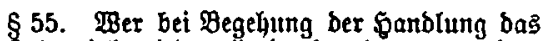
12. Lebeusjiahr nidht bollenbet hat, tann roegen ber= felben niaft frafreditlia verfolgt werden. Begen berifelsen tönnen jebod nađ Mapgabe ber lanbeš = gejebliden Boridjriften bie zur Bejierung und Beauffiðtigung gerigneten Dabregeln getroffen werben. Dite llnterbringung in eine famtlie, Erziehungsanjtalt oder Bejierungsanitalt fann nur eriolgen, nahbem bura Bejalup bes Bormberiaté bic Begehung Der \$antolung feît= geftellt und bie llnterbringung für zuläffigerflärt ijt.
タ. $\mathfrak{A r t .} 8(\Re .33$, (S. 34).

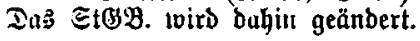

J. $3 \mathrm{~m} \S 34$ Rr. 6 werden Dic Morte: „2or munb, Rebenbonnunb, Rurator, geridtlider Beijtand ober Mitglied einte Familienrathes ${ }^{2}$ eriest burd bic $\mathfrak{B}$ orte:

Bormulb, Begenvormunt, Fileger, Beiftant ber Mutter, Mitglié cintes Familientathes ober Murator".

II. IIt bie Stelle bes $\$ 55$ treten folgenbe $\mathfrak{B u r}$ (đ)riften: *)

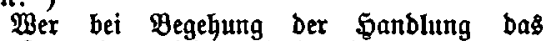
12. Debensjafr niajt volfentbet hat, tann wegen berfelben niat ftrajredtlid veriolgt werben.

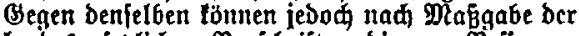
lanbesgefegliden Borjariften bie zur Befferung und Beauifid)tigung geeigneten Daß́regelı ge= trofien werben. Die unterbringung in cinte framilie Erziełungşanitalt ober Belferungşanftalt

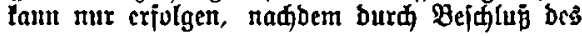

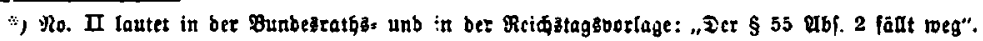


5 65. Der Berlebte, welđ́er baş 18. Rebeng: jahr bollenbet Gat, ift jellbftảnbig zu bem Qntrage auf Beitrafung beredtigt. Colange ber $\mathfrak{B e r}=$

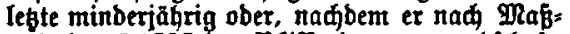

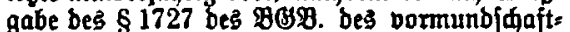
liden Eđubes für beburfitig exflärt worben, bie Bormunb/4ajt nidt beenbigt ift, hat ber gejebliđạe Bertreter beffelben, unabhängig von Der eigenen $\mathfrak{B} e f u g r t i b$ bes Berleßsten, bas Redt, ben $\mathscr{A}$ ntrag zu ftellen.

Bei Đer|onen, welde twegen Geiftestrant: heit entrober entmunbigt ober nad Mabiabe

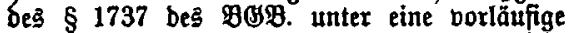
Bormunojuaft geftellt jint, ift ber gejezliae Bertreter der zur Etellung bes 2Intrages $\mathfrak{B}_{e}=$ reditigte.

$\$ 170$ a. Wit Selbitraje bisె zu 1000 MR. ober Befängnißitraje biş zu 1 Jahre mirb Geitraft:

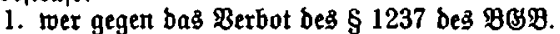
eine Che fáliest;

2. Die Frau, welhe gegen bas Berbot bes

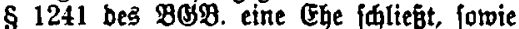

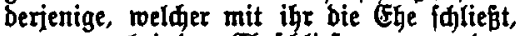
wenn er bei ber Egefaliebung bon bem Ginberniffe Renntniō hatte.

8 195. Sinb Ehefrauen beleibigt roorben, io haben fowohl bie Beleidigtent als beren (Ege= männer bas Medjt, auf Beftrajung anzutragen.

\$ 237. Wer eine minberjährige, unbereheliđte frauenşperfon mit ihrem $\mathfrak{k i f l e n , ~ j e b o d ~ o h n e ~}$ Einwilligung bes gejegliden Bertreters ober beșjentigent Eltemtheiles, beffen Cinwilligung zur Ehefaliebung erforberlid ift, entfilart, um fie zur lnzudt ober zur Che zu bringen, wirb mit Bsefängniß beftraft.

Die ઊerfolgung tritt nur auf $\mathfrak{X}$ trag ein.

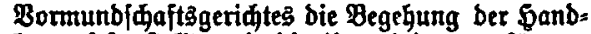
lung feftgeftellt unb bie Unterbringung für zu= Ialjịg extlărt ift.

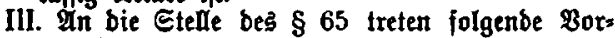
ifriften:

Der Berleß̧te, weld̄er baș 18. Lebers: jahr vollendet hat, ift jelbitänbig zu bem $\mathfrak{A n}$ = trage auf Beftrafung beredtigt. Solange er minberjābrig ijt, hat unab̧ăngis von feiner

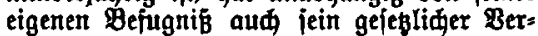
treter bas Medt, ben Alntrag ju itellen.

3ft Der Berleß̧te geiđājtక̈unjāhig ober hat er bas 18. ¿ebensjałr nođ nimt vollenbet, jo ijit fein gejebliduer Bertreter ber zur Etellung Des Intrages Bereditigte.

IV. $\mathfrak{A}$ క $\S 145$ a wirb jolgenbe Boridrift eingeitellt: Wer im Yulanbe SAjulbver|dreibungen auf best Ingaber, in benten bie Jahlung einer beftimmten Geldfumme beriprodien wirb, ofne bie eriorberlide (Benebmigung bes Bunbes: rathes ausptell und in Bertehr bringt, wirb mit einer Belbjtraje beftraft, bie bem 5 . Theile bes Rennwerthes ber ausgegebenen छquld: berfकreibungen gleiđfommen tann, niubeitens aber 300 git. beträgt.

V. $3 \mathfrak{m} \$ 171$ 9bi. 1. und थٔbj. 3 twerben bie Worte: "allfgelölt, fiur ungültig ober niatig ertlärt worben ifit eriebt burm bie 130 rte: "aufgelofit ober für nidtig ertlärt worben iî".

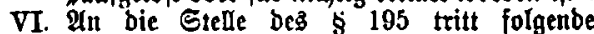
Boridriit: 3it eine Eheirau beleibigt worben, io hat jowohl fie als ihr Ghemann

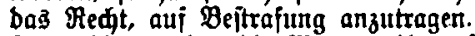

VII. $\mathfrak{I m}_{\mathfrak{m}} \S 235$ werben bie $\mathfrak{M}$ orte: "ihren Eltern ober ihrem Bormumbe erjęt bura bie Worte: „ihren Gltern, ifrean Bormunbe ober ifrem Prleger.

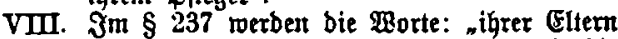
ober ihres Bormunbeg crjeßt Durd bie \$orte: ihrer Eltern, ihres Bormumbes ober ihres \$flegers".

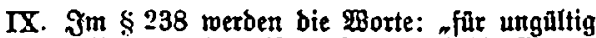
ertlärt roorben ift" erjęt burd bie \$orte:

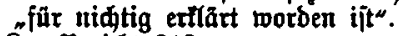

I. 2rt. 17.

Ter $\$ 149$ भbj. 2 ber StßD. twird baljin geänbert:

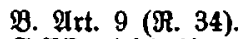

(3). Att. 35. Die St\$D. mirb bahin geänbert: I Tie St $\$$ D. wirb bahin geănbert:

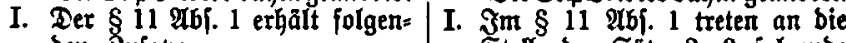

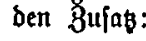

Stelle ber Єä̧ze 2, 3 jolgenbe Boridjriften: 
Daffelbe gill bon bem gejeb: liden Bettreter eines ange: Nlagten.
Behỏnt ein Deutidar einem Bunbesiftacte nidht an, fo gilt als fein Wohnits ein burd allgemeine Intoronung bes भieidsfanjlers zu beftimmenber Geridtsbezirt berStabtgerlin.

II. In bie Stelle Desิ $§ 149$ 16 f. 2 tritt folgenbe Borjurift:

Taffelbe gilt bon bem geieg: lidhen Bettreter eines Ûnge= Ilagten.
In Grmangelung cints iolüen 20 obnitges gill bie Gauptflabt bes geimothftantes als the 28 ohufts; ift bte Gaupt. ftabt in mehrere Geridtsbegitte getbeilt, fo wirb ber als 30 hll. fit geltenbe Begirl vou ber Ranoesinftijoerwaltung burd allgemeine Pnorbnung bC. ftimmt. Behört ein Deutider einem Bunbesitaate nidt an, fo gilt als fein $\mathfrak{s o h n f i ł ~ b i e ~}$ Stabt Berlin; ift bie Stad Berlin in mehrere (sertibts. bejirfe netbeilt, fo wirb ber als $2 B 0 h n i n s$ geltenbe $B$ egir bon bem Heifsęander burd allgemeinc Anorbnung be ftimmt.

II. In bie Ctelle bes $\$ 149$ UbF. 2 tritt folgenbe Boridrift:

Daffelbe gilt bon bem gefefs liđort Bertreter eintes OInge= llagten.

Motioc 7 i., Prototolle 122 f., Ston:Berid)t 312, StenBeridte 345.

I Irt. 18.

Die Boridriiten Der BD. werben burf bie

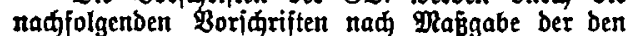
Iegteren gegebenen Bezeidjungen erfegt:

$\S 11$. Tass Bejifledit begrünbet itt $\mathfrak{B}_{e}=$ zitebung aư bie Befugnì zum jelbitãnbigen Betriebe eines Bemerbez teinen Utnterified.

Frauen, welde jelbittänbig ein Bewerbe bes treiben, tonnen in Angelegenbeiten ifres Be:

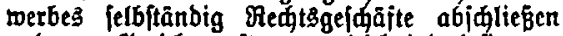
unb oor Bseridt auftreten, gleiduiel of ite ver= Geirathet ober unberheirathet finb. Sie töntert

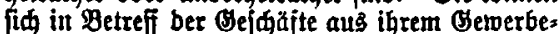
betriebe auf bie in ben einzelnen Bunbesitaaten bejtehenben Rewtsionohlthaten ber Frauen nidt berulen. EEs madt hierbei teinen Unterjuied, of fie bas Serwerbe allein ober in Bemeinimaft mit anberen Berionen, ob fie baffelbe in eigener Berion ober ourd einen Stellbertretcr betreiben.

In Infelgung bes bon eitter Egejrau felb: ftănoig berriebenen Berverbes finbent bie Bor

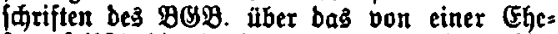

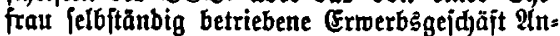
wenbung.
B. 2\{t. 10 (R. 35, B. 36)

Die BD. wirb bahin geāntert:

I. Der $\S 11 \mathfrak{A}(6 j .2$ fällt weg; als $\S 11$ a werben folgettbe Borjdriften eingeftellt:

Betreibt eine (Egefrau, für beren güterred)t.

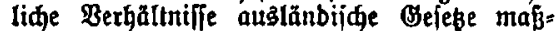
gebend funb, im Jnlande jelbftändig cin of:

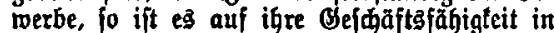
Ingelegertheiten bes Betwerbes ohne (sinfluti), bas̆ fic Éçefrau ift.

Eotveit bie fraul in folge bes Batcritandes in ber Beriügung über ihr : Bermögen bejfräntt iit, finben bie Boridriften bes $\$ 1390$ (G). 1405)

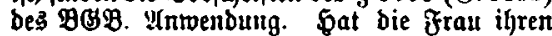
2Bognfis nidt im 3nlanbe, fo ift ber (Einiprud) beg Mtanneg gegen Den Betrieb bes (S):

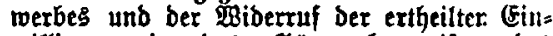

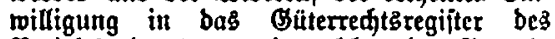
Bezirtes cinzutragen, in weldem baz \&roverbe betrieben twizb.

getreibt bie Fraul baş Bemerbe mil Gin= willigung bes Manncs obcr gilt bie Eirwilli=

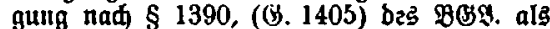
ertheilt, to baftet für bie Berbindlidfeiten ber listau aus berm Berwerbebctriebs ihr Bermögen ogne Büdfidt auf bie bem Tante fraft bes Butitcritanbes zuftehenben Gedite: im Falle bes Beftehens einter eheliden Büter=

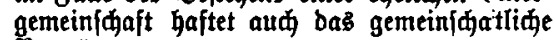
Bermögen.

II. $\Im \mathfrak{m} \S 107 \mathfrak{T b}[1$ werben

1. im Sak 4 bie $\$$ Bormunb, lofern bieje es berlangen" riegt burd bie Borte: wan ben gefeblifinen Bertreter, jpfern biejer es verlangt",

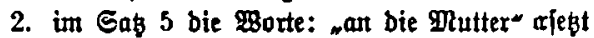
Durd bie $\mathfrak{B}$ Borte:

„an bie zur gefeţliden Bertretung nift bereffigte Mutter*. 


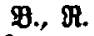

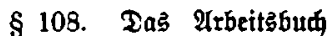
wirb bem Mrbeiter burh bie Bolizeibehõbe Desjenigent Drs tes, an weldem er zullest feinent bauternben 2ufenthalt gehabt hat, wenn aber ein foldaer im

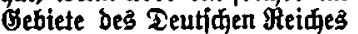
niat [tattgefunben hat, von ber Bolizeibehärbe beş von iłm juerit erwählten beutiden Arbbeitsortes toften $=1 \mathrm{mb}$. item= pelirei ausgeitellt. Tie $\mathfrak{A l}_{1}=$ ftellung eriolgt auf ântrag ober mit Buftimmung bes ge= feslidien Bertreters. Jit ber Jithaber ber elterlidgen Gervalt ber gejebliae Bertreter unb iît Defien Ertlärung nidit zu be: idaffen ober wirb beffen $\mathfrak{B u}=$ ftimmung oh้e getūgendeยt Bntub unb zum Raditbcile bes Arbeiterz verweigert, fo fann die Bemeinhebehörbe bie 及ื ftimmeung ergäızen. Bor

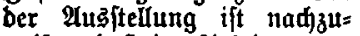
weilen, baй bet $\mathfrak{A}$ rbeiter zunt Bejudje ber Bolfgjidule nid)t mehr berpiliatet ift, unl glaubfait 3 u madjen, baß biझger cin 2irbcit3bud) für iłn nodi nidjt altşgeitefft toar.
III. $\Im \mathrm{m} \S 108$ tretent an bie Stelle bes Sages 3 folgende Bor: \{drifien:

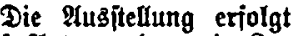
auj Intrag ober mit $\mathbb{8} \mathbf{u}=$ ftimmung bez gejęlidien Bettreters. Steht bie gejeg: lidje Bertretung trajt elter= liaper Gerwalt bem Bater ober ber Mutter 3 u utb ijt die Ertlärung bes Bertreters nidit ju bejagfien ober ver= tweigert biejer bie Buitim= mung ohne gettugenben Brund unb zum Radtheile bes Itrbetters, fo tann bie Bemeinbegehörbe bie $3 u=$ fitimmung ergänzen. c.

III. Эth $\S 108$ treten an bie Etelle besె Gab̧es 2 folgenbe Bor: fdriften:

Die Auş̄itelung erfolgt ouf Intrag ober mit $\mathbf{B u}=$ ftimmung be Bertreters. Jit bie Er= Ilärung bes geietiliden $\mathfrak{B e r}=$ treters niqt zu bejwajien ober bertweigert biejer bie Buftimmung ofne gentigen: ber Frund und zum Rad): theile bes Arbeiters, fo fant bie Bemeinbebegorbe bie 及uftimmung ergănzen.
$\S 131 \mathfrak{A b}$. 1. Wirb volt bem gejeptlident $\mathfrak{B e r}=$ treter bes Lehrlinges ober, fojern ber Qełtere groß jährig ift, bon ifm felbịt bem Lehrherrn bie (d)rijtlid)e Erflärung abgegeben, bā̄ ber Lelirling zu cintem anberen Bemerbe vber anberen Beruje übergehen tocrbe, fo gilt baš Lehroerhăltniß̄, wenn ber \&chrling nid) I friber entlaffen wirb, nad $\mathfrak{A}$ (alaif bon 4 Mudjen als aufgeloft. Ten Brrunb ber Uuflojung hat ber Lehrbert in bem Trbeitsbutic zu vermerten.

$\$ 133$ Ab 2 . Fitt bie Bablung ber Ent= fäitoigung funb als Eelbftidulbuer mitoerhaftet ber ßater bes 2ehrlinges, fojern er bie Eorge für bie ßerjon Des Rehrlinge马 hat, fotwie berjenige 2Trbeit= geber, weldjer ben Lefrling zum Berlafien ber \&ehre berleitet ober weldher ihn in $\mathfrak{H}$ rbeit genommen hat, obroohl er wubte, baj ber Ichrling zur Fortjęung eittes Lelyrberhältniffes nud verplididtet war. \$at

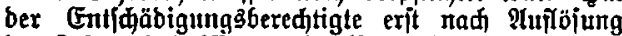

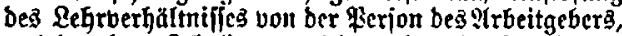
weluger ben \&ehrling berleitet ober in Arbeit ge= nommen hat, feunttiti ethalten, fo erlijat gegen biepe ber Gntjă̈bigungsamiprud) crit. toenut berjelbe

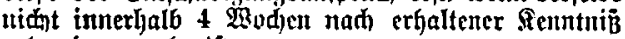
$8^{\text {eltertb gentadit iit. }}$
IV. $\mathfrak{3 m} \$ 110$ भbj. 1 werben bie $\mathfrak{B o r t e : ~ j i c i n e s ~}$ Bater sober Bormundes" erjebt burd bic \$orte: -fcines gejegliacn Bertreterä.

V. Эm $\$ 113$ tritt an bie 〔telle bes $9 b i .4$ fols gende Borfarift:

Jit ber $\mathfrak{A}$ rbeiter mintberiährig, jo sann bas Beugnis bon bem gejęlichen Bertreter ge= forbert werben. Diefer tann verlangen, $b a \bar{B}$ bas Beugnie an ihn, nidjt an ben Mtinber: jährigen aussgehănbigt werbe. Mit Beneh, ntigung ber Gemeinbebehöbe bes int $\$ 108$ bezeidneten Drtes fann aud gegen ben 2 iñen

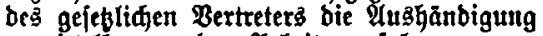
Inmittelbar an ben Arbeiter exfolgen.

VI. $3 \mathfrak{m} \$ 131$ abj. 1 Gał 1 werben bie Worte: von bem Bater ober Bormunbe erjeßt burd bie Worte:

noon bem gejebuldon Bertreter".

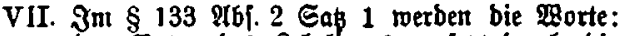
"Der Bater bes Lehrlingeš" erjeb̧t bură bie Morte:

"Oer Bater bes Rehrlinges, jojern er bie Eơrge für bie ßerjon besె \&ebrlinges hat". 
\$ 137 Ab8. 2, 3. Die Arbeitskarten verden auf Antrag oder mit Zustimmung des gessetzlichie Tertreters durch die Ortspolizeibehörde kosten- und stempelfrei ausgestellt; ist der Inhaber der ellierliche: Gevoalt der gesetzliche Vertreter und ist dessen Erklärung nicht zu beschaffen, so kann die Gremeinde behörde die Zustimmung ergänzen. Die drbeitskarten haben den Namen, Iag und Jahr der Geburi souvie die Religion des Kindes, den Namen, Stand und letzten Wohnort des gesetslichen Verlreters un. ausserdem die zur Erfüllung der gesetzlichen Schulpflicht (\$135) getroffenen Einrichtungen anizuyeben

Der Arbeitgeber hat die Arbeitskarte zu vericahren, auf amtliches Verlangen jederzeit vorrzulege? und am Ende des Arbeitserhältnisses dem gesetzlichen Vertreter wieder auszuhündigen. Ist der In haber der elterlichen Gewalt der gesetzliche Vertreter und ist dessen Wohnung nicht zu ermittteln, si erfolgt die Zustellung der Arbeitskarte an den anderen Elterntheil oder den sonstigen nächsiten An gehörigen dcs Kindes.

Mrotive 89, Prototolle 123 fi., Somigeridt 312 f.

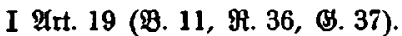

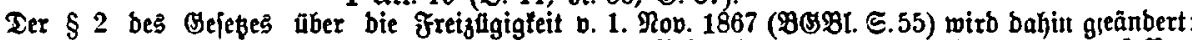

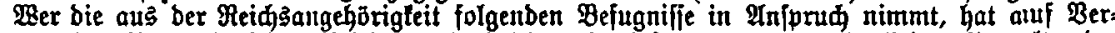

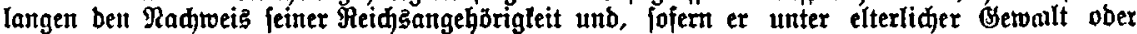

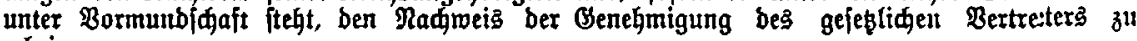
exbringen.

Eine Ehefrau bedarf ber Bentegmigung bes Egemannes.

Protive 9, Prototolle -.

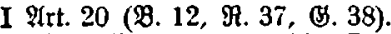

Die Boridriften ber $\$ \$ 16,17$ bes Befepes, betr. Die Erganifation Der Bumbeztonjulatie jorvie

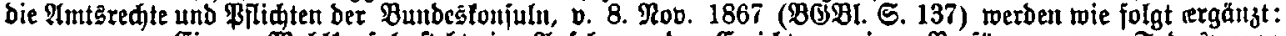

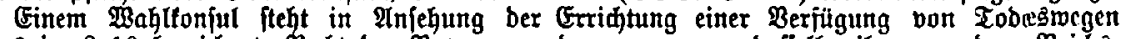

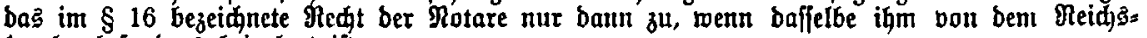
fanzler bejonders beigelegt ift.

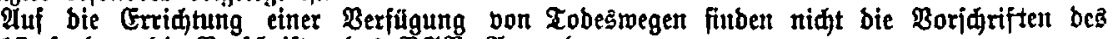
\$ 17, fonbern bie Borfinriften bes 9898 . Antwendung.

Motive $9 \mathrm{~F}$., Protololle 126.

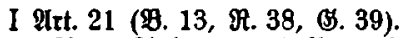

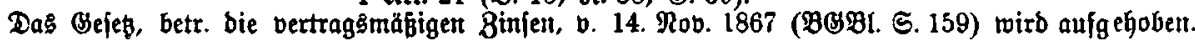
Motive 10, Protololle -

I $\mathfrak{A r t} .22$.

Die Boridriften beả Bejekes, betr. Die Eheidließung unb bie Deurtunbung bes Perjonenitandes von Bunbeşangehärigen im $\mathcal{A}$ lanbe, v. 4. MRai 1870 (B)BI. 5. 599) trerden burd bie rah= folgenben Borianriftert nad $\mathfrak{M a}=$ gabe ber ben lesteren gegebenen Bezeidanungen erję̧t uno ergänzt:

\$ 7. Zur (5yejdliefung ift crforderlid, baś bie Ber= lobten bor bem Seamten bei gleidjzeitiger Antwejenheit per= fönlif unb in Begentwart von 2 Beugen bett Billen ber Eghe ¡̈bliep̧ung ertlären und bas bierauf bie Ebe bon bem Peamten fât geldhloffen extlărt wirb.

Die Ertlärungen fönnen ni.ดt unter Beifügung einer Bebin= gung ober Beitbeftimmung ex= juIgent.

\& 7a. Ter Beamte foll bei Der Ergefdliefung an bie Ber=

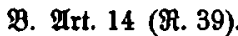

Tas Befes, betr. bie Che =

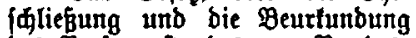
bez Berjonenftallbeg von Bunbegs: angehỏrigen im Muslande, v. 4. Mai 1870 (9B98I. Є. 599) wirb bahin geănbert:

I. $\dddot{3}$ bem $\$ 3 \mathfrak{A b j} 1$ Saß 1 , bem \& 9, bem \& 11 भbf. 2

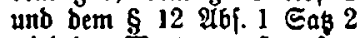
wirb bas burd bas 280 ort: "loll".

1I. In bie Etelle ber $\S \S 7,8$ treten folgenbe Boridariften:

§ 7. Tle Ehe wirb baburd Beidiloffen, bás bie Berlobter vor bem Beamten perfünlim und bei gleidseitiger Antwe [en: heit extlăren, bie Ége mit eitt= anber eingehen zu wollen, und Daß́ Gierauf ber geamte bie Ebe für gefíloffen extlărt.

Die Ertlänungen tönnen niat unter einer Bebingung ober einer Beitbeftimmung $a b=$ gegeban werben.

$\S 7$ a. Ter Beamte foll bei

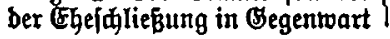

(G. $\mathfrak{A}$ tt. 40.

Das Srejeßs, betr. bic Fhes [dfliefsung und bic Beurtunbung bes Berfonenftandes von Butbes:

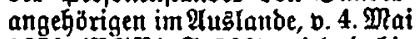
1870 (8981. ङ. 599) wirb bahitt geănbert:

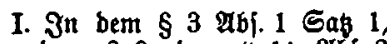
bem $\S 9$, bem $\$ 11$ AbF. 2

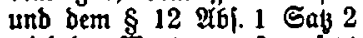
wirb bas 230 ort: "mus" erjept burd bas Bort: , joul

II. $\mathfrak{A n}_{\mathfrak{n}}$ bie Gtelle ber $\$ \$ 7,8$ treten folgenbe Boridurften:

8 7. Die Ehe wirb baburd geidilofifen, baß bie Berlobten vor bem Beamten perfönlia unb bei gleidzeitiger 2 nwejengeit er= tlären, bie Ébe mit einaltber eingehen zu wollen. Der Bes amte mub jur Entgegentrabme ber Ertlärangen bereit fein.

Die Extlărungen tönnen nidt unter einer Bebiugung ober einer Beitbejtimmung $a b=$ gegeben roerber.

57a. Der Beamte foll bei Der EGgejdließung in Begentwart 
Lobten einzeln unb nacheinanber bie Frage ridten:

ob fie extlären, bas fie bie Che mit einanber eingehen mollen,

uno, nałbem bieje frage bon ben Berlobten bejaht ift, aus: fpreden, bas̄ er trafít bes Sejeges fie nunmehr für redt= mäB̈ig verbundere Écleute extlầte.

AIS Beuger jollen bei ber (5hejdliebung Perjonen, twelden bie bürgerlithen (Ghrenredte $a b=$ erfaunt finb, wåhrenb ber für Dent Berluft biefer Mechte im Urtheile beitimmten Beit fowie Dinberjährige nidht zugezuger werben. Berionen, welue mit eitrem ber Berlobten, bem $\mathfrak{B e}=$ amten ober mit einanber ber= roandt ober veridroägert find, bürfen als Beugen zugezogett twerben.

\$8. Die Ehe erlangt mit bem $\mathfrak{A b j}$ dulfie vor bem Beanten bürgerlid)e Oültigleit.

Bent cin Beamter altper halb feittes 2 mtäbezirfes ober beiber ङaliebung jeiner eigenen Ehe als $\mathfrak{B}$ camter hanbelt, fo gill er nidt als ein nad bem $\$ 1$ zur Bornabme einer (5he=

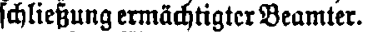

$\$ 8$ a. Fine Ehe, weldie vor einem nad פlabgabe beş \$1 1 zur Bornahme bon Ehe= |ळliebungent ermåd)tigten $\mathfrak{B} e=$ amten gefolofien worben ift, ift wegen Formmangels nur bann niditig, wenn bie Ehe: idjliegung niat unter $\mathbb{B} \mathfrak{c}=$ obadjtung ber Poridriften ber $\S \S 7,8$ erfolgt ift. von 2 Bengen an bie Bers Iobten einzeIn unb nad einanber bie Frage rigten, ob fie bie Ehe mit einanber eingehen wollen, unb, naळbem bie $\mathfrak{B e r}$ lobten bie frrage bejaht haben, ausjpreden, bajer frajt Bejęez fie für reditmäbig berbundente Cheleute extläre.

$\mathfrak{A}[$ Ba Beugen jollen Rerjonen,

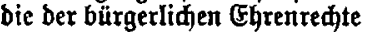
für verluftig entlärt finto, wăh rend ber Beit, jür toeldje bie atherfenum ber (Ehrenredte erfolgt ift, fowie Minberjährige nid,t zugezogen werben. Fer= fouten, bie mit eittem ber $\mathfrak{B e r}=$ lobten, mit bem Beamtent ober mit einanber vermanbt ober verjd)wägert fiub, bürien als Beugent jugezugent werbett.

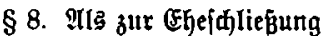
emẳ aud berienige, peldier, ohne ein folder Beanter zu jein,

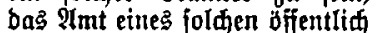
aนsెübt, ez fei beutt, baś bie Berlobten ben Mangel ber amtliđen Befugnī̄ bei ber

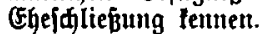

\$8a. Einte Ehe, die vor einem zur Cheidlieb̆ung er= miătigten Beamten (\$1) ober vor einer im $\$ 8$ einem jolfjent Beamten gleidggeftellten \$erion geidjloffen wirb, ift wegen fromt= mangels nur bauts niajtig, wenn bei ber Eheidliegung bie im $\S 7$ vorgefátiebene frorm nidht beobadtet worben ift.

Jit bie (5he in bas \$eiraths: regiiter eingetragen worben unb Gaben bie Ehegatten nah ber Ehejalließ̧ung 10 Зahre als Chegatten mit einanber gelebt, fo ift bie EGe als von infang an gültig anzujehen. bon 2 Beugen an bie BerIobten eingeln unb nad einander bie Frage rinter, ob fie bie Ege mit einanber eingehen wollen und, nadbem bie Berlobten bie Frage bejaht haben, augfprehen, ba $B$ fie Itaft Diefes Gefettro nunmehr reatmäb̄ig verbunbette Eheleute feien.

UIs Beugen joller ßerjoner, bie ber bürgerlihen Eלrentedte filt verluitig erflärt fino, wåh rento ber Beit, für weldhe bie Abertentung ber Ehrentedte erjolgt ijt, forvie Minberjährige nidht zugezogen werben. Per joren, bie mit einem ber $\mathfrak{B e r}$ lobten, mit Dem Beamten ober ntit einanber verwanbt ober beridwågert finb, bürfen als Beugen jugezugen werbett.

\$ 8. 2Als zur Fheidliefung ermẩatigter Beamter (\$ 1) gilt aud berienige, weldjer, ohne ein foldjer Beamter zu fein, bas 2 tmt eitues folden iffentlia altşubt, eક fei benn, Das bie Berlobten ben Dantil ber amtlichent Befugnió bei ber Ehejđjliểung tenten.

\$ 8a. Eine Ege, bie vor cinem aur Egejdliefung er= mähtigten Beamten (\$1) ober vor einer im $\$ 8$ cinem foldsen Beamten gleidgeitellen Berjou geidlofien wirb, iftwegen Jorm: mangels nur bann niahtig, went bei ber Ehejめlie巨ung bie im $\$ 7$ vorgejकriebene form nidt beobahtet worben iift.

Jit bie Ehe in bas Seirath regifter eingetragen morben unb haben bie Ehegatten nadh ber Egejdliefung 10 Jahre ober, falls einer vou thnen borber neftorben ift, bis zu beflen zobe lebod minbeftens 3 gabre als Ehegatten mit einarber gelebt, fo ift bie che als bon Rinfang an gultig anzuleben. Diefe:Bor. förift finbet teine Inmenbung menn bei bem astaufe ber 10 Jabre ober jut gelt bes gobes bes einen Ggegatten bie Rithtig. tellstlage erhoben iff.

Potibe 10, Protololle 126 f., Pomgeridt 313.

I $\mathfrak{A}$ rt. 23.

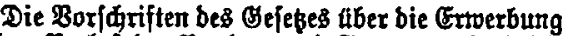
unb ben Berluft ber Bumbes = unb Staatzangehjortgleit v. 1. Juni 1870 (9BBI. S. 355) werben burd bie nadfolgenben Borfdxiften nad Masgabe ber ben Iebteren gegebenten Bezeidnungen erfekst:

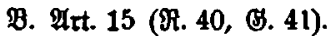

Das Befeb aber bie (Enwerbung unb ben Betlujt

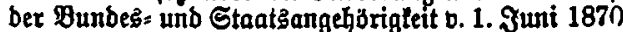
(BßB:I. S. 355) toirb Dahin geănbert:

I. $\mathfrak{A n}_{\mathfrak{n}}$ bie Stelle bes $\$ 11$ treten folgenbe Bor: iffrifter: 


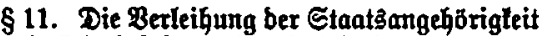

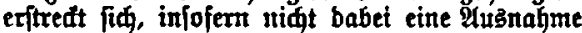
gemaht mirb, zugleid ouf bie Ehefrau unb auf biejentigen minberiährigen Rinber, in $\mathscr{A}$ njébung

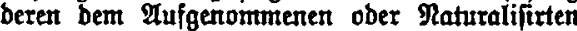
bie gefeglide Bertrehurg frajt elterlider Bewalt zufteht, auf Todfter jebod nur bann, wenn fie weber berbeirathet futb nod berbeirathet marer.

\$ 19. Die Entlafiung erjtredt fid, injojern

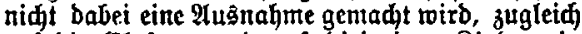
auf bie Ehefrall unb auf biejenigen Sinber, in Anjehung beren bem Entlafienen bie gejeslidae Bertretung traft elterlicher Berwalt zufteht, auf Töhter jebod nur bann, wenn fie weber ber: Geirathet find nod verheirathet waren.

Puj Stinber, weldye unter clterlidjer Getwalt ber Mutter fteben, finbet bie Borjarifi bes eriten 26jabes leine 21mivenbung, went zu bem Intrage ber giutter auf Entlafiung Der Stinber bie Be: neh̆migung eineş Beijtanbes erforberliđ fein würbe.

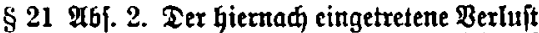
ber Staatsangebörigfeit critredt fid zugleid auf bie Ehefrau unb auf biejenigen Finber, in $\mathscr{M} \mathfrak{n}=$ fehung beren bem ILşgetretenen bie gefeslide Bertretumg traft elterlider Bewalt zulteht, joweit biejelfen bei bent Ehemanne $b_{3}$. Dem Elterntheile (ïळ) befinben, auf Tödter jebod mur bann, toenn fie weber berbcirathet finb nod berbeiratfet waretr.

Die Berleifung ber Etaatêangehbrigtei

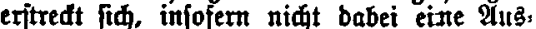
nahme gemadt mirb, zugleid auf bie Egejrau unb auf biejenigen minberjährigen finber, beren geję̧lidge Bertretung bem Aufgenon: menen ober $\mathfrak{R}$ aturalifirten trait elterlidicr

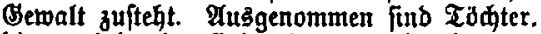
bie verheirathet finb ober berheirathet ge= wejen fimb.

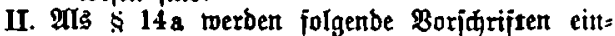
geitellt:

Die Entlafinth eines Etaatsangeförigen. ber unter elterlider Gerwalt ober $\mathfrak{B}$ ormund:

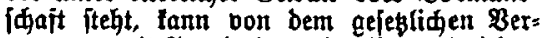
treter nur mit (Bentehmigung bes Borm(3eria)tes beantragt werben.

Tie (Senehmigung bes Borm(Seridtes ift niकt exforberlid, went ber Bater ober bie Mutter die Entlaffung für fíd und zugleid fraft elterlider (Sewalt jür ein Silto beantragt. Eritredt fid ber eines ber Mutter beftellten Beiftanbes auf bie Sorge fït bie Rerion bes Riubes, jo bebari bie Mutter in einem joldjen Falle ber Gerlehmigung bes $\mathfrak{B e i f t a n b e s ~ z u ~ b e m ~ U n t r a g e ~}$ aui Entlafiung bes Pindez.

III. In bie Etelle bes $\S 19$ treter folganbe Bor: fariiten:

Die Entlafiung eritredt fí, infofern nid]t babei eine अušnabme gemadt wirb, zugleid auf bie Ghefrau und auf biejentigen Sinber, beren gefeglidge Bertretung bem Entlaffenen traft elterlider (sewalt zulteht.

Dieje Borjurift finbet feine Armentung auf Tibhter, bie verheirathet find ober bcr: Geirathet gewefen finb, forwie auf Rinber, bie unter ber elterliden (Sewalt ber Mutter ftehen, falls bie Mutter zu bem Mtntrage auf Gnt: Iaffung ber Finber nad $\$ 14$ a $\mathcal{A} 6 f .2$ Cab 2 ber Benehmigung bes Beiftanbes bebari.

IV. In bie Stelle bes $\$ 21$ Abj. 2 treten folgenbe Boriqriften :

Der hientad cingetretene Berluft ber Stants: angehörigleit exjtredt fin zuglein auf bie Ehefrau und auj biejenigen Sinber, bercu

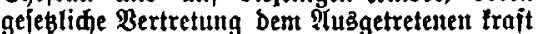
clterlid)er (Semalt zulteht, joweit fiđ bie Gheirall voer bie finber bei bem Altgge:

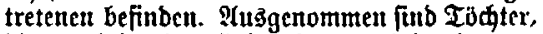
bic berheirathet fitb ober verijeirathet ge tocien finb.

Motipe 10, Protololle 127 f.

I $\mathfrak{A r t .} 24$.

Dic Burjariften beả Gejebes, betr. bic Berbind:

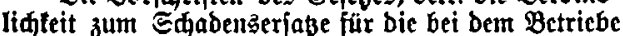
bon Eijenbahnen, Bergwerfen ujw. herbeigejührten Tobnutgen und Rörperverleßsungen, v. 7. Juni 1871 (Mßg1. ऽ. 207) werben bura) bie nadjolgenbent Boriariften nah Má́gabe bet ben Eesterett ge= gebenen Bezeidnungen erję̧t:

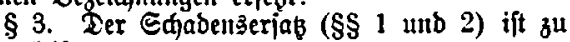
leititen:

1. im Falle ber Tobbung bura Griab ber Roften einer veriuften Seilung unb ber Beerbigung jowie bes Bermogenßanahtheiles̄, weldent ber Betöbtete während ber Srantheit burd $\mathfrak{C}_{r}=$ werbsunjähigteit ober Berminberung ber $\mathcal{E r}_{r}=$
B. Art. 16 (M. 41, (H. 42).

Das Bciebs, betr. bie Berbinblidjeit zum ङめabentserjaß̧e für bic bei bem Betricbe von Eijent= bahnen, Bergiverfen ujw. herbeigeführten Tobtungen

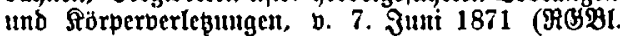
5. 207) wirb bahin geẩıbert:

I. IIn die Ctelle beș $\$ 3$ treten folgende Bor= \{ărijten:

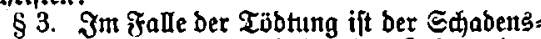
erjak ( $\$ \S 1$ umb 2) burd (ETaßs ber Stoften einter

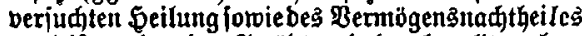
zu Ieifiten, ben ber ßetobstete baburd erlitten hat, baš währenb ber Strantheit feine Grroerbajähigfeit aufgehoben ober gemintert ober eine Bermehrung fetter Bebürintifie eingetreten war. Der Erjaţ= 


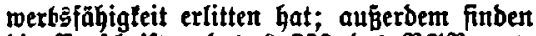
bie Boridriften bes $\$ 723$ bes 959 . ent= [predente Rntwentoung;

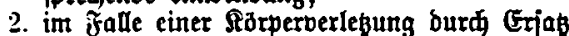
ber Seilungsfojten und bes Bermögensnađ: theiles, welden ber Berlegte bura eine in Folge ber Berlegung eingetretene zettweije ober bauernbe Grwerbsunjä̧bigfeit ober Bes minberung ber Exwerbşfähigleit erleibet.

§7. Tui bie Cntidăbigung finben bie $\mathfrak{B o r}=$

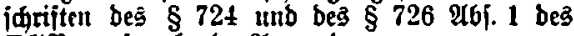
BOBP. entipredienbe Ptrmenbung.

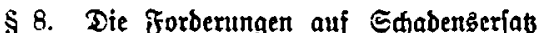
( $\$ \$ 1$ bis 3) veriăhren in 2 Jahren vom Tage bez unfalles ant. Begen benjentgen, weldem ber Betöbtete unterhalt zu geroảhren hatte (\$ 3 Nr. l), beginnt Die Berjährung mit bem Tobeḡtage. $3 m$ thebrigent finben bie Borjariftent bes $\mathfrak{B G S}$. uber bie \$erjăhrung Inwentung.

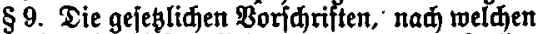
auber ben in biejem Bejeste vorgejebenten fallen ber unternehmer einer in ben $\$ \$ \$ 1,2$ bezeid)= neten $\mathfrak{A}$ lage ober eine anbere ßerion, intabef. wegen eines eigenen Berjaulbenş, für ben bei bem Betriebe ber 2tnlage burd ₹obtung ober Rörperverlez̧ung eiues Menjøen entftanbenen Shaben haftet, bleiben unberfihrt. pflidtige Gat auBerbem bie Roften ber Beerbigung bemjenigen zu eriezen, bem bie Berpflidturtg obliegt, biefe Poften zu tragen.

Etanb ber Getobtete zur Beit ber Berlebung 孔u einem Dritten in einem Berhăltniffe, bermỏge befien er biejem gegenüber traft Befebes unter haltspiflidtig war ober unterhaltşpfliðtig toerben fonnte, unb ift bem Iritten in ₹rolge ber Tobtung bas Feat auf bent untethalt entzogen, fo hat

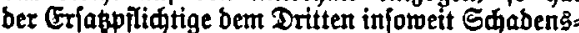
eriał zu Ieijten, als ber Oretabtete toährend ber muthmaplidien Dauer feines Lebers zur Be: mährung bes lunterhaltes berpllidtet gewejen jein mürbe. Tie Erjaßpflidgt tritt auq Dann ein, wenn ber 2 ritte zur Beit ber Berleß̧ung erzeugt, aber noh niat geboren war.

$\$ 3 \mathrm{a}$. 3m Falle eitter Sörperberlebung iît

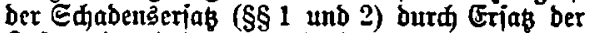

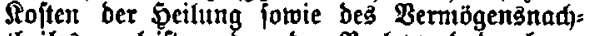
theiles zu leiften, ben ber Berlebte baburd er: leibet, bas in folge ber Berlesung zeitweije ober bauento feine Ermetbałähigteit aufgehoben ober gemitibert ober cine germehrung feiter $\mathscr{B}_{\text {. }}$. büriniffe eingetreten ift.

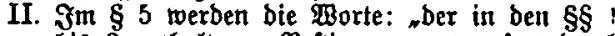
bis 3 enthaltenen $B$ eftimmungen" erjest burd bie Morte:

"ber in bent $\$ S \$$ bis 3 a enthaltenten $\mathfrak{B} c$ ftimmungen".

III. $\mathfrak{A n}$ bie Gtelle ber $\S \S \tau, 8$ treten jolgenbe Boridjrifiten:

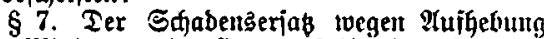
ober Minberung ber Erwerbäjäbigfeit uno wegen Bermehrung ber Bebürinifie bes Berlegten jomie ber nah $\$ 3$ Mbj. 2 einent Iritten zu getwährentos

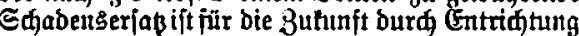
einer Geldrente zu leiftent.

Tie Borjdyiften bes $\$ 828$ (B. 84.1) Abj. 2 bis 4 BMg. und bes $\$ 648$ Mr. 6 ber $(5 \Re D$ finbent entipredenbe Ptumenbung. Tas Hleidic gilt für bie bem Berlebtent zu entridtenbe Beld: rente von ber Borjurift bes $\S 749$ $\mathfrak{A b j} 3$ und für bie bent 2 rittet 31 entridtende Selbrente vout ber Borjdurift bes \$ 749 Qbj. 1 Rr. 2 ber CRE.

3it bei ber Berurtheilumg be 3 Berpfliditeten 3ur Entriatung einter Belbrente niđt auf હidjer= heitsleiftung ertannt worben, fo fann ber $\mathfrak{B e}$ redtigte gleidymohl હiđhetheitslciftung verlangen. renr bie Bermógentsverhăltniffe bes $\mathfrak{B}$ erpflidjteten (idh) erfeblid verf(hledtert haben; unter ber gleidjen Borausjesung taun er citte Erhobung ber it bem Ilrtheile beitinumten Ciderheit verlangen.

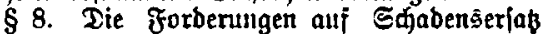
(\$\$ 1 bis 3a) verjähren in 2 Jahren von bem Unjalle an. (Segen benjenigen, weldem ber Bse=

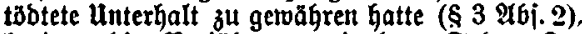
Geginnt bie Berjährung mit bem Tobe. $3 m$ Uebrigen finden bie Borjdriften bes $\mathbf{8 B 9}$. über bie Beriährung Ansoenbung.

$89^{*}$ ). Die gefeslidien Boridriften, nad weldhen auber bett in biefem Sejebe vorgejehenen fällen ber Unternehmer einer in ben $\$ S 1,2$ bezeidneten Anlage ober eitte andere ßerion, inşer. wegen eitues eigenen Berjळulbents, für ben bci bem Betriebe ber Tnlage burd Tobtung

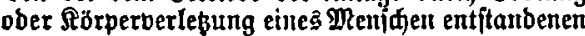
Edjaben hajtet, bleiben unberiigrt.

Motive $11 \mathrm{f}$., Prototolle 128 if.

*) Der $\$ 9$ feglt in ber Bunbešratherborlage. 
I $\mathfrak{A}$ rt. 25.

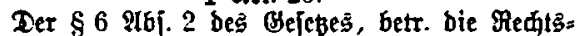

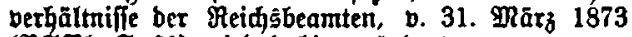
(R®P!. E. 61) wirb bahin geânbert:

Die Boridrift beg § 311 bes $\mathfrak{B G g}$. Findet Pnwendung.

Motive 12, Prototolle 130.

I $\mathfrak{A r t} .26$.

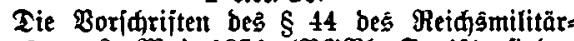

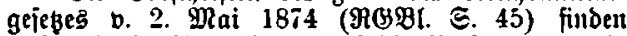
entipredende $\mathfrak{A n w e n b u n g}$ ouf bic Berionen, welde zur Bejakung eines in Dienft geitellten Ediines ober Frafrzenges ber fraif. Marine gehören, jolange bas ๔aiff ober Fahrjeug auberhalb eines in= Iändiffen Gafens fid) befuibet ober bie Perjonent als Striegsgefangene oder Beipeln in ber Bretualt bes Zreinbes find, ingleidyen auf anbere an Borb

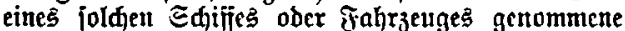
Ferjonen, jolange baffelbe auperlyalb eines inlänbijđjen Dajers fid befindet unb bie Perionen an $\mathfrak{B}$ ord

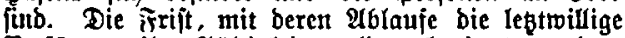
Berfügutg ihre Giñltigleit verliert, begitut vout bem Tage, an weldhem bas @đifi ober Fahrjeug in eitten inlänbijdjen \$ajen jurildfgetehrt ift ober ber Berfïgettbe aufgefob hat, jtt jenem zut gehören, ober ale Sricgsgefangenter ober Beipel aus ber Bewalt bes freindes entluffen ijt.

\section{Motive 12, Protololle -}

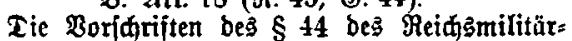

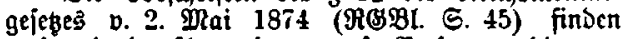
entfpredende 2lnwenbung auf Rerjonen, bie zur Bejapung eines in Tienft geftellten Éfiffes ber Maij. Marine gebören, folange bas Edjif fid

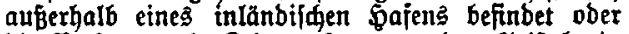
bie Perionen als Striegsefangene ober Beipeln in ber Betwalt bes feinbes finb, ingleiden auf anbere an Borb eines jolden Eđiffes genommene Ferfoncn,

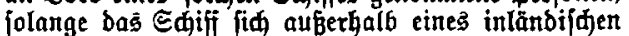
$\tilde{\text { Dafens }}$ befindet und bie Rerioner an Borb fint. Tie Frrijt, ntit berent Ablaufe bie lestrillige $\mathfrak{B e r}=$ fügung ihre (S)altigleit verliert, beginnt mit bem Beitpantte, in weldem bag Édjiff itt einen itt länbijaent Seäfett unrïdfehrt ober ber Berfügentbe aufbòrt. zu Dem Ediffe zu gehjoren, ober als Rriegşgefangener oder Bseigel aus ber Berbalt bes Feintbes entlafient wirb. Ten 厄aifien fitehen bie jonftigen Ffahrzeuge ber Ŝtaif. Mtarine glcid.

I $\mathfrak{A r t} .27$.

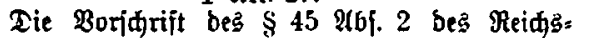

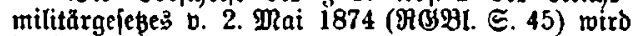
bahin geănbert:

Den $\mathfrak{A}$ inprud aui Bahlung bon Dienft: eintiniten, $\mathfrak{k a r t e g e l b e r n}$ ober $\mathfrak{B}$ enfionen fönten

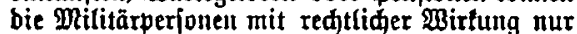
injoweit abtreten, berpfänden ober fonft über= tragen, als cinc Bejalagnahme im Falle einer Broangşvollftredung zuläifig getwejent wäre. Tie

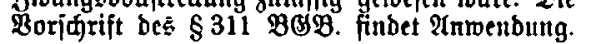

Motive 12, Mrototolle 130.

I $\mathfrak{A r t} .28$.

Tie Borjđriftell Des Beiebes über bie Beurfullutug bes $\mathbb{H}_{\mathrm{er}}$ fonenitanbes unb bic Ehcidliçung

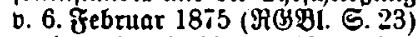
werben burd bic nadifolgenben Bor(driften uad Magaabe ber ben Ecbterent gegebencu $B e z$ cid)= nungen crieß̧t und crgängt:

$\S 28$ (für bie $\$ \$ 29$ biz 40 ).

In $\mathfrak{A n}$ jehung ber Erjorbernific ber Ehefaliépung unb in Pll= féung ber redtliden Folgen einer gegen bie gejeplid)en $\mathfrak{B o r}=$ juriftent vorgenommtenen (Eye= fđlicbung finton bie $\mathfrak{B o r =}$

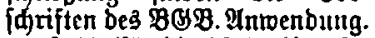
$\S 41$ (für bie $\$ \S 41$ bi 43 ).

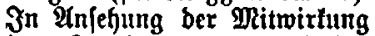
bes 厄tanbegbeamten bei ber Eheidlicbung finben bie $B o r=$

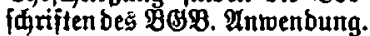
\$44. Der Ehejalieg̈ung foll ein Aufgefot vorangehen.

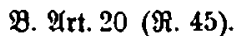

Tas Gejek liber bie Beur= tutbung bes Perfonenitandes und bie Eheidlicbing $\mathfrak{b}$. 6 . Februar

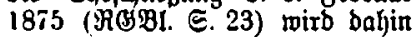
geăllocrt:

I. Tic $\$ \$ 28$ bỉ $40,42,43$, 51 biš 53 merben aufgehoben.

II. 2 In bie Etelle ber $\$ \$ 41,44$, 50,55 treten folgende $\mathfrak{B o r}=$ fdrifiten:

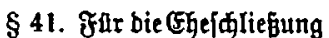
finb bie Borfuriften bes $\mathfrak{B O B B}$. masgebertb.

§44. Fftir bie Unoronung beș vor ber Eheldhliefung gu erlaffenden Rufgebotes ift jeber

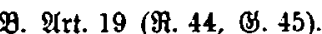

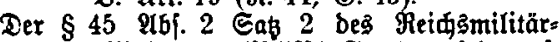

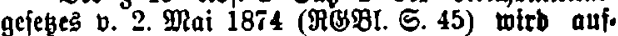
gebobent. 
Flar bie Anorbmung beffelben ift jeber Etanbesbeamte $311=$ ftänoig vor meldien nad bem $\$ 1246$ bes $\mathfrak{B O B}$. Die Ehe gejd)lofien merben tant.

\$50. Tic Pefugní zur Tizpenfation von bem QIuf= gcbote jteht nur bem Etaate

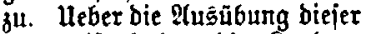
Bejugniž haben bic Lanbes: regierungent 34 bejtimmen.

$\mathfrak{n}$ iro eitre lebenżgejăhrlide frantheit, welde cinen 2ufidub ber Eheidliebung nid)t ge= ftattet, ärztlid bejめeinigt, jo tann ber Stanbesbeamte $(\$ 1246$ bes̈ $\mathfrak{B O P}$.) and ofne 9 uf: gebot bie Ehridliebung oor= nefment.

$\$ 52$ (für bie $\$ \$ 52,53$ ). In Pnlehimg ber Bornahme Der Ehejuliebang finben bie

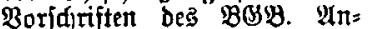
toettoultg.

\$5. Jit eine Efe für un= gültig erflärt ober ifit it eirtem Recitêitreite, welfier bie Feit= jellumg bes Beftehens ober bes 9lintbeitchens eincr Ehe zwijucn ben Parteicst zun Gegenitanbe hat, baz $\mathfrak{i d d t =}$ bejtegell ber Ege jeftgeitellt ober ijt eine Ege bor bem Zobe einez ber Eljegatten au $\bar{i}$ gelijit, jo ijt bies am Ranto

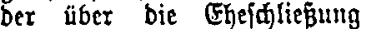
bervirften Gintragung 3 u ver= merlen.
Etanbeâbcamte zuftănbig, vor bem ná $\S 1305$ BOB: bie Ehe gejolofilen werben tann.

850. Ter Єtanbes6eamte joll ohnte Aufgebot bie che= j内liefung nur vormehmen, menn igm ärztlid bejaeinigt wirb, bas bie lebensgeiahnrlide Ertrantung eittes ber Berlobten

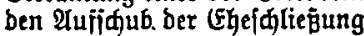
nidit geitattet.

\$55. Sift eine Ege fiur nidutig erllärt ober ijt in einem Redtajtreite, ber bic Feft= ftellung bes Beitehens ober bes Tixtbeftefiens einer EGe zijiden ben Barteten zum

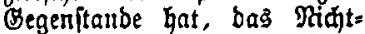
bejtehen ber Ehe feftgeitell. ober ijt eine Ege bor bem Tobe eintes ber Ehegatten auf: geloft. fo ift bies am Ranbe ber über bic Ehejdliebuttg bewirlten Cintragung $3 \mathrm{H}$ ver= merlen.

III. Im $\$ 69$ werben bie $\mathscr{P o r t e :}$ in "biefem Beicbe" eriebt bura bie Borte: "in biefem Befebe unb in bem $B A D^{\circ}$.

IV. $\Im \mathfrak{m} \S 75$ $\mathfrak{A b} .1$ werben bie Worte: „nad ben Boridrifter biefes Grefeşes" erjest bura bie Worte: "nad ben Bor= intiften bes $\mathfrak{B B S}$.

V. $3 \mathrm{~m} \$ 82$ merben bie Morte: Durh biejes ciejes" erfest burd bie $30 r t e:$ ourd bie Boríntiften biejes Bejeges unb bes $\mathfrak{B} \leftrightarrow \mathfrak{B}$ ".
Stanbeşbeamte zuftănbig, vor bem nă $\S 1320$ bez $\mathfrak{D} G \mathfrak{B}$. bie Ehe gejulofien werben barf.

\$ 50. Ter Stanbeşbeamte joll ohne Aujgebot bie Ehe 佔liebung nur vornefmen, wettr igm ärgtlið bejめeinigt wirb, baś bie lebenţgefähr = lique Ertrantung eimeả ber Berlobten ben Iufidub ber Ghejめließung nidt gejtattet.

§55. Jit eine Ebe für niưtig erllârt, ift in einem

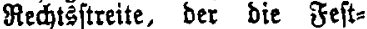
ftellung bes Beftehens ober Des Nintbeftehens cinter Ege zwifden ben Barteien zum Gegenftande hat, bas Sinit= beftehen ber Ehe feftgeftent, ift eine che bor bem robe eintes ber Ehegatten aufgelöit ober ift ná $81575 \mathfrak{B O B}$. bie chelide Gemetridaft auj. gehofen, fo ijt biez am Ranbe ber iber bie Gyejhliebung be: toirtten Eintragung zu ber= merten.

2 irs bie efelide Bemeitt.

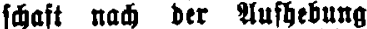
wteberhergeftellt, io ift bies auf Intrag am Hanbe 34 vermterlen.

III. [I, $\mathfrak{B}$. u. $\mathfrak{R}$. fehlt.] Der $\$ 67$ erhălt folgentoett 2ibjas 2 :

Fine frrafbare Sanblung ift nidit borhanben, wentt ber Geiftlidie ober ber Religionabiener im falle einer Iebensigefăhrlid)en, einen Ruffqub nidt ge= itattenben Extrankung eines bex Berlobten zu ben reli= giölen freierlialeiten ber

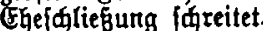

IV. $\$ \mathrm{~m} \$ 69$ merber bie $\$$ in biejem Bejebe erjeşt bura bie Morte: "in biejem Bejebe unb in bem $\mathbb{B S B}^{\circ}$.

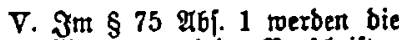
Borte: na⿱ ben Boridriften biefes Brejesez" erfegt burd

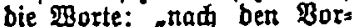

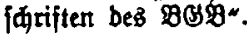




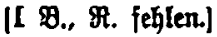

[I feglt.]

PomBorlage 2rt. 45a (8. 47).

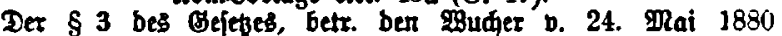

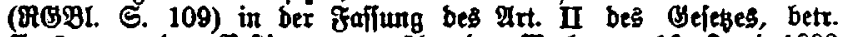

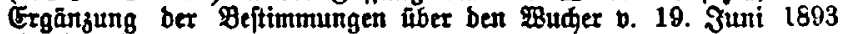
(अ(S)LL. ธ. 197) wirb aufgehoben.

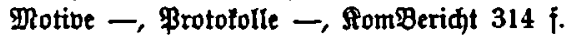

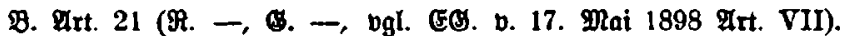

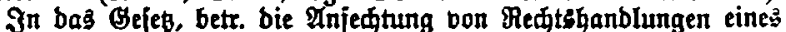

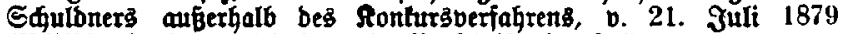
(MMBI. S. 27\%) wirb forgenbe Borfidrift eingeftellt:

\& 3a. Hnt der Erbe aus dem Nachlasse Pflichttheils. ansprüche. Vermächtnisse odor Auflagen erfüllt, so kann ein Nachlassgläubiger, der im Konkursverfahren über den Nachlass dem Empfänger der Leistung im Range vorgehen oder gleichstehen würde, die Leistung in gleicher Weise anfechten wie eine unentgeltliche Verfügung des Erben.

Eine nach den $\$ \$ 1950,1951,1966$ BGB. eingetretene Beschränkung des Rechtes des Gläubigers bleibt ausser Betracht, wenn der Gläubiger dem Empfanger der Leistung im Range vorgehen würde.

Potive -, Brototolle 133 f.

I 29.

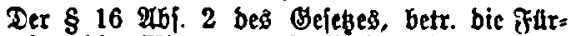
forge für bie $\mathfrak{B B i t t w e n}$ und $\mathfrak{B}$ aijen ber Reides: beamten ber Civilberwaltung $\mathfrak{v}$. 20. April 1881 (શOBgI. $€$. 85) wirb bahin geănbert:

Ridjt abgehobene Theilbetråge beş Bittreett= und Baifengelbes veriähren binnen 4 Jahren; bie Berjăhnung beginut mit bem Ediuffe bes Şahres, in weldem bic Theilbeträgc fällig geworben find.

I $\mathfrak{A r t} .30$.

Der $\$ 18$ ab 2 beż Gejebes, betr. bie frit:

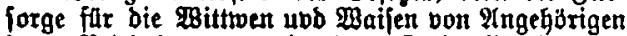

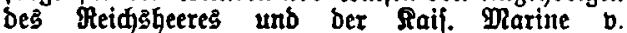
7. Juni 1887 (ROPL. S. 237) wirb bahin ge= äthbert:

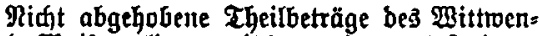

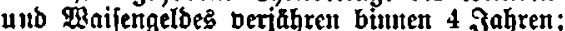
bie Berjäbrung beginnt mit bem Ealurfie bes

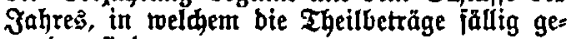
worben finto.

[I fehlt.]

[I fehít.]
Motive 14 f., Frotofolle 133.

Motide $14 f$, Prototude $133 \mathrm{f}$.

9. 22 (Я. 46, (5. 48).

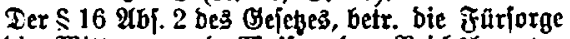

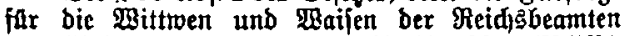
Der Civilbcrwaltung, D. 20. April 1881 (MBPI. 巨. 58) wirb auigehoben.

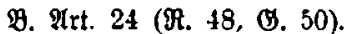

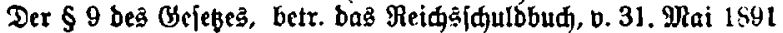
(RG91. હ. 321) twirb bahin geänbert:

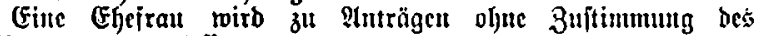
Eheminutes zugclafient.

Tie Efefrau bebari ber 3uffinmmung bes Ehemantes, rocun eim Bermert $z^{u}$ beffen Bunften sintgetragen ift. CFin folder Bermert ift eimzutragen, wenn bie Ehefralt ober mit berell Buftimmung ber Ebemanu bie Eintragung beantragt. Tie Ehefrau ift Dem Egemante gegenaber zur Ertheilutg ber But ftimmung berpfliftet, wenn fie stad bem unter ihnen beftehenben Bsiterftande inber bie Yudjforberung 1 me mit Buftumuntg bes (Ehemannesి veriügen tann.

Motive -, Brotololle 133 i.

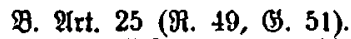

Ter $\S 8$ 2aj. 2 bes Bejeses, betr. bic foürforge jür die

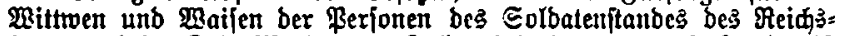
Keeres unb ber $\mathfrak{T} a i j$. Marine vom Felbrwebel abtwärț v. 13. Sunt 1895

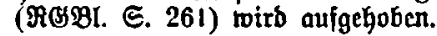

Mlotive -, Brototolle 133. 
I $\mathfrak{A r t} .31$.

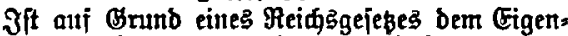
thümer einer Sadie wegent ber im Jff. Intereffe er: folgenber Gntziehung, Bejdäbigung ober Benusung

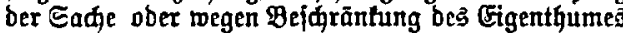
eine Entiøäbigung zu gewähren und ftegt zur Beit ber Entîtehung bes (Entidăbigungąaniprudeez einem

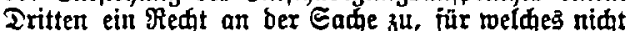
eine bejonbere Entjuăbigung geroăhrt wirb, jo wirb worjen. Befteht bas Recht in einer Gypotbet, Brumb=

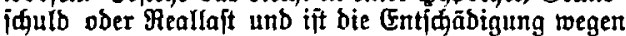

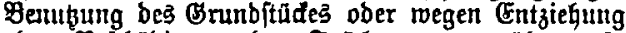
ober Bejuäbigung ber frü̆te zu gerwähren, fo

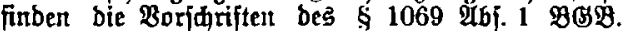

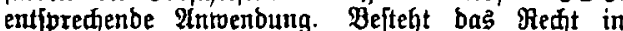
einem शiē̄braudje, jo finden bie Borjariftent über

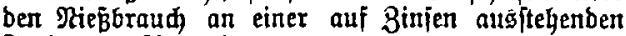
Fुorberung Pfnwendung.

2Biro burd bie ben Entfdäbigungsanjprud begranbenbe Maß̈regel ein Reht an ber Sađhe be= cinträdhtigt, weldhes an einer frorbernng nidft beftehen latn, fo hat bet Eigenthümer aus ber ifm $z^{u}$ ge= wăhrenden Entinăbigung bem Beredtigten wegen

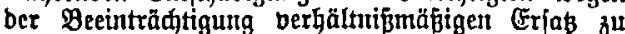
Icifter. Dem 8 eredtigten f́teht wegen biejes Erjak anfprudes ein geieslides Pfandredt an bem (Ent=

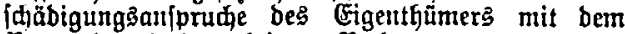
Range bes beeintråntigten Rechteŝ 3".

Die Boridrift bes \$ 36 भbj. 4 bea ('ejeb̧es, betr. Die Bejofränfungen bez Brundeigenthumeż in Der umgebung bon Feftungen, $\mathfrak{v}$. 21. Tez. 1871

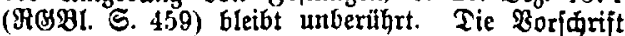

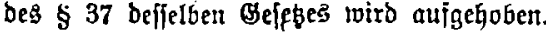

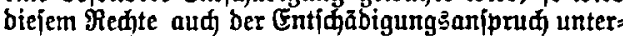

Motibe 15, 16, Protololle 134-137.

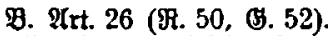

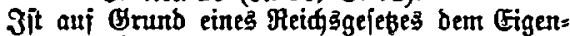
thümer einer Eađe wegen ber im off. Snterefie ex. folgenden Entziehurg, Bejdăbigung ober Benuburtg Der Gađae ober wegen Bej eine Entiøăbigung zu getwähren unb fteh̆t einem Dritten ein Redt an ber Sache zu, für tweldjes niđt cine bejonbere Entidăbigung gewābrt wirb, fo bat ber 2ritte. foweit fein Redt betinträ̉tigt wirb, an bem Gntidanbigungsanjprudie biefelben

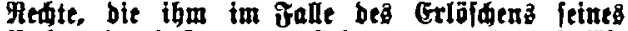

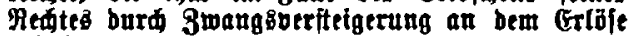
zufteben.

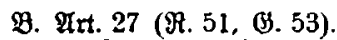

Sft in einem Falle beg ?ltt. 26 (G. 52) bie

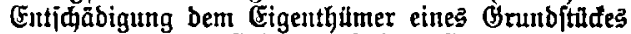

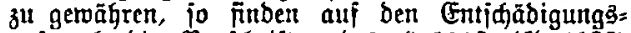
anjprud bie Boridriften bes $\$ 1112$ (B̈. 1128)

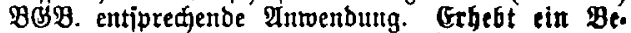
reditigiter innerhalb ber im 81112 ((8. 1128) be. fitimaten Frift $\mathfrak{B}$ iberiprud gegen bit $3 a \mathfrak{a} l$ lung ber (Entiaübigung an ben Gigenthümer, fo tann ber Gigenthumer und jeber Pereditigte bie Gröfinung eint Bs Bertheilungsourfahrens tad ben für bie Bertheilung bes Eriöles tm Falle ber 3wangB. verftetgerung geltenben Boridriften beantragen. Dit Bahlung hat in bieiem folle an bas für bas

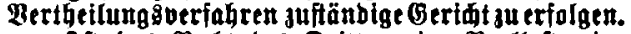

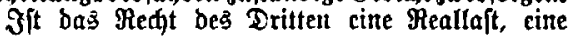
פypolhel, eine Brundjauld ober tine Ptentenifulb,

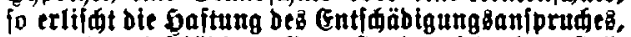
wenn ber befuäbigte Gegenftand wieberhergeftellt ober für bie entjogene betweglidie Sade Erfak be.

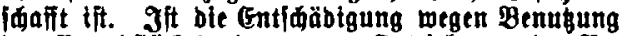
Ded Grunbftüdes ober wegen Gntgiehung ober Be. | ju getwähren, fo finben bie Borfariften bes 81107

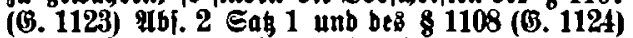
$26 \mid$ 1, 3 $9 G 9$. ettfpredenbe Inwentung.

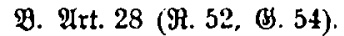

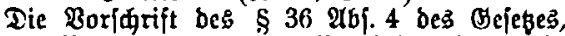
betr. Die Bejđräntungen bes Grunbeigentgumeß in ber Umgebung von Feftungen, $\mathfrak{v}$. 21. Dez. 1871

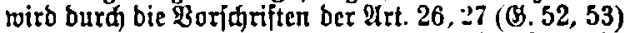
nidht berilhrt. Foftnbet nad biefen goridriften ein Bertheilung Bverfabren ftatt, fo ift bie Gntfaübigung auf Erfumen bes̄ für baß Berfabren juftänbigen Geridetes an biefes ju Ieiften, foweit fie jur 3eit ber Stellang bes Griutiens nod auştegt.

Die Borfigrift bes 837 beffielben Gefeges wirb bahin geänbert:

Sit bas Granbftid mit einem Medite belaftet,

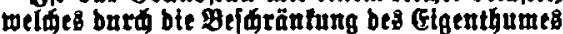

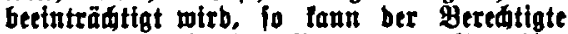
bis jum भblanfe tines montates, nadbem ibm ber Gigenthïmer bie Beidränlung bes Eigen. thumes mitgethetit hat, bte Griffnung des Bertheilungsuerfahrens beantragen.

\section{Ub/chnitt: Derhăltnif̧ des 363 . ju Den Landesgefetgen.}

Die pribatredtlidien Boridriften ber Ranbeg̈=

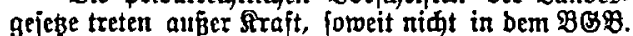
ober in biefem Bejebe beftimmt ift, bá̈ fie in Strajt bleibelt follen.

Plotive 16-20, Protololle 137.

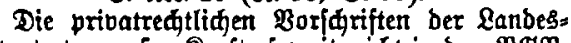

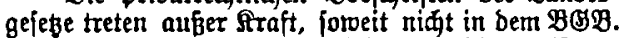
ober in biefem Gefeb̧e ein Olnberes beftimmt ift. 


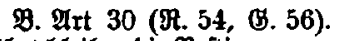

[I feglt.]

Unberibtt bleiben bie $\mathfrak{B e f t i m m u n g e n ~ b e r ~ C t a a t s : ~}$ vertrãge, bie ein Bunbesitaat mit einem aug: länbijự Staate vor bem Infrafttreten beả $\mathfrak{B O S}$. gejdlofien hat.

Motive -, Brotololle 137.

I $\mathfrak{A}$ rt. 33 (P. 31, M. 55).

In Unfehung ber Rarbeşherten und ber 9Rit= glieber ber lanbeşhertlidien framilien fowie ber Mitglieber ber färuftliden familie Sobenzollern finben bie Boridriften beś $\mathbf{B O B}$. nur injoweit Inwenbung, als nimt bejonbere Boridriften ber 5ausberfafiungen ober ber \&anbesggejese abweidenbe Beftimmungen enthalter.
Motibe 21, Prototolle 137, SomPeriat 315, Sten Berint 345 .

B. 21rt. 57.

In Anjehung ber Landesherren unb ber $\mathfrak{D i t}$ glieber ber lanbeşhertiduen f̧amilien fowie ber Ditglieber ber Füritlifien Familie জobenzollern

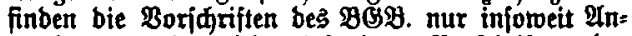
menbung, als niđt bejonbere Borfdriften bet Gausberfafiungen ober ber Lanbeşgeję̧e abrweidenbe Bejtimmungen enthalten.

Tas Öleide gilt in Anjehung ber Mitglieber

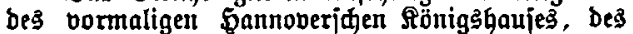

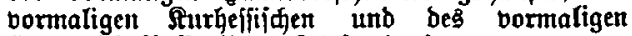
Đerzogliq Rafiauijaljen F̈üritenhaujes.

I $\mathfrak{A r t} .34$ (P. 32).

צn Anjehung ber Y̛amilientuerbălniffe unb

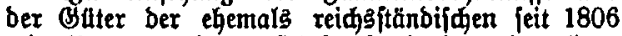
mittelbar getworbenen $\mathfrak{\$}$ ăujer fotwie bes ehemaligen Reiđgabels Bleiben bie Borjuriften ber Ranbes:

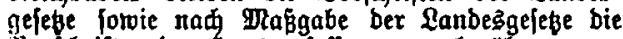
Borjariften ber \$auşberfaffungen unberibgrt.

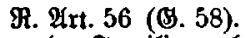

3it 2(njefutg ber Familienverhältniffe unb ber

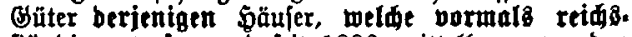
ftânbig gewelen unb feit 1806 nittelbar gewarben finb ober welde biefen \$äufern bejügltd ber

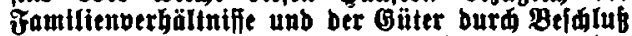
ber vormaltien beutfinen Bunbesverfammlung ober

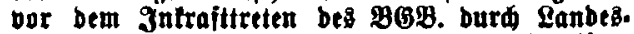
gejes gletidgeftellt worben finb, bleiben bie $\mathfrak{B o r}=$

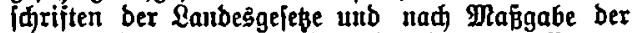
Lanbeggejeßze bie Borjurijten ber \$ausuerfaffungen unberibrt.

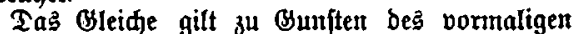
Reiđjabels unb berjentgen テjamilien Des lanb:

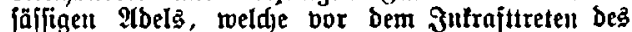
B\&OB. Dem vormaligen Reidsabel buth Ranbes: gejes gleidgeitellt worben find.

Protive 21-24, Protofolle 137-139, fomperidt 315 .

I $\mathfrak{A}$ rt. 35.

unberlihtt bleiben bie \oriariften ber Laubes: gefebe über Familienfibeitommiffe und Lehen, ein= idlieflid ber allobifizirten \&egen, forwie über bie Etammgüter.

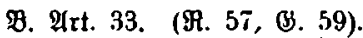

linberïhrt bleiben bie Ianbesgelebliden Bor= jdriften riber irantilienfibeifonmiffe unb Lehen, mit Einjalup ber allodifizirten Rehen, jomie faber Etanmt= güter.

Mative 24, 25, Brototulle 139 biz 141, PomBeridyt $\$ 315$.

I 9 rt. 36

lnberührt bleiben bie lanbeggejegliden Bor= jăriften, weldje bie Bejđräntung ciner Gypotbet voer B́nundfaulb an einem Brnnoftude, befien Belaftung nah bent in ben $\mathcal{A r t}$. 33 big 35 be:

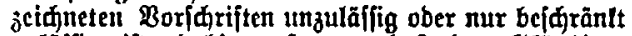

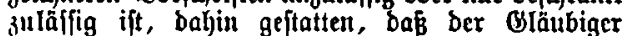
Wefriebigung aus bem Bnutujtüde nur im 2 sge ber 3wangsberwaltung berlangen faum.

\section{Motibe 25, 26, Protofolle 141.}

I $\mathfrak{A r t .} 37$.

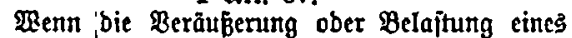
Begentitanbés nạ ben in ben Mrt. 33 bis 35 be= 3cid)ncten Borjarifiten unzuläifig ober nur bejđränlt zuläifig ift, fo finben gleidroobl bie zu Ouniten

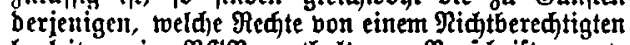
Gerleiten, im $\mathfrak{B} \mathbb{B} \mathbb{B}$. enthaltenen Borjuriften ent= ipred)ende Pinwentung.
8. 21rt. 34. (H. 58, (5. 60).

llubcrührt bleiben bit lanbeşgejeplidjen Bor= idriften, welde bie Bejtellumg einer Snpotbež.

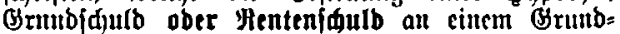
ftüde, befien Belaitumg naW Den in ben Mrt. 31 bis 33 (B. 57 bis 59 ) bezcidneten Borjariften

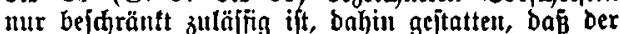
Blänbiger Bejriebigung aus bem Grundftüde lebiglida) int Rege ber Bmangşocrwaltutig fuden tamt.

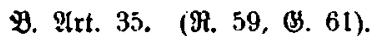

Ift bie Beräuß̈erung vber Belaitung eines Begenftanbes nad) bett in ben $\mathcal{A r t} .31$ bis 33 (\$. 57 bis 59) bezeichneten $\mathfrak{B}$ oridiriften unzuläffig oder nur beiđränıtt zuläifïg, fo finben auf einen Ermerb, bem bicie Borfdriten entgegenftchen, die Bur= [đriften bes $\mathfrak{B G S}$. zu Gunften berienigen, weld) Red)te bon cinem Ridjtbredtigten herleiten, ent= ipred)ende Antuenbing. 
I Art. 38.

Unberäht bleiben bie lanbeęgejeglifien Bor= 諙riften, welde bem gergredite angehören.

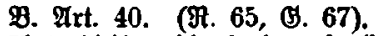

Unberühtt bleiber bie larbegacieslidien Bor= intiiten, welde bem Bergredte angehören.

Yit nad lambesgefesliger Boriarift megen Beidảbigung eines Gronditüđes burd Bergbau eine Enti币äbigung zu gewähren, fo finben bie Boridriften ber $\mathfrak{A}$ rt. 26, 27 (G. 52, 53) Atubendung, forweit niajt bie Lanbeşgeję̧e cin Anbereş be= fitimmen.

Motive 26, Brototolle 141, 342, Stomgeridt 316, Stengeridt 347 .

9. 2rt. 36. (ఆ.62).

[I jeglt].

Unberührt Gleiben bie lanbeägejegliden Bor= iđ̆riften über Mentengüter. $\left.{ }^{*}\right)$

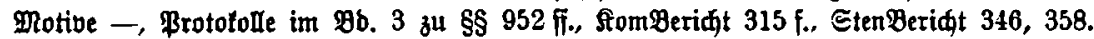

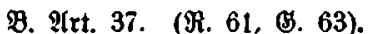

untberügrt bleiben bie Iandesgejeßliđen Bor=

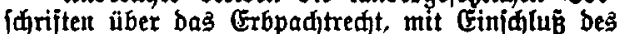

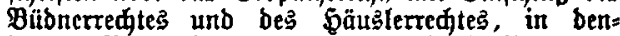
jenigen Punbesftaten, in meldien jolfie Redte be ftehen. Die Boridriften beg \$1002, (B). 1017)

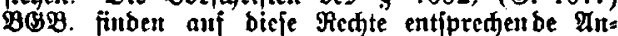
roendung.

Motibe -, Protololle im $9 b .3$ zu $\$ \S 952$ ff.

I $\mathfrak{A r t .} 39(\mathfrak{B} .38, \mathfrak{R} .65, \mathfrak{B} .65)$

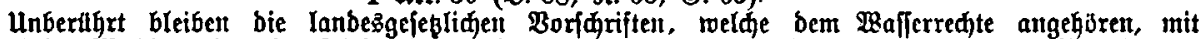

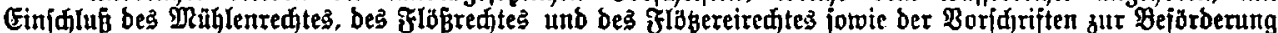

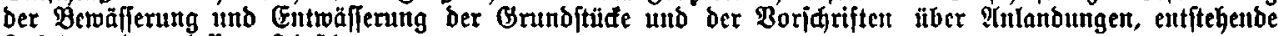

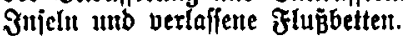

Potibe 26, 27, Prototolle -, Somberidt 316, Stenberidte 347.

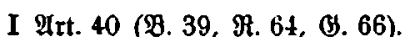

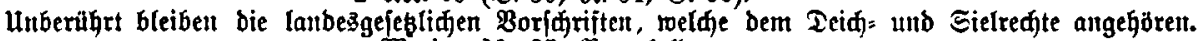
Motive 26, 27, Protofulle -

I $\mathfrak{A}$ rt. 41 .

Unberührt bleiben bie Ianbeg: gefestidien Boridriften, welde bie Semeinheitstheilung, bic $3 u=$ fammenlegung von Grounbftuden, bie Regulinung ber gutsherrlid)= bãuerlidien BerhäItniffie und bie qfbrofurg von Dienftbarteitert unt Reallaften betreffer, inşbei. aud infoweit, als bie Boriduriften auf bie Erwerbung bes Eigen= thumes, bie Begrünbung und 2uffhebung bon anderen Rediten an Erunbitiden unb bie $\mathfrak{B e}_{e}=$ ridtigung bes orrunbbudes fid beziehent.

Die auf bie Mblojung fid beziefenben lanbeşgefeslidjen Bor: ínifter finben teite Amwenburtg auf bie in ben 8585 bis 860 , 863 unt im $\$ 971$ 96 . 3 B@P. bezeidgneten Rehte.
B. $\mathfrak{A r t} 86$.

lnberüht bleiben bic lanbes:

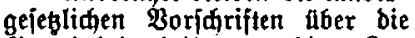
Gemeinhcits̄tl)eilung, dic $8 \mathrm{u}=$ fammenlegung volt Ornubitüden,

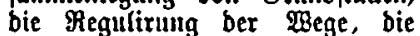
Drbnung ber gut3hertlid)=bäuer: lidien Berbältmifíc fowie bic $\mathfrak{A b}=$ lojung, Hmwanblung ober Fin: fdränłung bon Sienftbarteitent unb Reallajten. Dies̉ gilt insbci. aud von bell Boridriften , weláe fĭ auf bent Grmerb bes Cigenthumes, auj bie Begrïloung, Aenbenung und $\mathfrak{A}$ ifhebung von anberett Redten an Bnmbitudent unb auf bie Beriðtigung bezె Grunbbudes beziehen.
R. 2rt. 112 (\$. 113).

Uluberührt bleiben bie landess: gejeglidyen Boridgriften über bic Bujammenlegung von Brunb= ituden, äber bie Gemeinheits: theilung, bie Regultiruttg ber $\mathfrak{B}$ ege, bie Eronung ber gutढ̧herrlia, băuerlidłen Berfältuiffe jorvie ûber bie ablöjutg, Ilmnantulung ober Gitijuränlung von Dicuritbarteiten unb Reallaften. Ties gilt inşbej. aud bon ben 2oriduriftel, meĺde bie burd ein Meriabren btejer yrt begrünbetten gentin. fhaftliben IIngelegenbelten gum Gegenftanbe baben ober welde fich auj ben Frtwerb bes Gigen= thumes, auf bie Pegründung, $\mathfrak{A}$ est= berung unb 2 ufhebutg von an= beren Mediten an Grunditiden unb auj bie Beriđtigung bes

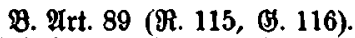

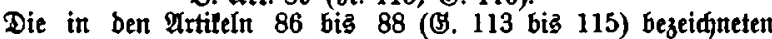
lanbesgejegliden Borjariften finben teine $\mathfrak{A}$ nwenbung auf bie nad ben $\$ \S 897,901,902$ (अ. 912, 916, 917) bes $\mathfrak{B O B}$. zu entriqtenben Belbrenter und auf bic in ben $\$ S 1006,1007$ (G. 1021, 1022) bes B(SB. beptimmten Unterfyaltungsppflid)ten.

Motibe 27, Brototolle 142-144.

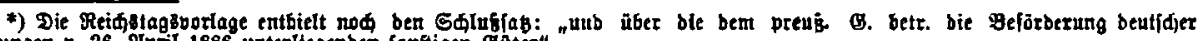
Unitebelungen v. 26. April 1886 unterliegenber forfitigen Gater". 
[I feglt].

1 2rt. 42.

Untberührt beiben bie Bor|driften ber Ranbes= geieße über bie 3wangsenteignung.

3it auf Brunb einer lanbeşgejeglimen Boríntijt bem Eigenthümer eitter Eahe wegent ber im off. 3nterefie erfolgenben Entziehung, Beidabigung ober Benupung ber 巨ade ober twegen Bejurănhung bę Figenthumes eine Entiąäbigung zu getwähren, jo finben, foweit ridt bie $\mathfrak{Z}$ anbesgejeze ein Anberes

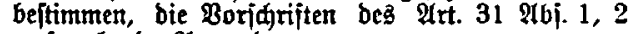
entipredjende Antoendung.

Mrotive $27 \mathrm{j} .$, Brototolle 144.
J Irt. 43.

Unberlihrt bleiben bie Borfariften ber Lanbes= gefę̧e aber 3ago unb Jijherei, mit Finjd)lus ber Borfariften äber bell Erją Des $\mathfrak{B}$ illofdabents.

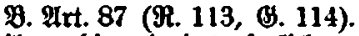

unberüht bleiben bie Ianbesgefesliden Boriđjriften, nath welder bie bem Staate ober einer off. PInftalt in Jolge ber Dronung

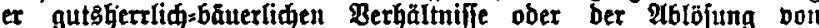

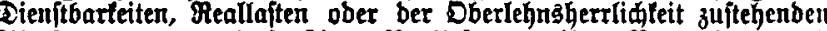
Ablöjungşrenten unb fonftigen Reallaiten zu ihrer Begrünbung unb

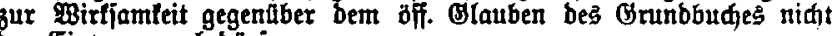
ber Eintragung bebitrien.

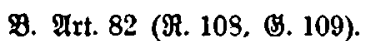

unberuhrt Gleiben bie lanbesgejebliden Bor= fatriften über bie im aff. Interefie erfolgenbe Ent= ziehung, Bejđäbigung oder \$enub̧ung cimer 巨a⿱je, Bejørănhung bes Cigenthuntes uno (Entjithung obet

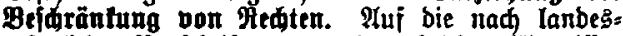
gejeslider Bor\{qrift rogen eines joldhen Eingriffes zu getadhrenbe Entjhäbigung finben bie Borihntiften ber Urt. 26, 27 (B. 52, 53) श्ntwentung, jotweit nid)t bie Lanbes̄gejeß̧e ein Ánberes̄ bejtimmen.

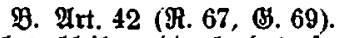

llnberubrt bleiben bic Ianbesgejeblidien $\mathfrak{B o r}=$

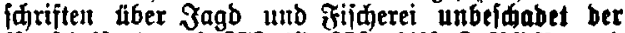

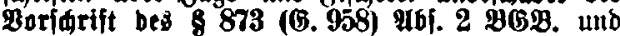
ber Boriariften bes $\mathfrak{B G 9}$. über bett Griał bes Wilbjadabents.
Potive 23 f., Prototolle $144 \mathrm{f}$. und $\mathscr{b b} .2$ zu $\S 758$.

B. Art. 43 (भ. 68, ß. 70).

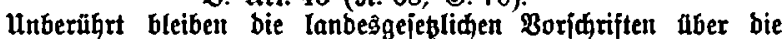

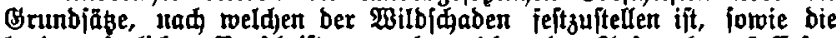

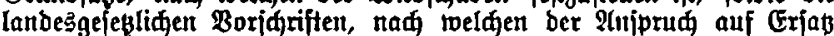
beş Wilbianabens innerhalb einer beftimmter frijt bet ber zuftănoigen Behörbe geltenb gemadt twerben mus.

Motive -, Brotololle 145.

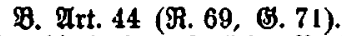

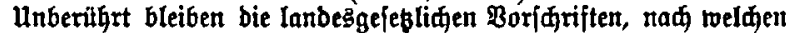

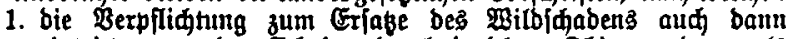
eintritt, went ber Edaben burd jagbbare Thiere anberer als

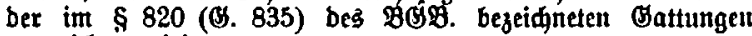
angeriditet mirb;

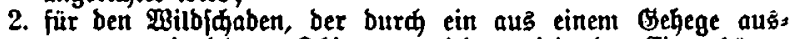
getretenes iagbbares zhier angeriatet witb, ber Gigenthüner ober ber Befiger bes Eeheges berantwortlid ift;

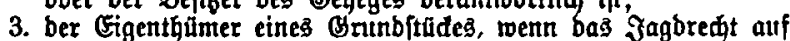
einem anberen Branbftitde nur gemeinfdjaftlid mit bem Jago= redite auf feinem Snninbitide ausgeibt werben bari, für ben

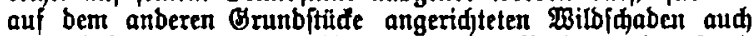
bann Gaitet, toent er bie ignt angebotente Bahtung ber $\mathfrak{3} a \mathrm{~g}$ abgelehnt hat;

[I feblt].

4. Der Wilbihaben, ber an Bärten, Dbitgãrten, פeinbergen, Baumidullen mb einzelftchenben $\mathfrak{B a n m e n}$ angeriatet wirb, bann midt zu erjesen ijt, wenn bie Serltellung bon saub: borridtungen unterblieben ift, bie unter gewöhntiajen Hniftäuben zur Ubtoendung bes Edjabens austeiden;

5. bie Berpfliđtung zum Edabens̄erjabe im Falle beß $\$ 820$

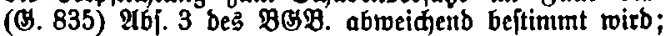

6. bie Bemeinbe an Etelle ber Gigenthưmer ber zul eintem $\mathfrak{J} a g \delta=$

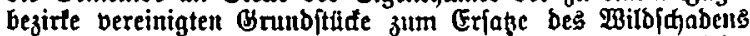

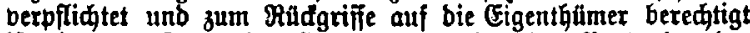
ift ober an Stelle ber (Figenthümer oder bes Berbanbes ber Gigenthümer ober ber Gemeinbe ober neben ihnen ber Sagbs

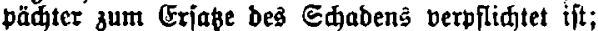

7. Der zum Erjabe bes \$ilbjajabens Berpflidtete Critattung bes geleifteten Erjakes bon bemjenigen berlangen lam, welaher in

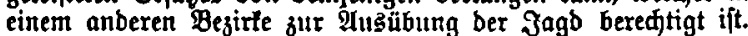
(शr. 7 ift in Som

Protive -, Protololle 145 u. Bb. 2 zu $\S 734$ a, SomBeridt 316. 


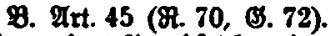

[I feglt].

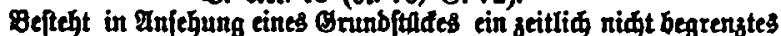

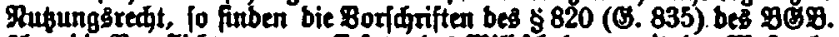

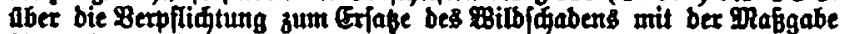
antenbung, baß an bie Stelle bes Eigentgatmers bet gaupungsbes redigte tritt.

Motive -, Protololle 145 und im Bb. 2 zu $\S 734$.

I Prt. 44.

Unberaht bleiben bie Borfitriften ber Ranbes:

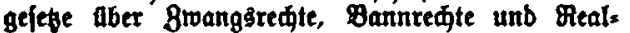
getwerbeberedigungert.
9. Prt. 47 (M. 72, (3. 74)

Unberilgt bieiben bie lanbesgelebliden Bor:

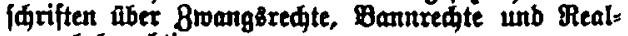
gewerbebertdigungen.

Motive 29, Prototolle -, Pomperidit 317 .
I 9rt. 45.

unberlynt bleiben bie Porfdriften ber Larbes: gefebe dber bie regalien.

[I feglt].

[I feğli].

I 9rt 46.

Unberthert bleiben bie lanbes: gelesliden gorjhriften, welde bem Gefuberechte angebdren, unbe:

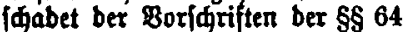
bis 71, bes \$ 224 थb . 2, ber 85364,711 bis 713,1277 bes

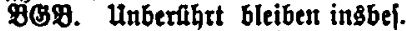
aud bie Borfकriften ber Lanbesigeiese aber bie Shabens: exfałpflidt beşjenigen, welder Cefinbe zum toiberregttidien Ber: laffen bes Dienfes verleitet ober in Penrtnis eines nod beftehenben Gefinbebientoerbaltnifes in Dienit nimmt ober meloger ein unriatiges Sefinbeblenftgeugnis extheilt.

8. 2xt. 46 (M. 71, 73)

unberlibut bleiben bie lantbesgelebliden Bor: idriften aber Megalien.

Motibe 29, Brotololle $145 \mathrm{f}$.

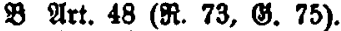

unberahrt bleiben bie lanbesgelegliden Borfdriften, welde bem

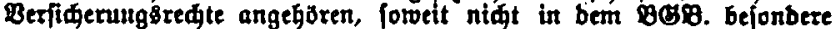
Beftimmutgen getroffen finb.

Motive -, Brotololle $179 \mathrm{f}$.

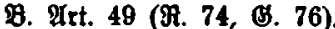

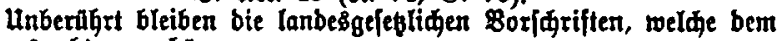
Berlags̈redte angehören.

Motibe -, Brotololle $170 \mathrm{f}$.

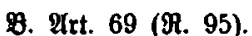

Unberibut bleiben bie Ianbes: gelesliden Borjariften, welde bem Gefinberedte angeboren, unbes fáabet ber Borjariften ber $\$ \$ 100$ bis $11 i, 127,272,610,615,816$

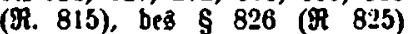
96j. 2 unb Des $\$ 1343$ (भ. 1341) bes aud bon ben Borfdriften tber bie SAabenserjaßpflidt besjenigen, welder Sefinbe zum toiberredts Iiden Berlaffen bes Dienites ber leitet ober in Renntrif eines nod beftehenben Gefubeverhd̆tniffes in Dienft nimmt ober ein unriळtiges Dienitzeugnīß extheilt.

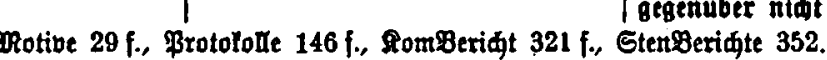

B. 2rt. 95. gejeblident bleiben bie lanbes: Gefinberedte angehoren. Dies gill insbel. and von ben Bor: |d riftett aber bie Edabengerfas: pflidt besjenigen, welder Befiube zum triberreditliden Berlafien bes Dienftes verleitet ober in Renutuis eines nod beftehenben Befinbeder: băltniffes in Dienft nimmt ober ein untiatiges DienftzengniB ers theilt.

Die Borfdriften ber 68104 bis $115,131,278,617$ bis 619 624,831 , bes $\$ 840$ 9bi. 2 unb bes $\$ 1358$ beş 909 . finben Anwenbung, ble Borfurtften bes 8617 iebod unr injowett, als bte sanbesgefese bem Befinbe nitht weittrgebenbe Finlpribe be. währen.

Ctn gübttgungsredt fteht bem Dienftberedigten beu Gefinbe gegenüber nigh iu.
I 2 rt. 47.

unberalyrt bleiben bie lanbesgejebliđen Bor*

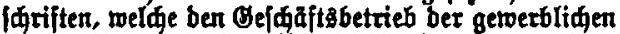
Bjanbleiger unb ber Pfanbleiganltalten betreffen.
刃. 9t. 68 (9. 94, (3. 94). unberlurt bleiben bie lanbesigejegligen $\mathfrak{B o r}$

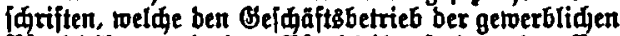
Pianblether unb ber : Bfandlelhanltalten betrefien. Luberahrt bleiben bie lanbesgejegliden $\mathbf{B o r}=$ idriften, nad welden off. Bfanbleihanftalten

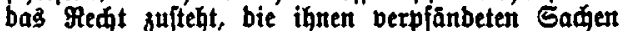
bem Perechtigten nur gegen Bezaflung des auf bie

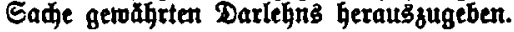

Potibe 30, Prototulle 147, Pom Bexint 321, StenBeriate 352.

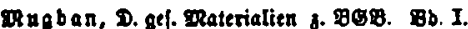


I 9.t. 48.

Unberabet bleiben bie lanbes.

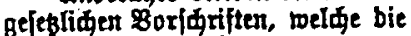
Bitflamieit von Edentunger an Pitglieber religiofer Drben ober orbenasbnliger Pongregationen bon ftaatlider Sentebmigung $a b$, Găngig maßen.

unnberlbat bleiben bie lanbegz: gefeblifen Borfariften, welde bes fimmen, bof Dritglieber religiőfex Drben ober orbensabnlider fon: gregationen bon Tobesibegen nux mit ftantlider Benebmigung $e x$ : werben Ionnen. $\mathfrak{B}$ irb bie Ges rebmigung extbrilt, fo gilt fie als ffon bor bom Erbfalle ertheilt; witb bie Benehmigung berjagt, fo ijt bie zum Crtwerbe berufene Berjon als bor bem Erblaffer geftorben anzuleben; ber $\$ 2154$ bes 989 . findet entipredenbe Invenbung.
๑. Art. 62 (भ. 87).

unberahrt bleiben bie lanbes.

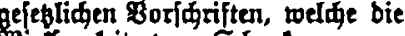
Butfamieit bon Edentungen an Pritglieber religioj/er Drben ober orbensabnliaber Rongregationen von ftaatliger Benthmigung $a b=$ Găngig mađen.

Unberifht bleiben bie lanbes: gejebliden Borjdriften, naळ welden Mitglieber religiofer Drben obet orbensabnitider Qongregaz tionen mut mit ftaatlidier Be. nebmigung bon robestoegen cr: mexben tönnen. Die Boridriften bes Art. 61 9bj. 1 Sab 2 finber entipręugnbe Artwentung.

Dotive 30 ff., Brototolle 14 i ff., Somperidt 310 ff.

[I, : P. feflen].

I Art. 49.

Unberithrt bleiben die Vorschriften der Landesgesetze über die Verualtung und Beaufsiehtiguny jur. Prrsonen.

unberligrt bleifen bic Ianbes.

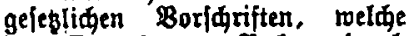
ben Ermetb bon Pledten burd jur. Ber[onen bejđrănten ober von ftaatlider Benthmigung abyăngig madien. Jift zil einem Ertwerbe bon Tobeswegen ftaatlide Be: nelymigung erforberlid, $f_{0}$ finben bie Boridriften bes 9rt. 48 Mbl. 2 Sas 2 ent/predenbe Antenbung. श्uf jur. Berfouten, berest jur. Berjönlidhteit auf befonberer reidis. geleblider Borfdrift berubt, finben bie Borfuriften bes 2. 206. leine Qnivenbung.

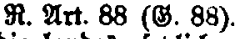

unberabut bleiben bie lanbesgejeģligen Borjuriften, welde ben

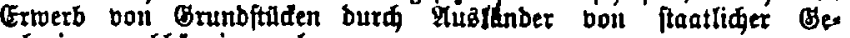
nehmigung ab̧ăngig mađ̆en.

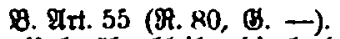

Unberlhtt bleiben bie lanbes: geleblidien Borjariften Aber bie Beauffidigung jur. Berfonen.

B. भrt. 61 (ஜ. 86).

unberllgrt bleiben bie lanbes. gelegliden Borfiriften, welde ben Ermerb bon Medien bura jur. Ferfonen befdrănfen ober bon ftaatliner Bestebmigung abhăngig madell. \$Birb bie nad bem Ranbesgelebe zu einem Erwerbe von Tobestregen exforberlide Be: nebmigurg ertheilt, fo gilt fie als vor bem Ẽtbfalle ertheilt; roird fie berweigert, jo gilt bie jur. Perjon

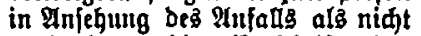
vorbanben; bie Borfarift bess $\$ 2020$ bes $¥ \circlearrowleft 9$. Findet ents iprechenbe Entwentung.

Die Vorschrijten des Abs. 1 finden keine duwendung anf jur. Personen deren Rechtsfähiykeit auf reichrgenetzlichen, neben dem $B G B$. besteheriden Vorschriften beruht.*)
B. Frt. 87.

unberifht bleiben bie Ianbes: gejeglidgen Borfdyriften, toelde bie isgitfamieit bon Shentungen an Dritglieber religiojer Drben ober orbensabnliager fongregationen bon ftaallider Bentegmigung $a b$. băngig madien.

linberalgrt bleifen bie lanbes: gelestiden Boriđuriften, na出 welden Mtitglieber religid jer Drben ober orbensabunlider Aongrega. tionen mur mit ftatrifier nebmigung bon Sobesivegent er. reetben tönnen. Die Borfdriften bes 2 rt. 86 Eas 2 finbent ent ipredenbe Anwentung. Mitglieber folder refigiojex Drben ober orbensagntid,er gon: gregationen, bei benen Gelabbe auf Rebenşzeit ober auf un: bejtimmte geit nidt abgelegt werben, unterliegen uidt ben in ben $\mathfrak{A b j}$ 1, 2 bezeiqneten finriften. 


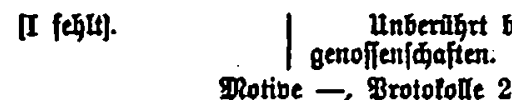

D. Frt. 57 (भ. 82, (0. 83). \$Rotive -, \$rototolle 214 ff., Somberift 318.

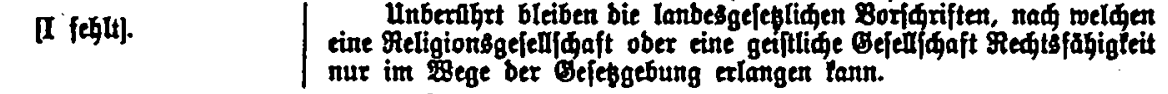

8. Gxt. 58 (भ. 83, 9. 84).

Qomperidt 318.

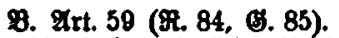

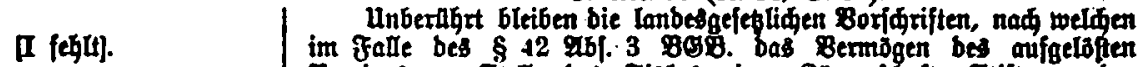
Percines an Stelle bes IFishus einer gasperinaft, Stifung ober Inftalt bes off. Redtes anfăt.

Motibe -, Prototolle $154 \mathrm{f}$., Qomberidgt $318 \mathrm{f}$.
[I feglt]. $\quad$ Cnberïhrt bleiben die Landrgesedzlichen Vorechriftew über das Erlöichen oder die Lmioandeluny ron Stifturgen.

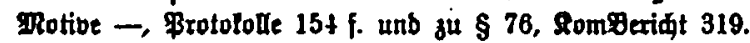

$$
\text { I Art. } 50(B, B .-, \text { G. }-) \text {. }
$$

Onberiuhrt bleiben die landesgesetzlichien Vormchriftern. ucelche die Zulässigkeit des Konkurecs über das Vermögen der in $\& 15^{4}$ des EG. zur CPO. bezeichneten jur. Personen beschränken oder ausschliessen.

\author{
IRotibe 35' 'Brototolle -
}

I Art. 51 (B. - , B. -, G. -).

Onberithrt bleiben die landengeseszlichen Vorschrifien, nach welchen die privatrechtlichen Vor. schriften der CPO. auf die nicht nach den Vorschriften der CPO. zu erledigenden Bechtsstreitigkeiten Anwendung finder.

Protibe 35, 36, \$rotololle 155.

I Irt. 52.

Unberdhrt bleiben bie Boridriften ber Ranbes: gefeßze, fofern fie beftimmen, bon welden Borgängent in ben nidt nad ben Borjariften ber E\$D. 34 er: Iebigenbent Bedisftretigteiten bie nad ben Bor 俰riften bes $\mathrm{BOS}$. an bie Slagerhebung unb an

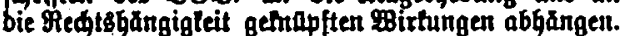
On Ermangelung polder lanbesgejeslider $\mathfrak{B O T}^{\circ}$

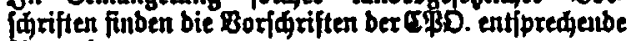
Yintoenbung.

Mlotive 35, 36, \$rotololle -

I It. 53.

unberllyt bieiben bie Boridriften ber Lanbes: gelebe aber bie Redistoergalmiffe aus einer Siders heitsleiftung, welde auf Eranb, einer im off. Pedte beruhenber Berpflidturg regen ber fatñulg eines Amtes ober wegen bes Oetriebes eires Setverbes exfolgt.

Mlotive 37, \$rotolode 155, 156.
I Irt. 54.

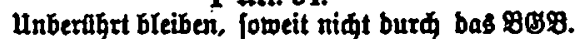
cine belonbere Beftimmung getroffen if bie Bor: fhriftent ber ganbesgefege aber bie vermögensredt= liden Anfprafe unb Berbinbliditeiter ber Đeanten

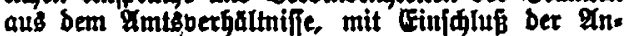
iprudige ber finterbfiebenten.
8. Irt. 125 ( 9.152, (7. 152).

Unberthet bleiben bie lanbeşgeiesliden Bor. fdriften, welde far bie nimt nad ben Borfdriften ber CQD. Ju exrebigentben Fledtşfreitigleiten bie Borgange beftimmen, mit bener bie nad ben $\mathbf{B o r}$ [ariften bes 909 . an bie llagergebung unb an bie Peehtsbăngigleit gehıpften oirfungen eintreten. Soweit folde Borjariftent feblen, finben bie Bor: |

Unberalbrt bleiben bie Ianbeseletelidet Bor. idriften aber bie Megtsvergalinifie, welde lí aus einer auf Brunb bes off. Medites wegen ber fothrung

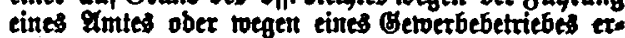
folgten Sidpergeitsteifturg exgebent.

8. Irt. 53 ( $\Re .78$, (6. 80).

Unberdhat bieiben, loweit nimt in bem $\mathbf{B G P}$. eine bejonbere Beftimumung detroffen int, bie lanbes. gejétididet Boridriftent aber bie bermogens redtliden Injprlide unb Berbinbliditeiten ber geamten, ber

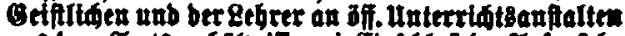
aus bem Imtspergåmifie, mit Ginf bex Ginterbliebenen.

unteraht bleiben bie lanbesgejefliden Bora 俩riften aber bas \$rrainbenredt.

grotive 37-39, Brotololle 156, 157. 
[I feglt].

P. Prt. 54 (P. 79, (3. 81)

unberaht bleiber bie lanbesgefestiden Soridriften, weldhe bi

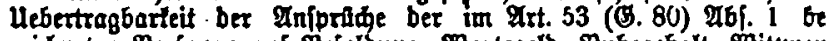
zeigneter Berfoner auf Befolbung, Bartegelb, Muhegehalt, \$oittwen

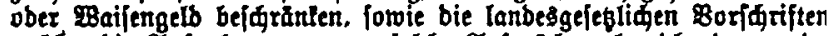
welde bie Eufredmung geges folde Infpridie abreidiend yon be

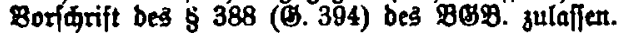

Mlotive -, Frotololle 156 f.

1 Art. 55 (B. - , R. -. G. - ).

Unberührt bleiben die Forschriften der Lanlesgesetze, welche bestimmen, dass ein Beamter wegc, des aus fahrlässiger Verletzung einer Amtspflicht entstandenen Sihadens erst dann in Anspruch gc nonimen verden kann, winn der Beschädigte auf andere Weise Ersatz des Schadens nicht zu er langen vermag.

Motibe 39, \$rotololle -

I $\mathfrak{A r t} .56$.

unberdfrt bleiben bie Boridriften ber Ranbegs: gefese aber bie ఏaftung bes Staates, ber Oremeinber und anberer Rommunalberbāube (Brobinzials, Preig:。 Amtsoerbănbe) füt bet bon ihren Beamten zugefígten Shaben, unbejuabet ber Borfurifter ber $\$ \$ 46,63$ Des $\$ 8 B$.

8. Irt. 30 (श. 75, 9. 77).

unberübrt bleiben bie lanbeşgefeg liđen Bor. |áriften afer bie Sajtung bes Staates, ber (Bemeinben unb anberer Pommunalberbănte (Brobingials, Strig:

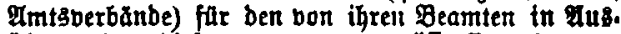
ïbung ber biejen auvertreuten iff. Gewalt juge.

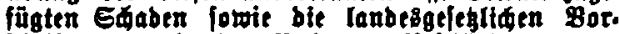

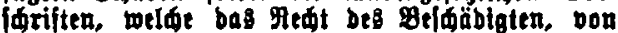
bem Peamten ben Erjas eints folden Stabens ju perlangen, in/owett ausinilieben, aIs ber Staat ober ber Rommunalberbanb baftet.

Mrotive $39 \mathrm{f}$., Brotololle $157 \mathrm{f}$., Rom8eridt 317 .

9. Ant. 51 ( (R. 76).

Linberahyt bieiben bie lanbeğ: gefeglident Borfdriftert uber bie 5̧aftung ber Beamten für bie bon ibnen angenommenen Stellbertreter unb Beburfen. Seotive -, Prototolle 157 f., Romberidt 317.

B. Art. 78.

Unberahrt bleiber bie lanbes. géesbliden Boridriften, ná meI. den bie germten far bie bon ifnen angenommenten Stellbertreter unt Bebulfer in weiterem umfange alg ná bein $\mathbf{8 0 B}$. baften.

9. Art. 52 (Я. 77).

unberahrt bletben bie lanbes: gefeslidien Borjdrifter aber bie Saftung ber zur amiliden fefit:

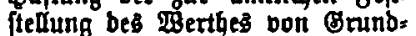
ftiderl beftellten Sadverftanbigen für benz ous einer Berlebung ihrer Berufäpflidit entffegenbent sđaben.

$$
\text { Mlotive - Frotololle } 157 \text { f. }
$$

B. Art. 79.

unberahrt bleiben bie lanbes. géeslider Borínriften, nán wel. wen bie zur amtlighen iseffitetlung bes gserthes von Grumbitaden be: ftellen Gaduerftändiger far ben aus einer Berlegung ihrer Berufs. pflidi entfanbenen Sajaben ta weiterem unfange als nad bem $\mathfrak{B G P}$, haften.

\section{2.4t. 57.}

Unberthart bleiben bie lanbesgejebliaten Bors

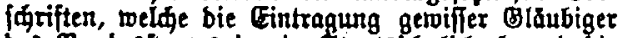

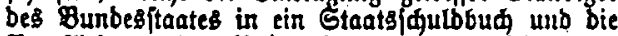

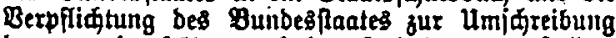
ber von bemielben auf ben Jnhaber ausgeftellten

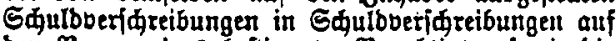
ben Namen eines beftimmien \$eredtigten fowie bie auss einer jolden Eintragung ober limfareibung

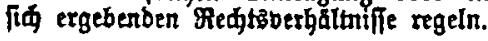

B. 2rt. i1 ( 97 , (3. 97)

Unberabrt bleiben bie Iandesgejebliden Bor:

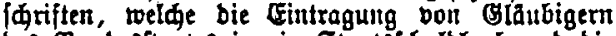

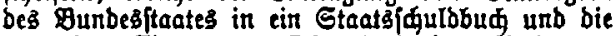
aus ber Eintragung fi申 ergebenben Redtsber. Găltnifi]e, insbef. bie Hebertragung unb Belaftung eture $\gg$ ubforberung, regelu.

Sotweit nad biejen Bor|ळrijtett eine Ehefrau beredtigt ift, felbftănbig Untrăge gu ftellen, ifít

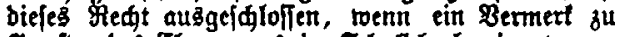
Outften bes Ehemantmes im Shutbbude eitigetragent ift. Ein folder Bermert ift eirzutrager, vern bie EGefrau obes mit ihres Buftimmung ber Egemann bie Cintragung beantragt. Die Ehefrau ift bem Egemanne gegentiber zur Extheilung ber Buftimmung berpflidgtet, wenn fee nad bem unter ihnten bejtchenben Suterftanbe aber bie Oudforberung nur mit $\mathcal{B}^{4}$. ftimmung bes Egemannes verfügell lann. 
[I, 8., $\boldsymbol{\text { P. }}$ fehlen].

[I feglt].

\section{PomBorlage 9rt. 97a (G. 98).
bleiben bie lanbesgéeblichen \\ Unberligt bleiben bie lanbesgefesliden Boridriften aber bie

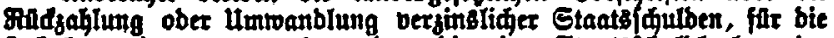

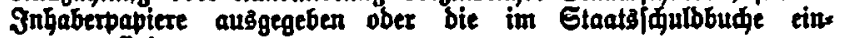 getrager finb.}

Rotive -, Protololle -, lomberimt 322 .

9. Frt. 72 (M. 98, 9. 99).

Unberabrt bleiben bie Ianbesgefesliden \$oridiften ther bie off. Spartafien, unbefjabet ber Borfiniften bes \& 793 (B. 808)

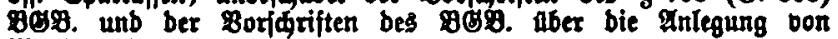
Dainbelgelb.

Motibe -, Protololle $161 \mathrm{f}$.

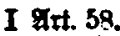

Unberahet bleiben bie Borfdriften ber Lanbeg.: gefebe aber bie Friften, binnen welder eine gemietbete 280 hrung bei Peenbigung beş Miethss berbătniffes von bem MRietger zu răumen ift.

Motibe 40, Prototolle 164f.

I Art. 59.

Unberabrt bleiben bit lanbesgejegliden Bor:

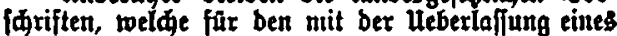
Sutes in Berbinbung ftefgenben Reibgebingsuertrag.

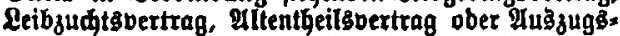

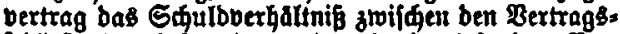
ifliebenben injoreit regeln, als eine bClonbere Ber: einbarung nidt getroffen wirb.

Potive 40, 41, Brototolle 165 .

9. Irt. 67 (भ. 93, อ. 93).

unberahrt bleiben bie lanbesgejebliden Bor. 佁rifteh âber bie Friften, gentietbete Pänme bei Peenbigung beș gRietḩs. berbăltniffeș zu răumer fint.

9. Art. 70 ( R. 96, 0. 96)

Unberagrt GTeiben bie Ianbesgefabliden Bor. fdriften aber einen mit ber Uleberlaffung eines

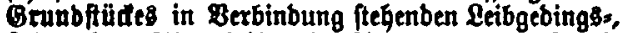
Leib zuक fie bass fin aus bem Bertrage ergebenbe Sdulb:

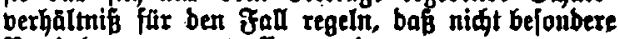
Beteinbarumgen getroffert wetben.

I $\mathfrak{\text { Ixt. }} 60$.

unberahrt bleiben bie lanbesgejegliden Bor= idriften, nah welden in Pnfehung ber bon bem

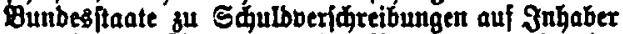
ousgeftellten Sinsfdeine ober Fententhupons ber im

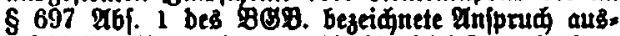
geidloifen ift, aum wenn bie Musjifliefung in bem ginşकeine ober Rententupon nidt ertlärt ift.
Shotibe 41, Protololle 165 f.

9. Art. 73 (R. 99, (5. 100).

unberührt bleiben bie Ianbesgeleblitien Bor.

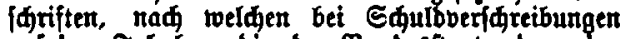
auf ben 3uhaber, bie ber \$umbeşteat ober etre thm angetörembe förperianaft, Stiftung obe ginftalt bes off. Fedites augftent:

1. bie Gilttglett ber unterietinang bon ber

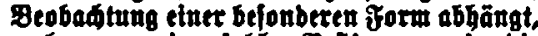
aud werna etue folde geftimmang in bie urtunbe aidt aufgenommen ift;

2. bet im $\$ 789$ (\$9. 808) צ65. 1 be 989 . beseidnete Anipmi auggejdlofen ift, aud wern bic Rusidließung in bem Birgs ober Fenten/fueine nidgt beftimmt ift.

9. Art. 74 (भ. 100, 3. 101).

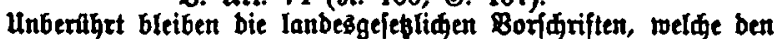
Bunbesflaat ober ign angehorenbe dorperidaften, Stiftungen unb OInftalten bes off. Feedtes abrveidend von ber Borfdrift bes

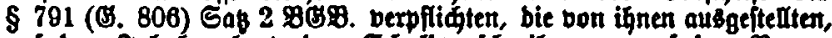

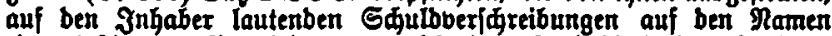
eineş befitimmten Beredtigten umbul|

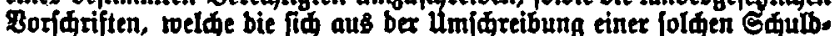
beridreibung ergebenben Fed ettlarnang, regeln.

$$
\text { Motive -, Protololle } 158 \text { fi. }
$$

I भit. 61 .

unberthrt bleiben bie Borfariften ber Ranbes. gefege aber ftraftlosettarung unb Bablungsfperte

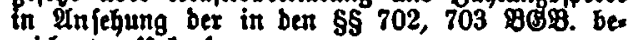
zeidneten urtunben.
B. Itt. 75 (भ. 10L, \&. 102).

Unberabrt Gleiben bie Ianbesgejektiden Box.

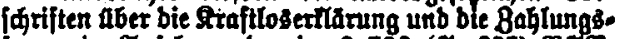

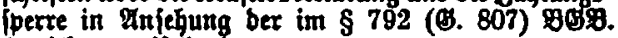
bezeidneten urtumber.

ulnberabrt bleiben bie Ianbeşgejęliden Bor-

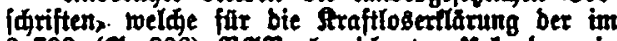
\$ 793 (ङ. 808) 809 . bezeidneten uthurber ein anberes Berfagren als bas Yufgebotsoerfagren beftimmen.

Motibe 41, Protololle 166 unb วu $§ 736$. 
P. Prt. 76 (9t. 10?, \&. 104)

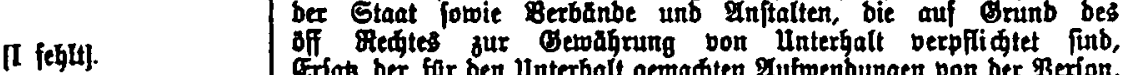

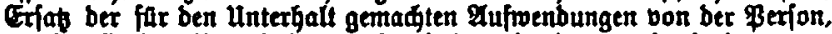
welder fie ber lunterhalt gewabrt haber, forwie bon benjenigen ber:

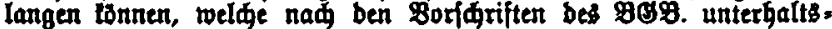
pflifitig waren.

Protibe -, Protololle in Bb. 4 zu $\S 1487$ unter II.

I Art. 63.

Unberahnt Gleiben bie Borifriften ber Ranbegs gefese aber bas zum Ediube von Enunbitaden und beren Erzeugniffen geftattele Redt ber Ppanbung bon Saden unb aber bie Entridtung bon Pfardogelb ober Exabgelb.

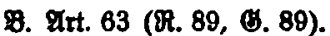

unberabrt bleiben bie Ianbesgefestiden Bot:

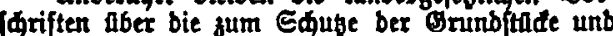
ber Erzeugriffie von Onnunbitiden geftattete \$fänbung von Gadien, mit Ginfiflus ber Borjdriften aber bie Entridtung von \$fanbgellb ober Erfakgelb.

Dotibe $41-43$, Brototolle 167 f.

I Irt. 63.

unberahyt bleiben bie Borfdriften ber Lanbes: geiebe aber bie Sqabenserjappflifit in ben frallen bes gurviberganbelns gegen bie zum Eqube von Grunbituden exlaffenen Etrafgeleşe.

Mrotioe

I $\mathscr{A r t} .6+$

Unberabrt bleiben bie Borfdriften ber Lanbes. gefebe aber ben Erjas bes Shabens, welder bei eines 8ujammenrottung, cinem E̊uflaupe obet einem Sufruhre entitanben ift

Motibe 43, Protololle -, Romperidt 323.

I 97t 65

Unberlbnt bleiben bie Borfdriften ber Lanbes. gefebe aber ben Pulprud auf onderftattung bon Jff. Abgaben unb Roften eines Betfahrens, a beten Entridtung cine Berpflidtung midt beftenben bat. Motive 43, Brotololle 168

จ. Art. 80 (Я. 1ก6. H. 107).

Unberibnt bleiben bie lanbesgefesliden Bor: 低riften uber bie Berpflifitung zum Exjase bes Exabens, ber burn bas 8uwiberbanbeln gegen ein zum Sqube bon Bumbitiden erlaffenes Strafgefet berurfact twiro.

Brotololle -

タ. शrt. 81 (9. 107, (3. 108).

Unberthrt bleiben bie lanbesgefesliaten Bor: Ifriften uber bie Berpflidhtung zum Criage bes Edabens, ber bei ciner Bufammentothung einem guflaufe ober cinem gufrubre entfteht.

B. 9tt. 77 (Ot. 103, (3. 104).

unberlyrt bleiben bie lambesgejestiden Bor: futiften aber ben 9ujprú auf Prider|tattung mit Intredt exbobener off. Ébaben ober Roften eines

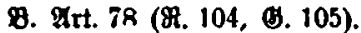

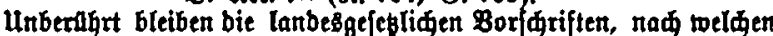
ber Unternehmer eints Cifenbahnbetriebes ober eines anberen mit gemeiner Befahr verbunbenen Detriebes far ben aus bem Betriebe entftebenben Shaben in weiterem Lmfange als nad ber Borfidriften

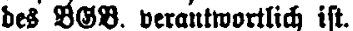

Potibe -, Protololle $166 \mathrm{f}$.

B Frt. 79 (M. 103, E. 106).

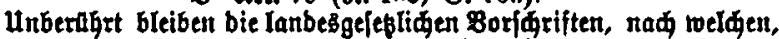
wern ein bem off. Bebrauge bienenbes gunbftild su einer Inlage ober gu einem Betriebe benust werben barf, ber luntermehmer ber Rnlage ober bes Petriebes fär ben Sqaben berantwortliq ift, ber bei bem sff. Bebraude bes Grunbftades burळ bie Anlage ober ben Betrieb vecurfact wirb.

Motive - Protololle $166 \mathrm{f}$.

I Art. 66.

Unberthet bleiben bie Ianbesgefegliden $80 r=$

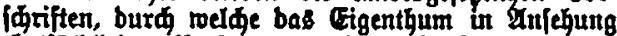
thatfadlider Berfingungen in off. Sntereffe be: 低rånt witro.

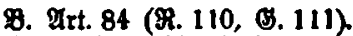

unberilhrt bleiben bie Ianbesigefebliduen Bor. iariften, welae in off. Intereffe bas Etgenthum in

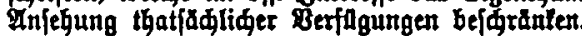

Motive 43, 44, Brotololle 170.

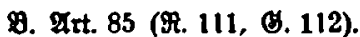

unberahnt bleiben bie Ianbesgefesliळen Borfariften uber bie

[I ferft]. Behanblung ber einem Gifenbahn. ober RIetnbahnunternebmen ge mibmeten Grandftide und fonftiger Bermögensgegenftänbe als Cinheit (Bagneingeit), ther bie Berăupenung unb Belaftung einer foldgen 
Bahneingeit ober ifrex Peftanbtheile, insbef. bie Belaftung in Zalfe

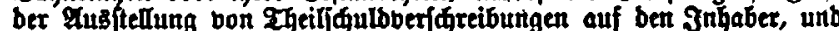

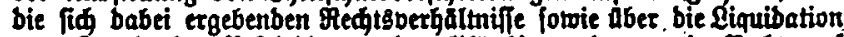
zum groede ber Befriebigung ber Blăubiger, benten ein Fedt auf abgefonberte Befriebigung aus ben Beftanbtheilen ber Bahneinheit zuftebt.

Potive -, Brotololle 170.

1 Irt. 07.

Unberdhrt bleiben bie Ianbessgefeslidien Griften burth toel bie Peate bes Eigen. thamers bes eirem 2 alb= grunbitide benadbarten Grunbitides in $\mathfrak{A n}_{\mathbf{n}}$ felung ber auf ber Grenze ober auf bem Balbgrunbftude ftehenben Dåume unb Străuder anbers als im $\$ 855$ घb5. 2 unb im 8861 BOP. beftimmt toerben.
B. 2rt. 95 .

Unberifht bleiben bie Ianbesgefegliden Bor:

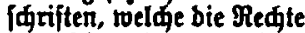
bes Eigenthlumers eines Grunbltades in भnfegung ber auf ber Brrenze ober auf bem Radbararunb: itfide ftehenben gaxume uno Străugher făr bent 子all, bas bas Radbar. grunbitid ein ærals: grunbftid ift, abroidenb von ben Borfariften bes $\$ 895$ unb bes $\$ 904$ abf. 2, 3 bes 889 . be fimmen.
भ. Irt. 121.

lunberlhyt bleiben bie lanbesgelebliden Bor =

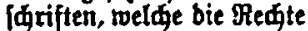
bes Gigenthâmers eineş Orunbitades in OAnjehung ber auf ber Brenze ober auf bem Nałbargrunb= ftuffe ftehenben garume unb Strôuder far ben Fall, baş bas গałbar: gnunblata ein 2 alb. grunbitud ift, abreidenb von ber Borfdriften bes \$ 894 unb beş 507 Q6 2,3 beB 989 . be= ftimmen.

Hnberahat Eleiben bie lanbeşgejesliden $\mathbf{B o r}=$ [Ariften, weldje bie Fed,te bes Eigenthamers eines (S) nunbitudes in Anjebung ber auf ber Grenze ober auf bem Madbargrumb. ftude ftehenben 0 bftbăume abreidend bon ben $B$ or: furiften beg \$ 894 bes \$OS. bejtumen.
0. 9rt. 122.

utrberifgrt bleiben bie Ianbessgelesliquen Bor: |qriften, welde bie Redite bes Gigentgumers eites Brumbitudes in ernjegung ber auf ber Grenje ober auf bem Radfargrumb. itade fegenben bbitbaume abreidenb bon ben Bor. idriften bess $\$ 910$ unb bes 5 9.3 261 . 2 bes $9 B B$. be[timmen.

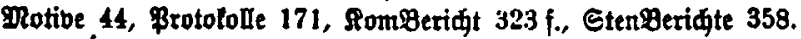

\section{Art. 122 (ङ. 123).}

[I, 8. feglen].

Unberibrt bleiben bie lanbes sejebliquen Borfariften, weldhe bas Redt bes Rolbweges zum 810efe ber Berbinbung eines Brunbitlides

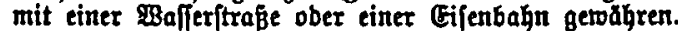

Dotive -, Brotololle $171 \mathrm{f}$.

B. Prt. 96 (\$. 123)

Unberdhrt bleiben bie lanbes: gefeslidien Borfdriften, welde bas Eigentbum an Grumbitiden ju Buniten ber Rałbarm nod anberen als ben im $\mathbb{B} B \mathbb{O}$. bes ftimmten Bef̧rănhungen unters wexfen.
[I feblt].

[I fegtut].

B. Irt. $12 t$.

unberlibt bleiber bie lanbes: gefesliden Borldriften, weldhe bas Eigenthum an Brunbftiden au Gumften ber Rahbam nod anberen als ben im $B O B$. be= [tiumten Befarănfungen unter= werfer. Dies gttt talobef. and bon

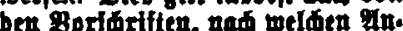
lagen fowle Bănue unb Strängher

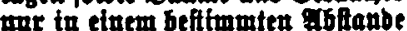
von ber Gremse gebalten werben bilfer.

Rotive $\rightarrow$, Brotololle 170, SomBeridt 324 .

9 9rt. 97 (9. 12, 0. 125)

unberabrt bleiben bie lanbesgefégliden Borfariften, welde bie

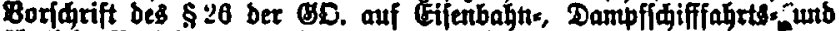

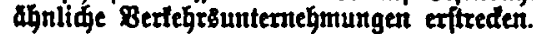
SRotive -, \$rotololle $170 \mathrm{f}$

I 9rt. 68.

Durn Rambesgefes Pann bas bem Staate zus ftebenbe Eigentbum an einem Granbitude einer Gemeinbe ober einem anberen fommunalberbanbe

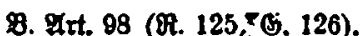

Dura Lanbesgefes tami bas bem Staute ant cinem (Snunbftite suftegenbe Etgenthum auf einen Sommunalberbanb unb basi einem Sommunalberbanbe 
(Probingtal, Areis", Pmtsverbanbe) unb bes einem Roumaunafiberbanbe zuftehenbe Cigenthum an einem Grunbptade bem Staate ober cinem Sommmals Detbenbe thettragen toerben.

Motibe 44, Prototolle 172 .

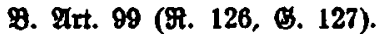

[I fellit].

[I, 円. félem].

[I feflt]. Motibe -, Brotololle 172.

9. Art. 127 (ङ. 128). \{ariften ber GrunbbD. nidjt eingetragen gu werben braudat.

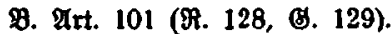

an eitem Grunbphate zuftehenbe Eigenthum anf einten anberen Pommunaloerbanb ober auf bent Staat abertragen toerber.

unberthat bleiben bie lanbesgefebliden Hebertragung bes Cigenthumes an cinem Corunbftide, bas in Grunb.

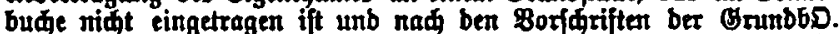
aú nad ber lebertragung niat eingetragen zu werben braudt

unberahrt Gleiben bie Iambesgejeblinen Boríntiften aber bie Pegranbung unb Rufhebung einer Dienftbarteit an einem Orunb: fitide, bas im Grunbbude niat eingetragen ift unb nad ben Bor:

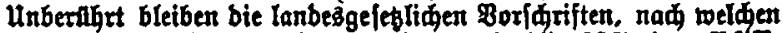

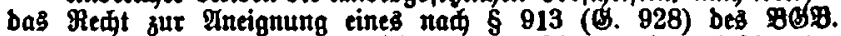
aufgegebenten Grunbltides an Stelle bes Fistus einer beftimmten anberen \$erion zufteht.

Motive -, Protololle $173 \%$.

I $\mathfrak{A r t .} 69$.

Unberahrt Gleiben bie Bor|driften ber Ranbes: gefege aber bie Bueignung ber im freien betroffenen nidt berrenlojen Zauben.

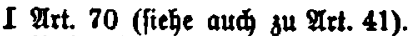
Unberalgrt bleiben:

1. bie lanbezgefejtiden Bor= idriften, tweldue bie Theilung bon Grunbitiden unterfagent ober befuranter;
8. bie Iambesgefeslidien Bor=

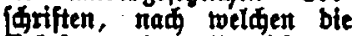
Belaftung eines Gumbpiades mit getwiffen Brunbbterifts barfeiten ober befdrantten per. forligen Dienftbarfeiten obex mit Beallaften auggeidloffen obex bejarảntt ober in ât: fegung gewifier Bruutbbienft. borteiten ober befácănlter perjönliquer Dienitbarleiten Inbalt unb grafi berfelben naher bejtimmt finb;

3. bie Iambesgefeslianen Bor: idriften, nad tolduen bie Belaftung eines Sontubltides

B. Art. 102 (F, 129, B. 130)

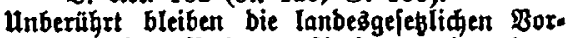
¡đriften uber bas Fect zur Aneignung ber cinem Anberen gehörenben, im \}reien betroffenen Zauben.

Motibe 44, 45, Protololle 174.

9. 91. 92 .

Unberilhrt bleiben bie Ianbes. gejesliqen Boriariften, weløe bie Lyeilung eines Srunditifides ober bie getrennte Berảuferung von Brumbitiden, bie bigher zulammen bewirthidaftet worben finb, unters lagen ober bejమränlen.

9. Mrt. 88 .

unberlfrt bleiben bie lanbes: gejebliqen Boriariften, weløe bie Gelajtung eines Szunbitlides mit getwiffen Granbbien[tbarteiten ober bejarăntten perfönliaen Dienjt: barleiten ober mit Peallaiter unter. jagen ober bejuränten, forvie bie Ianbesgejeblifien Borfकriften, welde ben Эnthalt unb bas gRag folder Redite năber befitimmer.

9. Frt. 90 .

unberafrt bleiben bie Ianbes: gefegliden Borfdriften, welde bie
9. 9xt. 118 (O. 119)

unberliht bleiber bic lanbes. geies lidien Bor|driften, toeldhe

1. bießeränferung elues Brunb. fìdes beforänlea;

2. bie Theilung cines Srunb. ftides ober bie getrennte Ber. auperung bon Grunbitiden, bie bişber zufammen betwitth. idaftet worben finb, unters jagen ober bejaranten;

3. bie naw 8874 (890) 965 . 1 bes einigung melserer Brnmb. ftude obcr bie nad $\$ 874$

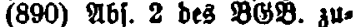
Iaffige 8 ufdreibung eines Srunbitudes gu einem anberen Grunbitude unterjagen ober bejđ̆rănten.

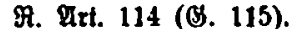

unberihrt bleiben bie lanbes. gejeblidjet Borfariften, melळe bie Gelaptung eines (Smunbftüdes mit gewifien Branbbienftbarfeitent ober

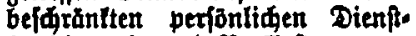
batteiten ober mit Meallaften unter. fagen ober bejarăniten, forvie bie Ianbesgelesliben Boríntiften, weIde ben Inhalt unb bas grab́ folger Fedite naber beftinmen.

ท. Grt. 116 (\$. 117).

unberthin bleiber bie lambes. gefeslidien Borfidriften, toeldye bie 
mit einer unfihtnbGaren $\mathfrak{S} \mathfrak{y p o}=$ thet ober (Srundjiduld ober bie

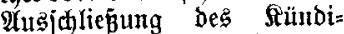
gungärechtes über eine be= fimmte Beit hinats unter= jagt ijt

Die Morjdrift des 1. Afbf. unter $\$$ x. 2 findet feine Inwentoung auf Die in ben $\$ \$ 857$ biz 860 , 863 unb int $\$ 971$ Mbi. 3 bes B(SB. bezeiduteten Red)te.
Belaftung eines (Srundîtüdes mit enter untünbbaren $\mathfrak{s}$ ypothef oder Grundidald anteriagell oder bie

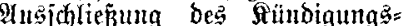
red)tes bes (Eigenthimers bei Sonpothefenforberungen und (\$) ruto= (d)ulben zeitlia bejaränten bei Rentenfiduldon mur für eine fürzere als bie im $\$ 1187$ Ibj. 2 B@B. beftimmte Beit zulafien.

Motive 45, Protolulle 174 ff.
Belajtung eines Srumbitüđę über eine beftimute Berthgrenze hinaus witteriaget.

Unberübrt bleiben bie landes= gejeblidien Borfdriftet, welde bie Belaitung eines (Sruntopitüfes mit eitter Intüntbaren Fुgpothe ober (6) rutbidjuld unteriagen ober bie

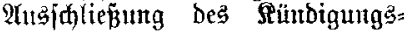
rechtes bes Eigenthimers bei 5ybothefenforderntget und (O)rund = fa)tben zettlich beighänten und bei Rentenichulden mur fïr eine fürzere als die in $\$ 1185$ (\$S. 1202) $\mathfrak{A} 5$. 2 BOSB. bejtimmte Beit $\mathfrak{j}^{\mathrm{u}}=$ Iajien.

I $\mathfrak{A}$ rt. 71 (II 41, 凡. 66, (H. 68).

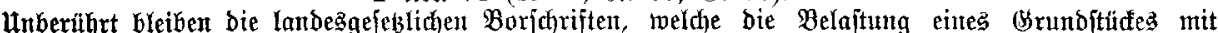

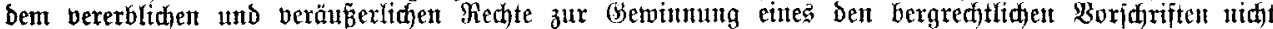

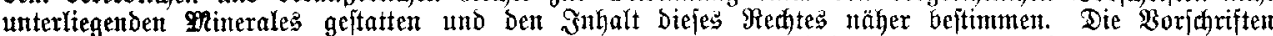
ber $\$ \$ 962,964,965$ (S. 874 bis 876, 1015, 1017) Des BSBS. finden entiprechende Antwendung.

Motive 45, 46, \$rototolle 176 .

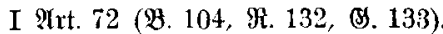

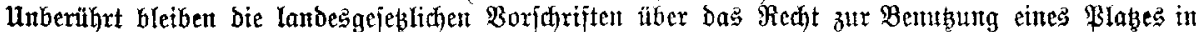

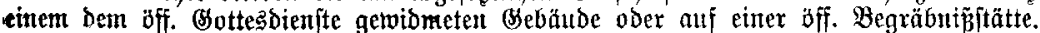

Mative 46, Brotofolle $176 \mathrm{~F}$.

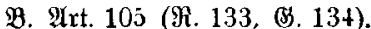

[I feblt]. religioje Ergichung Der Rinber.

Motive - Protofolle 180 und in Familientedte zu $\$ 1528$.

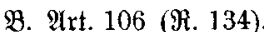

Unberïht bleiben die landes= gejeblichest $\mathfrak{B}_{\text {orjoriften }}$ iber bie 3wangser ziehung Minderiähriger. Die 3mangaerziellung ift jedoh, unbeidadet ber Boridriften bes $\$ 56$ St(S\$, nur zuläjfín, went fie bon bem Bormberichte auf (G) rund be $\$ 1645$ voer bes $\$ 1816$ des $\mathfrak{B} \leftrightarrow \mathfrak{B}$. angevronet wird

Die Lanbesgeję̧e tönnen die Entideibung bariber, ob ber Mintorjährtge itt ciner Familie ober in einer Erziehungs: voer Befferungsanitalt unterzubringen fei, einer Bertoaltung 5 behobde über= traget, wetn die Unterbringung aul off. Sloftett zu erfolgen hat.
(S). Art. 135.

Ittberilfrt bleiben bie Yandes= gejeblidien Boridgriften iber Die 3wangserziehung $\mathfrak{M i n b e r j a ̈ h r i g e r . ~}$ Die 3rangerfiehntts ijt jesod, unbejahadet ber Borjdriftent ber $\$ 855,56$ St(H:, nur zuläjítg. toem fie von dem Borm(Serinte algeoronet twirs. Dit Mnord: mung tann auber ben Fällen ber $\$ 8$ 1666, 1838 g(s). nut tr folgen, wenn die Bwang eraitebutg jur gerbiltung bes völtgen fittlitaen Berberbens noth. twendig ift.

Die Qandesgaefese tönter bie Entideibung Darüber, ob ber Minberjährige, befien Bwangąer. fiehung angeoronet ift, in einer Familie ober in einer Erziefung voer Befferungsanjtalt unterzu= bringert jei, einer Bertwaltunges= behörde übertragen, went bie Unterbringung auf iff. Soiten zu exfolgen hat.

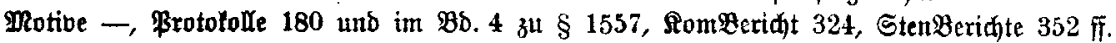

I 2 rt. 73.

Unberührt bleiben bie lanbes= gejeblidyen Borjariften, nad wel= Gen bei einem im Mriteigenthume Stehenden, mit einem \$ebäube ber= fehenen Grunditade bie antheile
B. Mrt. 103.

Unberifhrt bleiben bie landeg= gefeblidaen $\mathfrak{B}$ oridyriftert, welche für Den Fall, bá jebem ber Miteigen= thümer cines mit einem (Sebăube verjehenen (Sruttojtüifes bie aus=
R. 21rt. 130 (\$. 131).

unberifhrt bleiben bie tandes. gejeblichen Borfdriften, weldye für bell Fall, bafi jebem ber Mriteigen= thümer eites mit cinem (Sebäube verjehenter Brunditiofes bie aus: 
ber Miteigentbumer in ber $\mathfrak{x e i f e}$ belaftet toerben tonnen, bas cinem Seben ber jeweiligen shiteigen:

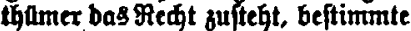

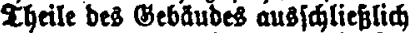
su benuben, unb burd welde far ben Fall einer folden Belaftung bie Anmenbung ber Borjariften

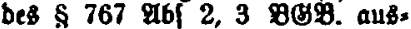
gefdilofien unb bas Bemeinj berb̆altnif ber Dtiteigentfatmer naber beftinumt wirb.j

[I, 8. feglen].

I Art. 74

unberührt bleiber bis Innbeğgefegliden Bor: [मriften, nah welnen bem fistus ober einer anberent ur. Berfon bas æhedt zufteht, zur Sidenung geviffer Forberungen bie Eintragung einer \$ypothet all bell (s)mbltaden bes Equlbuers it bas Brumbbud zu berlangen, unb naळ welden bie Cintragung biejer Sypothet auf bas Erjuden einer beftimmten geborbe zu erfolgen hat. Die Gypotbet fann nur als Siderung 8hypothel eingetragen werben. Die Bor: fariften bes $\$ 1130$ abj. 2 und bes $\$ 1131$ bes BGB. finben entipredents Intwendung.

\section{Mrotive 47 fo, Protololle 178}

B. Nrt. 66 (æ 92, (3. 92).

[I feglt].

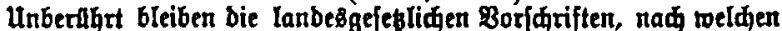
Bablungen aus bff. Paffen an ber Saffe in Empfang zu nehmen finb. Mrotibe -, \$rototolle 165.

I 2 rt. 75.

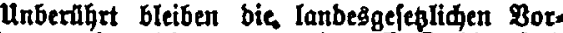
|d triften, nad welcen, wenn eine off Ireditanftalt zur Berbefferung cines Brunbittides cin Darlehen gegeben bat, ber twegen biefes Darlehens an bem Brunbitude begranbeten Belbrente, \$ypothet ober Branbidulb ber Borralig bor anberen Belajtungen bes Grandftides zufteben foll, fofern ber Borrang in bas crrumbbum eingetragen ijt, unb naq welnen, wenn burd bie Renberung bes Ranges eine Brief: gypotgel ober eine Brunbidulb betroffen toirb, zu bex Cintragung bie Borlegung bes জypotgetenbriefeß̊ ober Orunb/Aulbbriefes nidt exforberlid ift.

Motine 48, Protololle $178 \mathrm{f}$.

I 9 rt. 76.

Unberahrt bleiben bie Ianbesgefeßtiden Bor.

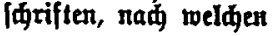

1. im Falle ber Berăuferung cines Theiles eintes Branbftades biejer Theil bon ben Belaftungen bes Branbitudes befreit wirb,

2. im Falle ber Zutilung eints mit einer Meallaft belajteten Brunbjtades bie Fieallaft auf bie cingelnen Theile bes Granbftades vertbeilt witb,
9. 2rt. 93 (R. 119, (3. 120).

Unberulhrt bleiben bie lanbesgefefliđen Bor:

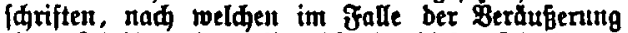
eines Theiles eines Orumbitudes biejer Zheil von ben Belaitungen bes Brumbitudes befreit wirb, went von ber zuftănbigen Debarbe feftgeftelit wirb, baß bie Red tsanberustg fár bie Beredtigten unjळablia ijt.

unberabrt bieiben bie lanbesgelegliden bor. 伍riften, naळ welden unter ber gleiden Borause fegung:

1. im Fralle ber Theilung cines mit einer Reallaft belafteten Brunbitades bie Meallaft auf bie einzelnen Theile bes Gunbitades vertheilt wixb;

2. im fralle ber fuffebung eines bem jetweiligen Gigentbumer eines Brumbftlides an cinem anberen Grunbitude zuftehenben Redtes bie Buftinmung berientigen night exforberlid in 
3. im Falle bes Berziates auf ein bem jes weiligen Gigenthumet eines Sinubitides zuftehenbes Feat an einem anberen Branb. ftude biefes Grunbftild bon ber Belaftung aud ohne Cinwilligung berjentigen befreit wirb, fur welde bas erftere (smunbitid belaftet ift,

4. im Falle bes $\mathfrak{A n t} .31$ ber bem Eigenthamer

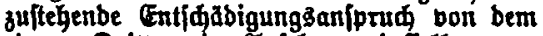
einem Dritten it Anfehung beffelben zu= ftehenben Fedte Gefreit wirb,

wern bor ber zuftånbigen Bebzrbe feftgeitellt roirb, bas bie Befreiung bert Beredtigten unfádbliq ift, unb nad welden in folden frallen zur \&ojoung ciner Briefgypotbet ober (Snunb fulb bie Borlegung

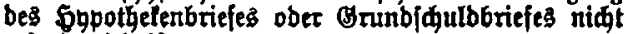
exforberlia ift.

unberabrt bleiben bie lanbeşgefesliden Bor: jariften, nad welden im falle ber Theilung eines far ben Fishus mit einer Reallaft belafteten Srunbitides mur ein Theil bes Srunbltádes mit ber Reallaft belaftet bleibt unb bie abrigen Theile bes Granbftades mit Beallaften far ben ierveiligen Eigenthimer bess erfteren rheiles belaftet werben. gu beren Sinfen bas Grunbfind bes rechtigten belaftet ift:

3. in ber Gatlen bes $\$ 1128 \$ 99$, unt bes Irt. 52 biejes Befebes ber bem Gigentbaner

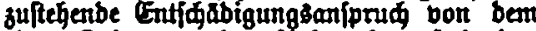
einem Dritten an bem Enjprufie zuftegenben Redte befreit wirb.*)

unberthint bleiben bie lánbesgelebligent Boto

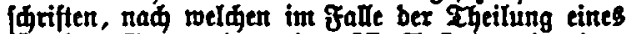

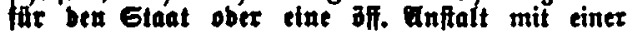
Meallaft belafteten osrunbftates nur ein Theil bes Grunbftildes mit ber Meallaft belajtet bleibt unb bafur ju Gunften bes jeweiligen Cigentgumers biefes Theiles bie abrigen Igeile mit gleidartigen Feallaften belaftet werben.

Motibe 18, 49, Protolulle 179, Romberidt 323.

I 9tt. 77 (P. 83, 9. 109, B. 110).

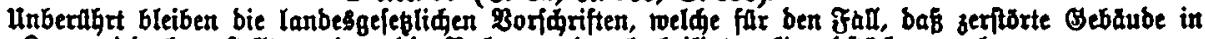

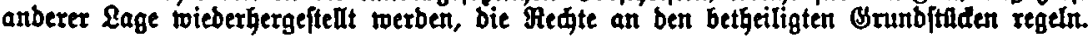

$$
\text { Motive 49, Brotololle -. }
$$

I Art. 78 (B. -, R. -, G. -).

Unberïhrt bleiben die landesgesetslichen Forschriften, nach welchen die im $\$ 846 B G B$. bezeichneten Eintragungen und Löschungen nur auf Ersuchen des Vollstreckungegerichies erfolgen.

Motibe 49, 30, Brotololle 180.

I Irt. 79.

unberibrt bleiben bie lanbesgefesliden Bor: (d)riften, ná toeløen ber Borftanb einer unter Bertvaltung bes Staates ober einer Bemeinbe: begorbe Pehenben Berpflegungsanftalt in Fnfegung

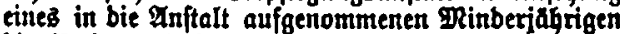
bie Feळhte unb Pfliaten eines Bormunbes bis zur Boljahrigleit bes granbels Gat, unbejdabet ber Befugnif bes Bormbseriates, ftatt bes Borftanbes cinen Inberen sum Botmunbe zu befteller, unb nad welfen im Falle einer foldien Bevormunbung burd ben Inftaltsoorfanb an Begentormunb nidt zu beftellen ift unb bem Inftaltsoorftanbe bie nad ben

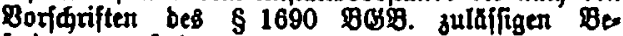
freiungen zuftehen.
B. Ant. 107 (भ. 135, (5. 136).

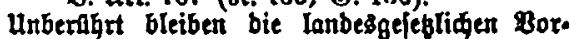

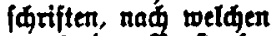

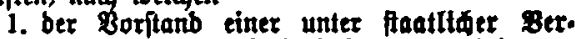
maltung ober guffít febenben Grilehungs. ober Berbliegung8anfalt ober ein Beamter alle ober elmelne Predte unb \$fliden eines Bormunbes für biefentgen olinbertährtgen bat, wilde in bet anfalt ober unter bef Inffict bes Borfanbes obet bes Beamter ta einer bou thm anigetäbIten Gamilte ober aldfalt exjogen ober berpfiegt werben, unb ber Borftanb ber Inffalt ober ber Beamte and uaf ber Peenbtgung ber $\mathrm{Ct}_{\text {. }}$ tebung obex bex Berpflegung bts jur $9 \circ$ lährtgiett bes müubels blefe Fente unb Butbten bebält, unbejळabet ber Befugnis bes Borm(seridites, einen anberen Bormunb 3u beftellen;

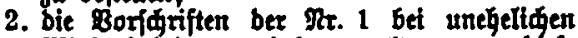
Dinberiahrigen aud bann gelten, wenn bieje unter ber Guffidt bes Borftanbes ober bes Beamten in bet matterliagen Familic exjogen ober beepflegt merben;

3. ber Borfanb einet unter faatlider Ber: waltung ober Fuffiłt ftehenben Crjiegungs: 
Mrotibe 30, Protololle 182 fi., SomBeridit 324.

ober Bexpflegurgsarftalt ober ein bon ibm bezeidnnter Ingeftellter ber Inftalt ober ein Peamter vor bent nad $\$ 1754$ (B. 1776) PBos. als Bormunber berufenen Perfoner zum Bormunbe ber in $9 x$ 1, 2 bezeidneten PRinderjahrigen beftellt roerben lann;

4. im Falle einet nad ben Poridriftem bex Rr. I bis 3 ftattfinbenber Pebormurnbung ein Gegenbormunb nift zu beftellen if unb Dem Bormunbe bie nad \& 1630 (S. 1852) 9BSP zulafifigen Befreiurger zufteber.

I.Art. 80 (B. - , R. -, G. -).

Onberiuhrt bleiben die Forschriften der Iandesgesetze über die Einrichtung des Gemeindeuraisenrathes.

Mrotive 50, Protololite 184.

I Grt. 81 (\$. 111, F. 138, B. 139)

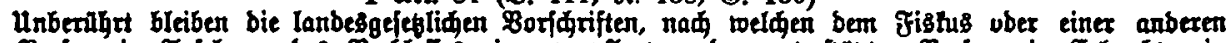
jur. Berion in Infehung bes Radilafes einet berpflegten ober unteritabten Perjon ein Crbredt, ein Pflidtheilsan|prud ober ein Redt auf beftimmte Saden zuftegt.

DRotibe 50, 51, Prototolle 184, Pom Peridt 327.

1 Irt. 82.

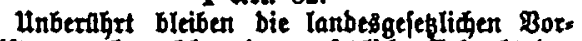
iditiften, naक welden bas geleglide Erbredt bes Oftstus anberen Perforten als bem ofizhus zulteht.
B Vrt. 110 (P. 137, (3) 138).

Unberabrt bteiben bie lanbesgejeblidgen Bors |

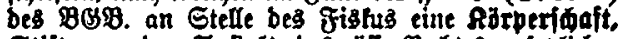
Stiftung ober פ্ffalt bes öf. Pedte gefeglider Erbe ift.

Motide 54, Protololle 184 \%.

I Irt 83.

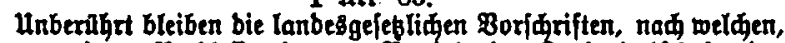
wern zu einem Radlaffe eir zum \$etriebe ber Lanbwirthinaft ober

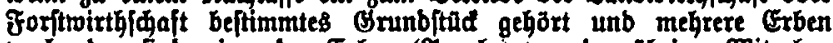
vorhanden finb, einer ber Erben (Anerbe) bon ben abrigen MRiterben

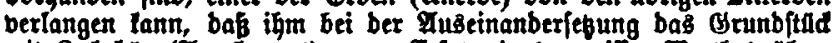
mit Bubehor (Ílnerbengut) gegen Grjaß eines geviffen 2Berthes aber: laffen werbe (Îtrerbetredt)

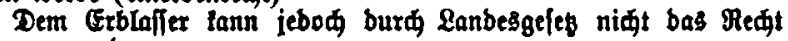
cutzogen werben:

1. bas Inerbentedt burch Betfigung von Tobesivegen augizus iditiejen ober zu bejdránten;

2. an Elelle ber im Beiebe als Mnerbe beftimmten Berion einen Inberen aus bem im Befebe beftimuten, jene Berfon eins [Aliekenden Qtrife von Berfonen als Ánerben zu emennen.

I :rt. 84.

Urberibat bleiben ferner:

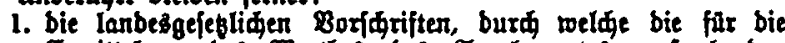
Crmittelung bes $\mathfrak{B}$ erthes bes Arerbengutes másgebenbent Grunblabe beftimumt werben;

2. Die Janbeşgejęliden Borihriften, nađ welden Dem Inerben aus bem Eutsmerthe ein Boraus gebăhrt;

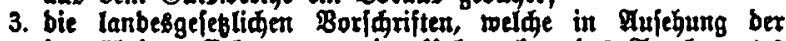
ben fibrigen Erben wegen ber Hebernabme bes Anerbergutes geger ben Grerben zuftegenben Forberungen bie Făthigleit,

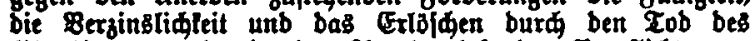
SIanbigers regeln ober bem Anerben bejonbere Berpflidtungen gegen bie abrigen Grben, inşbef. in Anjebung ber Siders fiellung, auferlegen;

4. bie lanbesgefebliment Borfifriften, nad welden im Falle bes

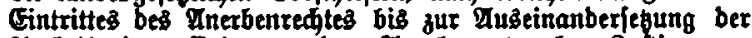
Intheil eines Erben an bem Anerbengute ofne Buftimmung bex abrigen Exben niđt veräufert ober belaftet werben lann, unbef habet bet Bularingleit ber Btoangsvouffrectung toegen

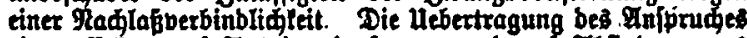

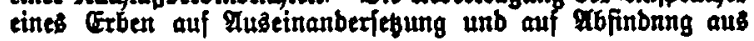

9. 9rt. 108 (F. 62, (3. 64).

unberahrt bleiben bie Ianbess. gelestident Borfdriften äber bas Anerbenxedft in Injegung lanb. virthififtlider unb forftrieth. idaftlider Buntbftide nebft beren Bubehör.

Die Lanbesgefépe tönnen bas Medit bes Erblaffers, theer bas bem Irrerbentedte unterliegenbe Grunbitid bon Tobeszegen zu berfügen, nidat bejळtánlen. 
bem İnerbengute tann buth Lanbesgefes niळht für unjuläfíg extlăt werber.

\author{
I $9 x t .85$.
}

Bebärt ein Brumbfthd, bei ppeldem nad ben Ranbesgeleben bas Unerbenredit eirtreten lann, zum grablaffe, to beftinmut fth bas

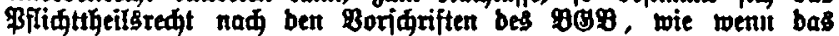
Grumbftad nimt bon ber bezeidneten Befdaffenheit warke. Die $\mathbf{B o r}=$

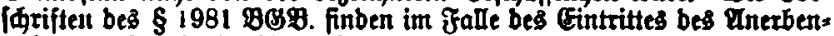
ređttes entipredjende Innmenbung.

Unberdifnt bleiben bie lanbesgefesliden Borfidriften, nad welden bei Beftimmung bes. Pflidttheiles bas Brumbftüd mit Bubebor nur

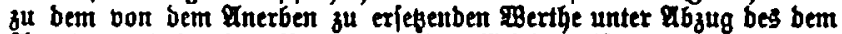
Anterben gebahrenten Boraus zu berfidinhtigent ift.

\title{
I Irt. 86
}

Dex Anerbe, welder bas Prnerbengut abernimmt, ift gegentaber jebem ber äbrigen Erben verpflidtet, bie bemjelten obliegenben Madlasberbinblidfleiten inforveit $z^{\mathfrak{u}}$ tragen, als zur Yeridtigung ber

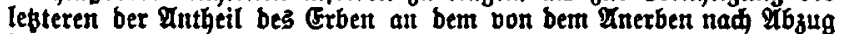
bes Boraus zu eriebenben 98 erthe bes Tnerbengutes unb an ben

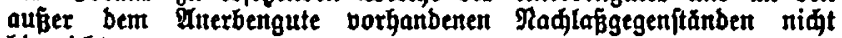
Giureidt.

I 2 rt. 87.

Unberabrt bieiben bie lanbesgejegliden Boridriften, nađ welden, wenn zu bem Befammtgute einer burd ben Tob eines ber Egegatten aufgelöfter allgemeinten Batergemeinidaft ober Crrungenfinafts:

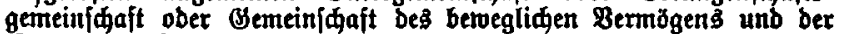
Errungenjidaft ober zu bem Befammtgute einer aufgeloffen fortgefesten

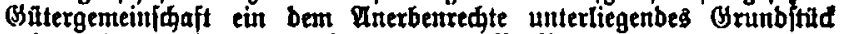

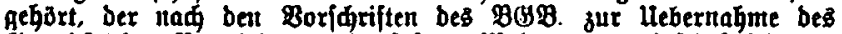

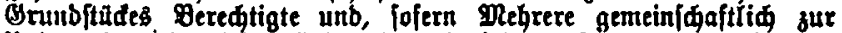
Hebernabme beredigt finb, einer berielben, foferm aber ein zur Hebernafme Beredhtigter nidt borhanben ift, einer ber Theilgaber am Briamemtgute von ben fibrigert Theilgabern verlangen tan, Daß

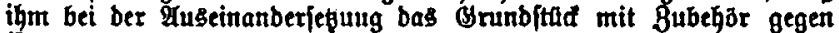
Erjag eitreş getwiffer 9 Berthes überlaffer werbe.

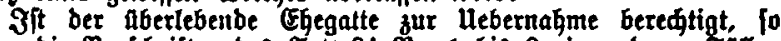

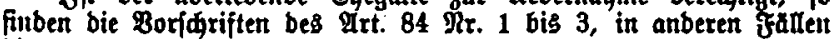

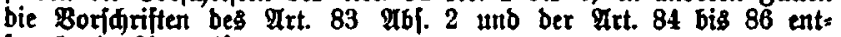

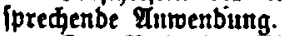

Das Redt ber Ehegatten, burd Ehevertrag ein Inberes ju beftimmen, tann burd Lambesgefes nidt ausgefdiloffen werben.

Motibe 31 fi., Protololle 189 fi., Somberift 316.

[I feglt].

8. Irt. 109 ( $\Re .136$, (3. 137).

Unberdhyt bleiben bie lanbesgejegliden Borjuriften aber bie

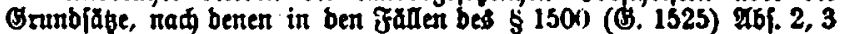
und bet $\$ \$ 2026,2286$ (\$. 2049, 2312) $90 \%$. Der Ertragswerth eines Lanbgutes fétzuftellen ift.

Motive -, Frotololle $185 \mathrm{ff}$.

I थrt. 88.

unberulht bleiben bie Ianbes: gejesfichen Boriqriften, naq

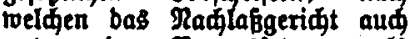
unter anberen Borausfesurgen als ullter ben in $\$ 2058$ qb 1 bes $\mathfrak{B O P}$. beseiqueten, unbeldabet ber

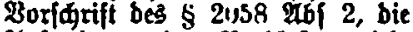
Anfertigung eines RađIlabberzeiq: niffes fotwte bis zut beffen Boll. enbung bie erforberlident Side rungsmafiregeln, inşbel bie $\mathfrak{A n}=$ legung bon Siegeln, von $\mathscr{A}$ mts. toegen antorbnen fann.
9. Art. 112 (M. 139).

unberlihat bleiben bie lanbes: gefesliden Borfdriften, raф

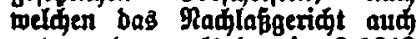
unter anberen als ben in $819: 38$

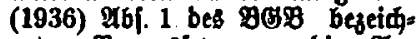
jeten Borausfebunget bie $\mathbb{A n}_{\mathrm{n}}=$

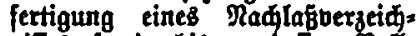
nifies forvie bis zu beffen $\mathfrak{B o l l}$. entung bie erforberliden Sidge nungsimafircgeln, inşbef. bie Qun: legung bou Siegeln, bon Amts: wegen antoronelt faut.
B. 2rt. 140.

unberibrt bleiben bie lanbes. gefesliden Borfintiften, nad weldien bas Nadlapgerígt aud unter anberen als bert im \$ 1960 abf. I bes 889 bezeidneten 80 ors auşebungen bie घี1fertigung eines Rablafoerzeidnifjes forvie bis zu beflen Bollenbung bie exforberliden Siderungsmafregeln, insbef. bie ध्nlegung von Siegeln, bon İmt\$s wegen anorbnen tann ober loll. 
[I feglt].

B. Art. 113 (R. 110, G. -).

Die Landesgesetze könmen bestimmen. dars die Forschriften des \$2225 BGB. auf Testamente der Gesandten des Bundenstagten und der zu der Gesandtschaft gehörenden, im Dienste des Bundes. stautes stehonden Persmen Anwendung finden. An die Stelle des Beichnkanzlers tritt die landesgesetzlich bestimmte Behörde.

SRotive -, Frototolle 202, $327 \mathrm{f}$.

Art. 89 (B. - , R. - , G. $\rightarrow$.

Onberwhrt bleiben die landesgesetzlichen Vorschriften, nach welchen, wenn Hiterben binnen einer bestimmten Frist die Auseinandersetzung in Ansehung des Nachlasses nicht bevoirkt haben, die nach denz $\& 2136$ des BGB. dem Nachlassgerichle obliegende Vermittelung auch ohne Antrag anes Miterben eintreten soll.

Protive 65, Protololle 2 ri3.

Art 90 (B. - . B. - , G. $\rightarrow$ ).

Unberiuhrt bleiben die Forschriflen der Landexgesetze ïber die Verpflichtung der Notare sur Annahme des Amtes eines Testamentsvollstreckers.

Motive 65, Protololle 203.

Art. 91 (B. - . R. -, G. - ).

Unberiuhrt bleiben, soweit nicht durch das $B G B$. oder durch dieses Gesetz eine besondere $B e$ stimmung getroffen ist die Vorschriften der Landesgesetze über die Znsständigkeit der Behörden und Beamten in Angelegenheiten der nichtstrentiven Rechtspflege und ïber das in solchen Angelcyenheiten einzuhallende Verfahren.

Unberithrt bleiben insbes. die Frrschriften der Landesgesetze über die sachliche und örtliche Zuständigkeit der Beh r̈rden und Bermiten, mit Einschluss der Notare. in Ansehung der Errichtusng ler Verfügungen von Todesioeyen und anderer öf Orkunden sowie der off Beghabigung von Urkunden und über die Foolgen der Unewsrändigkeit.

Unberdigt bleiben bie lanbesgefebliden Bor.

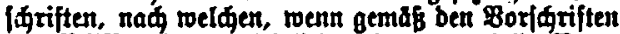

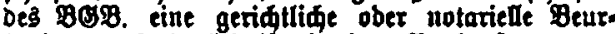
lunbung exforberlid ift, in bem Bundesftate ent. weber utur bie Geridte ober nut bie Rotare fitr bie Beuthumbung zuftanbig furb.

Onberührt bleiben die landesgesetzlichen Virschriften, welche die nach Massgabe des \$2156 BGB. dem Ne hlassyerichte swotehende Vermitteling Notaren ihhertragen.

Legen die Landesyrsetze die Verrichtungen des Nachlassgerinhtes einer anderen Behörde als dem Amt.gerichte bei, so ist für das Aufyebot der N.chlassyläubiger das Amlsgericht zuständig, in dessen Besirke die Nachlassbehörde ihren Sitz hat.

Die Vorschriften der Art 33, 34 finden in Ansehung der im 1. Abs. bezeichneten besonderen Bestimmungen des $B Q B$. und dieses Gesetzes entsprechende Anvendung.

Motive 6j fi., Brotololle 201 ff.

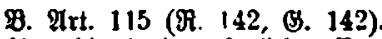

Unberabrt bleiben bie lantes aelebliden Borldififten, welde in

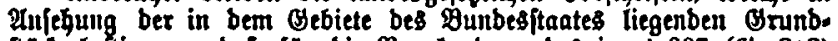
ftâde beftimmen, baß fïr bie Beurfunbung bes im $\$ 307$ (S. 313) be $9 B 2$. bestidneten Bertrages forvie fur bie nad $\$ 858$ (E. 873) Abj. 2 bes BosB. zur Pinbung bet Betheiligten exforberlide Deurtumbung ber Certánungen auber ben Beridten unb Rotaren aud anbere Pehörben unb Beamte zuftanbig finb.

Motibe -, Protololle 162 ff.

9. 9rt. 116.

Unberthert bleiben bie Ianbes, gelestiden \$orjariften, welde in anjegung ber in bem Gebiete bes Bumbegftantes liegenben Grunb. ptide beltimmen, ba $\bar{B}$ bie Einigung ber Parteien in ben frallen ber

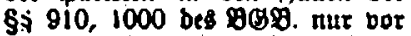
bem Brumbbuhamte ober bas fie aud vor einer anberen Beborbe als-vor bem Grunbsudamte ober cinem Beriøte exflät merben fann.
M. Art. 143 (\$. 143).

Unberahrt bleiben bie lanbes. gefebliquelt Borjániften, roelde in Anfehung ber in Dem Bebiete bes Ounbesftaates liegenben Grunb. ftide beftimmen, baf bie cinigung ber Parteien in beu fallen ber $\$ \Omega 909,999$ (अ. 925, 1015) bes BHS. anfer bor bem Grunbbud. amte aud oor Beridt, oor ctuem Rotare, vor elnet anberen Oebörbe ober por einem anberen Beamten, erlărt toerben lann.

Dlotive -, Brotololle 162 ff. RomBeridt 328 . 
9 Irt 100.

Unberdbut bleiben bie Imbes. geiestigien. Borjdriften, nad twelden es bei ber guflafimg eires Brumbftudes ber gleidzeitigen Inwelengeit beiber Zheile nidt bebarf, wenn bas Grunbftad burd einen Rotar berfteigert worben ift und bie Auflaffung nod in bem Bexfteigerungstermine ftatt: finbet.

Motive -, Brotololle 162 ff.

9. Art. 117 (9. 144, B. 144).

unberbigrt bleiben bie lanbesgefesliden Borfariften aber bie

[I fegld].

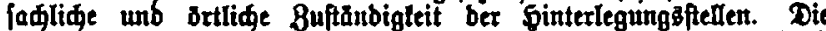
Lanbesgefeße tonnen beftimmen, baß bie Anlegung bon Wanbelgeth

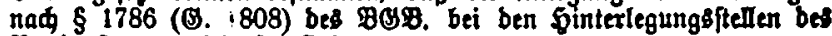
Bunbesfftates nidst ftattfinbet.

glotive -, \$rotololle $207 \mathrm{f}$.

B. Ext 118 (भ. 145, B. 145).

Die Sanbesgefege tơnnen aber bie Giuterlegung năgere $B$ ftimmungen treffen, insbef. ben Rađiweis ber Empfangsberedtigung

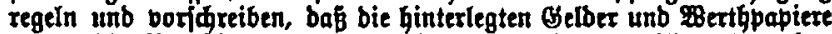
gegen bie Berpflidtung zur Maderftattung ill baš Eigenthum bes Jistus ober ber als Sinterlegungsftelle beftimmten Inftalt übergeben, baß ber Berlauf ber binterlegten Eadjen bon Fimtsweg nt angeoronet werben lann fowie baß ber Finfpruf auf Maderftathing mit bem ablaufe einer gewiffen Beit ober unter fonftigen Boraugiesungen zu

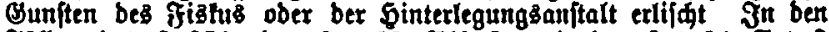
Fallen bes $\$ 376$, bes $\$ 1155$ a6t 3 unb bes $\$ 1: 54$ Sab 3

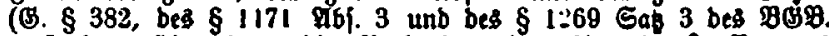
mus bem Sinterleger bie Radnabme bes Ginterlegteh Betrages minbeltens todhrenb eines $3 a$ hres vou bem Beitpunite an geftattet werben, mit weldem bas Bedt bes Blaubigers auf ben hinterlegten Betrag exlijø.

Bon einer geriđtliđen Anorbnung lann bie Sinterlegung niळt abjängig gemadit toerber.

Rotive -, Brotololle 207 f., Romberiat 328.

9. Art. 119 (M. 146, (3. 146).

Sit burd Lanbeşgeles beftimmt, baß bie Jinterlegungsfellen aud anbere Eadien als Gelb, Werthpapiere unb fonftige Urtunben fowie Roftbarleiten anjunebmen baben, fo finben auf Sdulbberbalmifie. bie auf Reifung berartiger Gaden geriqtet finb, bie Boridriften

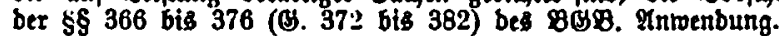

Mrotibe -, Protololle 203 bis 207.
9. Irt. 120.

unberifhert bleiben bie lanbes. gefesliqen Boridriften, nad welden far bie bem Bormunds fadftsgerifite ober bem Madlaf: geriqte offiegenber Berridtungett anbere als geriatliak Begörben zuftănbig finb.

Sinb burd Lanbesgeleb bie

[I feglt]. ciner anderen Gmtsperidgte abertragen, fo if fur bie Ebnabme bes im \& 983 \$OSB. borge/d位benen Dfferbarungseibes bas Intlgeriat zuftanbig, in beffen Pegirfe bie gladlaßbegorbe ifren Sis bat.

R. פ्At. 147 (G. 147).

unberabrt bleiben bie lanbes, gefegliquen Bor[qriften. nad velden fur bie bem Bormunb: 佁aftggeridte ober bem Radlaßs: geriate obliegenben Berriøtungen anbere als geriatlide Peborben guftánbig ftnb

Eino burd Lambesgejes bie Betridtungen bes Radjaggeridtes einer anberen Bebjobe als etuem Bertote abertragen, fo ift far bie qunahme bes im $\$ 1981$ (s(n6) அBB. vorgejdriebenen Dffer: barungseibes bas Fmtsgeriat ju= ftanbig, in beffen Bejirfe bie Rac. laßbehörbe intent Sib gat.

Mrotibe -, Prototolle 203 ff. 
[I feglt].

[I feglts.

[I feglt\}.

[I fehłt).

\$. 21t. 121 (Я. 148, (9. 148)

Die Ranbeşgeiese tônnent bie 8 uptăndigleit bes Radlabgeridte

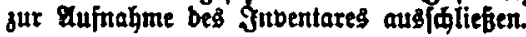

Motibe - Frotololle -

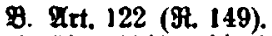

Unberibnt bleiben bie lanbegs: gefebliden Boridriften, naळ welden bei ber Grriduturg einer Berfigung von Tobesmegen ber भiditer an Etelle bes Geridts: fíreibers ober ber gwei Beugen eine befonbers bazu beftellte $\mathfrak{u} \mathfrak{r}$ : hunbsperjon, ber Motar an Stelle ber zwei Beugen einent zweiten Notar zuzieher tauts.

Quf bie Utrundsperion und ben ztweiten Motar fintben bie Bors idriften ber $\$ \S 2208$ bis 2210

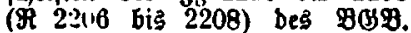
Prtwenturg.

Mlotibe -, \$rototolle 202, Stom Beridt 328.

9. Mrt. 123.

unberihtt bleiben bic lanbes: gejegliden Boridriften, na五

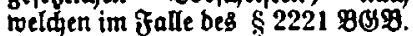
ein Ieftamest aud vor einem zur Bornahme von êtten ber frei: roilligen Beridhtşarfeit far bie Bemeinbe beftellten Beamter er: riditet toerben tann.

Motive -, Protololle 202.

$$
\text { P. शrt. } 124 \text { (R. 151, B. 151). }
$$

Durd bie Boridriften ber $\$ \S 2208$ bi 2219, 2250 (\$. 2234

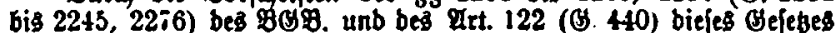
werben bie allgemeinen Borfigriften der Ranbesgejeße taber bie Ex. ridgung geridftlider ober notarieller urhunben nidt berthrt. Fin Berfos gegen eine lolde Borfdrift ift, unbefdabet ber Borfintiften

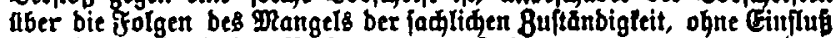
auf bie Esiltiglett ber Berfïgung bon Tobesmegen.

Motibe -, Protololie 203, PomBeridt 328 f.

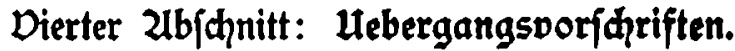

I 9 rt. 92.

Die Esixtungen einer bor bem \$nltafttreten bes BBg. exfolgten Zobesetrlarung befimmen fí nad ben bisherifen Brefenen. Mud bei einet lolden

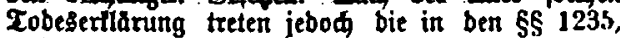
$1464,1543,155 i, 1560,1587,1611,1703,1704$, $1710,1724,1728,1735,1737,1748$ 8B8. be: zeidineten 2 girturgen ein.
9. Irt. 131 (OP. 138, Bs. 158).

Die 28 irlungen einer vor bem Intrafttreten bes

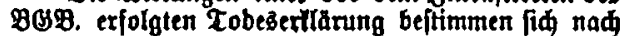
ber bisherigen Befesen, forweit fid nidit aus ben Art. 132, 133 (S. 159, 160) ein Irberes ergiebt.

B. Irt. 132 (M. 159, B. 159).

Der Ehegatte einer bor bem Sittaftreten bes OGB. für tobt extlă Intraftrreten bes $\mathbf{B G P}$. eine neue Ehe eirfgehen, aud wenu bie פsieberberheiratbung nad ben bis: herigen Gorésen nidgt zulăfifig feiut roirtbe. Die Bor-

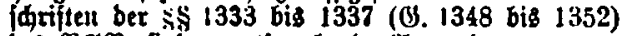
bes $90 \%$. Finber entiprediende Hutwenbung.

$$
\text { 9. Ârt. } 133 \text { (श. 16\%, G. 160). }
$$

Eoweit nad) bet Borfuriften bes 289 . in Folge einer Tobegertlärung bie elterlide Bservalt bes Beridollenten, bie Bormunbidaft, bie Pregidaft fowie bas̉ Almt als Bormunb, Gegettoormunb, Bileger. Beiftand ober Witglieb eines Familienratges enbigt, gelten bieje Borjhriften von bem Infraftreten beś 9Bog. ait aud fiur eine vorher erfolgte Zobese ertlärung. 
I $\mathfrak{9}$ rt. 93.

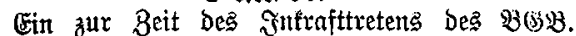
anhängiges $\mathfrak{B e r f a h r e n , ~ w e l d h e s ~ e i n e ~ T o n e z e r f l a ̈ u t u g ~}$

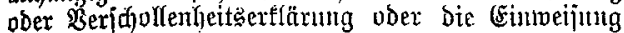

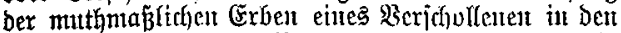

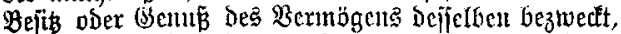

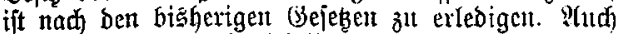

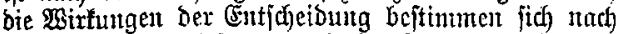
ben biahcrigent (s)ejelzen und im Falle Der Tobes= exflärung tad Den Boridyriftent Des STrt. 92.

\section{1 ख⿰氵.t. 94.}

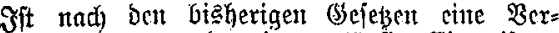
idgolferheitserflärutg vber eiste vorlä̈t fige Finweijung

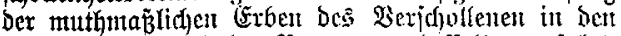

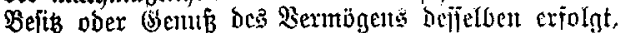

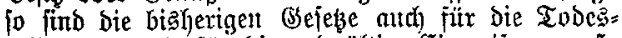

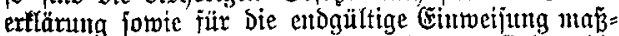
gebend; int Fafle Der Tobearerfläruth findet bie

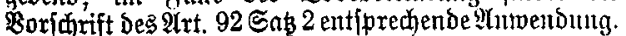

Mutibe 68-ī1, ßrototolle 209.

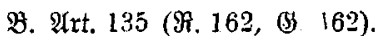

Solweit eine nady Den bisherigen bet sen erfolgte ober ntad

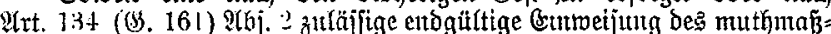

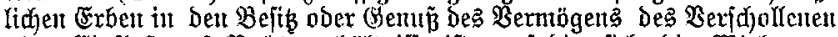

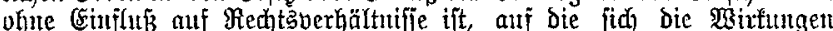

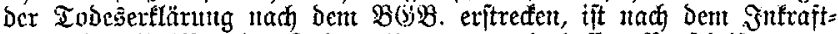

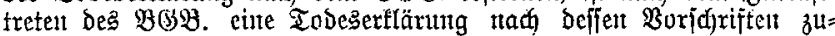

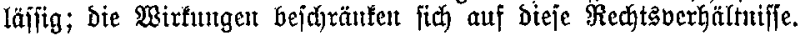

Motibe -, \$rotofulle $209 \mathrm{ff}$.

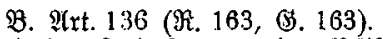

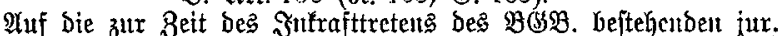

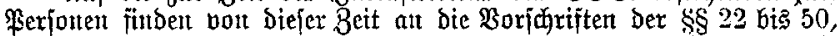

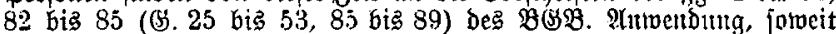

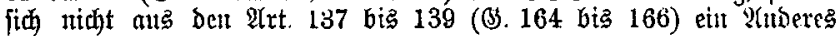
ergiebt.

Motibe -, Frotololle 214 ff.

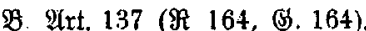

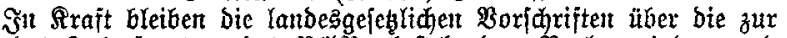

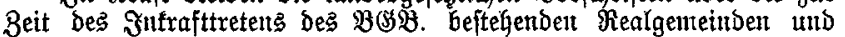

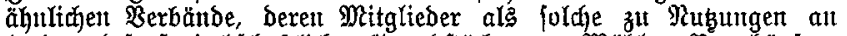

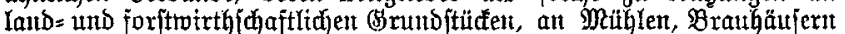

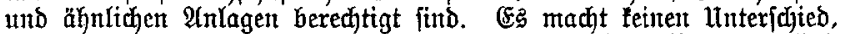

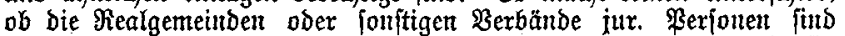
ober nidut und of bie Peredftigung ber Mitglieber an Gintrobefith geturtipft ift ober nticht.

Motibe -, Brotololle 214 ff.

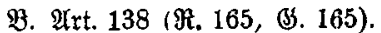

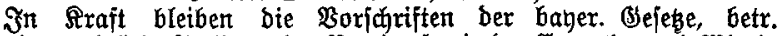

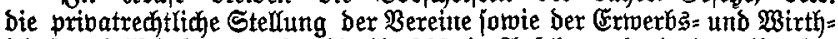

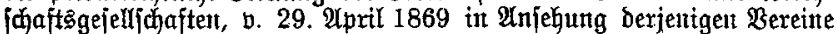

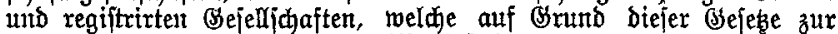

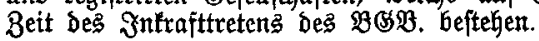

Motive -, Brotofolle 214 ff.

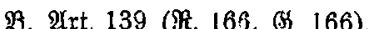

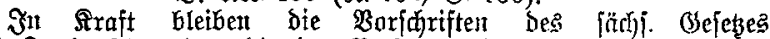

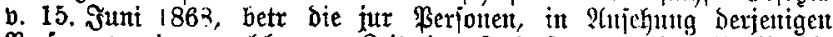

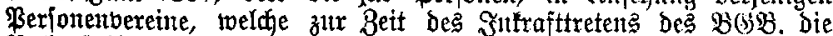

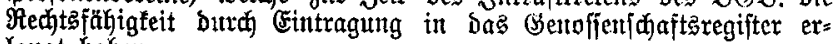
langt haben.

Motibe -, Prototolle 214 ff. 


\section{[I, D. feglen].}

M. Art. 167 (B. 167).

In Strajt bleiben bie lanbesgefesliden Borfdriften, welde bie

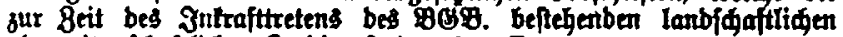
ober ritteridaftlider Strebitan/talten betreffen.

Romberift 3:9.

I Trt. 95.

Auf eine Ferfon, weldje das 21. Lebensiahr now nidit zuridgelegt, aber bor bem Inlrafttreten

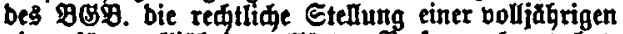
ober fâr bolfiăhrig etrlarten Berfon erlangt hat, finben bon bem Infrafttreten bes $B$ GBP. an beffen Borjariften aber bie Boljährigen Antoenbung.

\section{Motive 71, 72, Brotololle -.}

I צrt. 96.

Iuf eine Ferfon, weløe vor bem 3ntrafttreten bes $\mathfrak{B S P}$. nad bett Borjariften bes frang. ober bes bab. Medtes emanizipirt ober ber Betwalt ent=

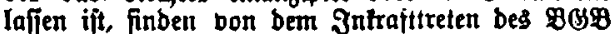
an, went bie Rerion zu biejer Beit bas 8 Lebensjabr

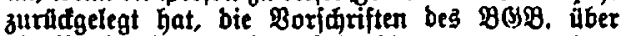
bic Bonjăhrigen, anberenfaula bie Borjuriften bes: felben aber bie Minberjăhrigen Mntwenbung.

Motive 72, 73, ProtoloLle -

I 9rt. 97.

Auf eine Ber[on, weldje bor bem Intrafttreten bes $\mathfrak{B O S P}$. roegen Gijeiftestrantheit entmünbigt ijt, finben bon bem Intraftreten bes $\mathfrak{B O B}$. an beffen Borjariften aber bic entminbigter Geiftestranlen Tutwentoung.

Die nad ben Boridriften besీ fraitz. ober bes bab gechtes fü

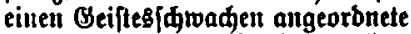
Bejtellung eines Beiftanbes verliert

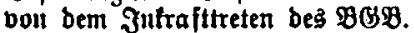
an igre Wirturg.

\section{g. Art. 128}

\$Ber zur Beit bes Infraft

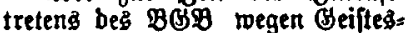
trantheit entmunbigt ift, fteht von biefer Beit an einem ná ben $B o r=$ jariften bes 948 . wegen BSeiftes: tranflyeit Entmulnbigten gleiф.

B. Art. 181.

Die nă ben franz. ober ben bab Gefeben für cinen Beiftes: (d)roadjen angeorónete Deftellung eines geiftanbes verliert mit bem Intraittretest bes $\mathfrak{B} 98$. ihre Mirtung.

Motive 73, 74, Brototolle 211 ff.

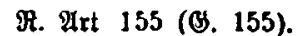

æer zur Beit beš Ĵntraft, tretens bes $\mathfrak{B}$ trantheit entmulnbigt ift, fteht bon bieler Beit an einem ná ben $B o r=$

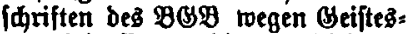
frantheit Entminbigten gleid.

भ. 21tt. 210 (S. 2।1).

Die naw ben franz. ober bert bab. Sefezen fint einen Beiftez: ¡átoadell angeoronete Beitellung eines seiftanbes berliert mit bem Iblaufe von 6 monaten nat bem

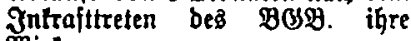
Birtung.
I 2 rt. 98.

Uuf eine Berion, toelde bor bem Intrafttreten

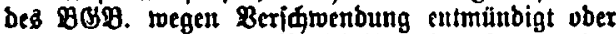
fär welde nad bett Borjdriften bes franz. ober bes bab. Redtes wegen Berjळwendung bie Beftellung eines Beiftanbes augeoronet ift, finben von bem Intrafttreten bes $\mathfrak{B G S}$. an beffen Borjariften laber bie entmünbigten Berfめwenber 21uwenbung.
B. Art. 129 (\$ 156, (3. 156).

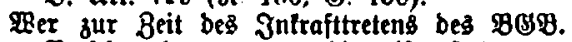
wegen Berfinenbung entmanbigt ift, fteht von biejer Beit an einem naq ben Borfitiften bes BßB. wegen Berfaroendung Entmünbigten gleid.

Taffelbe gilt bon bemjenigen, fît welden nad ben fraltz ober ben bab Eefeben wegen Bers fámenbung bie Beftellung cines Beiftanbes an:

Protive 74, Brotololle -

I $\mathfrak{A r t} .99$.

भuf eine Berfon, tiber welhe, weil fie taub, blinb ober fhmm

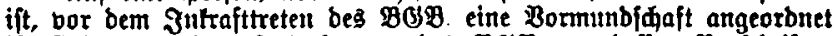
ijt, finden bon bem Intrafttreten bes $\mathbb{B}(B) B$. an befien Boridriften

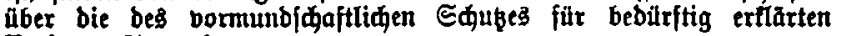
Qerfonen Antenbung.

Mrotive 74, 75, Brototolle $211 \mathrm{ff}$.

[Bgl. 3น I $\mathfrak{1}$ rt. 128].

I Irt. 100.

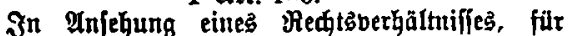
welates bas franz. ober bas bab. Medt mabgetuenb

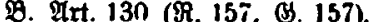

Die $\mathfrak{B o r f} \not r i f t e n$ bes franz. und ber bab. Befeßse

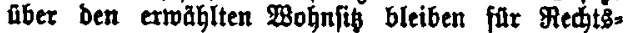


if, Bleiben, lofern vor bem Snlrajtteten bes $B G B$.

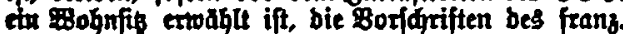

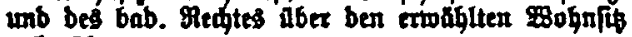
untoerifint.

grotive 75, 9rotololle 214.
I 9.t. 101.

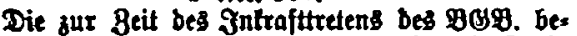
ftchenben Bexfugungsbejurăntungen bleiben in Sraft, unbefuabet ber Borfuriften bes 9 BP. zu Sunjten berienigen, welde Redte von cinem Miळtberedtigtent Gerleiten. verbaltnilfe, bie fiळ nă biejen Beję̧en Eeftimmen.

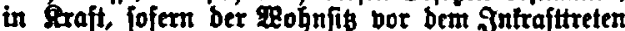
bes BGB. ertoushtt morben ift. Motive 75, \$rotololle 223.

I Art. 102.

Die Borfdriften bes $\mathscr{B}$ veriathung finben aum auf bie bor bem Intrafts treten bes $\mathscr{B S B}$. entftanbenen, noळ nidgt berjabrten भnfpride Anwenbung. Der Beginn powie bie Semmung und unterbrehung ber Beriahntng be= fimmen fin jebod fur bie 8 eit oor bem Intrafts treten bes PGg. nam ben bisherigen Bejegen.

Ift bie Beriăhnungsfrift nad bem $B \circlearrowleft B$ tarzer als nad ben bisherigen Gejesen, fo wirb bie tarzere Frift von bem Intrafttreten bes $B S B$. an berednet. \$Benn jebod bie in ben bişgerigen Befegen beftimmte

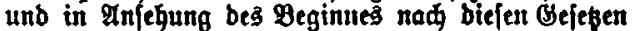
zu berénnenbe lăngere Frift fraber ablăuft als bie im $\mathscr{B}$ G9 beftimmte tilrzere frift, fo ift bie $B e r=$ jafrung mit jenem frigeren geitpuntte vollenbet.

9. Art. 140 (⿻上. 168, G. 168).

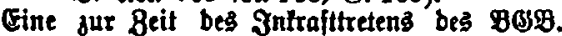
beftehenbe Berfügungşbejărānhung bleibt wirtfam,

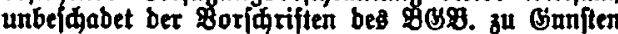

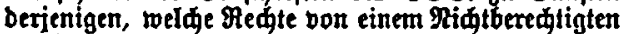

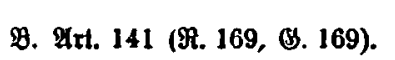

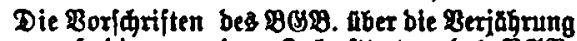

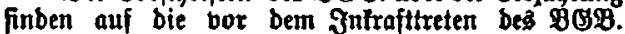

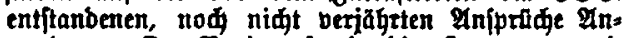
reenbung Der Beginll porvie bie Semmung unb unterbredung ber Berjăhrung beftimmen fí jebod far bie Beit vor bem Intraftreten bes $\mathfrak{B Q S}$. naq ben bishterigen Gefesen.

Ift bie Berjahnungs frift nađ bem $B(S B$. Harzer als ná ben bis̆herigen Gépepen, fo toirb bie turgere

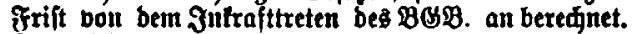
Enuft jebod bie in ben bisherigen sefegen beftimmte

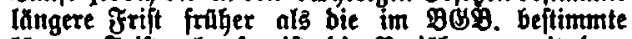
tarzere frift $a b$, fo ij́t bie Berjăhrung mit bem Tblaufe ber lăngeren Frift bollentet.

\section{Motive 75-78, Brotololle 223.}

I Art. 103.

Cin Squlbverbalmis, meldes bor bem $\Im_{n=}$ trafttreten bes $9 \leftrightarrow \mathscr{B}$. entftanben ift, wirb nad ben bisherigen seleten beurtheilt.

Motive $88 \mathrm{ff}$. Brotololle $223 \mathrm{f}$.

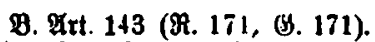

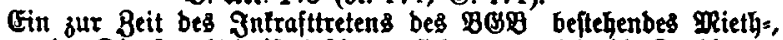
Bagt = ober 2ienftwergalnif beftimmt fiq, wenn nidt bie Stunbigung nad bem Intrafttreten bes $\mathfrak{B} \circlearrowleft \mathscr{P}$. für ben exfen Termin exfolgt, fâr ben fie nah ben bisherigen befegen aulaffig ift, bon biefem

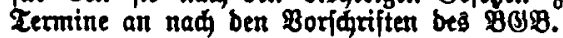

Motibe -, Brotololle 22\$f.

I Art. 104.

Gin Miethbertrag ober ßadtbertrag, welder bor bem Intraftreten bes $\mathfrak{B Q S P}$. aber tin (S)mbltīa

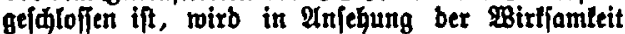
gegen benjenigen, weld,er nah bem 3ntrafttreten bes $80 S 9$. bas Figenthum ober ein anberes, ben

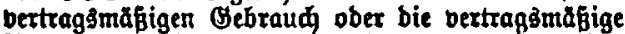
Yhabung bes Miethers ober Păhters aufbebenbes ober bejurantenbes Redit an bem Srunbjtude ertoirbt, nad ben bisherigen Gejeben beurtgeilt.

Gin Bleides gî́t bon bem aus einem anberen Exalboerbaltniffe entifanbenen Finipruge, fofern biejer naq ben biskerigen Bejesen bura Ein= tragung in ein off. Bú פoirtiamleit gegen Dritte erlangt hat.

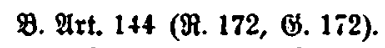

æBitb eine Sadje, bie zur Beit bes Jntraft. treten 8 bes $\mathscr{B} B \mathscr{B}$. bermiethet ober verpahtet war, na⿱ biejer Beit verăubert ober mit einem Reate belajtet, fo hat ber Mietger ober Fadjter bem Er. werber ber Sadie ober bes Medtes gegenuber bie

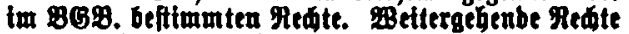
bes ghtethers ober Pädters, bte fí aus ben bis. Gerigen Gefeben ergeben, bieiben unberubrt, un. Defoabet ber \$orldrift bes Fit. 143 (171).

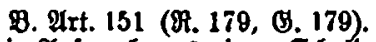

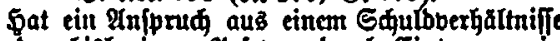
nad ben bişgerigen Bsefeben burd Eintragung in ein off. Bud 98 irtiamleit gegen Dritte exlangt, fo behălt er bieje 9 Birtfanteit aud naळ bem 3ntraft. treten $\operatorname{DCB} \mathfrak{B O S}$. 
[I fehlt].
P. Irt. 145 (M. 173, (3. 173).

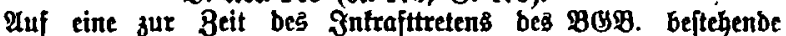

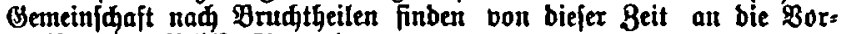

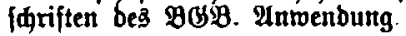

Mlotive -, Prototolle 227.

I 2 rt. 10:.

Auf bie vor bem 3ntrafttreten beg $\mathfrak{B G g}$. aug = geftllten Shulboerifreibungen auf Jnhaber unb

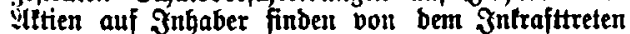

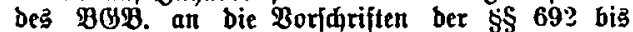
696, 699, 700 befielben Anwentbung. Die bis= ferigen Gefepe finb jeboh mas̄gebend in Unjegung ber Berpflidtung bes Pusftellers zur llmidreibung

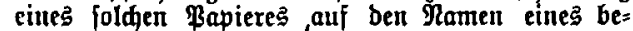
itimmten $\mathfrak{B e r c h t i g t e n ~ u n b ~ i n ~} \mathfrak{A n j e h u n g}$ ber $\mathfrak{B i r}=$ tungen biejer llmiłreibung. Bei ßapieren ber im $\leqslant$ 69:- Sab 2 DeS $\mathfrak{B G P}$. bezeidneten $\mathscr{A}$ rt, bei Gruetterungs̈jueinen uno bei ben auf ban Ramen cines bejtimmten Beredtigten umgejdriebenen $\mathfrak{B}_{\mathfrak{a}}=$ vieren find bie bişherigen Hejebe aud mas= gebend in Anjegung ber frajtloserflänutg unb ber Bahlungşiperre.

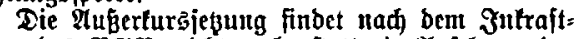
tretent bes $\mathfrak{B O B}$. nid)t mehr ftatt; in $\mathfrak{A}$ trehunt ber Mirtungen eincr bor bem Jntrafttreten beffelben

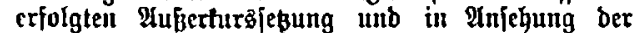
IBieberintursfesunt fint die bisherigen Öejeßse แå̃gebend.

Die Berjährung ber Injprilde aus bell bor

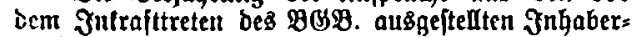

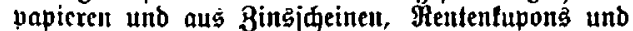
(Servinnantheiljdeinen, weldje zu folden Ynbaber: uapieren nad bem Yntrafttreten beg $\mathfrak{B}$ acgeben werben, wirb, unbejaabet ber Borjariften

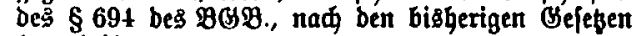
bcurtheilt.

Ein zur Beit bes 3nltaftretens bes $\mathfrak{B G B .}$ anlängiges, bie Fraftloşerllărung ober Bahlungs: iperre bezwedenbea Berfahren ijt nađ ben bisherigen (vejeben zu erlebigen; aud bie Mirfungen bes $\mathfrak{B e r}=$ fabrests beftimment fid nad ben bisherigen Gelesen.

Eoweit rad ben Borjariften bes 1.-4. Rbi. Die bisherigen Urefege Antwendung finben, tontut bicje aud tah bem 3ntrafttreten beś $\mathfrak{B O B}$. rurd) Laubesgefę geänbert toerben.

Protive 82, 83, Rrotololle 214 fi., 227 ff.

B. Art. 147 (भ. 175, (S. 175).

Fiur Bints=, Benten: unb Betwinuantheiljdeine, bie nad bem

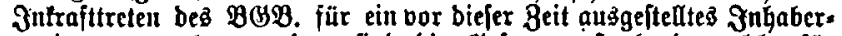
papier augageben werben, finb bie Beleze masgebenb, welde far bic bor bem Jntrafttreten bę $\mathfrak{B G P}$. auggegebentı Sdjeite gleider Prt gelten.

Mrotive -, Protololle 227 ff.

B. Qrt. 149 (9. 177, ఆ. 177).

Bon bem Intraftreten beg $\mathfrak{B G B}$. all gelten für borher aug= gegebente Urfunben ber im $\$ 793$ (B). 808 , bes $9 \leftrightarrow 9$. bezeidnuetent

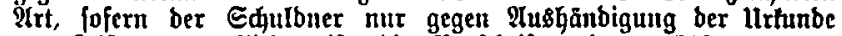
jur Reiftung verpflidtet ift, bie Boridriften bes $₫ 793$ (\$. 800)

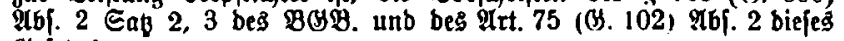
Bejekcs.

Motive -, Brotololle 230, 231.

I Yrt. 106.

Puf Eigenthum, Befis und §nhabung. weldye zur Beit bes Jntrafttretenta Des $\mathfrak{B}(5)$. beftehen,
9. 2rt. 152 (M 180, (H. 180).

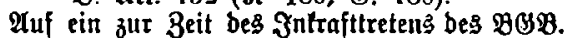
beftehendes Befibuerhăltnis finden von biefer Beit 
finden bon biejem Beitpuntte an bie Borfinziften Des $9 \$ 5$. Anmenbung.

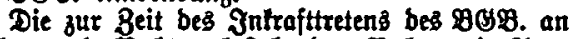

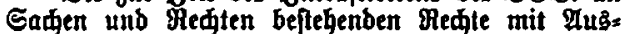
nahme bes Ceigenthumes bleiben mit bem aus ben bisherigen Breleben fí ergebenben 3nbalte bejtehen.

g ot:ve 83, 84, Protololle 231 ff., Romberift 329 fi.

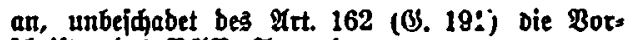

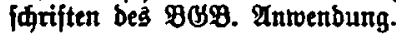

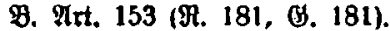

Tuf bas zur Beit bes Эntraftretens be马 BOSB. bejtehenbe Eigenthum finden von biejer Beit an bie Boriduiften bes $\mathfrak{B}(5 \mathscr{B}$. Indentung.

Eteht unt Bett bes Gntraftretens bes 909 .

bas Eigenthum an einer Sade DRebreten nidt nam grumtheilen ju ober ift ju biejer 3 ett ein Gonberelgenthum an ftehenben Erjeugniffen eines Granbftüăes, insbti. ał Päumen, begriunbet, fo bieiber biefe Redte beftegen.

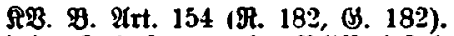

[I feglt].

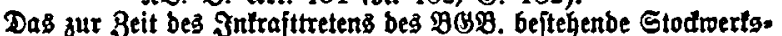

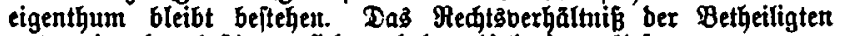
unter einanber bejtimmt fid naw ben bisherigen Oeję̧en.

Dlotive -, Brototolle $231 \mathrm{ff}$.

Prt. 182 a (G. 183).

Bu Guniten eirtes Brumbitudedes, bas zur Beit bes Jutraftreten!

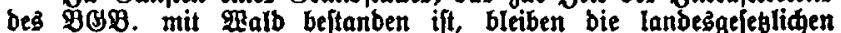

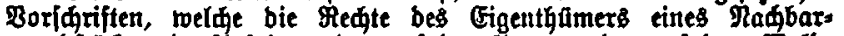

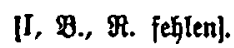

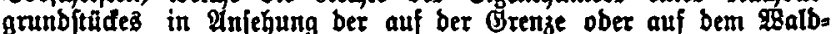

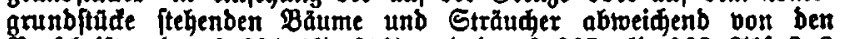

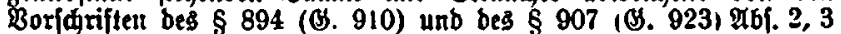
bes $\mathfrak{B} B \mathfrak{B}$. beftimmen, bis zur nădften Beriüngung bes 2 albeş in Straft.

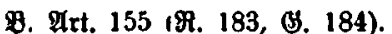

Pedte, mit benen eine Sade oder ein Bedt zur Beil bes 3nfrafttretens bes $\mathscr{B O P}$. belaftet ift, bleiben mit bem fin aus ben bišberigen Befegen ergebenben Jnhalt unb Pange beftehen, foweit [I feh̆lt].

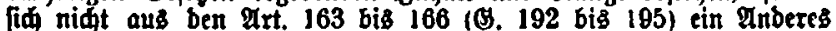

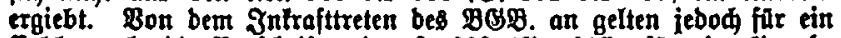
Erbbauredt bie Borjuriften be $\$ 1002$ (B. 1017), für eine \&runb: bienftbarleit bie Borfmriften ber $\$ \S 1003$ bis 1012 (\$. 1020 bi\$ 1028) be\$ 9019 .

Rotive -, Brototolle 231 fi.

I थitt. IC7.

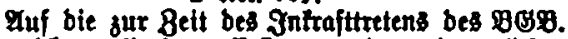
nod nidt bollenbete Exfibung einer betwegliden Same finben bie Boridriften bes Ant. 102 ente ipređenbe Arwerbung.

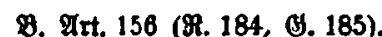

3it 3 ur Beit bes Intraftretens bes 898 . bie Erfigung bes Eigenthumes ober Rieß̧brounes an einter betwegliden Sadje nod nidt vollenbet, io finben auf bie Erfikung bie Boridrifter bes aut. 141

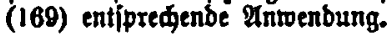

Drotive 84, Prototolle 234.

I $\mathfrak{q t r t} 108$.

Das zum 8wede ber Anlegung ber Orunbbáder einzuhaltenbe Berfahren wirb fur jeben Burbes fteat burd lanbesherrlide Berorbmung beftimmt.

Durd landesberrlide Berorbnung wird aud beftimmt, ob bisher gefahrte Badder als Grumbs buduer im Sinne bes BOB. gelten follen unb in wel' als angelegt anjuleben ift.

3if bas Brunbbuक far einen Bezirt als angelegt anzulehen, fo ift bie antegung aud fat folde zu bem Bezirte gehbrente brunbptude, welde nod lein Blatt in Grunbbudfe exhalter haber, als exfolgt anzufehen, foweit nimt beftimmte Branbftade Durd befonbere Anorbnung auggenommen finb.
9. Prt. 157 ( 9.185, B. 186).

Das Berfabren, in weldem bie Anlegung ber Brumbbuher exfolgt, forvie ber Beitpuntt, in weldem bas Bjrumbbud für einen Bezint als angelegt an: zufehen ift, werben fate jeben Bunbesfteat burc lanbesherrlice Berorbonumg beftimmt.

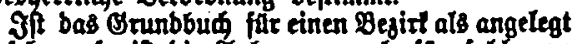
anzufeben, fo ift bie Qrnlegung aud far folde zu

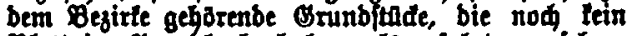
Olatt im (srunbbude haben, als erfolgt angulehen, forveit nidit beftimmte Granbitade bur befonbere Trorbnung ausgenommen finb. 
I Ixt. 109.

Durch Iandesherrliche Berorbnung fant beftimut

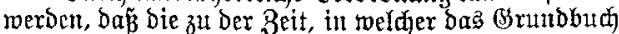
ale angelegt anzujehen ijt, beftehentoen (S)runboienjt= barfeiten, mit welchen bas Salten einer Dauternben Anlage verbunben ift, jolange bieje 2lutage beiteht, andere zu jener Beit bejtehente (Grundoienftbarfeiten jowie bie zu jener Beit beftehenten gejeblichen \$iand= rechte binnen eimer 10 Jahre nidgt iberfteigenden,

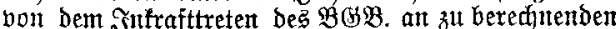
Frift und Die zu jener Beit alg Redte att eintem Grumbitiice bejtehenben Miethrechte unt ßadtredte äberhaupt ber Cintragung in ba弓 (Stundbatch zur Erhaltutg Der bollen wirfiamfeit gegent Dritte nicht bebürfen.

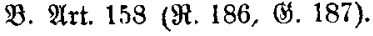

Bitte Grundoienjtbarfett, bie zu Der Beit beitegt,

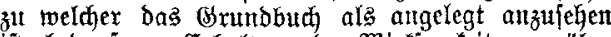
if́t, bebarf zux Erfaltung ber Wirkjamtett gegentiber

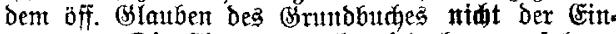
tragung. Die Gintragung hat jedod zh erfolgen, ment fie von bem Beredigtent ober von bem (sigenthümer bez belaiteten Grundftüues verlangt wird; bie Soften find von bemjentigen fu tragen unb vorauditejen, welder bie Gintraguttg verlangt.

Durch Laubesgejes fant hejtinmt werden, da bie beftehenden Grundotemitbarteiten ober einzelne

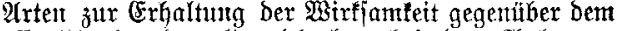
iff. (S)Lauben Des (Srunbbudbes bei ber Integung

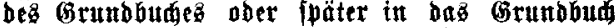
eingetragen werben nuifien. Die Beftmmutg fanu auf einzelne Grundbubbezirfe befdräntt werben.

B. Irt. 159 (円. 187, (3. 188).

Durd lanbesberrliche Berorbmung tann beftimmt

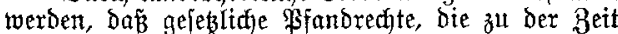
beftehen, zu welcher bas (brntobuth ala angelegt attzulehen ift, zur Erhaltung ber Wirfiamfeit gegen=

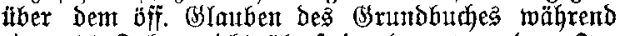
eitter 10 Safre nicht ïberfteigenden, bon bem $\mathfrak{s}=$ frafttreten bes $B(S B S$. alt $z$ bered)nenden $\mathfrak{F}$ rijt nidht ber Eutragung Geditren.

Durd lanbesherrlidge Beroromung faun bejtimmt

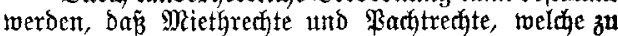
ber im $\mathfrak{X b j} 1$ bezeichneten 3 eit ala Rechte an einem

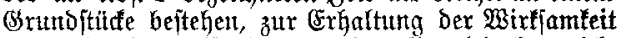
gegentuber Dem öff. (SIlauben bes (Srundbudies nidjt ber Eintragung bedürfent.

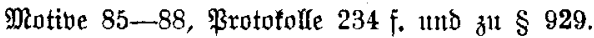

I $\mathfrak{A r t .} 110$.

Der Ermerb unb Berlupt bes Eigenthumes jowie Die Begrändung, Uebertragantg, Belajtuntg und Aufhebunt cines anderen Redites an eittem

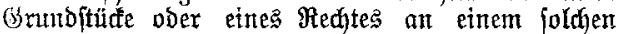
Rechte erfolgen atd nadi bem 3 nfrafttreten bes

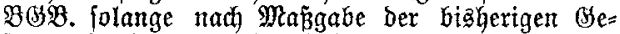

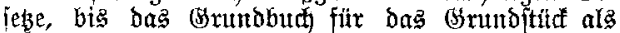
angelegt anzulehen iit.

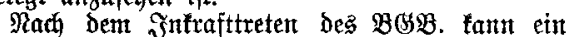

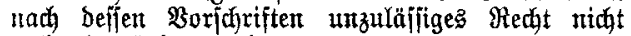
nethr begrilndet werden.

Muf bie YHfhebung eines zu bex Beit, itt weld)er bas (S) numbbud als angelegt anzultehen ift,

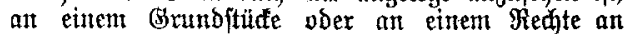
cinem (Srumbitidfe bejtehenben Redhtes finben aud Für Die fpätere Beit bie bißkerigen (Sefese folange Antondutg, bis bas Redt in bas Grundbud ein: getragen tit. Benn bas eingetragente Reht nad

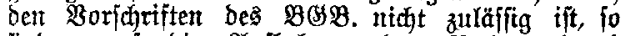

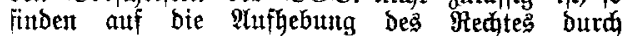
Rechtggejäät bie Boridriften bes $\$ 977$ unb, jojern Das Redt nit Dem Rchte eines Dritten belajtet ijt, bie Borjariften bes $\$ 965$ abj. 2 des BSS. entipred)ende Antonding.

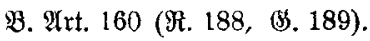

Der Errwerb und Berlujt des Eigentfyumes fowte bie Begrindung, Ulebertragung, Belaftung and Aufhebuttg eines anderen Rechtes an einem

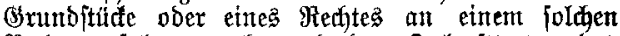
Rechte exfolgett auch nach ben Grttraftrretent bes BBSB. nach ben bisherigen (Stejeben, biä bas Grutb Guth als angelegt anzujehett ijt. Das Glethe gilt von ber Aenberung bes Jnhaltes unb bes Ranges ber Mtedte. Fin nach ben Boridriften

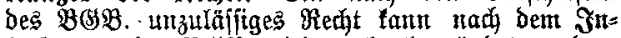
fraftretest be $\mathfrak{B} \mathfrak{B} \mathfrak{S B}$. ntidt meht begrünbet werben.

Jit zu ber 3 eit, za welder bas Grunbbud als angelegt antulehen ift, ber Befiser als ber Berentigte tm Grunbbude eingetragen, io finben auf etne zu biefer Beit nod ntat vollendete, tad

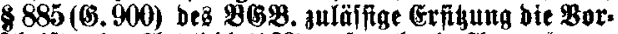

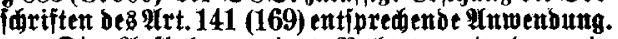

Die Aufhebung eines Red tes, mit bent eit

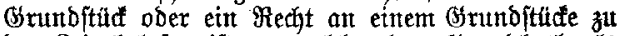
Der Beit belaftet ijt, zu melcher bas (5rulobuh als angelegt anzulehen ift, erfolgt aud nadi biejex

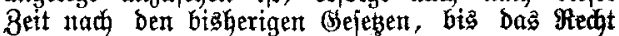
in bas Grunbbuch eingetragen twirb. 


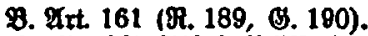

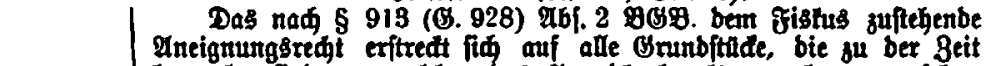

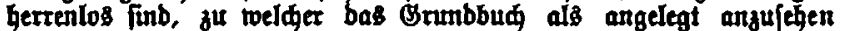

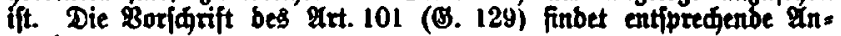
wenbung.

Motive -, Prototolle 236 unb in 80.3 zu $\$ 841$.

I Art. 111.

Die bisherigen Brejese aber ben Shus im Be: fithe einer Ornunbbienftbarteit ober einer bejigrăntten perjönliden Dienfigarteit finben aud nad bem Yntrafttretent bes $\mathrm{BBS}$. folange Antwenbung, biB

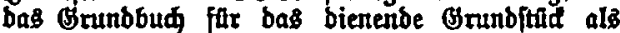
angelegt anjufegen ift.

Motive -, \$rototolle $236 \mathrm{f}$.

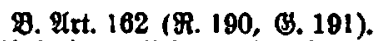

Die bisherigen Bsejese abet ben Shut im Befibe ciner Brunbbienjtbarteit ober einer be idrănlten perfönliden Dienftbarteit finben aud nad bem 3ntraftretert bes 9079 . Antwenbung, bi bas Brunbbud fir bas belaftete Grunbltad als angelegt anjufeben ift.

Bon ber Beit an, zu welder bas Brunbbum als angelegt anzuiehen ift, finben zum Sqube ber

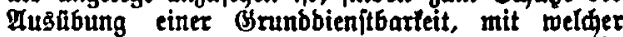
bas Salten einer bauernben 2frlage verbunben ift,

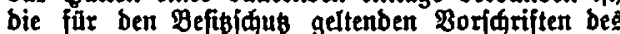
BGSB. entipredenbe Ân barteiten biejer $\mathfrak{A n t}_{\text {nad }} \mathscr{A}$ tt. $158(\mathfrak{M} 127$ ober 186, B. 128 ober 187) zur Erhaltung ber 2Birffanteit gegentuber bem off. Glauben bes Brumbbudes nidt ber Cintragung beburfen. Das BIleide gill für Brunbbienftbarteiten anderer $\mathscr{P}$ tt

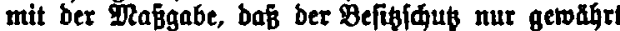
wirb, went bie Dientharteit in jebem ber 3 Ieptell Jafre vor ber Stönung minbefitens einmal aub: gethbt worben ift.

I Iint. 112.

Fin gu ber Beit, in welder bas Grunbbud als angelegt angujehen ift, an einem (Frunbitude beftehenbes $\$$ fanbrewt wirb far bie fpatere Beit als sypotget ofne sppothetenbrief unb, toenn ber Fetrag ber forberung, fur welde bas \$fandredt befteht, nidht beftimmt ift, als Siderungshypothet im Sinne bes $\mathfrak{B O P}$. beurtheilt.

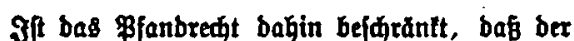
Brlăubiger Befriebigung aus bem Brunbitude mux im Bege ber Bmangsbertvaltung verlangen lann. To bleibt biefe Bejdräntung beftegen.

Durd Sarbesseejes tann beftimut werben, bas ein nad bem 1. $\mathscr{A b}$. als \$ypotget ohne \$ypotheten: Grief zu Geurtheilenbes \$fanbredt als Briefhypothet ober als Siderungshypothet unb eine aber bas $\mathfrak{B f a n b r e d}$ fraber entheilte utrunbe als sqpotheiten: Grief int Einne bes \$OBB. zu beurtbeilen feien.

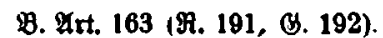

Cin zu ber Beit, ju welder bas Grzurbbú als angelegt anjulegen ift, an einem Brunbotade beftchenbes Pfanbredt gilt von biejer Beit als eine sqpothet, für welde bie Ertheilung beß इypothetenbriefes aubgeffilofien ift. Yit ber Betrag ber Forberung, fur bie bas Pfanbrefit befteht,

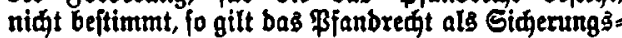
hapothet

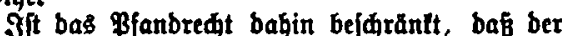
Blăubiget Pefriebigung aus bem Grnunbittlde nur im Sege ber 3rongsvertwaltung fuden tann, io Gleibt biefe Befäräntung beftehen.

$$
\text { 9. Art. } 164 \text { (M. 192, 9. 193). }
$$

Durc Landesgejes lann bejtimmt werben, baß̃ ein Pfanbredt, weldes nad Prt. 163 (M. 191, B. 192) nidt alś Sidenungshgpothet gilt, als Stherungshopothet ober als eire 5ypothet gelten foll, far welde bie Ertbeilung bes sypothetenbriefes nidt ausgejdLoffen ift, unb baß eine uber bas Pfand. reht ettheilte urturbe als \$ypothelenbrief gelten foul.

Motive 89 f., Brototolle 237.

9. art. 165.

Durd Eanbeşgefé tant fât ein Bfanbredt, bas nad ben Art. 163, 164 als Siderurng Gypotbet gilt, beftimmt wetber, bab bem SHábiger bas Medt, bie \&binutg ber sypothet zu verlangen, went fie fifi mit bem Eigentigume in einer Perfon vers einigt, in gletwer 38 cije zufteht, wie wenn jur Siderung bes Fedtes eine Bormertung im Grunbbud eingetragen ware.
M. Trt. 193 (G. 101).

Durd Ianbesgeles Taum bes fitimmt werben, baf etr gläubtget; befien Pianbredt in ber lin

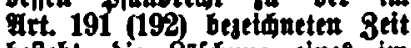
befieht, bie Sobjung eizes in Rauge vorgebenben ober gletí. fithenben 9 ianbredtes, fallo biefes in unit bem Eigenthume in eirer Perfon vereinigt, in gleider 28 eife 3u verlauger berthitgt th, wie ment zur Sidjerung bes Redtes auf Qbjung eine Bormertung im Grantbude eingetragen toăre. 
I Frt. 113.

Eine zu ber Beit, in weldher bas Grunbbus als argelegt ans zulehen ift, an einem onntoptade beftegenbe Oninbifult toirb far Die ipātere Beit als Grunbidulb und eine aber bie Srunbjath fraher ertheilte Urtunbe als Grumb:

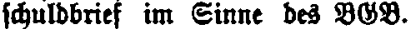
beurtheilt.

Die Borfdrift bes $\mathfrak{A r t} 112$ Ibj. 2 finbet entfprederbe $\mathfrak{A} \mathfrak{n}=$ wenbung.
9. Irt. 166.

Gine zuber Beit, zu welder bas Brunbbuh als angelegt arjuleben ift, Geftehende Brnumbifulb gilt von biejer geit an als orunbjuutb in Sinne be3 909 . und eine atber bie Brunb finulb extheilte Mrtunbe als Granbifulbsrief.

Die Poridrift bes Ant. 163 $\mathfrak{A} 61.2$ finbet entipredentbe $\mathfrak{A} \mathfrak{n}=$ wenoung.

Protive 89, 90, Protololle -
M. 194 (ङ. 195).

Cine zu ber Beit, zu weldier bas Grundbud als angelegt anzuiegen ift, beftehende Brunb: 低ulb gill bon biefer Beit art als ơnandidulb im Sinne bes̆

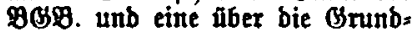
ifulb ertheilte urtunbe als Grand: faulbbrief. Die Borjđrift bes Art. 191 (182) $\mathfrak{A b f} 2$ finbet ents iprewenbe $\mathfrak{A n t w}_{\text {endung. }}$

Durd Lanbesgejes tann bes ftimmt toerben, bas eine fu ber im 9bf. I bezeidneten geit bes ftegenbe Grnunbifulb als eine Sppottel, für trelde bie $\mathfrak{E}_{r=}$ theilung bes snpothefenbriefes nidt ausigejulloffer ift, ober als Sidie: rungaghpothet gelten foll unb Dá̧ eine äber bie Ornunbifuld ertheilte urtunbe als sypotbefert. brief gelten foll.

I. Art. $144(I I-$, R. - , G. -) .

Ist bei der Anlegung des Grunbbuches ein bestehendes Recht in das Grundbuch nicht eingetragen, so kann der Berechtigte die Eintragung verlangen; die Vorschriften des \$ 843 BGB. finden entsprechende Anwendung.

Mrotive 90, 91, Brototolle 237.

I. Art. 115 .

Durd Lanbesgeles tann bejtimmt werben, ba的 ein an eirem \&runditude beftegenbes verån unb vererblides Tausungs reedt, werm es bei bem bes Iafteten Brumbithide eingetragen ift, ein glatt im Brunbbude erbalte.

[I unb 9. feglt].
P. Art. 167 (R. 195, (S. 196).

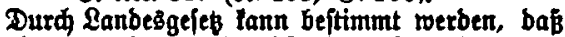
auf ein an einem Grunbitade beftehenbes ber: erblides und abertragbares Sugung Bredt bit fid auf Grunbftüte bestehenben Borfirtften unb auf ben Crmerb eines folden Retites bit fît ben Erwerb bes Gigenthumes an etrem Crunbltüate

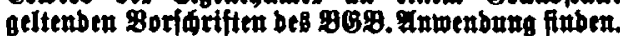

Motive 91, Frotololle 237 \%

タ. Art 196 (\$. 197).

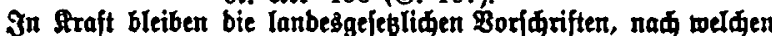

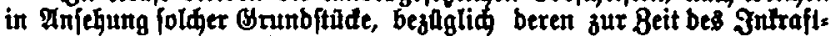
tretens bes $B B 9$. eir nidit unter ben $\mathcal{M r t .} 61$ (\$. 63) fallenbes

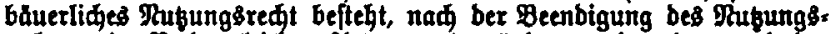
redte\$ cin Redit gleider $\mathfrak{A}$ t nen begranbet werben tann und ber Gutş̧⿻上丨 zu ber Begrinbung berpflidtet ift.

I $\mathfrak{A r t} .116$.

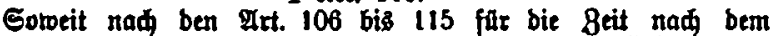

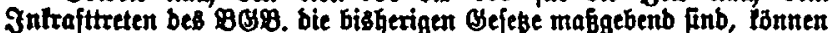

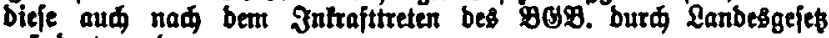
geounbert werben.

Motive 91, \$rotololle -

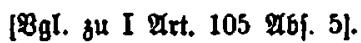

I Art. 117.

Die Battigfeit einer bor bem Sntraftreten bes

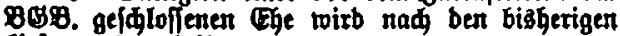
Befepen beurtheilt.

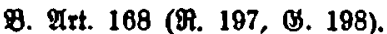

Die Gultigleit einer bor bem Intraftreten bes BOBD. geidlofienten Ge beftimt fid nad ben Gisherigen Esefegen.

Eine nad ben bisherigen (Sejegen nidtige ober ungultige Che ift als bont anfang an gültig anx zufehen, wenn bie Chegatten zur Beit bes Snltaft

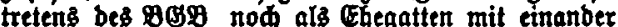
leben und ber Brunb, auf bem bie Niqutigleit ober

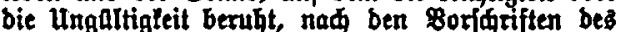
BOP. bie Midfigleit ober bie Anfedtbarteit ber Cobe nidt jur Folge haben ober biefe gBithung berloren haben warbe. Die far bie Anfedtung im PGP. beftimmte Frift beginnt nidt bor bem Intraftreten bes 9 @8. 
Die năb ben bis̈berigen Grejęen erjolgte

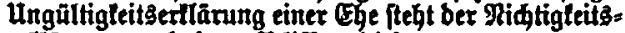

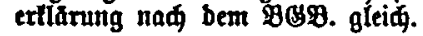

Mrotive 91, 92, Protololle 238\%月.

I 2rt. 118

3n Anjehung einer zur Beit besె Yntrafttreteng bes 939 . beflehenden che beftimmen fid fur bie

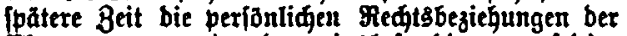
Énegalten zu cinanber, insbef. Die gegenfeitige

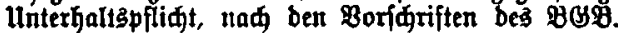

9. Int. 169 (M. 198, (H. 199).

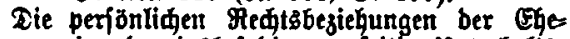
gatten zu einanber, ingbel. bie gegenleitige Ulnterbalta:

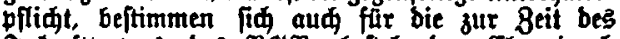
Intrajtreters bes $\mathfrak{B O B}$. bejtehenben (Ehen inad beffer $\mathfrak{B o r j}_{\text {orifter. }}$

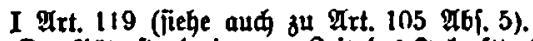

Der Gulterftant einer zur Beit beş Jnfrafttretens

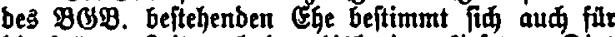

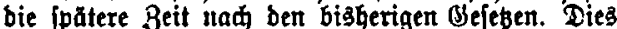
gill intšbef. bout ber in Folge bes OHitteritanbes ein:

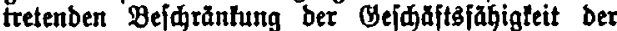
Ehefrau, bon ber Bulâffigleit und 2 irtjamfeit eines (5hebertrages und bon ben erbredtliden 2 sithungen bes Gaterftanbes. Die Gisherigen Befese tonnen

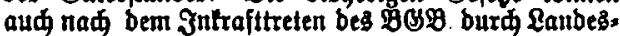
geję geăntbert twerben.

Soweit in Hemågheit bes 1. T6j. fitr ben ebes lifhell Gaterftanb bas franj. ober bas bab. Meat másgebend ift, bleiben aud bie Boridriften bes frang. unb bes bab. Pedtes aber bas Berfabren bei Bermogengabjonberungen unter Ehegatten unberilhrt.
B. Art. 170 (अ. 199, (G. 200).

Für ben Gaterftant einer zur Beit bes Inlraft

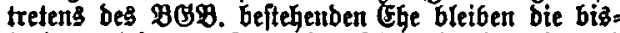
beriger Brejese masgebent. Dies gilt inşbej. aú

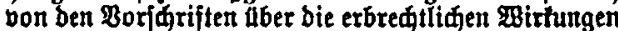

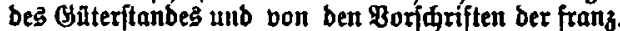
und ber bad. Gelebe liber bas Berfahren bei Ber mőgensెabjonberungen unter Ehegatten.

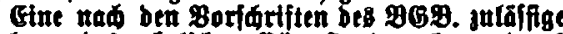
भegelung bes ebeltuen Giterfanbes lann burd Ggebertrag aum bann getrofien werben, wenn nad ben btohertgen Gefegen ein Ghevertrag unouläfifg fett wilitbe.

Soweit bie Egefrau nad ben flt ben bigherigen Bateritand másgebenben Befeken in Folge bes

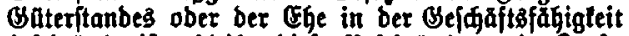
bejardult ift, bleibt bieje Bejaräntung in 9raft.

polange ber bisherige Bsterftand bejteht.

Motive 93-97, Brotololle 244 f., Stomperiकt 331.

I Urt. 120.

Far bie Egefdacibung unb für bie Erennung ber Ehegatten bon Zija unb Bett finb nad bem Sintrafttreten bes $\mathrm{BHg}$. beffen Borfdriften mafgebenb. Gine Thatfadie, welde vorger fid er: eignet bat, lann als Sheibungs"s grunb ober Trenuungsgrunb nur geltenb gemant werben, wenn bie Ihatfade aud naw ben bisherigen Befeber ein Equeibungşgrunb ober Zrenumggిgrunb ift.
B. Att. 171 ( (R. 200).

Die Sdeibung exfolgt bon bem Intraftreten bes 9098 . an naर́ beffen Borfuriften.

Sat fid ein Ebegatte bor bem

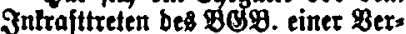
feglung ber in ben $\$ \$ 1650$ bis 1553 (1548 bis 1551 ) bes 939 . bezeidneten $\mathfrak{A x t}$ |qulbig gemadt, jo lann auf Edoibung nur ertannt werben, wenn bie Berfehlung aú nad ben bisherigen Bejeben ein Sqeibunggranb ober cin Tren: nung\$grumb war.

:Protive 97-99, Protololle 250.

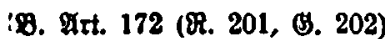

Fan bie EBthungen einer beftanbigen ober geitweiligen Irennun

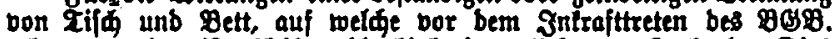
ertannt toorben ifl, bleiben bie bisherigen Befebe másgebenb. Dies gilt insbef. aú bon ben Borfintiften, nad benen etre bis gu bem Zobe eines ber Ehegatten fortbeftegenbe Irenurug in lallen ober eingelnen Begiełungen bet Fuflofung bet (Ehe gleightegt.
1 art. 181.

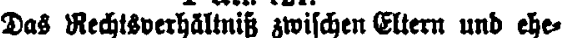
Itanen Pinbern beftimmt fid bon bem Intrafttreten

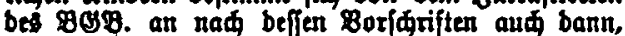
wenn bas Tinb vorher geboren ift. Dies gilt aud in Sinjehung bes Bermägens, weínes bon bem finbe vorbet ertoorbert ift.

\section{B: Art. 173 1R. 202, (9. 203).}

Das Rectsberhaltnis zwif́nen ben Elten unb einem bor bem Intrafttreten bes $\$$ eheliden Rinbe beftimm fic bon bem 3ntraftreten bes $\mathfrak{O B D}$. an nad beffen Boridxiften. Dies gill insbef. aud in anjegung bes Bermögents, weldes bas find vorher ertoorben bat. 
I Frt. 122.

3it bet Bater ober bie Rutter vor bem 3 ntraft

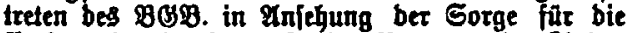
Berfon ober ber Corge far bas Bermogen bes hinbes burd eine Inorbnung bet zuftănbigen Beğorbe be-

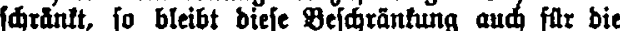
(pätere 8eit in Iraft; in Pniehung ber Aufbebung ber Anotonunt finben bie Borjuriftent bes \& 1551 bes $\mathbf{B B P}$. entipredienbe Anwenbung.

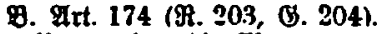

Jit ber Bater ober bie Mutter zur Beit be

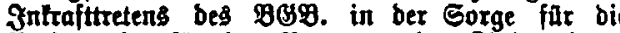
Berion ober für baş Bermőgen bes Rittoes burd

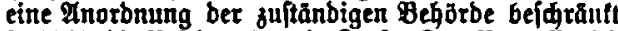
jo bleibt bie Bejurăntung in Rraft. Das Bormetrid lanu bie Anorbnung nađ $\$ 1630$ (\$. 1671) bes $\mathfrak{B H B}$ aufbeben.

Ift bem Bater ober ber Plutter bie Paz̧niefung an bem Bermognen bes Rinbes burd Aroronung ber zuitänbigen geborbe entzogen, io Gat Das Bormseriat bie Anorbnung auf Mntrag aufaubeben, es Jei benn, bas bie Entziehung ber Rabnießsung

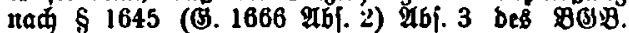
geredifertigt ift.

Plotive 101, Prototolle 251, Pomberidt 331.

I $\mathfrak{A r t}$ 12:s.

Sat ber Bater bor bem Intraftreten bes $\mathfrak{B}$ (S)

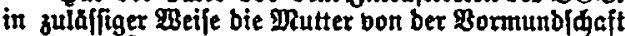
Aber bas finb ausgefdolofen ober ber Mutter eitten Beiftand zugeorbnet, io wirb bie Anorbnung bes Baterg far Die Beit nad bem Intrafttreten bes

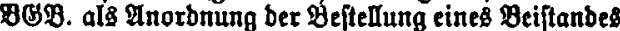
fít bie Mutter im Sirnte besి $\$ 1538$ besి $B 39$. beurtheilt.

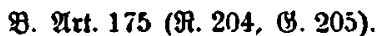

Sat ber Bater vor bem Infraftreten beş $\mathfrak{B H B}$. anf Grunb ber bishetigen Beflet bie Putter bon

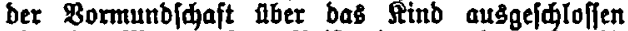
oder ber Datter einen Seiftand zugeorbnet, fo gilt bie Anorbnung beß̊ Batexß bout bem Infrafttretetl bes $\mathfrak{B O B}$. an als $\mathfrak{A}$ norbnung ber Beftellung eiues

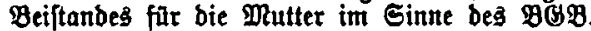

\section{Motibe 101, Brotololle -}

I Irt. 124.

उit nad Mabgabe ber bisherigen (sefese eine Che gejuteber ober in Folge Zobeserllanung auf: geloft ober anf Trennung ber Ebegatten bon Xif unb Bett anerfannt, fo fint far bie Deurtheilung, weldem Elterntheile bie Sorge fur bie Berjon ber mgeeinjळaftlident finber zufteht, bie bisherigen (Befese majgebent; bie Borjariften bes $\$ 1456$ 96j. 1

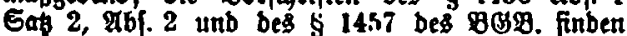
jebod Rnwenbung.

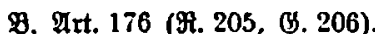

Sit auf Grund ber bisherigen Selese einte Che geläieben ober in folge ber Tobesertläung eines ber EGegatten aufgelofit ober ift auf Trennuta ber Egegatter bon Tifd unb Bett ertannt worben, fo beftimmen fí bas Reht unb bte Pfildt ber

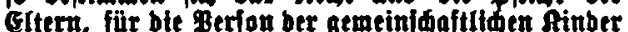
ju forgen, nad ben bisherigen Gefegen; bie Bor=

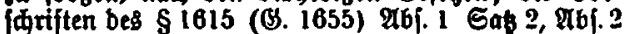
unb beß $\S 1616$ (\$. 1636) bes $\mathfrak{B O B B}$. finben jebod Arwenbutg.

Motive 101, Brotololle --

I Art. 125 (B. 177, M. 206, \&. 207).

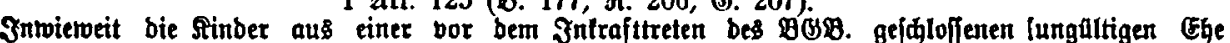

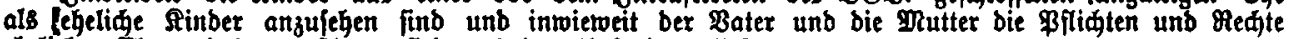

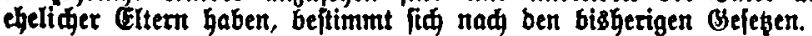

Dotive 101, 102, Protololle -.

I Irt. 126.

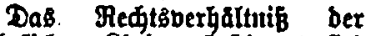
unebelinen finber beltimmt fif bon bem Infrafttreten beS $\mathfrak{B G B}$. an aud in Mnjebuttg ber vorber geborenten Stinber, mit Cinfiflus berjenigen, welde naw ben Bor: 14riften bes franz. ober bes bab. Redites arerlannt finb, nad ben

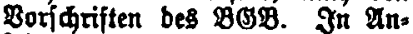
fehung ber vorber geborenen ftinber beftimmt fiø jebod bas Fedt, ben framiliennamen bes Baters gu fabren, forvie bie Unterbalts: berpflidutung bes Baters nad ben bisherigen Geleben.

Inmieweit untheltøe, vor bem Intrafttreten bes $\$ B \mathcal{B}$. emp angene finber, aud went fie niagt legitimirt fino, bie redtline Stellung eheliळer Rinber unb inmiemeit ber Bater
ஒ. Art. 178.7

Die ređtlidue Etellung eintes bor bem Yntraftreten bes $\mathfrak{B} \leftrightarrow \mathscr{8}$. geborenten untheliden finbes beftimmt fin bon bem 3ntrafts treten bes $\mathfrak{B} \mathfrak{S B}$. an nam beffen Borjđriften; fur bas Bedyt bes finbez, bent familiennamen bez Baters zu fübren, Jowie fur bie

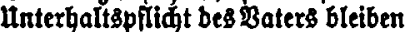
jebod bie bisberigen Gelebe maf= geberio.

Inwietoeit einem bor bem Intraftreten bes $B M B$. aufier= ebelid ergeugten flinbe aus einem befonberen (s) munbe, insbef. toegen Erzeugung im Brautitanbe, bie redtliळe Stellung eines eheliøen Alnbes zulommt unb intoietocit ber Bater unb bie $\$$ Putter eines foldyen Pinbes bie \$flidten unb
भ. Frt. 207 (G. 208).

Lie rehtlide Stellung eines vor bem Intrafttreten beß borenten untehelidien frinbes be: ftimmt fid oon bem 3ntrafttreten bes $\mathfrak{B} \leftrightarrow \mathscr{B}$. an nad beffen Borjdriften; für bie Grforfoung ber Baterfiafit. für bass Redt bes Rinbes, ben Familiennamen bes Baters zu fahren, fowie für bic Unterbalts: pflidit bes Baters bleiben jebod bie bisheriger Beieß̧e maß̧gebent.

Intwieweit eiutem bor bem Intrafttrten bes $\mathfrak{D G B}$. auber. ehelin erzeugten fitinbe aus cinem befonberen (O) runbe, insbef. wegen Erzengung im Brautitambe, bie redutline Stellung eines chelinen Stinbes jufommt anb inmietbett ber Bater unb-bie \$utter tine\$ folden Sinbes bie Pflimten unb 
und bie Mutter foldyer finber die Bffiditen und Feate ehelidber Eltern haben, beftimmt fich nad ben bisherigen Bsejęen.
Sechte ehelicher Eltern haben, beftimmt fin nad ben bigherigen Gejefen.

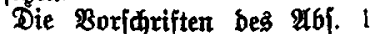
gelten aud fïr eit nad bent franz. ober ben bab. Bejęzen ant $=$ extanntes Sino.

Motive 102 bis 105, Prototolfe 251 ff.

I $\mathfrak{A}$ rt. 127

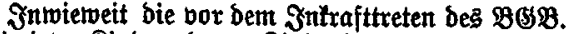
legitimirten Pinber ober an Sindeştatt angenomment Perfonen bie rechtliche Stellung ehelicher Rinber und intwietweit ber $\mathfrak{B a t e r}$ und bie Mutter bie Pffichten und Fechte ebelidjer Eltern haben, bejtimmt fid nach Den btäherigen Sejebent.

I $\mathfrak{A r t .} 128$.

Die Borfhriften bes $\mathfrak{B} \& \mathfrak{B}$. aber Boxmunbiajaftert und Pflegs fduften finben bon bem Snfraft= treten bes $2 B S B$. an ausich auf bie Geftehenden Bormunbfíaften und

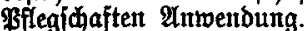

Die bisherigen Bormuinder und \$fleger berbleiben in ihrem Amte, jofern niagt bie Bormunbfáajt ober Pflegicjaft mit Dem Yntrait = treten bes $\mathfrak{B O S B}$. nach beffen $\mathfrak{B o r}=$ inriften beentigt twirb. Das (J) Ieidue gilt im Bseltungşbereidue ber preup. Borms. v. 5. Jult 1875 in :Injehung ber beftehenoen Framilienräthe und beren Mit= glieber.

\section{Motibe 105, 106, \$rotofolle -}

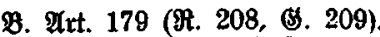

Intwierweit ein bor Dem Intrafttreten bes $\mathfrak{B S B}$. legitimittes ober an Rinbesftatt angenommenes Rinb bie rechtliðe Stelfung eines ehelichen Mindes hat und invierweit ber Bater und bie Mutter bie

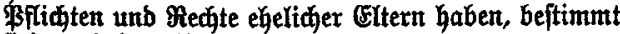
fid nac bett bisherigen (Sefesen.

B. Urt. 180.

Auf eine zur Beit bes Sntraft=

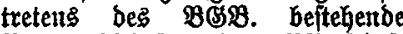
Bormutbfonaft ober Bflegidaft finben von biejer Beit an bie $\mathfrak{B} 0 \mathrm{r}=$ idriften bes $\mathfrak{B}(\mathfrak{S} \mathfrak{B}$. Anwendung Sit bie Bormund faft megen eines förperliden (Sebrediens an = georonet, fo gilt fie als eine nath

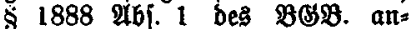
georonete Fflegfinaft. ऊít bie Bormunb|chaft wegen Seiftes= ¡đjtolache angeorbnet, ohne $\delta a \hat{z}$ eine Cntmulnoigung exfolgt ift, fo gilt fite als eitne nah $\S 1888$ 161.2 Des $\mathfrak{B H O}$. fitr bie angelegenheiten bes Beilteg: jhwahen angeoronete \$flegifoft.

Die bighterigen Bormüttber und Pfleger bleiben in Amte. Das (S)leidje gilt im Beltungs: Gereiche ber preus. BormD b. 5. Juli 1875 für bent Familienrath uno beffen Mitglieber.

Motive 106, 107, Prototolle $253 \mathrm{f}$

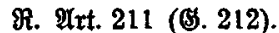

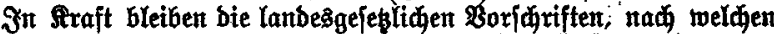

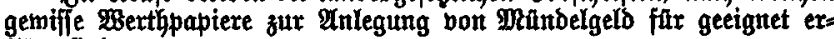
tlärt finto.

Motibe -, Frototolle -, RomBexidyt 331

I Ext. 129.

Die erbredftlifien Berballtniffe, mit cinfolufi ber exbrectlichen Sogulboeryaltuifie, wexben, wenn ber Crblaffer bor bem Sntraft= treten bes $9 O S P$ : geftorben ift, na. ben btoherigen ejejeben, wenn ber Geblafier ipdtex geftorben ift,

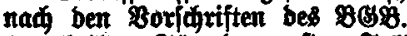
beurtheill. F̧ut bent erften f̧all bleiben aud bie Boxjariften bet Qanbesgefese iber bas erbidaft: liche $\mathfrak{L}$ tquibationsonerfahren unber rifibrt.

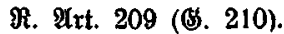

Ôf eine zur Beit bez Jntraft= treten bes $B$ BSB. bejtehende Bormunbj內aft ober. Bfleginaft finden bout biejer Beit an bie Borjariften Desె $\mathfrak{B} \mathscr{B}$ Ânwenbung. Sit bie Bormuntofifaft wegent eines torberlichen (S) ebrechen angeorontet. fo gilt fie als eine nac $\$ 1886$ (\$. 1910) $\mathfrak{a b} 1$ bes $\mathfrak{B}(\mathfrak{B S}$. an= georonete \$flegidaft. \$it bie Sormundichaft megent Seiftes: ¡đutwäđ̆e angeorbnet, ohne baß eine Entmitnoigung exfolgt ift, fo gilt fite als eine tad $\$ 1886$

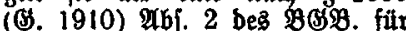
bie Bermb̈gengangelegenheiten bes

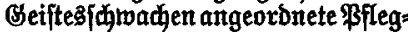
inaft.

Die Giakherigen Bormünber und Pfleger bletben im Omte. Das OSLeinge gilt im Beltung bereidie der prenf 9 Borm D. b. 5. Sulfi 1875 für ben đamilienrath und deffen Mitglieber. Ein Gegen. vormunb ift iu entlafien, wenn nad ben Boridutfiten bes $\mathfrak{B C S}$. ein Gegenvormuns nidot ju ber ftellen fetn würbe.
[I u. $\mathfrak{B}$. Feglent.

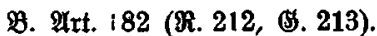

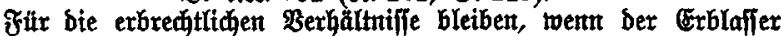

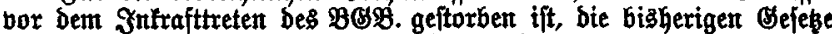

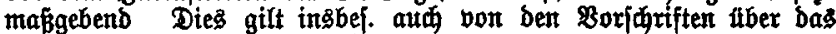

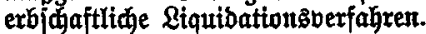

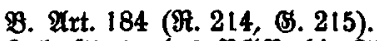

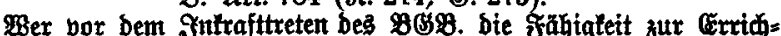
tung einer Berfügung von Fobeşwegen erlangt unt einte folde Bers

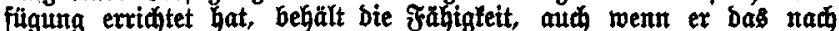

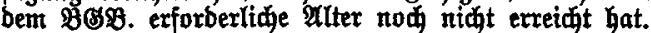

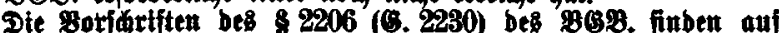
etn Ieftament Inwenbung, bas ein nah bem Jintrafttreten bes Bog. geftorbenet Grblafier bot biejem Bettpunte ertibtet bat. 
Die vor bem Intrafttretent bes BOBB. exfolgte Erriftung ober Pulbebung einet Berfigung bon Tobeşvegen wirb nad ben bi herigen Eejébert aud bann beur. theill, wern ber Grblafier. nad bent

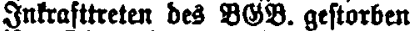

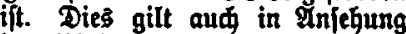
Der Binbung bes Exblaffers bei einem Erbbertrage ober bei einer wedfelfeitigen legtwilligen Bers fügung.

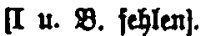

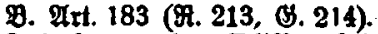

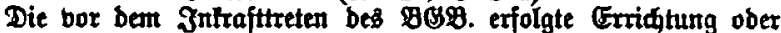
Aufbebung einer Berfigung oon Iobesswegent wirb na屯 ben bisherigen Befegen beurtheilt, aum wern bet Grblafier nah bem 3ntraftreten Des $\mathbf{B}(\mathbf{S})$. Ftirbt.

Das Bjleidie gilt fâr bie Binbung bes Erblaferş bei einem Erbs bertrage ober einem gemeinidaftlider Teftamente, fofern ber Grbbers trag ober bas Teftament bor bem Jntraftreten bes $B G 9$. erridtet worben ift.

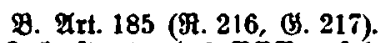

Die bor bem Intrafttreten beg 969 . exiolgte Grribtung etues

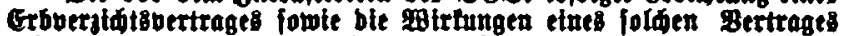
beftimmen fí nad ben bigherigen Befezen.

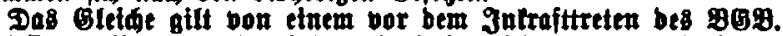
gefdolofienen Bertrage, butd ben ein Erbverjtotspertrag aufgehoben morben $\mathrm{t}$.

Dlotive 107-112, Frototolfe -

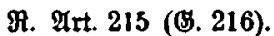

Die lanbeşgeleglidien Borifriftel, ná welden Mitglieber ge= wifier rilterfdaftlider Framilien bei ber Drbnung ber Exbfolge in

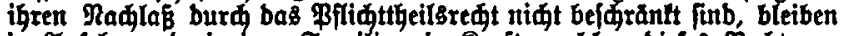
in Anjehung berjenigen Yamilien in Rraft, welden biefes Reft jut Beit bes 3ntrafttretenz bes $\mathfrak{B}$ GB. zufteht.

Somberidite 331.

\section{Räumliche Gerrichaft der Rechtsnormen.}

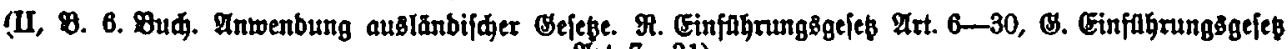
Q1t. 7-31).

II $\S 2236$ (B. § 2363).

Cin Berjobllener tann im 3nlanbe nam ben beutiden bex jegen fiur tobt extlărt werben, wern er bei bem Peginne ber Berfdollenheit ein Deutf fer war.

Beborte ber Berfdodente bei bem Peginte ber Berdiollenheit einem frember Staate an, fo lann ex in Jnlanbe naw ben beutider Gefeben mit wirtung filr bies jenigen Reditsberbaltrifie, welde fí naw ben beutfiden Befeben bettimmen, forvie mit ${ }^{2}$ isturtg fât bas im Snlanbe befindlidue get $^{2}$ mỏgen far tobt extlart werben; bie Borfánziften Des \$ 2234 (2343) $\mathfrak{A b}$. 2 finben entfpredenbe $\mathfrak{A n}$. twenbung.

Protololle $263 f . *$ )
ER. Art. 8 (\$. Art. 9).

Gin Beridollener lann im Snlanbe naw Dent beutífen Bes feben far tobt extlatrt werben, wenn er bei bent Beginue bet Bers finollenheit ein Deutífer war.

Gehörte ber Beridollene bei bem geginne ber Beridollenbeit einem fremben Staate an, fo tann ex im Inlanbe na⿱ ben beutfigen Gejegen mit Esirtung far biejenigen Medisoerbăltmiffe, welde fíd nad ben beutfiden Befépen beftimmen, forvie mit Pitlung falr bas im 3nlanbe befinblide Bermogent fũr tobt etllărt toetben; bie 23orífriften bes \& 2342 (2369) $\mathfrak{4} 6$;. 2 bes

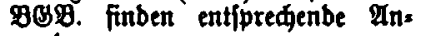
menbung.

5atte ein berifollener aus: Iănbijder Chemann feinen Iesten Wohnith im Jnlanbe unb ift bie im Jnlanbe zuridgebliebene ober babin zurildgefegrte Egefrau Deutide ober bis zu igrer Berheirathung mit bem Beridollenen Deutide

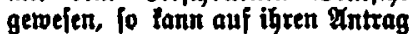
bex Berifollente im Jnlanbe nad bert beutfinen Geieken ohne bie

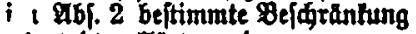
ur tobt extlast werber.

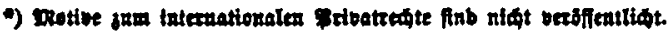


I $\$ 1$.

Die jur. Berföntidteit witb nady Dent Bejesen bes Drtes bcurtheilt, an weldem bie jur. Berion ifren Sip hat.
II $\S 2237$ (\$. 2364).

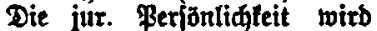
naw Den Bejéeser bes Drtes beurtheilt, an bem bic jur. Berfon ihren Sig hat.

Gin Bereit, ber naw ben

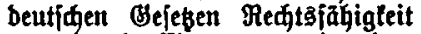
uur burd Gintragung in baz Bereinżregifter ober burd fraatlide Berleihung exlangen fonn, itt, wenn ex feinen Sib im $\mathfrak{Z}$ thlande hat, nur baltn reftsfabig, wenn

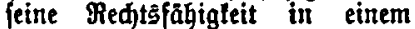
Bundeşftante anerlannt ift. Die Intertentung und bie Burüdnahme Der Anerfennung bejtimmen fí nă ben Befeksen biefes Staates. Brotololle 265 ff.
भ. Fit. 9 (ㅇ. Fitt 10).

Ein cinem fremben Etaste angelüreaber nab nad befien

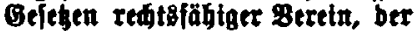
bie Remtsfäbigleti im Jnianbe nur uá ber Borfartiten beB $21(21,22)$ beg $\mathfrak{B O P}$. rllangen

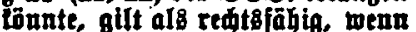

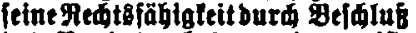
bes Bunbesratbes autriant if. IIuf aidit anertannte auslänbilante Bereine ber bejeidneten girt

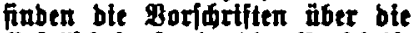
Gejellifaft fomie bie Boridrift

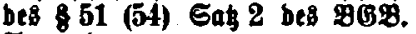
Inwenbung.

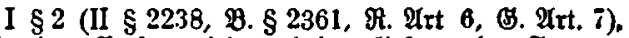
angebört.

Die Bejđăftsfăbiglcit cinter Ferjout wirb nad ben Befezent bes Staates beurtheilt, bem bie Berfon

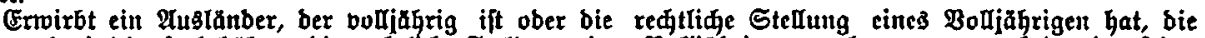

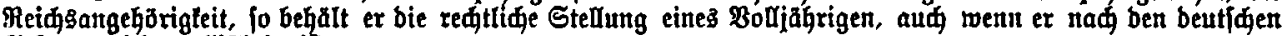
Befében nidht bolljăbrig ift.

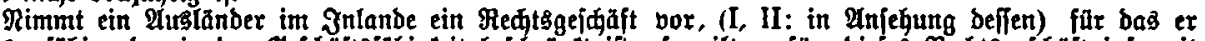

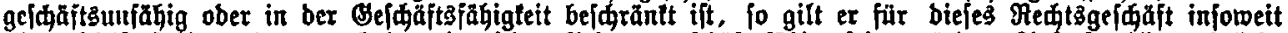

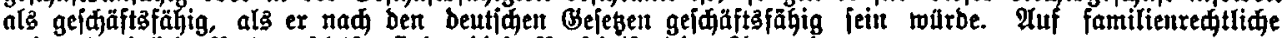
unb erbred)tlithe Redtsgejdäfte finbet bieje Boridrift teinte \&utwenbung.

Brototolle 269 f.

II $\S 2239$ (: $§ 2362$ ).

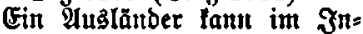
lanbe naw ben beutidien Befében entmünbigt werbell, wenn er feinen 2rognfib im Inlautbe hat.

\section{Brotololfe 270 ff.}

\section{I \& 3.}

Dic Form eines̄ Međt beftimmt fich nah ben Bseleben, melde fïr bas ben Begenftand Des Ređtisgeldaftes Bilbenbe Medt $1=$

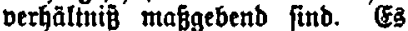
genfigt jebod, wenn bie form ben Befepen bes Drtes entipridt, ant

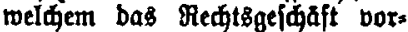
getrommen toirb.
II $\$ 2240(\mathscr{B} . \$ 2365)$.

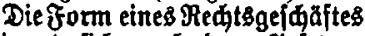
beftimmt fi welde für bas ben Begenftand bes

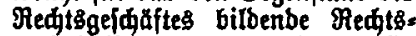
verbalmis majgebend fint. (58 gestugt jebod, fojern ni⿱中⿰㇀丶㇀ bieje Gejese entgegenlitehen, bie Beob= adtung ber Gejebe bes Drtes, an

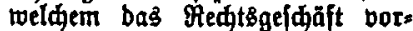
gettomment toiro.

Protololle 272 ff.

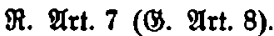

Ein भus̆länber fann im $\mathfrak{3}=$ lande nad ben beutjaen Bejesen entmünoigt werben, wenn er feinen Wohntis ober, falls it tetnen Bohnfts bat, fetnen Iufentbalt im Snlanbe hat.

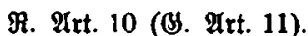

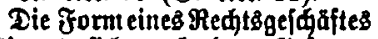
beftimmt fid nad ben Sejesen, twelde für bas ben Gegenftand bes

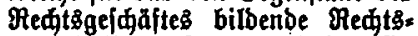
verhaltmif masgebent funb. Es genagt jebod bie Beobahtung ber Brefege bes Drtes, an bem bas Reat ţgei丸åft vorgenommen toiro. Die Boridrift bes 2 b|. 1 Saß 2 findet leine Antwenbung auf ein Ređtsigejăaft, burd bas ein Hedt an einer Sade begranbet ober lber ein [oldez Recht ber= fifigt wirb.
$I \S 4$.

Die Rechte an einer Sache sovoie der Besitz innl die Inhrbung einer Sache werden nach den Gesetzen des Ortes beurtheilt, an woelchem die Sache sich befindet. Der Erwerb und der Verlust eines Rechtes an einer beuceglichen Sache sowie des Besitzes und der Inhabung einer solchen Sache toerden nach den Gesetzen des Ortes beurtheilt, an welchem die Sache sur Zeit der Verwirklichung des für den Enoerb oder Verlust in Betracht kommenden Thatbestandes sich befunden hat.
$U \S 2211$ (B. \& 2369, R. -, G. -).

Die Rechte an einer Sache sowie der Besitz werden nach den Gesetzen des Ortes beurtheilt, an dem sich die Sache befindet. Der Erwerb und der Verlust eines Rechtes an einer bewoglichen Sache soroie des Besitzes einer solchen Sache werden nach den Gesetzen des Ortes beurtheill, an dem sich die Sache zur Zeit der Verwirklichung des für den Erwerb oder den Verlust in Betracht kominenden Thatbestandes befunden hat. 
Die Torschrift des 83 Satz 2 findet keine Anuendurg auf ein Bechtogeschäft, durch welches ein Becht an einer Sache begründet, übertragen ader awfgehoben wird.

Protololle $2 \overline{i 5}$.

$I \$ 5$.

Das Sehuldoerhältniss aus einem Rechtsgeschäfte unter Lebenden wird nach den Grsetzen des Ortes beurtheilt, an ucelchem das Rechtsgeschäft zum Abschluse gelangt ist.

Wenn nach den Umständen des Falles die Anwendbarkeit der Gesetze eines anderen Ortes als getooll anzusehen ist, o sind die Gesetze dieses Ortes massgebend. Ist jedoch das Rechtsgeschäft im Inlande errichtet, so bleiben für dasselbe die am Orte der Errichtung üler das Erforderniss einer besonderen Form geltenden Gesetze massgebend.

\section{Brototolle 275 in.}

I 66.

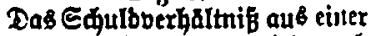
unerlaubten Sanblung twirb nad ben Brefepen bes Drtes beurtheilit. an weldem bie unerlaubte Sanb: lung begangen ift.
II $\$ 2243 \cdot \mathscr{1}$. $\$ 2367$ ).

Easీ હૈulbberhaltniß aus einer unerlaubten \$andimg wiro naळ ben Hejezen bes Ortes beurtheilt, an bem bie unerlaubte Sanblung begangen wirb.

Corveit fí cin beutidies (Hefeß auf cinc im Auslanbe begangene unerlaubte \$antolutg erftredt, finbet bas beut|dje Bejeb Tutwenbung. Brotololle 2;8\%.
$I \S 7$.

Das Schuldverhältniss aus einem anderen Grunde als aus einem Rechtsgeschäfte unter Lebenden oder aus ciner unerluubten Handlung ist nach den Gesetsen des Ortes zu beurtheilin, an toekchem der für die Entstehung des Schuldverhältnisses in Betracht kommende Thatbestand sich verwirklicht hat, soferm nicht aus dem Gesetze ein Anderes sich ergiebt.

\section{88.}

Die Eingehung einer Ehe mirb in Anfehung eires jeben ber [Ge: id litpenten nam ben Befepen bes Staates beurtheilt, weldem ber: felbe angebjot.

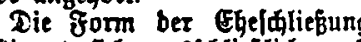

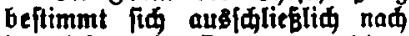
ben Befeben bes Drtes, an weldem bie Ege gefdloffen toiro.

\section{Brotololle :779 $\mathrm{f}$.}

II $\$ 2244$ (B. $\$ 2.368, R .-$, G. -).

Ein Schuldverhältniss, das auf einem anderen Grumbe als auf einem Rechtsgeschäfte unter Lebenden cder einer unerlaubten Handlung beruht, wird nach den Gesetzen des Ortes beurtheilt. an tolchrm sich der für die Entstehung des Schuldverhältnisses in Betracht kommende Thatbestand rerwirklicht. sofern sich nicht nach den deutschen Gexetzen ein Anderes ergiebt.

II $\$ 2245$ (ஜ. $\$ 2370$ ).

Die Cingehung ber CEhe mirb in Injehumg eines jebcut ber $\mathfrak{B e r}=$ lobten nad ben Bricken beg Etaates beurtbeilt, wclaem ber Berlobte augebört Beftattet baş Mecht biejez Etaates, bás ber Ber= lobte bic (Ehe nah ben Gefesen friues $\mathfrak{x}_{0 h n f i b e s}$ ober naq ben (3elepen bes Drtes eingeht, an weldem bie Ebe geidloifen wirb, fo genügt für ing bie scobahtung biejer Sejebe.

Tie Fom sinet Elje, bie im Snlanbe gefulofien wirb, beftimmt

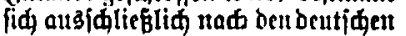
Beleben. Ein Teutider fann im Plualaube bie (Ehe aud it bes am Erte ber Ehefdliebung geltenben

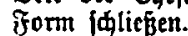

Brototolle 280 fi., RomBeriat 309.
भ. 11 (B) Ort 12)

Uus etner in Muslanbe be gangenen unerlaubten Ganblung mettergebenbe Aufprübe geltenb gemant werben, alb nad finb.
R. Art. 12 (G. Rrt. 13)

Die Eingehung ber Ehe wirb, fofern nud mur etuet ber Ber. lobten ein Deut|jer ift, in $\mathfrak{A}$ th: jehung einç jeben ber Berlobten nađ ben Beferen beş Єtaates bes urtheilt, bem er angehort. Das Olețe gilt für qualdanber, bte im Inlaube etne Ghe etugehen. In Anlebung ber Ehefrau eints naळ धrt. 8 (0.9) श्व6f. 3 fïr tobt erllärten भu\&länber toitb bie Eingebung ber Gbe nad ben beutinen Gefefen beurtbetit.

Tie form einer Che, bie in Inlanbe geidloffen witb, beftimmt

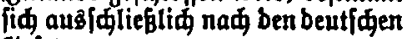
(Jefegen.
$\$ 9$ (II $\$ 2246$, \$. $\$ 2371)$

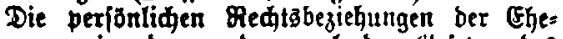
gatten zu einamber werben nah ben (Hejesen bes Staates beurtheilt, twelめhem ber Mann angehŏrt.

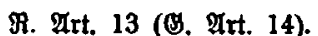

Tie perfönliđien Fedisbegiebungen beutffer (Eryegatten zu einanber toerben nad ben beutfoen Geleger beurtheilt, aud wenn bie t5hegatten thren gohnin im Puglanbe baben. 


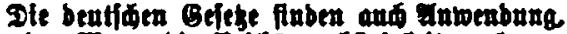

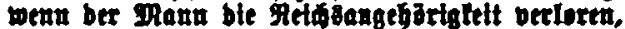 bte frau fie aber behalten bat.}

\section{Brotololle 283 .}

I $\$ 10$.

Die Âflojung einer Ege wirb nad ben Gejegen bes Staates Geurtheilt, welónem ber Ehemann zur 8eit ber Bertoirllifung bes fifr bie guflöjung in Betradt tommenben 2hat: bejtanbes angebört hat

Fflt bie Ehejdeibung unb fü bie Trernung bex Chegatten bon $\boldsymbol{T i j}$. und Bett fint bie Bejege bez Etaates mabigefenb, weldem ber Egemann zur Beit ber Erbebung ber Allage auf Edeibung ober auf Zrennung angehört.

Eine Ihatladie, welde fiळ ereignet hat, wăhrenb ber Egemantl einem anderen Staate angehörte, tant als Shetbungs: grunb ober Zrennungs: grumb uur geltenb gemadt merben, wenl bie That= fadje aud nach ben Be: leben biejes Staategి ein Sheibungsgarunb ober Irenuungsgrunb ift.

Tuf Edribung forwie auf Zrenmung bon $\mathfrak{T i} j \dot{\phi}$ unb Bett fann aud im Falle ber $\mathcal{A}$ noenbbarteit aušlānbijăer Bsejege vont eirem beutianen Seriate nur erfannt werben, twenn unb foweit bie Rlage aud

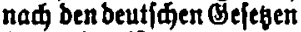
begrinbet ift

Ift nad ben mas. gebenben ausianbijकen (seicben nidit bie Shei. bung, fonbern nur bie Irennung bon Zija unb Bett zulăfiftg, fo finber bie Borfariften bes $\$ 1440$

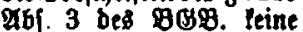
Anwerbung.
II 62247.

Die Auflojung ber Ebe wirb ná ben Beiesen bes Staates beurtheilt, weldem ber Mrann zur Beit ber Berwirftidung bes für bie Îflolung in Petraht commenben That6eftanbes angehört Yat

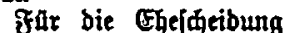
unb fưr bie beftánbige ober zeittoeilige Z remnung ber Egegatten bon Ti|山 unb Bett finb bie Befebe besె Staates másgebend, tweldem Der Marn zur Beit ber Gerfebung ber Plage auf Squeibung ober auf Zrennung angehjobt. Gine Ihat fadte, bie fin ereignet bat, wăhrent ber Mrann einem anberen Staate angeharte, fann als Sdeibung Bెgrumb ober als Trennungsgarunb mur geltenb gemadt merben. menti bie Thatfade aud naw ben Gejeken biejes Staateg ein Écheibung grunb ober ein? retmung $\vec{g}=$ garnb ift.

Sind nad bem Redite bes Stantes, beffer Bses lebe naw biejen Bor= G̈riften Inteendung fins ben tourben, bie am 20 ohns fike bes Mannes gelterbent Gejege anzumeliben, io finb Ditfe Oुefebe maßs= gebend.

Tuf Sheibung forie auf beftănbige ober jeit= weilige Trenutung von Tifめ unb Bett lann auf Brunto eires ausläns biffien Srejeges im 3ns lanbe nur erfannt retber, wenn zugleid nad ben beutfinen Bejesen bie Sheibung zulâjtis pein tourto.

Yit bie Steidsangehörigleit bes Ehemannts erlofden, bie Eheftau aber Deutlibe geblicber, fo finben, foweit nad ben $\$ \S 2246,2247$ ( $(9.2371$

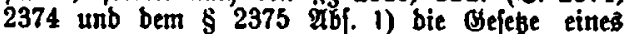

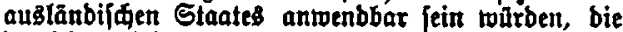
beutfiden OSefeße Antwenbung.

9. § 2374.

Die Aluff jung ber Che wirb nah ben Bejeben bes Staates beurtheill, bem ber Mann zur Beit ber Betwittliqung bes far bie Iuflalung in Petrant lommenben Fhat. beftanbes angehört. Sinb nađ bem Redite biefes Staates bie am $280 \mathrm{hn}=$ fike bes 9lannes geltenben Sejeßse anzumenben, fo find biefe Gefese mafs= gebend.
II 52249.

Il 62248

\$. \$ 2375.

Fã bic Éfeibung und fur bie beftánbige ober seitweifige Trenunng ber Egegatten von Ti|a unb Bett finb bie Guejebe des Stantes maßzgebeno, dem Der DlartI zut Beit ber Grhebung ber slage auf Sdeibung vber auf Trentung angehört. Die Bor|drift bes \$2374 Sas 2 finbet Antoentoung. Eine Egatjade, bie fid ereiguet hat, wahrent ber Mann cinem anberen Staate angehörte, fann

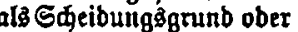
als Trentungsgenumb nur geltentb gemant merben menn bie Thatfadje aud nach ben Befesen biefé Staatę ein Emeiburgs: grumb ober ein Trennungs grunb ift.

Fuf Squeibung fowie auf beftanbige ober zeits weilige Irennung bon Iifd unb gett tann auf Brunb cines augláns bijden Brejestes im $\mathfrak{3}$. lanbe nur extannt werben, peñ aud nad ben beutfinen Beféten bie Squeibung bulâffig pein waltre.

Brotololle 283 fi., Stomgeri币t 311.

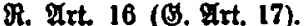
Ffar bie Squeibung ber Cre find bie Brefebe bes Staates maßsgeberb, Dem ber Ehemann zur Beit ber Erhebung ber Alage angebart.

Cine Iratjade bie fid ereignet hat, wadhrenb bet Pann einem anberent Staate angehörte, laum als Edeibungşgrunb nur geltend gemadit werben. wern bie Thatfade aud nah ben Beleben biefes Etaate ein Edyeidungs: gramb ober ein Trenunigs. grund ift.

3it zur gett ber Gio Gebung ber Rlage bie Reidsangebörigleit bes Drantres enlolíen, bie firau aber Deutfde, fo finben bie beutiden $\mathrm{OH}_{\mathrm{H}}=$ lepe Antwenbung.

Iuf Edeibung fowit anf fufbebung bet the. Iiben Cemetnifiaft tann auf Cruab cturs aus. länbilíen Cefeter im Inlanbe mut erlannt werben, weun fowohl zad bem anslänbtínen Gefefe als nad bea beutiden Gelesen ble Extbung juláfite (tein milrbe.") 
I $\$ 11$.

Das ehelide Güterredt wirb nac bell Brejegen bes Ctaates beurtheilt, weldem ber Egemann zur Beit ber Eheldifiegung ange= hört. Dites gill aum bann, wenn eine $\mathfrak{A}$ enderung ber $\widehat{S}_{\text {taatange }}=$ hörigleit eingetretent ift.
II $\$ 2250$ (B. $§ 237$ ).

Das eheline Butterredit mitb nad ben Bejesen bes Gtaates bes urtheilt, bem ber Mant zur geit ber Ebejdliejuntg angehört. Dies gilt aud bann, twenn eine भienbe= rung ber Etaatzangeförigleit eins tritt; Das Berbot, einen Ehever= trag zu idilieben, berliert jebod feine Sraft, wenn ber Bertrag

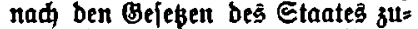
lăifig ift, in weldem ber Masn Die Etaatsantgehorigleit entwirbt.

Fin Deutiner tann im $\mathfrak{I} u s=$ lautbe einetr (Ehebertrag autd in ber Frorm [diliefent, weldje ben am Orte bes Bertragşabidiufies gel: tender Bejesent entipridt. Frotolollc 237 iा
9. 2rt. 14 (\$. 2rt. 15).

Dass ehelide Buterredt mirb nad ben beutiden Gefegen beur: theilt, toenn ber Ghemann sur 3eit ber Chelditefung ein Deut. fifer toar.

Erwirbt ber Ebemann nat ber Eingehung ber Ehe bie Metds. angebörigleit ober haben auslän. bifoe Chegatten thren Mohnft im gnlanbe, jo finb für bas the. lide Güterredt bie Gelege bes Etaates mafigebenb, bem ber grana jur Geit ber Gingehung ber Ghe angehörte; bie Chrgatten tönnen jebog einen Ggebertrag foltefen, aud menn er nab btejen Gefetgen unzulälfig fein würbe.

I. $\$ 12$.

Sabett auslånoifdje Ehegatten, welde nad

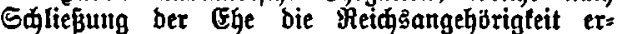
roerber, ben Mohnfis im Inlanbe, fo finben bie Borfatiftent ber $\$ \$ 1335,13.17$ (bes $\mathfrak{B O B}$.) mit ber

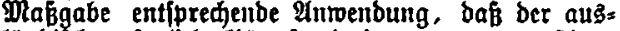
länơił Suteritanbe gleiajiteht.

$\$ 13$ (II 2252, $\mathfrak{B}$. $\$ 2378$ ).

Die Eheliditeit eiutes Stinbes mird nă ben Befeben bes Etaates beurtheilt, welduem ber Che: manu ber Mutter zur Beit ber Beburt bes Pinbes augehört ober, wenn er bor beffen Beburt geftorbeit ift, zulest angehort hat.

I $\$ 14$.

Die Legitimation eines $u n=$ eheliđen ftindes wird beurtheilt in Pulehung beş Baterş nađ ben Befckell bes Ctaates, welf́pen ber Bater, in Ânlehung bes Sinbeş nađ ben Bejesell bes Staateş, weldem bas \$inb zur Beit ber Eegitimation angebört.

Die Eheliăfeişertlänung fteht bemienigen Staate $z \mathfrak{H}$, welhem ber Bater angehört 'Nad ben Befegent bicię Staates bejtimmt fid and ausfaliepliti bie für bie Crllänungen ber Betheiligten er= forberlidue form.

Die Mithingen ber Legiti= mation werben nad) ben (Bejegen bes Staates beurtheill, weldem ber Bater jur Beit ber Regitimation angehört.

Die Borjariften bes 1. bis 3. AGf finben auf bie Innabme an Findesftatt entfpredyende $\mathscr{A} \mathbf{n}=$ wenbung.

I $\$ 15$.

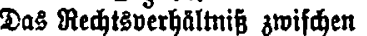
Eltetn unb eheliðen Finbern mirb

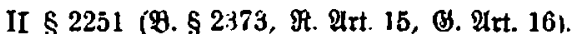

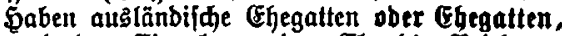
bie nad̆ ber Eingehung ber Ehe bie Meidgan=

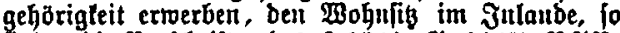

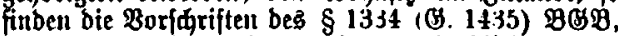
entipreçenbe Inwenbung; ber auslänbijae gejes.

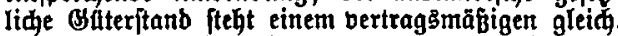
Die Boriđriften ber $\$ \$ 12 i 7,1262$ (G. 1357,

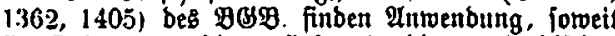
fie Dritten gû́nftiger finb alş bie auşlănbijqen Seieze.

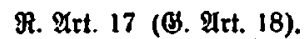

Die ehelide $\mathfrak{A b}$ tammung eines finbes toirb nad ben beutfínen Gefesen beurthetlt, wenn ber Ehemann ber Mutter zur Beit ber Beburt bes Pinbez Deut|der ift ober, falls er vor ber Beburt bes Siubes geitorben ift, juleht Deutfíter war.

\section{Brotololle -}

II $\$ 2253$ (․ $\S 2382)$.

Die Eegitimation eines uns chelidjen Finbes Geftimmt fiđ tad ben Bejépen beș Staateśs, bem ber Bater zur Beit ber Regitimation angebort. Das Erforberuib ber Cinnilligung bes finbes ober ber Eintwilligung Dritter, zu benen bas ftinb in einem fanilienredit: liden Berbălniffe fteht, Geftimmt fin nad ben Esefezen bes Staatesి, bem bas Rinb zur Beit ber \&egi= timation angehỏrt.

Die für bie Ertläruntgent ber Betheiligten erjorberliace from

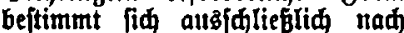
ben Befeben bes Staates, weldem ber Bater zur Beit ber \&egitimation angehört.

II $\$ 2254$ (B. § 2383).

Die Borjuriften bes \$ 2253 (2382) finben auf bie Tutugnte

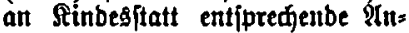
wenbung

\section{Brotololle $290 \mathrm{ff}$.}

II $\S 2255$ (B. $\$ 2379$.

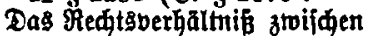
bert Eltern unb einem ehelident

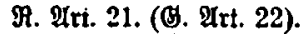

Die \&egitimation cines uns: eheliden Findes fowie bie $\mathfrak{T}_{11}=$ nahme an Sinbeştatt beftimmt fid, wenn ber Bater zur Beit ber Qegitimation ober ber Annehmente

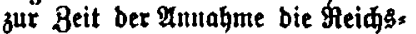
angebörigleit befikt, nad bent beutiduen Beleben.

Sebört ber Bater ober ber Runehmenbe einem fremben Staate

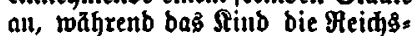
angebobrigleit befigt, fo find bie Segitimation und (\$s. ober) bie Innahme untwirtjam, twenn bie nad ben beutiden Breiezen cr: forberlid,e (Fintwilligung bes Sinbes ober eines Tritten, fu bem ins Sind in cinem fanilienredtlid) Berbăltuiffe ftebt, utat erfolgt ift.

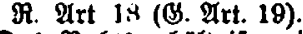

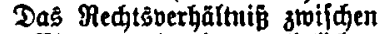




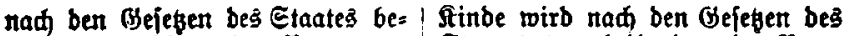
urtheilt, weldem ber Bater an= Staates beurtheilt, bem ber Bater gehört, unb, sent ber Bater ge= angehört, unb, wenn ber Bater torber ift, nad ben Gejesen bes gejtorben ijt, nad ben Gejeben bes Staates, weldjent bie Mutter angehort.
Rinbe twirb nad ben bentfón Gefeben beurtheilt, wenn ber Bater unb, falls ber $\$$ ater geitorben ift. bie Mlutter bie Meigosangehörtglett befigt. Daš Éleige gilt, went

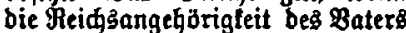
ober ber Mutter exlojajen, die

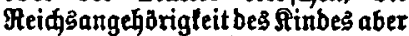
bejteher geblieber ift. 3it bie Reidsangehörigfeit bes Bater $\hat{\mathfrak{s}}$ ober ber Putter erlojijen, bas (Entw. II) ehelidge find aber Teutjuer geblieben, jo finben, joweit nah $\mathfrak{A} 6\}$. 1 bie Gejese eines aus: lättbijđhen Єtaates antwenbbar jein würben, bie beutfihen Gejebe $\mathfrak{I} n=$ wenoung

$$
\text { Brototolle - }
$$

$I \& 16$ (II - $B-$, R. - , G. -$)$.

Wenn die Reichsangehörigkeit eines Ehemannes erloschen ist, die Ehefrau desselben aber die Reichsangehörigkeit behalten hat, so finden, souveit nach den Vorschriften des \& 9 und des $\& 10$ Abs. 1 bis 3 die Gesetze eines ausländischen Staates anwendbar sein würden, nicht diese Gesetze, sondern die deutschen Gesetze Anvendung.

Wenn die Reichsangehörigkeit eines Elterntheiles erloschen ist, das eheliche Find aber die Reichsangehörigkeit behalten hat. so finden, soveit nach den Vorschriften der $\mathcal{S} 13,15$ die Gesetze cines ausländischen Staates anwendbar sein woürden, nicht diese Gesstze, sondern die deutschen Gesetze Anwendung.

Protofolle 294.

1 \$ 17.

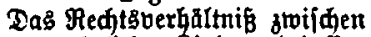
cinem uneheliden ginbe unb beffen Mutter wirb nad belt bejesen beş Єtaates beurtheilt, weldem die Wutter angebört. Went jebod

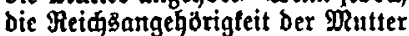
crlojden ift, bas Riub aber bic Reidsangehörigleit behalten hat,

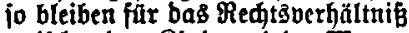
zroifden bem Pinbe und Der Mutter die beutifjen Sefese ntägebent.

Tie unterhaltsocrpflintung bes uneheliden $\mathfrak{B a t e r z}$ und beffen $\mathfrak{B} e r=$ piliditung, ber Mottter wegent ber Poften ber Entbinbung unb twegen bes Unterhaltes währeub bes

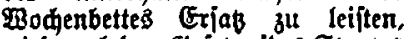

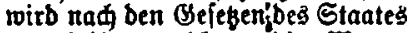
beurtheilt, weldem bic Mutter zur Beit ber Heburt Degె Rinbeß angehört.
II $\$ 2256$ (B. \$2380).

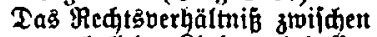
pincm unelyelidien Sinbe unb beffen Muttex wird nad ben Gejeben Des Staates beurtheilt, weldem bic Mutter attgebört.

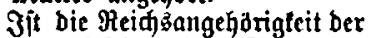
Mutter erlofden, bas Sind aber Teutjuer geblieben, jo finben bie

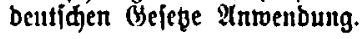

II $\$ 2257$ (B. $\$ 2381$ ).

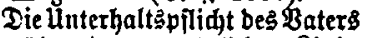
gegenüber Dem uneheliфen ftinde unb jeint 3 crpflidtung, ber $M$ atter bic Stoiten ber Entbinbung unb bes Unterhalteš zul crjeber, twirb naq ben Gejęell bes Staates bcurtfeilt, weldem bie Mutter aur Beit ber Geburt besి Rinbes autgeh̆̈rt.

Brotololle $294 \mathrm{f}$. , Pomperiat 311, Eten Beridte 345.

ク. Art. 19 (ษ. 20).

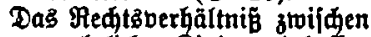
cinem uneheliden ßinbe unb beffen Mutter wirb nad ben beut|den Geleben beurtheilt, went bte Dutter tine Deutiae ift. Iaş Bleide gilt, wenn bie Reing: angeh s̈rigleit ber Mutter crlofdjen,

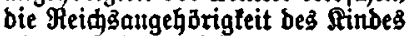
aber beftehen geblieben ift.

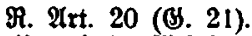

Ticltnterhaltspflidtbes Baters gegenüber bem unehelidien Pinbe unb feine Berpflidjtung, ber Drutter

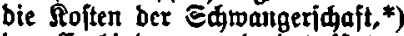
ber Entbinbung unb bes llnter: Galtes zll exieben, twirb ná ben (Bejeßsen bes్ Staates beurtheilt, ben bie Mutter zur Beit ber Geburt bes finbes angebort; $e$ s tžnnen jebod nidht weitergebenbe Anlprilde geltenb gemadt werben, als nad ben beutfaen Geleben begrilnbet finb.

\section{$I \S 18$ (II $\S 2258$, B. $\$ 237 \%, R .-$, G. 一).}

Die gesetsliche Unterlialtspflicht unter Verwandten wird, unbeschadet der Vorschriften der $\$ 15$ bis 17, nach den Gesetzen des Staates beurlheilt, teelchem dis Verwandten zu der für die Unterhaltopflicht in Betracht kommenden Zeit angehören. Gehören die Verwandten zu dieser Zeit verschiedenen Staaten an, so ist die Unterhaltspflicht nur insorceit begründet, als sie nach den Gesetzen jedes der leiden Staaten begrïndet ist.

$$
\text { Brotololle - }
$$

I $\$ 19$.

Gin $\mathscr{A} u$ slänber wirb im $\Im n=$ lanbe nur banll bebormunbet,

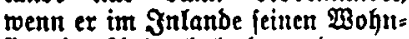
fibs ober 2(ufenthalt hat unb retu ber Etaat, toeldem ber Nusiänder

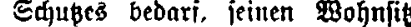

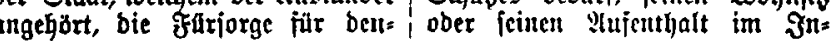

II $\$ 22.39$ (अ. \$ 2384).

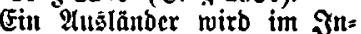
lanbe bebormultbet, wenn er nad Dett Beję̧en bes छtaateş, bem er antgefjört, bes pornumbjiaftliqen

") Die Esorte "bet Sqroangeridait" fehlen in ber Reidastagsborlage.

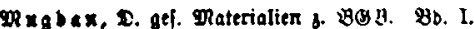

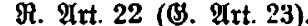

Gine Bormunbinaft ober eire Pflegidaft tann im Snlanbe auta uber einen $\mathcal{A}$ LEిlänber, fojern ber Etaat, bem er angehört, bie Fătr= forge niat abernimmt, angeorbstet werben, wenn ber 2ubilănber ná 
felben ablefint. Das beutidhe Bormகeridht tann jebō̆ bor ber ablehrung in Sntereffe bes $9 u 3$ : lanbers borlănfige mafregeln trefien und insbef. eine \$flegiafaft anorbnen.

Dic Borjariften bes 1. $\mathfrak{A} b\{$. finben in भiffehung einer atberen Prlegínaft entipredienbe anroen= bung mit ber Mlasgabe, ba $\beta$, fo: fern bie Mnorbnung ber Pflegínaft ben Mohnfis ober Aufenthalt bes Bflegebefoblenen innerbalb bes

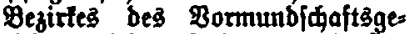

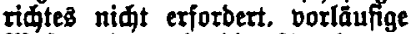
Mtásregeln unb bie Anorbmung einet Silegidaft aú bann zu= Iaffig finb, wenn ber Muslănber im Jnlanbe niđht feinen $2805 n$ in ober Aufenthalt hat.
Ianbe hat unb ber Ctaat, weldem ex angehört, bie Frurjorge ablehnt.

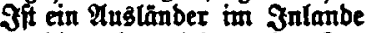
entununbigt, fo witb ex in $\Im_{n=}$ Ianbe bevormumber, wenn ber Staat, toeldem er angehort, bie Fürforge ablehnt.

Das beutfine Bormberidt fann vorläufige Mlafiregelin treffen,

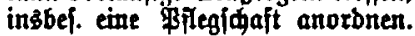

II $\$ 2260$ (\$. \$2385).

ริtur bie Anorbnung einer

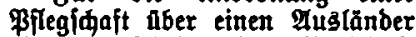
gilt, unbejaabet ber Borjarift Des $\$ 2254$ (\$8. 2384) A6f. 3, Das Bleide mie für bie Bebormunbung eines Mus̆lānbers. Eoweit bie Mnorbnung ber Pflegfóft ben wohniti ober ben Aufenthalt $\delta e z$ Bflegebefohlenen in bem Bezirfe bes Bormgeriates niat boraus: jest, ift fie aud bann zulajfig,

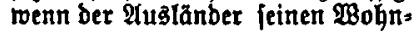
fib ober feinen Alujenthalt nidit im Jnlanbe Gat.

Brotololle 295 fif. ben Sefesen biefes Staates ber Ffirforge bebarf ober in Inlanbe entmindigt ift.

Das beutfile $B o \mathrm{rm}$ (B) tarn borlăufige Dloß̋regeIn treffen, folange eine Bormunbjanaft ober Pilegiafaft nicht angeorbnet ift.

$I \$ 20(I I-$. B. - , R. - , G. -).

Die Anordnung und Führung einer Vormundschaft, die Fürsorge und Aufsicht der VormBehörde sovoie die Verbindlichkeiten zwoischen dem Vormunde und dem Mündel werden nach den Gesetzen des Staates beurtheilt, welchem die VormBehörde angehört.

I $\$ 21$.

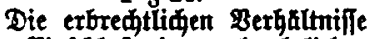
mit Ginidluś ber exbred̆tlichen €dulboerbaltniffe werben nad ben Shejesen bes Staates beurtheilt, reldem ber Crblaffer zur Geit feines robes angehort hat.

Die Erridtung unb bie $\mathfrak{A}$ ff Gebung einer Berfigung bun Tobes: wegen roerben naw ben Beieben beš Staates beurtheilt, weldem ber Erblaffer zur Beit ber Er:

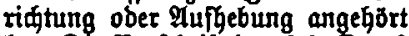
hat Die Borfdrift bes \& 3 Sas? Bleibt unberthrt.
II. $\$ 2261,9.52386)$.

Die erbredtliden Berbăltuifte werden nad ben Bejesen bes Etaates beurtheilt, weldem ber Erblaller zur Beit feines Iobes angehört hat.

Die Erridtung und bie $\mathfrak{T} u=$ hebung einer Berfägung von Tobes: twegen werben nad ben Befesen bes Staates beurtheilt, bem ber Erblaffer zur Beit ber Erriळtumg ober ber Aufbebung angebỏrt hat.

Ermirbt ein Auşländer, Der bie făhigleit zur Erriătung einer Berfingung von Tobeaswegen erlangt

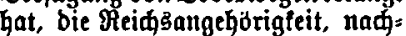
bem er eine folde Beriügung er= ridtet hat, 10 behalt er bie făbig= feit, aud toent er bas nad ben beutiben Gefeben erforberlide MIter nod nidt erreidt hat.

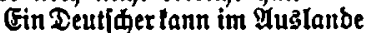
eitte Berfägung bon Zobestwegen aud in ber from erriften ober aulheben, weldie ben am Drte ber Erridtung ober ber $\mathfrak{A} u f$ febung geltenben Csejesen entipriat.
M. Irt 23 (B. Art. 24).

Ein Deutiber witb, aut went er feinen Mobnif im Yuslande batte, nad ben beutfoen (se. fegen beerbt.

gat ein seutimer zur Bett fetnes Tobes feinen Bobnfts $^{3}$ भuslanbe gebabt, fo Tönuen bie Grben fin in infehung ber Gaftung fïr bie Nablabverbinb. indetten aud auf bie an bem Mohnfize bes Grblafiers geltenben Gelese betuien.

Ermirbt ein Fluzlănoer, ber eine Berfügung vout erriftet ober aufgefoben hat, bic Reidzangehdrigteit, 10 wirb bie Bultigleit ber crriqutunt ober ber

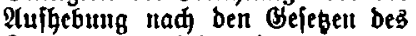
Staates beurtheilt, bem ex zur Beit ber Erridtung ober ber $\mathfrak{A}_{\mathfrak{u}}=$ hebung angehörte; aud behält er bie Z̊ăhigleit zur Frriatung einter Berfügung von Tobeảwegen, felbft toenn er bas̀ ná ben beutídeu Geleben erforberlide alter nod nidt erreidt hat. Dit Borfartft bes Art. 10 (G. 11) 9b5. 1 Sag 2 bletbt unberubet.

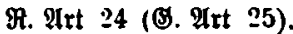

Fin Ruslänber, ber zur Beit feines Tobes feinen $\mathfrak{W}$ ohnfts im Ynlanbe hatte, wirb nad ben $B C=$ iebzen bes ভ Staatez beerbt. bem er jur Beit feines Tobes angehörte. 


\section{Brototolle 290 f.}

Ein Deutider lanu jebod erb: reditlidie grnipruidge aud bart geltent mader, renn fie nur nad, ben beutidier Bejeser begräiber finb, es fei benn, bafi nad bem ReÁte bes @trates, Dem ber Erb. laffer angehyorte, für bie Beerbung eines Teutfínen, weldier feinten 2Bohni is in biejers Staate hatte,

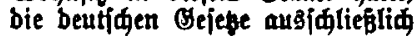
másgebenb find.

[I, II, D. feglen].

F. அrt. 25 (\$. शtrt. 26).

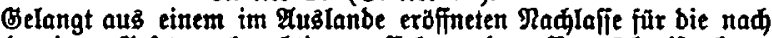
ben bortigen Bejesen bereditigten Erben ober Bermāhtnipuehmer

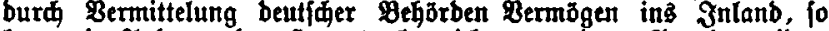

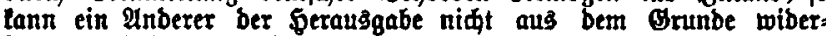

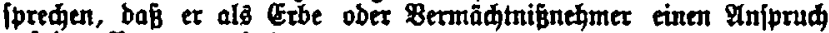
auf bas Bermögen habe.

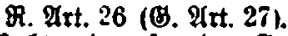

Einb nad bem Redte eirtes fremben Staates, belien Gelebe in

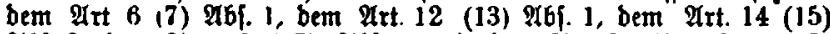

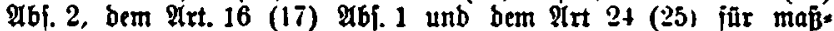

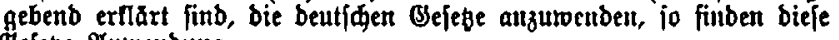

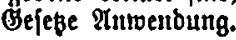

I $\$ 22$.

Die Borfariften ber $\$ \S 11,15$ und bes $\S 21$ ఇaf. 1 lommen nidt zur Anwenbung, forveit zu bem betr. Bermögen Begenftānde gebören, welne riat in bem Gebiete bes Staates, befien Gejepe nad jenen Borjuriften mágebend finb, fi befinben, in Qిnjebung biefer Begenftänbe befonbere Bor: färiften beftehen.

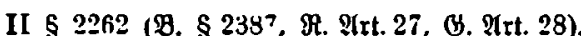
Die Borifriften ber $\$ \S 2250,2255$ unb be

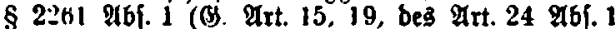
unt ber $\mathfrak{A r t} 25,27$ ) finden teine Anwendung auf Bregenitănbe, bie fĭ niđt in bem Gebiete bes Staates befinben, beffen Gejebe nad jenet Bor* juriften mafgebent find, und bie nah ben bejesen bes Etaatez, in beffen Bebicte fie fid befinben, be= jonberent Borjáriften unterliegen.

Prototolfe 36\%.

$I \$ 23$.

Fit eine ßerfon oh̆ne Etaatåangehörigleit, fo werben inge Meditsverbălnifie, fofern für biejelben bie Beurtheilung naథ ben Bejeben bes §taates, weldem bie Berfon angehört, borgefdrieben ift, nah ben Sefeken bes Etaates beurtheilt, weldem bie Berfon zulest angebort hat, unb, wenn fie aud fruber feinem Staate angehort hat, nad ben Bejeben

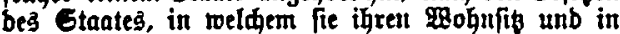

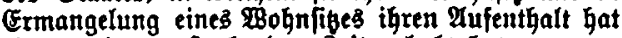
ober zu ber makgebenben Beit gehabt bat.

Prototolle 303.

$1 \$ 24$.

Die Anwenbung eines auss:

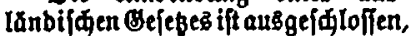
wenn bie Antoenbung gegen bie guten Eitten ober bie off. Dob: nung verftopen toürbe.

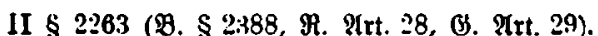
Wehört eine $\mathfrak{B}$ erfon leinem Staate an, fo werben igre Rehtsverbăltitifie, jorteit bie Gejese bes Staates, bem eine ßerion aligehỏrt, für maß́gebento erllărt finb, nad ben Gejeben bes Etaates beurtheilt, bem bie Berion zulest angehort hat, unb, weun fie aud friber einem Staate nidit angehört hat, nadh ben Gelepen bes Staates, in weldem fie ihren 280 hn if und in Ermantgelung eines $230 h n$ ibes igren $\mathfrak{R}$ (uF enthalt hat ober zu ber mafgebenben Beit gehabt hat.
II $\S 2264$ (ஒ. $\$ 2389$ ).

Dit Untwentung eintes aus:

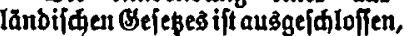
toenu bie Anwenbung gegen bie guten Gitten pder gegen ben Bwed eines beutidien Gejeses veritofen wilibe ober menn bas auslanbijae Befes bie Medte ber Fremben in unbil̋iger gBeife beeintrăळtigt.

Protololle 303 ff., RomBeriat 311.

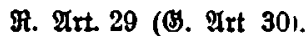

Die Anwentung eittes aus:

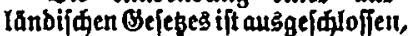
wenn bie Muroenbung gegent bie guten Sitten ober gegen ben 3 weat eines bentígen Beleses berítofien witrbe.

$$
I \$ 25(I I-, B .-, R .-, G .-) \text {. }
$$

Die Wirkungen eines Utheiles uerdén nach' den Gesetzen des Staates beustheilt, welchern das Prozessgericht angehört. Wirkungen geqen Dritte sind jedoch insorveit ausgeschlossen, als sie mit dem Urtheile eines deutschen Gerichtes nicht verbunden sein würden. 
Die Anerkennung des Ortheiles eines ausländischen Gerichtes ist ausgeschlossen:

1. weenn das Drtheil nach den für das ausländische Gericht geltenden Gesetzen die Rechts. kraft noch nicht erlangt hat;

2. wenn die Gerichte des Staates, welchem das ausländische Gericht angeliört, nach den deutschen Geretzen nicht zuständig sind;

3. wenn der unterlegene Beklagte ein Deutscher ist und sich auf den Prozess nicht eingelassen hat, sofern die den Prozess einteitende Ladung oder Verfügung ihm woeder in dem Staate des Prozessgerichtes in Person noch durch Gewährung deutscher Rechtshiulfe zugestellt ist:

4. wenn die Anerkennung des Urtheiles gegen die guten Sitten oder die öff. Ordnung verstossen woïrde.

5. wenn bei Erlassung des Urtheiles zum Nachtheile einer deutschen Partei von einer der Vorschriften des $\& 8$. des $\$ 10$ Abs 1 bis 3 und der $\$ 13,14$, sowie des $\$ 16$, soweit der Letztere auf die Vorschriften der \$S 10, 13 Bezug nimmt, abgewichen ist;

6. weenn die Gegenseitigkeit nicht verbürgt ist.

Prototolle 307 开.

§ 26 (II § 2265, 9. 2390).

Unter Buftimmung bes Bunbežrathes tant

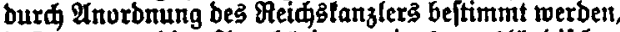

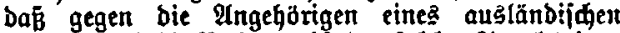

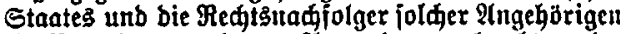
ein Bergeltungäredt zur Amwenbung gebradit twerbe.
M. Art. 30 (G. Art. 31).

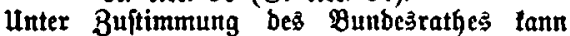

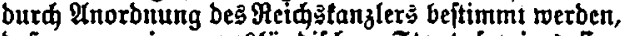
DáB gegen einent ausländifiden Staat fowie befien

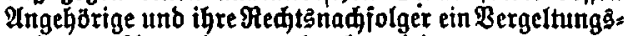
redit zur $\mathfrak{A}$ nwellbung gebradt wirb.

\section{Ullgemeiner Theil.}

\section{Red htsnormen.}

$I \S 1(I I-, B .-, R .-$ G. -$)$.

Auf Verhältnisse, für vollche das Gesetz keine Vorschrift enthäl, finden die für rechtsähnliche Verhältnisse gegebenen Vorschriften entsprechende Anwendung. In Ermangelung solcher Vorschriften sind die aus dem Geiste der Rechtsordnung sich ergebenden Grundsätze massgebend.

Motive 360 ff., Protololle 568.

$I \S 2(I I-$. B.,- R. - , G. -$)$. verioeist.

Gewohnheitsrechlliche Rechtsnormen geiten nur insoweit, als das Gesets auf Gewoknheitsrecht

Motive 360 f., Brotololle 568 fi.

\section{perionen. \\ Begint unb Cube ber Redtêfähigleit:}

I \& 3 . II \& 1 .

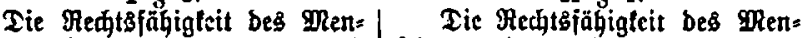
finen beginnt mit ber Beburt unb fíen beginut mit ber bollendeten endigt mit bem Tobe.
2. $\S 1$ (M. $\S 1$, B. $\S 1)$.

Dic Medtsfähigteit bes Menls $^{2}$

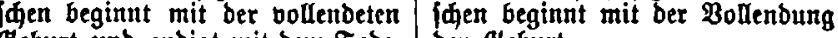
Geburt unb endigt mit bem Iobe. Der Beburt.

Mrotive $371 \mathrm{ff}$, Prutotolfe $570 \mathrm{f}$., Somberidt 949.

$I \S 4(I I-, B .-, R .-$, G. -$)$.

Dass eine Person noch lebe oller todt sei nder zu einer bestimmten Zeit gelebt oder nicht mehr gelebt habe, hat derjenige zu betceisen, welcher aus der betr. Thatsache ein Recht herleitet.

Ist ungeveiss, ob eine Person, ïber deren Leben oder Tod keine Gewissheit bestcht, einen Anfall von Todeswegen erlebt habe, 80 wird vermuthet, dass dieselbe bis zum Ablaufe des 70. Lebensjahres yelebt, später aber nicht mehr gelebt habe.

Dieselbe Vermuthung gilt, weenn ungewiss ist, ob ein Ehegntte den anderen Ehegatten überlebt habe, in Ansehung der Vortheile, velche dem ïberlelenden Ehegatten nach dem Gesetze oder auf Grund eines Ehevertrages fii den Todesfall des anderen Ehegatten gebïhren.

Dotive $373 \mathrm{f}$., Brotololle $571 \mathrm{ff}$.

\section{Tobe8ertlärung.}

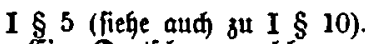

Eir Deutfider, welder ver idollen ift, fann burd ut utheil für tobt extlärt werbent.
II 2.

Ein Beridjollener lann far tobt ertlärt werber, wern feit 10 Jahren

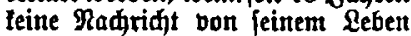
eingegangen ift. Einb feit ber Be=
9. § $13(\Re . \S 13$, B. \& 13).

şer verfdoulen ift, tann ná gmafgabe ber 14 bis $17 \mathrm{im}$ 2Bene bes nufgebotsoerfahrens fúr tobt extlatst werben. 
$I \$ 6$.

(Ei) शrmejendor gilt ala ber= jd)ollen, want jeit 10 Saburn teitte Sadiridlet bon feincm Lebes bor= foulden ift. Cind jeit bex Becbutert

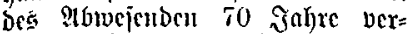
ftridjes, jo genügt ciut 5 jülpriger 3citraum.

Fer 10 jälyrige ober 5 jährige Beitraum begimnt ntit QAlatif Des

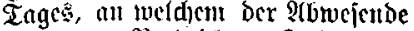

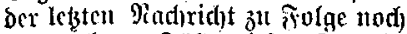
gelcht hat. Fiñlt Dicjer sag in bic Bcit vor bem surüfạclenten 21. \&ebensjofre, jo beginut ber 10 jährige Bcitraum mit bem 1.. Tage nad Burüalcging biejes Icbentsjabres.

butrt bes Beridhollenen 70 julfre werftridien, fo genügt cin 5 jäljriger Britraumt.

Ter $10=$ ober 5 jäfrige Bcituant beginnt mit bent હediltife bes Jahres, in toeldyen ber Beridullenc best borhanbencu Sadhridten ju Folge nnd gelebt fiat. હint alt biejer Beit jeit der \&eburt bes Berjalpltench nod nidjt 21 Jafire verftrid)en, jo begiuut ber 10 jül = rige 3ctraum crit mit Dent Ed)luffe Des 21. Juhtre

Motine 374 ff., Protofolle 575 ff., Denffinrift

$I \$ 7$.

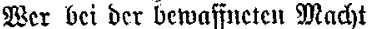
bes Deutfdent Reidics, mit weldier er it bett firicg gezogest war. währento Des firieges bentijizt twiro, gilt als veridjollen, werth jeit bem

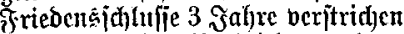
find uns feite Radiridgt borhan=

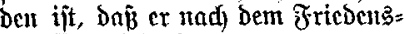
folutife gelebt hat.

Die Borjayrift bes 1. Stbi. finbet [owol)l auf bie zur bewafifue= ten Macht gehörenden ßerfouten ale auf biejenigett QYnwentutu, weldje fid it ètrem $\mathfrak{O m}$ șverlyältuiffe ober Dien|tberhältniffe vber zu Zweden freimilliger Sullfeleiftung bei ber betwaffneten Mad)t befmiden habent.
II $\$ 3$.

Ser als Pugehöriger ciucr be= wafficten Madit ant cillem Striegc Theil acuonmente hat, während Defielbel bemrijt worben und jeit: bent veridiollent ift, fant latf von 3 sahreat jeit bent Frte= Densjadlufie jür todt erflärt roeroest.

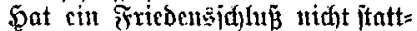
gefunton, fo beginut ber 3 jäfrige 3eitraum mit Dem ङd)lujic Des

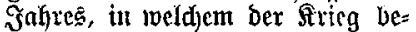
elloigt iit.

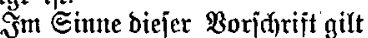
als $\mathfrak{i n g e h j o r t g e r ~ b e r ~ b e w a f j u m e t e n ~}$ Madyt and Derjenige, weldyer jid bei berjelten in cinem 2 mt Diemituerbălntifie oder za 3wedten freimilliger beülfeleijtung befiudet.

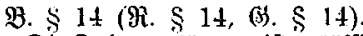

Tie Dobescrflämung ijt julltîifi

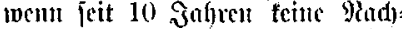
ridht bou bem Zeben bes 230 idnollenent cingegnngen ijt. Eie burf nid)t vor ben E(hluije Dç Golfres erfolgen, in weldim ber Barjallente bas 3:. Pebensiuflr bullenbet habent witrbe.

(Ein Berjd)ollencr, Der Da 70. Lebensiahr vufferbet hatuen

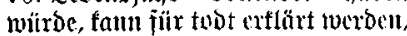
wenn jeit 5 Salfrest fine Yiad)richt bon jeinen leben cingegangen ijt.

Ier Beitrantm bour 10 ber 5 Sahren begiunt mit bem Ed)lufic bes lebten Jabres, in weltant ber Berjehollene ben borhandence Had) rid)ten zu \$olge uod) gelebt bat.

Mer als Ongehbriger einer be= wafifueten Madjt an cinent Siriege Theil genonumen hat, währens bes firiege vemijut worben luld jeit= Dem veridjollest $\mathrm{i} j \mathrm{t}$, faut für todt ertlärt werbes, mem feit Dem

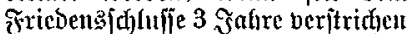
find. Sat ein Friebensjdyluí nidyt jitattgefunden, io beginut der 3jährige 3citram mit bem Sdyuffe bes Jahres, in weldyem der Prieg be enbigt worben ijt.

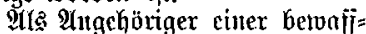
neten Madit gilt aud) brienige, welder fid it einem Mnt $_{3}=$ ober Dienjtoerbältuijife vocr zam Bwote fretuvilfiger bitljeleiftung bet bex betoffictert $\mathfrak{M a d} \mathrm{t}$ befintoet.

Motibe $377 \mathfrak{f}$., Protololle 578 \%., Tenfichrift $825 \mathrm{f}$.

\section{I $\S 8$.}

Wer bei eimer Eeefahrt auf einem Fahrzeltge fith bejumben hat, weldhes untergeganges ift, gillt ala berjajolfen, wenu feit bent unter= gange 1 Jahr verftrichest int feine

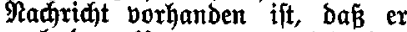
nad bem llntergange gelebt hat.

Der Untergang bes જ̛̣ahrzenges wirb bermuthet, wenn baffelbe entroeber am Drte feiner $\mathfrak{D e}=$ fitimmung niht eingetroffen ober bei Crmangelung eines feften Reifezieles nidht zuriudgefehrt ijt uno wert in beiben Făllen zugleich

bei $\mathfrak{F}$ ahrten innerhalb ber $D\{t=$ fee 1 Jahr

bei $\mathfrak{F a h r t e n ~ i n t e r b a l b ~ a n d e r e r ~}$ europăifder Meere, eiufihl. ber nidgt zu Europa ge: hörenben Theile bez Mittel= ländifaen, Stbwarzen und Azowidnen Meeres 2 Эahre,

bei fabrten, welde ilber auper= europäiláge Meere führen. 3 $\mathfrak{a} \mathfrak{a}$ re
II $\S 4$.

Mer bei einer Seefahrt jeit bem untergantge bez Farirzenges, auf bem ex fich befunden hat, ver= fajollen ift, fann nad ablauf 1 Jahres feit Dent untergange Des Frahrzenges für toot crllärt werbelt.

Der Ututergang bes Fahrzeuges wird vermuthet, wetn es cntweber am Drte jeiner Bejtimmung nidht eingetroffent ober in Ermangelung eires feften Reifezieles nicht zurüi: gefebrt ift und wenn

bei Fahrten innerhalb der Dit= fee 1 Jah $\mathfrak{r}$,

bet Fahrtell innerhalb anberer elropäijđ̈er Mleere, mit (sin= jŭla B̃ fïmmtlicher Zheile bes Mittelländifđen, Sdjwarzen

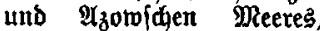
2 క̧ahre

bei Fahrtest, bie uber auß̧er= europäifdie Meere fuhren, 3 Jahbre,
B. $\S 16(\Re . \$ 16$, (5. $\S 16)$

Wer firt bei ciuer Ecejaldrt aut eittem während bor Fahrt unter= gegangentet F̧ałrzente bejumbett hat und feit bem unternange bes ofafrzetues veriđollen ift, funm rïr tobt extlärt werbelt, wenn feit bent Ulntergange 1 Jahr verftriçen if

Der luntergang be? Frahrzentges wirb bermuthet, wenn es an ben Drte jeiner $\mathfrak{B e f t i m m a n t g}$ nidht ein= getroffen ober in Ermangeluutg

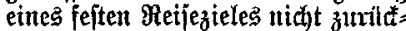
gefehrt ift unt wenn

bei F̧ahrten imerfalb ber Dit fee 1 Jahr

bet Frahrten innerfalb antocrer europäijđer Mecre, ntit (Eiıt=

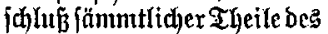
Mittelländifóden, Sdywarzen utito $\mathfrak{A l z o w}$ idfent Meeres 2 Эafre

bei îsahrten, bie über auß̌er= elrropäifáde Meere fübren, 3 Iabre 
veritriden funb. Der Beitroum be= gint mit Ablauf bes Tages, an weldem bas fohrzeug bie Fieife an: getreten hat. Jit nah biejem Zage gradriat bon bem frahrzeuge eingegangen, fo beginnt ber Beitraum ext mit Ablauf bes Tages, bis zu weldem bie leste gahridt retht. In cinem joldgen falle ift ber Beitraum mápgebenb, welder $a b$ : gelaufen fein mingte, wenn bas fabrzeug bonbem Drte abgegangen toåre, in treldjem $e$ ber lepten gladridt zu \&olge fí befumbert hat.

Mrotibe 377 f., Protololle 579 f., Denllørift

II 65 .

${ }_{\text {Ber }}$ unter anderen als ben in ben $\$ \S 3,4$ bezeiøneten $\mathrm{Um}$ |tăn= ben in eine Rebensgefahr gerathen unb feitbem veridollen i fy. fann

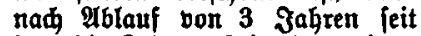
bem bie Rebensigefahr begrinben= ben Ereignifie für toot ertlăt toerben.

Motive -, Mrotololle $580 \mathrm{f}$. jeit bem Antritte ber Fieije ber trinen funb. Sinb Rađriaten aber bas f̧ahrzeug eingegangen, fo ift bet Yhlauf bes Beitraumes etforberlid, ber verftriden fein mabte, wenn bas fabrzeug bon bem Drte abgegangen trảre, an

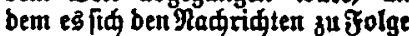
zulest befurber hat.

\section{I \& $9(I I-B .-, R .$, G. -$)$.}

Für die Todeserklärung ist das Gericht zuständig, in dessen Berirke der Ferschollene den letzten Wohnsifz im Inlande hatte. In Ermangelung eines solchen Gerichtes voird das zuständige Gericht von der obersten Justizverwaltungsbehörde des Heimathstaates bestimmt. Dotibe 378, Protololle 581, Dentiqrift $825 \mathrm{f}$.

I \& 10 .

Эom falle bes $\S 6$ exfolgt bie Tobesertlărung im Aujgebotşber= fahren.

Das Betfahren beftinunt fin nad bell $\$ \$ 824$ bis 836 ber (EPD. unb nad ben in bet $\$ \$ 11$ bis $19,23,24$ enthaltenen gor jdrifter.

\section{Motive 378, Brotololle 581, Dentjurift $825 \mathrm{f}$.} Gufgebotsiberfabren. iser veridollen ift, lant nad Tufaet zobesertiarung erfolgt im Mtáigabe bet 68 14 bis $17 \mathrm{im}$ \$ege bes âjigebotsberfahrens für tobt extlart twerben.

$I \& 11(I I .-B .-$, R. - . G. - ) .

Antragsberechtigt ist der Abroesenheitspfleger sowie der Formund des Verschollenen, ingleichen der Ehegatte desselben, sonvie ein Jeder, welcher an der Todeserklärung ein rechtliches Interesse hat. Das Interesse ist vor Einleitung des Verfahrens glaubhaft zu machen. Abwoesenheitspfleger und Vormund belürfen au dem Antrage der Ermächtigung des VormGerichtes.

Motive 378, Brototolle 581.

$$
I \& 12(I I-., B ., \text { R. }-, \text { G. - ) . }
$$

Die ïbrigen zur Begründung des Antrages erforderlichen Thatsachen sind gleichfalls wor Einleitung des Verfahrens glaubhaft zu machen.

Motive 378, Prototolle 581 .

$$
I \$ 13(I I-, B .-, R .- \text {, G. }-) \text {. }
$$

Das Gericht hat die Todeserklärung nur dann auszusprechen, wenn es won der Richtigkeit der im $\$ 12$ bezeichneten Thatsachen ibberzeugt ist. Es hat in jeder Lage des Verfahrens unter Benutzung der von dew Antragsteller angegebenen Benotiomithel von Amtowegen die eur Feststellung jener That. sachen erforderlichen Ernittelungen su bewoirken und die geeignet erscheinenden Beweise aufzunehmen. Motive 378, Brotololle 581.

$I \& 14(I T-, B .-, R .-, G \rightarrow)$.

In das Aufgebot ist ausser der Bezeichnung des Antragstellers und der Bestimmung des Aufgebotstermines ( $\$$ 824 CPO.) aufzumehmen:

1. die Aufforderung an den Abroesenden, den Widerspruch gegen die Tadeserklänung opätentens im Aufgebotstermine anzumelden, widrigenfalls er die Todeserklärung zu gewärtigen habe; 
2. die Aufforderung an alle Diejenigen, welche Auskunft ibber Leben oder Tod des Abwesenden zu ertheilen vermögen, spätestens im Aufgebotstermine dem Gerichte Anzeige zu erstatten.

Motive 378, Brotololle 581.

$I$ S $15(I I-, B .-R .-, G .-)$

Zwoischen dem Tage, an welchem die 1. Einrïckung des Aufgebotes in den Deutschen Reichsanzeiger erfolgt ist, und dem Aufgebotstermine muss ein Zeitraum von mindestens 6 Monaten liegen.

glotive 378, 9rotololle 581 .

$I \$ 16(I I-, B .-, R$. - G. -$)$. eintreten.

Jeder Antragsberechtigte kann neben dem Antragsteller oder statt desselben in das Verfahren Motibe 378, Frototolle 581 .

$I \$ 17(I I-, B .-, R$. - , G. -$)$.

Wird derjenige, welcher sich als der angeblich Verschollene meldet, als solcher von dem Antragsteller nicht anerkannt, 80 ist das Verfahren auszusetzen (\$ 830 CPO.).

Motive 378, Rrotololle 581 .

I $\$ 18(I I-, B .-$, R.,- G. $\rightarrow)$.

Die dem Antragsteller erwachsenen Kosten, welche zur ztoeckentsprechenden Durchfuihrung des Verfahrens nothwendig waren, sind im Falle der Todeserklärung aus dem Nachlasse des Verschollenen als Masseschulden zu ersetzen.

Motibe 378, Prototolle 581.

$$
I \$ 19(I I-, B .-, R .-, \text { G. }-) \text {. }
$$

Die Erledigung der Aufgebotsanträge kann durch die Landesjustizverwaltung für den Bexirk mehrerer Amtsgerichte desselben Landgerichtsbezirkes einem dieser Amtsgerichte ïbertragen werden. Auf Terlangen des Antragstellers erfolgt die Erledigung durch das nach dem $\$ 9$ zuständige Gericht.

Wird das Aufgebot durch ein anderes als das nach dem $\$ 9$ zuständige Gericht crlassen, so ist die öff. Bekanntmachung auch durch Anheftung an die Gerichtstafel des letzteren Gerichtes zu bewirken.

Mrotive 378, ßrotololle 581.

$I \$ 20(I I-, B .-, R .-, G .-)$.

In den Fällen der $\$ \$ 7,8$ unterbleibt das Aufgebot. Die Todeserklärung wird nach mündlicher Verhandlung in off. Sitzung ausgesprochen. Jeder zur Verhandlung oder Urtheilserlabsung bestimmte Termin ist durch Anheftung an die Gerichtstafel bekannt zu machen.

Im Debrigen finden die Vorschriften der $\$ \$ 11$ bis 13,16 bis 19 , sowie die im $\$ 824$ Abs. 1 wnd in den $\$ \$ 826,828,829,831,834$ bis 836 CPO. enthaltenen Vorschriften entsprechende Anwendung.

Mrotive 378, Frototolle 581.

$I \S 21$

Die Tobesertlarung begranbet bie Bermuthung bak ber Berfidollete ber Beitpuntit ifrer Erlafiung nidit aberlebt habe.

3ี ใniehung ber Beerbung beş Beridoulenen gilt bie Bermuthung, baß ex it biefem Beitpuntte geftorben fei.

Motibe 378 fi., \$rotololle 571 fi.

I $\$ 22$.

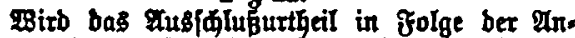
fechtungotlage aufgethoben, to berliett bie Tobess

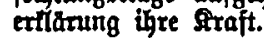

II $\$ 7$ (P. § 18, भ. § 18, \$. \$18).

Die Tobegertlănung begralnbet bie Bermuthung, baf ber Ber/dolleze in bem Beitpunlte geftorben

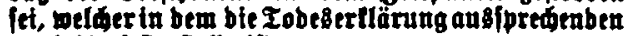
lirthelle ieftgeffent ift.

वIs Beitpuntt bes Iobes ift, jojern bie Er= mittelungen ni⿱口儿t ein Inberts ergeben, anjunthmen:

in ben fallen bes $\$ 2$ (\$ 14) bas (Enbe bes bajelbit bezeidneten geitraumes,

ir ben fratlen bes $\$ 3$ (\$ 15) ber geitpunlt

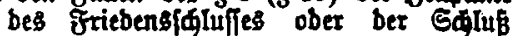
bes Jabres, in weldem ber strieg bes enbigt it.

in ben zañen bes $\$ 4(\$ 16)$ Der Beitpuntt, in weldetn bas ifabrzeug untergeganten ift ober als untergegargen vermuthet wirb,

in ben fraten bes $\$ 5$ (\$ 17) ber Beitpunli, in tweldem bas bie \&ebers gefagr begranbertoc Ereigniß ftattgefunben bat.

Sit bie Tobesseit nur Dem Tage nad feftgeftellt. to gill bas Enbe biefes Iages als geetpuntit bes Iobes.

II $\S 8$ (\$. - , भ. - , (9. - )

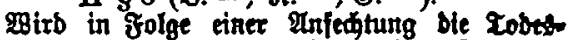
extlarung aufgechoben ober cine anbere Tobeszeit feitgejtellit, to wirtt bas urtigeil fír uns gegen alle. 


\begin{tabular}{|c|c|c|}
\hline eG(t). & 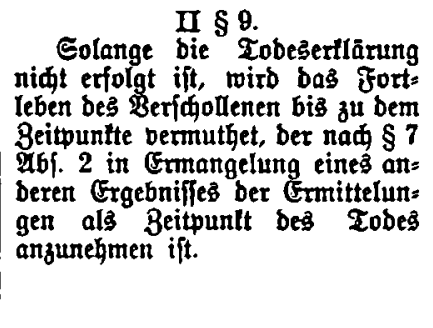 & 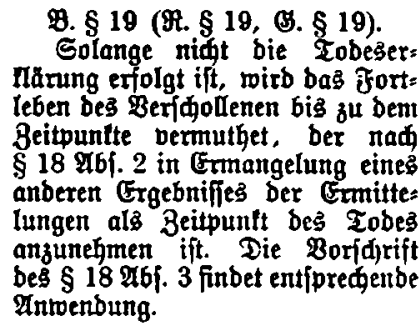 \\
\hline
\end{tabular}

[1 feglt].

II $\$ 10(9 . \S 20, \Re . \S 20$, B. $\$ 20)$.

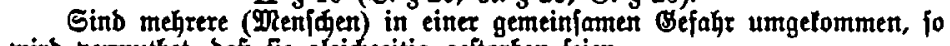
wirb vermuthet, bap fie gleidzeitig geftorben feien.

Motibe -, Brototolle $574 \mathrm{f}$.

Zur Erhebung der Anfechtungsklage ist sowohl der Ehegatte des Verschollenen als ein Jeder berechtigt, welcher an der Aufhebung der Todeserklärung ein rechtliches Interesse hat.

Motibe 381 .

$I \S 24\left(I I-, B .-, R_{.}-\right.$, G. -$)$.

Die Anfechtungsklage ist gegen denjenigen, welcher die Todeserklärung beantragt hatte, falls aber dieser verstorben oder sein Aufenthalt unbekannt oder im Auslande ist, gegen den Staatsanwalt zu richten.

Auf das Verfahren finden die Vorschriften der $\$ \$ 608,610,611$ CPO. entsprechende Anwendung.

Mrotive 381 .

Alteraftufen. Eutmanbigung.

I $\S 25$.

Das Stinbesalter bauest bis zum zurldgelegten 7., bie MRinberiăhrigleit bis zum zuridgelegten 21. \&ebersjabre.

I $\$ 26$.

Cin Mrinberiăhriger exlangt

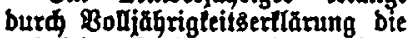
redtitie Stellutg eines BoI= jufrigen.

\section{I \& 27.}

Die Bođjåhrigleitzertlarung if nur bant zula/fig, wenn ber DRinberiăhrige bas 18. Lebensjahr zurafigelegt unb feine Eiswilligung ettheilf hat. Bei einem Mintber: jăbrigen, welder unter elterlider Getoalt fteht, ift auberbem bie 8 u. ftimmung bes Jnhabers ber elter: Itwen Berwalt erforberlid. Die Buftimmung eines Giterntheires ift nidt erforberlid, wenn befien Be: malt auf bie elterlide Rußniésung befmrantt ift.

Die Bouljăhbrigleitzertlănung ers folgt burw Befdius bes Borm.: Geridtę. Die Boljābrigleits: erflärutg foul nur bant erfolgen, wenn biefelbe bas Befte beś Dinberjagrigen beforbert.

Untragsbereditigt if ber Min: beriäbrige und berjentige gefeglidite
Mtotibe 381, \$rotololle $581 \mathrm{ff}$.

I $\$ 11$ (B. $\$ 2, \Re . \$ 2,(3 . \$ 2)$.

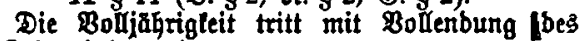
21. Дebensjahres ein.

\section{II $\S 12$.}

(cin Minberiắ̆ riger tann burd Berfilgung ber zuftảnbigen Bebjobbe fúr volljăgrig ertảnt werben.

Durd bie Boljăhrigleitsers= Ilārung erlangt ber Minberiăhrige bie rehtlide SteInng eines Doll= iăgrigen.

\section{II $\$ 13$.}

Die Boljūh̆rigleitsertlărung ift nur zuldffig, wenn ber Minber: jăbrige bass 18. Rebensiabr voll= enbet und feine Ginwilligung er: theilt hat. Steht ber Mkinberjăhrige unter elterlider Betwalt, fo ift aud bie Cinwilligung bes Betwalthabers exforberlia, es fei benn, bas ibm weber bie Sorge für bie \$erfon nod bie Corge für bas Bermögen bes Stinbes zufteht; eine minber= jăhrige \$ittwe bebarf ber Ein* willigung nidt.

Die Bollăhrigleiţertlănang foll nur erfolgen, mern fie bas Befte bes ghinberjăbrigen beföbert.

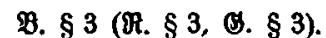

Ein Mtinberiăhriger, ber bas 18. Qebensiahr vollenbet hat, tann

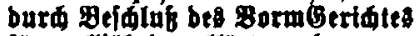
fár bolliährig extlàt toerben.

Durá bie Bolliăbrigleitser. Ilănung exlangt ber Minberiahntige

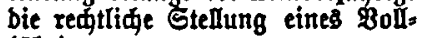
jăhrigen.

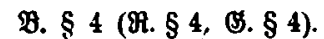

Die Bollăbrigletitsertlărung ift nur zuláfitg, went ber minber: iăhrige leine Cinmilligung ertheilt.

Steht ber Minberiahrige unter elterliger Bervalt, fo ift aús bie Einwilligung bes Bemalthabers erforberlid, es fei benn, baß biejem weber bie Sorge fulr die \$erfon nod bie Sorge fût baş Bermögen bes finbes zuiteht. Ffar cine

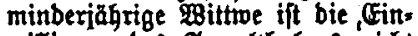
willigung bes Gewalthabers nidt erforberlía.

B. $\S 5$ ( $\Re$. $\S 5$, (3. $\S 5)$.

Die Bolljăbrigteitsertlarnng foll nur exfolgen, went jie bas Befte bes Minberjăhrigen beforbert. 
Bertreter beffelben, weldier bie Eorge für bie Berjon hat. Bor ber Entideibung foIlen Bertwanbte ober Perf fiwågerte bes Minber=

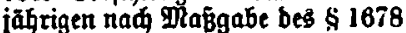
fomie bie \$ormünber unb \$fleger bes Minberiăbrigen gebört werben.

\section{I $\$ 28$.}

Eine Berjon, welde bes $\mathfrak{B e r}$ nunitgebraudes Geraubt ift, fann weger Beifteşfrantheit entruindigt werben.

Đört ber im 1. A65. bezeidntete 3ujtand auf. fo ift bie Entmulnoi= gung wieber aufzugeben.

I $\$ 29$.

Fine Berion, toelde burh ver: idivenberijase Lebensweife ober

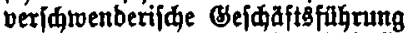
bie Beforgnis rehtfertigt, bas fie fid ober ihre familie bem Moth= ftanbe preisgiebt, lann wegen Beridwenbung entmutnbigt werben.

Sit bie im 1. $\mathfrak{A b}$. Eezeidnte Bejorgni 3 in Folge eingetretener Befferang nidt mehr geredtfertigt, 10 ift bie Entmanbigung roieber aufzuheber.

Motibe 381 fi., Protololle 583 ff.

II $\$ 14$.

Entmünbigung finbet ftatt:

1. wegen BSeijtestrantheit, wenn ber frrante in Folge berielben jeinte Angelegenheitert nidht zu beforgen bermag;

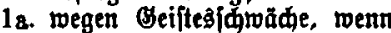
ber Beiftesjifinade in Folge berjelben jeine Angelegentheiten nidt zu bejorgen bermag;

2. twegen Berifrwentung, wenn ber Berfarmenter bura bie jelbe fid ober jeine framilie ber Gefahr bes Rothftanbes auşęt:

3. wegen Truntiugt, wenn ber Trinler in Folge berielben feiste Ungelegenbeitent niकt zu bejorgen bermag ober fid ober feitte Familie ber Befahr bes Notbitandes ansiest ober bie Siderheit Anberer geführbet.

Tie Entmũnbigung ift rieber aufauheben, wenn ber Brunb, aus bem fie erfolgte, weggefallen ift.
B. $\S 6(\Re . \S 6,(B) \S 6)$.

Entminoigt tann werben:

1. wer in Frolge bon Beiftes. trantheit ober bon Bfeiftes.

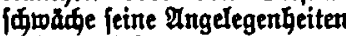
ticht zu bejorgen vermag;

2. wer burd Berifinentung fid obet feine framilie bet Befahr bes Rotbjtandes aus|ebt;

3. wer in folge bon Irunthuht peine Ingelegenteiten nidt zu bejorgen vermag ober fith ober feine Framilie ber Bsefahr bez Rothitartbes ausjest ober bie Sidherbeit Inberer gefăhrbet.

Die Cntmultobigung ift wieber aufzukeben, went ber Srunt ber Entmutinbigung wegfallt.

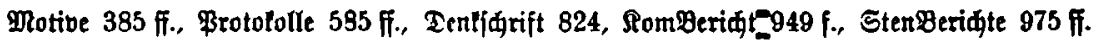

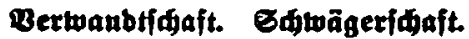

$$
\text { I } \$ 30 .
$$

Berfonen, beren eine vor ber anberen $a b f$ tammt, finb in geraber Sinie bertoanbt. Betjonen, welde nifit in geraber. Sinie bermanbt finb, aber bon berfelben britten Berfon abftammett, finb in ber Seitenlinie verwanbt.

Die Geitenbertwanbter finb voll= betrtig, wenn fie bon bemlelben Eltermpaare abftammen, halbbartig, wenn fie nur einen gemeinjamen Stammbater ober cine gemeinfame Stammmutter Gaben.

Durd unehelide abftammung toirb, potweit nicht bas Gefes ein Anberes beltimmt, eit Betwanbt.

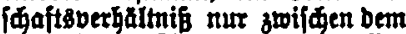
uneheliden Sinbe, formie beffent æbotommlinger einerfeits unb ber Matter bes Rinbes, fowie berent Bertoanbter anbererfeits begrlinbet.

$$
\text { I } \S 31 \text {. }
$$

Der Brab ber Berwanbtidaft toirb naw ber Bahl ber bas get:

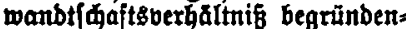
ben Beugungen beftimmt.
II $\S 15$ (B. $\S 1569, \Re . \S 1567)$. Berionten, beren eine von ber anberen abftammt, finb in geraber Sinie vertwandt. Ferfonen, bie nidt in geraber Linie vermanbt finb, aber bon berfelben britten Berfon abftammen, finb in ber Eeitenlinie verwanbt. Der Brab ber Bertoanbtidaft beftimmt fí na⿱ ber Bahl ber fie vermittelnben Beburten.

9roifhen einem uneheliqen Sinbe unb befien Bater befteht leine Bertwandtifaft.
3. $\$ 1589$.

Berfonen, beren eine von ber anberen abftammt, finb in geraber Linie vertoandt. Bexfoner, bic nidt in geraber Linie bernoandt finb, aber bort berfelben britten Berfon abftammen, finb in bex Settenlinie vertoanbt. Dex Brab ber Bertwanbtjdaft beftimmt fí nad ber $B a b I$ ber fie bermittelnben Beburten.

Ein unebelides Rinb unb beffen Bater gelten nimt als berwanbt. 
I $\S 32$.

Gin Thegatte ift mit ben Ber= wandten beš anberen Chegatten verf

Die linie untb ber Brab ber

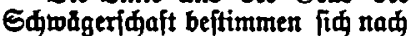
Der Linie und bem Grabe ber fie begranbenden Bertwantotidaft.

\section{I $\S 33$.}

Die an bas Edjmăgeridafts: verhältni仿 getnupften redtliden

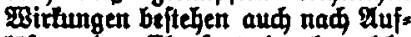
lojung ber che fort, burd welde bas Bertaltrnis begrainbet if
I \& 34.

Der an cirrem Drte ber 2 uff $=$ enthalt in ber Mbfidt nimmt, bott Ptänbig zu Gleiben, begrilnbet an biejemt Drte ben $280 h n j i s$.

Cine Berjon tann zur gleiden Beit an mehresen Drten bes $280 h n_{2}$ fit Gaben.

Der $\$ B$ ohnfib einer Berjon toitb aufgetgoben, wenn biefelbe bent

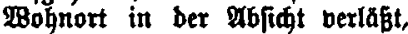
bort nidt mehr ftanbig zu Gleiben.
II $\S 16$.

Ein Ehegatte ift mit ben Ber: wanbter beş anberen EGegatten ber: jđiwägert. Die Livie unb ber Grab Der Edinägerfafaft beftimmen fid naw ber Rinie und bem (Brabe ber fie bermittelnben Betwanbtjdajt.

Die Étwågeridaft bauert fort, aud went bie EEge, buth bie fie begrünbet wurbe, aufgelöbt ift.

Motive 389 f., Prototolle 587 ff.

\section{Mognfik.}

\section{II $\$ 17$.}

פBer fid an einem Drte ftănbig nieberläbt, begrinbet bafelbft feirer कobn fib.

Eine Berion fann ifren 180 ohn= fib gleidzeitig an mehreren Drten Gaben.

Der 280hnifis wirb aufgehoben, wenn bie Rieberfaffung mit bem 28illen, fie aufgugeber, aufgelaft twirb.
P. $\S 1570$ (भ \$ 1568, (5. § 1590). Die Bernanbten eines Che= gatten fint mit bem anberen Ebes gatter berfdimăgert. Die Rinie unb ber Brab ber Sdidagerifaift beftimmer fí nad ber Qinie unb bem Grabe ber fie bermittelisen Berwandifinaft.

Die Equadgeridaft bouert fort, aud went bie Ebe, burd bie fie begrinbet twutbe, aufgeloft iff.

Drotive 390 f., Prototolle 589, Rom\$erift 950.

$$
I \$ 35(I-, B .-, R .-, \text { G. }- \text {;. }
$$

Der Aufenthalt in einer Strafanstalt bewirkt fïr sich allein noch nicht die Aufhebung des Wohnsitzes, welchen der Strafgefangene vor Beginn des Strafvollsuges hatte, selbst wenn der Straf. gefangene an dem bisherigen Wohnorte eine Wohnung oder eine häusliche Einrichtung nicht mehr hat.

Die Vorschrift des 1. Abs. Findet entsprechende Anwendung auf Untersuchungsgefangene und auf Persomen, welche in einer Brsiehungsanstalt, Besserungsanstalt oder Arbeitsanstalt zwangswoeise untergebracht sind.

Drotive 301 f., Frotololle 590.

I \& 36.

Cine Berjon, welde geifaftsunfăhig ober in

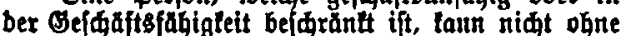

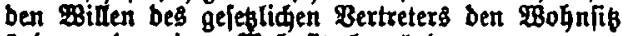
anbern ober einen 200 hinfic begrinden.

Mrotive 392, Stotololle 590.

$I \S 37$ (II $\S 19$ ).

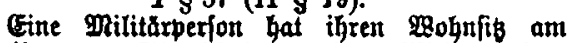

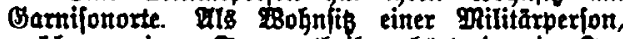
welde zu einem Truppentheile gehöst, ber im $3 \mathfrak{n}=$ lanbe teinen Garnifonort hat, gilt ber legte inlannbifhe Garniforort bes Truppentheiles.

Diele Borfdriften bes 1. Mbi. finben leine Anwenbung auf $\mathfrak{M i l i t a ̆ r p e r f o n e n , ~ w e l a ́ b e ~ n u r ~ z u r ~}$ Erfallung ber soebrpflidt bienent, ober welde felb:

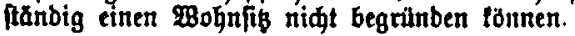

II $\S 18$ (B. $\$ 8, \Re . \S 8$, (s. § 8).

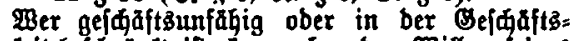
fäbigleit beldurantt ift, fann ofne ben $2 B i l l e n$ leires

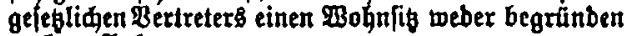
nod aufbeben.
9. § 7 (M. § 7, \$. § 7). nieberlást, begraindet an biejem

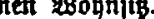

Defrob gleidzeitig

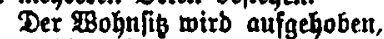
went bie giebeslafjung mit bem Biflen aufgeboben wirb, fie anf= zugeben.

\section{Motive $392 \mathrm{f}$., Protololle: 590 .}

$$
I \$ 38(I I-, \text { B. }-, \text { R. }-, \text { G. }-) \text {. }
$$

Ein Deutscher, welcher das Recht der Exterritorialität geniesst, sowoie ein im Auslande angestellter Beamter des Reiches oder eines Bundesstaates behält den Wohrsitz, welchen er in dem Heimathstaate hatte. In Ermangelung eines solchen Wohnsitzes gilt die Hauptstadt des Bundesstaates als der Wohrsitz.

Auf Wahlkonsuln finden die Vorschriften des 1. Abs. keine Anwendung. 
I $\$ 39$.

Die Ehefraut theilt ben $\mathfrak{B O h n i t h ~ b e s ~ C h e m a n n e s . ~}$

Tie Borjintift bes 1. Abj. findet feine Anwen.

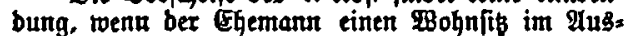
lanbe an einem Drte begrinbet, an welaem igm bie Ehefrau zu folgen nimt verpfliditet ift.

Die Ehefrau fann einen felbftändigen 20 ohnith begrumben unb haben, wenn unb folange ber Ehe mann teinen 280 gn th ober feinen bon ibr gethetiten Wohnjtic hat.

\section{I $\$ 40$.}

(Ein eqelides find theilt ben פohnf is bes Baters, eine an Rinbegifatt angenommene Perion ben $\$ 30 h n i b$ bes Annehmenten. Ein unebelides Rinb theilt ben פohnfis ber Matter. Flle biefe ftinber behalten ben bezeigneten Wohnfig, bis fie benfelben in ređtsgultiger Beife aufgebent.

Die Borfuriften bes 1. Eabes bes 1. $\mathfrak{A} b[$ finben auf legitiminte Sinber unb an Rinbesftatt ange= nommene Berfonen teine Anmen= bung, wenn bie Regitimation ober Fmahme an Rinbeśftatt er[t nad erreidter Bolljăbrigteit berfelben eriolgt ift.

Drotive $393 \mathrm{f}$. Protololle $591 \mathrm{f}$.

\section{II $\S 21$.}

Fin ehelides find theilt ben \$ohní, feines Baters, ein un= ehelides ben feinter Shutter, ein an Qinbesftatt angenommenes ben bes Annefmenben. Der Bobnfib verbleibt bem Sinbe, fis baffelbe ihn red)tsgultig aufhebt.

Fine erft nad Eintritt ber Bolliabrigteit bes Stinbes erfolgte Segitimation ober 2 mrahme an Pinbesftatt hat teinen Einflus auf ben शुohnifis beg Stinbes.

\section{Protive 394 f.. Prototolle 592.}

II $\leqslant 22$.

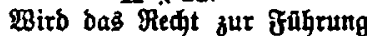
eites Mamens bem Beredtigten beftritten ober wirb biefer in leinem 3ntereffe baburd berlebt, baf cin ânberer fid unbefugt bes gleiden Ramens bebient, fo fant ex $\mathbf{B C}=$ jeitigung ber Beêntråđtigung unb Berurtheilung bur Unterla $\$$ ung weiterer Beeintrảbtigungen ber Iangen.
B. $\$ 11$ (R. § 11, \&. §11).

Cin ehelides Rinb theilt ben Mohnfin bez 3 aters, ein unehea lides Pind ben 930 hnits ber Prutter, ein an finbegjtatt ange

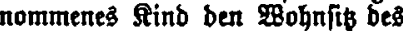
Intebmenben. Das Siutb behalt

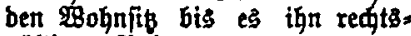
gultig aufbebt.

Fine erft nad bem Eintritte ber Mollährigfeit bes Rinbes er= folgenbe Segitimation ober $\mathfrak{A n}_{n}$. nahme an Sinbesftatt hat teinen Cinflas auf ben mohnits bes Rinbes.

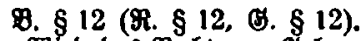

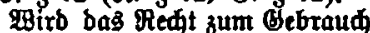
eines Tamens bem Bereditigten von einem 2 nberen beftritten ober wirb bas 3ntereffe bes Pereqtigten baburd berlebt, baf ein Anberer unbefugt ben gleiden Ramen ge: braunt, fo tann ber Beredtigte von bem Anberen Bejeitigung ber Beeintrăhtigung verlangent. Sints toeitere Beeintrådtigungen zu be: forgen, fo tant er auf tuters Iaffung flagen.

Mrotibe -, Brotololle 592 f., Denlldrift 824 f., StenPeridte 981.

\section{Juriftifdpe perjonen.}

I $\$ 41$.

Berjonenbereine unb Stiftungen töntren bie Fâbiglelt haben, als folde jelbjtånbig Bermögenss redte und Bermogens pilidien zu baben (jur. \$er[ð̈nliditeit)

\section{I $\$ 42$.}

Die jur ßerfontialeit eines \$erfonentereines unb ber Berluft biefex Pertonligiteit bejtimmen fin in Entangelung bes fonbertr reidigefeplider Borfdriften nad ben Qanbesgelesen bes Drtes,
II $\$ 23$.

Bereine gu gemein. nübigen, wobltbatigen, ge: jelltger, twiffenjळaftliden, tinfflerifoen ober anberen nidit auf einen wirth. juaftliden Befdaft\$be trieb geridteten 8 weden

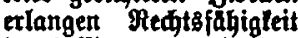
burd Cintragung in bas Bereingregifter bes zus ftanbigen antsgeriates ober burd ftaatlide Ber. Ieibung.

anbere Bereine er. Iangen Bechtsfabigteit in Crmangelung bejonberer reiäsgejestider
भ. $§ 21$.

Bereine fu gemein, nübigen, wohlthătigen, ge= jelligen, wiffenjuaftliळen, tanjtIeri|jen ober anberen nidit auf einen with.

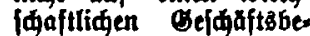
trieb geridgteten Broetien

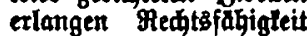
burd Eintragung in bas Bereinseregifter bes au* ftábigen Fintsigeriftes ober burd ftaatlide Ber: leigung.

Inbere Bereine $\mathrm{tr}$ Iangen Fedtbfăbigleit in Crmangelung befonberer reidygefesflider \$or:
B. 821 .

Ein Betein, befien 3med nidt auf eitrent wirthidaftl. Bejónts? betrieb geridtet ift. er: langt Medtsfăhigleit bura Eintragung in bas $\mathfrak{B e r}$ : cinsiregifter bos juftan. bigen Fimtsgeriates.

\section{c. $\S 22$.}

Ein Berein, befien gwed auf etten wirth. 闬tlliben Gejoütsbe. trieb gextbtet ift, erlangt 
an weldem ber Berjonens verein feinen Gis bat. [driften nur burd ftaat= lime Berleifurg. idriften nur burd ftaats lide Berleibung.
Die Berleifung ber

Die Berleifung ber Redtşfăhigleit fteht bem Bunbesftaate $z u$, in beffen Bebiete bet Berein feinen Sib hat.

Ars Sik beş Bercines gilt, wenn nidit ein $\mathfrak{A}_{\mathfrak{n}}=$ beres erhellt, ber Drt, an toeldem bie Berwaltung gefubrt wirb.
Medtäfăhigteit fteht bem Bunbesftaate zu, in beffen Bebiete ber Berein feinen Sib hat. Đat ber Berein feinen ङib nidst in einem Ounbesftaate, fo erfolgt Die Berleigung burd $\mathfrak{B}_{e}=$

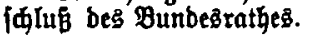

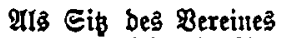
gill, went niфt ein Int $^{2}$ beres bejtimmt ift, ber Drt, an trelchem bie Ber= waltung gefüht wirb. in Ermangelung bejon:

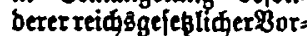

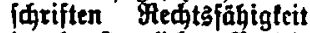
burd itaatliqe Berlei= Gung. Die Berleigung iteft bem Bunbeşftoate 3u, in befien Bebiete ber Berein feinen Eis hat.

$$
\text { G. } \$ 23 .
$$

Cinem Bereine, ber feinert $\mathcal{C}_{\text {ib }}$ nidht in einem Bunbesftaate hat, lann in Ermangelung befort. berer teidisaefeslidet Borføriften Feøtâäbta. Itti burd Be/filus bes Bunbesratas berliehell werben.

\section{B. $\$ 24$.}

$\mathfrak{A} 15$ Sib eines $\mathfrak{B}$ ercines gilt, went niøht ein $\mathfrak{A}_{\mathfrak{n}}=$ beres beftimmt ifft, ber Drt, an welduem bie Ber: waltung geführt wirb.

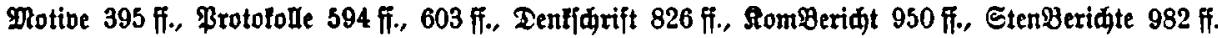

$I \$ 43$.

Die Berfaffung eines mit jur. \$erionlidileit verjebenen ßerjonen=

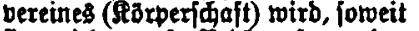
fre nidit auf Reidsgejes ober Lanbesgefes beruht, burd ben Brtunbungevertrag unb in $\mathfrak{A n}_{\mathbf{n}}$ febung ipăterer Abănberungen burf ben 2 Billent ber Mtitglieber ber äzperihaft beftimmt.

Motibe 403 f., Frotololle 594 fi, 607 fo, Dentifurift 826 ff., PomPeridt 950 ff.

I \$44.

Far jebe Aorperjáft muß cill Borftanb beftellt werber. Der Borftand ift ber gefegliaje Ber: treter ber Sorperidaft fowohl gegenuber Dritten als gegentaber ben Mitgliebern ber Piorperfáaft. Der Borftanb fann aus einer Gerion ober aus méreren \$er. fonen beftehen.

Tuf bie Recte unb Blidten bes Borftanbes gegenuber ber

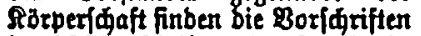
ber $\$ 585,588$ bi 596 entipredenbe Unwenbung.

Die Beltellung bes Boritanbes exfolgt burd Bejdiuß ber Pit: glieber.

Die Bertretungsmadt bes Bor: Panbes lann burक bie Berfafiung

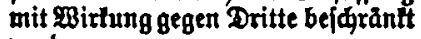
werben.
II $\$ 24$.

Die Berfaffung eines redts: făbigen Bereittes niro. porweit jie nidt auf ben nafifolgenben $B o r=$ färiften berubt, burd bie Ber: einsfabungen (@tatut) beftimmt.

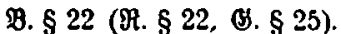

Die Berfaffung cines redts: făbigen Bereins wirb, foweit fie niaht auf ben nahfolgenden $\mathfrak{B o r =}$ fantiten berubt, burd bie Ber= einşą̧ung beftimmt.
II $§ 25$.

Der Berein mus eincn Bor= ftanb haben. Der Borftand lann aus mehreter Berjonen beftehen.

Der Borftanb bertritt ben Berein geriatlid unb auber= geriळtlid; er hat bie Stellung cines gejesliden Bertreters. Der Umfang feiner Bertretungsimadt lann burd bas @tatut mit \$irtung gegen Iritte beidrantt werben.

\section{II $\S 26$.}

Die Beftellumg bes Boritanbes exfolgt burd BejaluE ber Dit: glicberver|ammlung.

Die Deftellung ift jeberzeit mibermuflia, unbeimabet ber Cint:

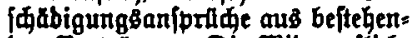
ben Bertrăger. Die $\mathfrak{B}$ iberruflit, Ieit tann burd bas Statut auf ben fall befarănlt werben, baß ein toidtiger Grunb fîr bett פgiberruf borliegt; ein jolder Brnunb ift insber. grobe Pfliditvers legung ober Unfahigleit zur ords

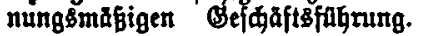

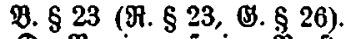

Tex Berein muB étuten Borftanb Gaben. Der Borjtand lann aus mehrezen Berjonen beftehelt.

Der Borftand bertritt ben Berein geridtlid und auber: geriqtlid; er hat bie @tellumg eines gefeslidien Bertreters. Ter Umfang feiner Bertretungsimađt fann burh bie Gajung mit wirtung gegen Dritte bejugrantt werber.

2. $\$ 24(\Re .624$, (3. \$27).

Die Beftellung bes Borftanbes erjolgt burd BefdLluE ber Mit. glieberberfammlung.

Tie Beftellung if jeberzeit

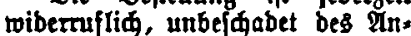
[prudes auf bie bertraģmákige Bergltumg. Die פoiberruflidfett Iann burd bie Sagung auf ben Fall befdrătit werben, baß ein widitiger Brrunb fit ben פBiber: nuf borliegt; ein folder (S) runb ift insbef. grobe Priatwerlebung ober Ünfăbiglett zur orbmungsిmăbigen

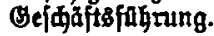


Befteht ber Borftand aus mebreren Rerjonen, fo ift zur Gültigfeit feiner ßsiflensertlārung bie Buftimmutg aller Mritglieber eriorberlid.

ifür bie Mittheilung ber $\mathfrak{W i l l e n s : ~}$ erflărunt eines Dritten, du beren Entgegentahme bie R̈orperiळajt ocrpfliditet $i f t$, genügt bie $\mathbb{P} i t=$ theilung an cit MRitglieb bes \$or= ftandes. Jịt zu ber Beit, in meldjer bie Dittheilung einer jolđen willenşertlärung erfolgen foll, einte zur Entgegennahme ber= felben berufene Berjon niat vor: hanben, fo hat bei Srefabr int Berzuge auf Antrag Dez Dritten. welder bie Mitthetlung betwitten will, bas 1 mtsgeriat, in beffen Bezirfe bie ९örperjळaft ihren Sib hat. zur Entgegennahme ber Willenక̧ertlăruntg eiten befonberen Bertreter zu beftellen.

Die Borjarifiten beş 2., 3. unb 5. थbF. finben nur injomeit Anmendung, als niđt bie $\mathfrak{B e r}=$ faffung ein Anberes beftimmt.

Motibe 404 ff., Brotololle 594 fi., 603 fi., Denff $\S \S 29,31$ (\$. 32, 34).
II $\$ 28$.

Soweit bie exforberlident Mit= glieber bes 2 orítanbes fehlen, finb fie bei Sefahr im Berzuge auf Untrag eitres Betheiligtent von bem Amtsgeriat, in beffen Besirte ber Berein feinell Sib hat, fitr bie Beit bis zur Debung bes Mangels zu bejtellen.

Iuf bie Gejĭâftsfungnung bes Borftanbes finden bie für ben Auftrag geltenben Borjariften ber $\S \S 651$ bis 657 (अ. 664 bis 670) entfprechenbe Intoenbung.

B. § 25 (M. § 25, (3. § 28).

Beptegt ber Borftand aus mehreren Berionen, fo exfolgt bie Bejalusfaffung nah ben für bie Bejळlüfe ber Ditglieber bes Bereines̉ geltenben Boridriften ber

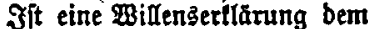
Bereine gegenüber abzugeben, fo gentügt bie $\mathfrak{a b g a b e}$ gegenuber einem Ditgliebe besิ Boritanbes.

B. $\S 26$ IR. $\S 26$, \&. $\S 29$ )

Someit bie erjorberlifien $\mathrm{Mit}$ glieber bes Borftanbez fehfen find fie in bringenben Fallen fut bie Bcit bis zur \$ebung bes Mangels auf Ontrag eines $\mathfrak{B e s}$ theiligten bon bem $\mathfrak{A}$ mts geriate zu beftellen, in beffen Pezirte ber Berein feinen Sib hat.

[l fehlt].

II $\S 29$ (9. § 27, (3. § 30$)$.

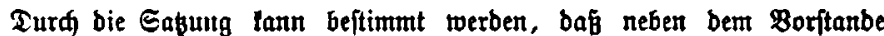
fiur getwiffe B̈efdăfte bejonbere Bertreter zu befteflen find. Die Bertretungs: madit eineż folden Bertreter

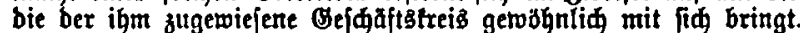

Motive -, Brototolle 594 fi., $617 \mathrm{f}$.

$I \S 45(I I-, B .-, R .-$, G. -$)$.

Bei einem nicht onssechliesslich in der Erfiullung einer Verbindlichkeit bestehenden Rechtsgeschäfte zuischen der Körperschaft und einem Mitgliede des Vorstandes sowie bei einem Rechtsstreite zuoischen denselben ist das betheiligle Mitglied von der gesetzlichen Vertretung der Körperschaft ausgeschlossen. I'ïd ein besonderer Vertreter für die Körperschaft erforderlich, 80 erfolgt die Bestellung nach Massgabe des $\S 44$ Abs. $3, \%$.

Motive 407 f., Brotololle 594 ff., 616 f., Dentfijrift $\$ 26$ f., StomBeriat 950 fi.

I $\S 46$.

Die Sorrperinaft haftet für ben Errjab bes Єđabents, weldent ihr Borttantb ober ein Ditglieb beffelben Durch eine in $\mathscr{Y}$ tișubung feiner Bertretungsmadt begangene twiber: redittidje, zum Edabenserfape ber= pflidtende \$anblung einem Dritter ougefugt hat
II $\S 30$.

Dex Berein ift fïr ber Shaben verantroortlid, welder ber Bors ftanb, ein $M$ Ritglied befielben ober ein fonft verfaffungsmadafig bes rufener Bertreter burd eine in Tusfahrung ber igm zutommenben Berridturgen begangerte, zum

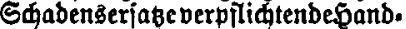
lung einem Tritten zufügt.

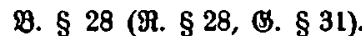

Der Berein ift für ben હđaben berantroortlid, ben ber Boritand, ein Pitglied bes Borftanbes ober ein anberer verfafingşmåsig be rufener Bertreter burd eine in Tus̊fahrung ber ing zuftehenben Berridtungen begangene, zum ธגaben berfage verpflidterbeşanb. lung eitem Dritten bufügt.

Motibe 408 i., Brototolle 594 fi., 618 i., Denliarift 826 fi., MomBeriat 950 fi. 
I $\$ 47$.

Im Falle bet ueberfoulbung ber Poxperfdaft ift ber Borftanb berpflidatet, unverzfiglid bie $\mathcal{E}_{x}$ Bffnung bes Ponturies au bean: tragen. Mitglieber bes Borftanbes, welde bieje 9expfliditung verlesten. haften ben Bläbigern ber Porper

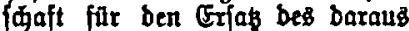

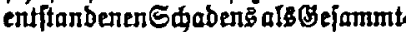
f千ulbner.
II § 39 (タ. § $39, \mathfrak{R} . \$ 39$ ).

Det Berein toirb cufgelöf burr Eroffung bes Ronturjes.

Der Borftanb hat im Falle ber uleberifulbung bie Eroffnung beg Ponfuries zu beantragen. शgirb bie Etellung bes Antrages ber: 3ogert, fo fund die Borfandsimit: glieber, benen eit Berjdulben gur

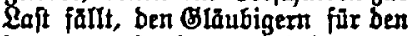
baraus entiftanberten Éaben ber: antwortlia; Tie baften als Be= fommt|dulbner.
3. § 42.

Der Berein verliert bie piects. fäbigleit bus内 bie Eröffnung bes Ponturies.

Der Borftand hat im Falle ber

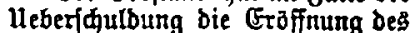
Fonturies zu beantragen. शुirb bie Stellung bez Antrages ber: zogert, io finb bie Borjtandsmit. glieber, benen ein Berjaulber jur Laft fällt, ben B̉lăubigern fúr den baraus entiteherton Edaben ber. antwortlid; fie hafter als Bes jammífuloner.

Motibe 410, Protololle 59+fi., 619, Dentjめrift 826 fi., PomBeriøt 950 fi.

I $\$ 48$.

In ben inneren Angelegen: Geiten ber Rörberjogit ift ber Sille ber Ritglieber mafiebenb.

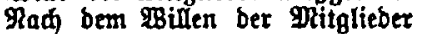
hat ber Borftand fid auth bei ber Gejめäftąührung zu riøten

Der 9 ille ber glitglieber wirb burd Befblü in einer Berjamm= lung berfelben feftgejtellt. Bei ber Bejulubfafiung entideibet bie Mehrbeit ber in ber Berfammlung eríbieneren Mitglieber. Bur Balti $g=$

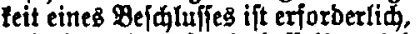
baj ber Hegenftand beffelbert bei Cinberufung ber glitglieber zur Berjammlung bezeidnet ift.

Cin auf ber Buftinmung aller Mitglieber berubenber Bejdlus ift aud barn gültig, wenn er nidt in einer Berjammlung ber Mit= glieber gefafit rorben ijt.

Bei ber Beidlubfáffung über

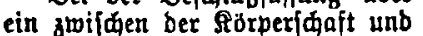
einem Initgliebe einzugehendes

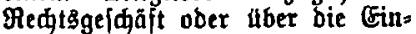
leitung vber bie Exlebigung eines Red)tgitreites stoi dien ber Rörper= falt und einem Mitgliebe ift bas betheiligte Ditglieb niđt ftimm: beređtigt.

Rur Baltigteit eines bura welden bie Berfafiung $a b=$ geănbert wirb, bebarf ea ber $8 \mathrm{~g}$. fimmung aller $\mathfrak{P i t g l i e b e r , ~ i n s ̧ b e f . ~}$ aud Derjenigen, welde in ber zur Bejglubfaffung einberufenen Ber= fammlung nidit eridienen finb.

\section{II $\S 31$.}

Die Angelegentheiten beş Ber= eines werden, foweit fie nidht von bem Borftanbe ober einem anberen Bereinsorgane ou bejorgen find, burd Befdlupgfaffung in einer Beriammiung bet Mitglicber ge orbitet. But Gultigfeit bes g̈e idluffes ift erjorberlia, baj ber Gegenftano befíflben bei Berufing ber Beriammlung bezeidutet ift. Bei ber Bej̧lubfaffung entidjeibet bie MRebrbeit ber erjuienenten Mit= glieber.

Fin auf Der Bujtimmung aller Ditglieber beruhenber Bejalub ift auch obne Berjamminng ber $\mathfrak{M i t}=$ glieber gũltig, wenn bie ßujtimmung

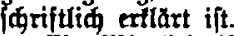

Ein Mitglieb ift nift ftinms=

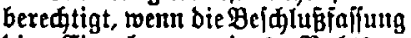

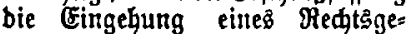
jäätes mit ihm ober bie Eint= lettung ober Erlebigung cines Red)t\&j|treitez ztoifuen ihm unb bem Bereine betrifft.

\section{II $\$ 32$.}

Bux Bultigleit eines Bejकluffes, bură reldyert bas Statut geănbert wirb, bebarf eg einer Wehrheit von brei Biertheilen ber erjaiencuen Mitglieber. Bur Renterung besి

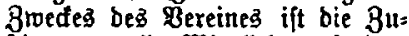
ftimmung aller Ditglieber erforberliq; Die 3uftimmung Der niळt erj申ienerten mus fáriftlid erfolgett.

Derubt bie Redtşfähigleit eines Bereines auf ftaatfider Berleibung, fo bebarf jebe Aenderung beg Statutes ber ftaatlidgetl Genthmi= gung.

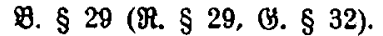

Die Angelegentheiten bes Ber=

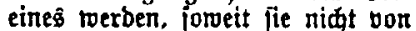
Dem Borftanbe ober einem allberen Bereinzorgane zu bejorgen finb,

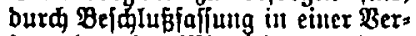
fammlung ber Mitglteber georbnet. Bur Saltigleit bes Beidluffes ift crforberlia, bas ber Begenítand bei ber Berufung bezeidnet toirb. Oei ber Bejđlubiaflung entideibet bie Mehrbeit ber erjaiestenen Mit= glieber.

Au山 ohne Berjammlung ber Mitglieber ijt ein $\mathfrak{B}$ ej山luß gultig, went alle mitglieber ihre $8 u=$ ftimmung zu bem Befdluffe farifts líd) erflären.

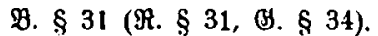

Fin Mitglied ift nidt fitum. beredigtigt, toent bie Beid)lub̈faffung bie Bornahme eintes Rechto̊ge= \{däftes mit ifm ober bie cein= leitung oder Erlebigung eimes Med)tâftreites zroifd)en ihm und Dem Bereine betrifft.

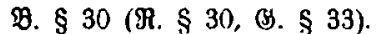

Bu einem Bejdlufte, ber eine Ienberung ber ভałung entbalt, ift eine Dehrheit bon brei $\mathfrak{B i e r}$ theilen ber erfóienenen Mitglieber erforberlic. Bur Menberung beş Brodes bes ३ereines ift bie $\beta u=$ ftimmung aller Mitglicber erfor: Derlid; bie Bujtimnung Des nidyt eriळiententen Mitglieber muś jarrift= lid erfolgen.

Beruht bie Redtsłăhagigfeit beg Bereines all Berleifung, fo ift zu jeber Ienderung ber Sajung ftaat= liaje (Senebmigung ober, falls bit Berleihung Duth den Pundegrath erfolgt ift, bie Genehmigung bes Bunbesratbes") erforberlia. 
II $\$ 37$.

Die Borifriften bes 1. bis 5. $\mathfrak{X b j}$. Finber unt infoweit $\mathscr{A n}=$ werbung, als nimt bie Berfaffung cin Inderes beftimmt.
Die Borjuriften bes $\$ 26$

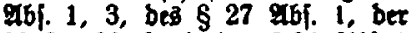
\$§ 31, 32, forvie bes \$36 צ́b5. 1 finben inforweit leine anmenbung, als bas Statut ein Anberes be: fitimmt.

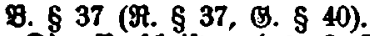

Die Borfdriften bes \& 24

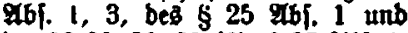
ber $\$ \$ 29,30,35$ (\$. § 27 श्भt. 1 , 3 , bes § 28 abi 1 und ber $\$ \S 32$, 33,38 ) finben inloweit teine $\mathfrak{A n}^{n}=$ wenbung, als bie Gapung ein
Anberess beftimmt.

Motibe 410 fi., Protololle 594 ரீ., 619 fi., Dentiđrift 826 ff., RomPeridt 950 fi.

III $\$ 33$.

Sorberredte ber 91itglieber tönnen

[I fegltit.

[I fehlt].

[I feglt].

[I feglut].

[I feglt]. ber MRitglieberberfammlung nidt be: eirttrảdtigt toerben.

II $\S 34$.

Die Mitglieberberjammlung ift auber ben im Statute beftimmter frăten zu berufen, wern es bas Эntereffe bes Bereines exforbert.

Motive -, Mrotololfe 624 f.

II $\$ 35$.

Die Mitglieberverfammlung ift ou berufen, went ber 10 . Theil ober ber im Statute hierfü beftimmte grōbere ober geringere Theil ber Mitglieber in cinter bon innen unteridriebenen Eingabe unter Antühning besీ 3medes und ber Branbe bie Berufung berlangt.

Birb bem Berlangen niaht ent: iproden, fo tann bas Ümts geriat, in Deffen Bejirte Der Berein feinten Sib hat, bie MRitglieber, welde bas 2 er= Iangen geftell haben, jur Berufung ber Berfammlung emăhtigen, aú aber bie Fübrung bes Borfibes in ber Berjanmlung Beftimmung treffen. Quf bie Ermăhtigung muB bei ber Betufung ber Berjammlung Bezug genomment werbent.

$$
\text { Protive -, Prototolle 624 f. }
$$

II $\$ 36$.

Die Mitgliebjafift ift nimt tiber= tragbar und nidt vererblim. Die

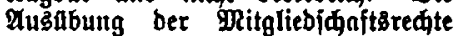
tann einem anberen nidit aberlaffen werben.

Die DRitglieber find zum $\mathfrak{A} u g$ tritte aus bem Bereine berentigt. Dura bas Etatut tant beftimmt werben, ba

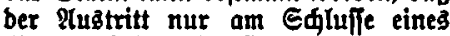

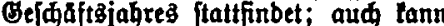
eine Qunbigung sfrift von hỏ fitens 2 3ahren bejtimmt werben.

Motive -, Protololle 625 f.

II § 38.

Ter Berein tann burd Beidilus bet Mritglieberverfammung aufgeläft ogne beren 3ujtimmung burd Befidiaffe

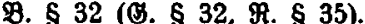

Sonderredte eines QRitgliebes tonnen niđt ohne beffen Buftintmung Durd Beiflup ber Dringlieberver: fammlutug beeintrădtigt werben.

2. $\S 33$ (भ. § 33, G. § 36)

Die glitglieberberfammlung ift in ben burc bie હaß̧ung beftimmten Fallen formie barn zu berufen, wenn

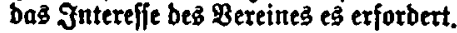

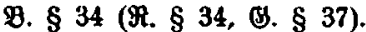

Die Mitglieberverfammlung ift zu betujen, went ber burd bie Sabutg beftimmte Theil ober in Crmangelung einter gejtimmung ber 10 . Their ber Mritglieber bie Berufung ifriftlid unter Ingabe bes Broedes unb ber Gruinbe berlangt.

Wirb bem Berlangen nift ent: [proden, io tann bas 2mts geridt, in beffen Bezirte ber Berein feinen Sib hat, bie פtitglieder, welde bas $\mathfrak{B e r}=$ langen geftelit baben, zur gerufung ber Berjammlung ermadtigen uno aber bie Fahnum bes Borfites in ber Berfanmling Beftimmung treffert. Ouf bie Ermádhtigung mus bei ber Berufung ber Berjammlung Bejug gettonmen werben.

ஒ. § 35 (भ. § 35, ‥ § 38).

Die פritgliebládaft in nidt über, tragbar uno nimt vererblim. Die

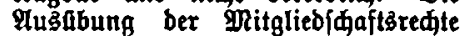
tann nimt einem $\mathfrak{A}$ (nberent itberlafien werbert.

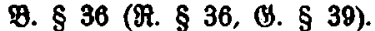

Die QRitglieber find zum Ausstritte aus bem Bereine bereftigt.

Durw bie Sagung tann beftimmt werben, bas ber Rustritt nur am Élufie cines Bseifaftsjabres ober erft nab bem gblaufe etuer sün. bigungefritt zulälfig ift; bie Stan= bigungsfrift tann bodftens 2 Jabre betragen.

Ð. § 38 (M. § 38, \$. § 41) Der Berein tann Surd DejuluB ber Mitglieberberfanumlung aufgelofit 


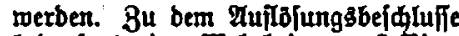
bebarf es einer Mehrheit bon 3 Bier: theilen ber erffienenen 9Ritglieber. foweit bas. Statut nidt ein গ̂̉beres beftimmt.

$$
\text { Mlotive -, Brotololle } 627 .
$$

[I fehlt].

[I fehlt].

II $\S 39$ fiehe з山 I $\S 47$.

II $\$ 40$.

Dex Berein tann auj= gelofit twerben, went er burd gefeswibrige $B_{e}=$ fd̆lüfe ber mitglieber berjammlung ober burf geieşwibriges Berbalten bes Borítanbes bas (se= meinwohl gefährbet.

Ein Berein, beffen 3 wed nad bem Etatute nidgt auf einen wirthjiajtliden

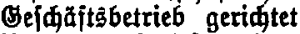
ift, lann aufgelöft werben, toenn ex eitter joldent Broed veriolgt.

Ein Berein, welder nạ́ bem Statute einen politifien, fozialpoli= tiidgen ober religiobjert Broed nidit hat, tann auj= gelöft werben, wenn er einen folden 3wed ber folgt.

Tas פerfahren und bie Buftānbigtcit ber Be: hörben riften fí ná ben fifr ftreitige $\mathfrak{B e r w a l}=$ tungş|aden lanbeşgeje liळ geltenten Bor|đriften. Wo ein Bermaltungs fitreit: berfahren niat befteht. finben bie Boridriften ber $\S \S 20,21$ ber $B D$. mit ber Mlab̧gabe $\mathfrak{I n}$ tonbung, baß bie Ent= føeibung in 1. Inftanz burd bie Göhere Ber= waltung sbefourbe crfolgt, in beren Bezitfe ber Berein feinen Sis bat.
פ. $\S 40(\mathfrak{H} . \S 40)$.

Der Berein tant auf gelofft werben, wenn e burd einen gefegtoibrigen BejđIuß́ ber Mtitglieber berjammlung ober burd gejeptwibriges Berfalten bes Boritanbes bas (Se= meinwohl gejährbet.

Ein Berein, beffen 3wed tad ber Sabung nidt auj einen wirtbjaftliden Bejđäjtşbetrieb gerid)tet if́t, fann aufgelojit werben, wenu er eiuter jolden Bwed verjolgt.

(Fin Berein, ber nax́ ber Gabung einen bem Bebicte ber Bolitil ober ber Sojialpolitif, ber Religion, ber Erziehung ober des unterriates angehörenben B̈wed nidat hat, tann aufgelofit werben, went er einen folden Broef verjolgt.

Ein Berein, beffen

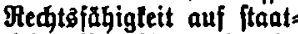
lider Berleibung beruht, lann aufgelojt merben, went er einen anberen als ben it ber Sabutg beftimmten 8wed ver= folgt.*)

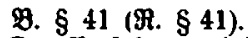
Das Berfahren unb bie

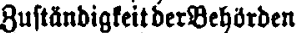
ridten fia in ben follten bez $\S 40$ nad bent far itreitige Berwaltung 3 . fahen geltenben Bors idriften ber Ranbesgejebe. Bo eit Bernaltung ģ ftreit= veriahrent niat befteht. finben bie Borjajriftell ber $\$ \S 20,21$ ber GD. II $n=$ twenbung; bie Entiłkibung exjolgt in 1. Jnitanz Durd bie höhere Ber= raltungsbebörbe, in beren Bezirt ber Berein feinen Sib hat.**)

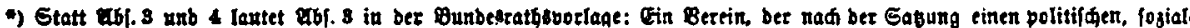

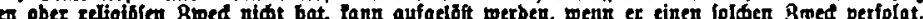

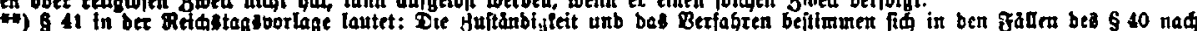
ben Gefesen bes Bubesfoates, in beffen Gebiet bet Beretn feinen Sib bat

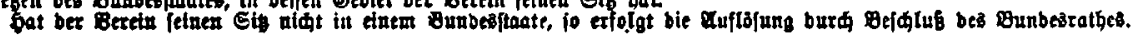




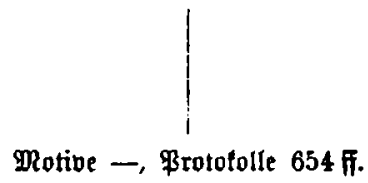

II $\S 41$.

Mit ber Ruflobiung beg

Daş Bermögen einer erlojकenen Rörperidaft fällt an benjentigen, toels der in ber Berfaffung unb jofern weber biefe

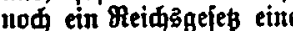
Inorbnung enthảl, in ben Lanbesigejeşen bes Drtes, an weldhem bie

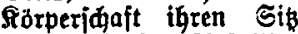
hatte, als ber Infallbe: rechtigte bejtimmt ift.

Das Bermögen if zu$^{\mathrm{u}}=$ nå丸[t zur Befriebigung ber \&lăıbiger ber Яörper: iळait zu berwenben. Die Borjartiften uber bie in Frmangelung anbercr $E_{r}=$ ben betn ffistus anfal= lember Erbjhaften finben entfpredende $\mathfrak{A}$ trwettoung unt bies aud bant, went ber Anfallberedtigte niat ber fishts ift. Eofern jeboh bas Bermögen ustter bie Mtitalieber ber Sxzrperíaft zu bertheilen iit, mus bie Qiquibation nad Maşabe ber $\$ 850$ bis 56 erfolger. ober bura einen im fonten. anjallbereatigt beftimmt iino.

Frehlt esి an eitter pol= den Beftimmung, fo făllt bns Bermógen, went ber Berpin nad bem Statute ansjidliefslid ben 3nter= effen leiner Mitglieber biente, alt bie zitr 3 eit ber Auflibjung vorban= benen Mritglieber zu gleidjen Theilen, attberent= falls an ben Fitshts bes Bunbesftaates, in befien Bebicte ber Berein leinen Sib Gatte.

Gebjort ber Berein ou ben int $\S 23$ थbj. I be= zeidueten Bereinen, io tann ber Anfall an bie Mitglieber ober an bent

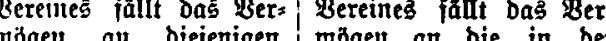
relihe bura bas Statut Eabung beftimmten $\mathfrak{B e r}$

Statute vorgejehenten $\mathfrak{B e}=$ Turh bie cakung

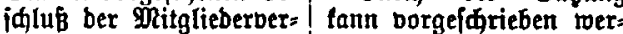

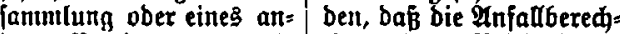
berent Bereinzorganes als tigtert burf Befflü ber fistus babura ausige = iflofien rerben, bas bie Mitglieberverfammlung bas Bermagen einer off. Stiftung ober Aritalt zuveift Bur Gultigleit besి Bejalufies genagt einiahe Etimmenmehr: geit.

\section{II $\$ 42$}

frăllt Dag Bereinsber. mönett an ben fishthos fo fuben bie Borjकriften ilber eine in Ermange= lung anberer Erben bem Fiştus anfallenbe $6+6=$ fhaft entipredenbe $\mathfrak{A} n=$ wentung.

Der Fişhts hat basి Bermögen thunlidit in einter ben Broeden bes Bereines entipredenben Weije zu bermenben.

Frăllt bas Bercinguer: mdgen nidat an ben fits= tus, fo mus eine Liqui= bation itattfutben

Motive 413 ff., Prototolle 627 ff., Denligrift 826 ff. Ditglieberberjammlung ober eine anberen $\mathfrak{B e r}=$ einso organtes beftimut twer ben. Behört ber Berein zu ben im $\$ 21$ शhb 1 begeidneten Bereinen, jo fantI bie Mitglieberber fammlung aud obne eine oløe Borjarift bas Ber= mögen einer öf. Stiftung ober $\mathfrak{A}$ iftalt zutweifen.

Fefjlt es an einer Be. ftimmung ber Mnjallbe. reditigten, fo fălt bas Bermdgen, went ber Berein nad ber Sagung

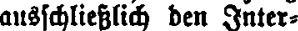
effen feinter Mitglieber biente, an bie zur Beit ber Iuflojung borban benen Mitglieber zu glciden Theilen, anberent

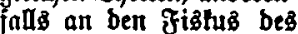
Bunbesiftaates, in beffen Gebiete ber Berein feinen Sis hatte.

9. 643 (भ. 843$)$

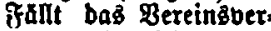
mögen an ben ffistus, 10 finben bie Borjariften flber eine bem offishis als gejeglidjem Crben an. fallenbe Erbidaft ent. iprediente Ánwenbung Der Fistus hat bas Ber. mögen thunltaft in einer ben Broden bes Bereines entipredyenden $\mathfrak{B e i l e ~ z u}$ verwenber.

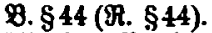

Fallt bas Bereinsber: mögen niळt an ben fis: fus, fo mus cine Qiqui= bation itattinben.
Berubt bie Reditsfähig Peit auf Berlethung burf ben Bunbersath, fo exfolat ble Entsiehung burd Pe. |⿵冂卄 Iufs bes Bunbesratbes.
‥ $\$ 45$

MRit ber भuflojung beg Bereins ober ber Gat jiebung ber Redtsfäbig. fett făllt bas Bermagen an bie in ber Cabung beftimmten Rerjonen.

Durd bie Sabung tann borgefdrieben wer ben, baß bie Infallbe ređtigten burळ Bejळlú ber Ditglieberberfamm: lung ober eines anderen Bereinşorganes beftimmt werber. 3ft ber 3wed bes Beretres utai an einen wirthidaftlinen Gefoüftöbetrieb gerta. tet, io tann bie $9 R$ tit glieberberjammlung aus ohne eine lolde Borjarif bas Bermögen einer bff Stiftung ober QTnftalt zu weifert.

Feb̆lt es an einer Bes ftimmung ber Infallbe rentigten, fo făll bas Bermögen, wenn ber Berein nad ber Sabung

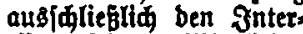
effent feiner Ditalieber biente, an bie zur Beit ber Fuftöfung ober ber Entstebung ber Hedts. fäbtgleit vorhanberen Mitglieber zu gleiden Theilen, anberenfalls an ben fFishus bes Bunbes. itaates, in beffen Bebiete ber Berein feinen Sig Gatte.

(B) $\$ 46$

z̧all bas Bereingber. mögen an ben fridhts, fo finbent bie Borfariften uber eine bem Sistüb als gefeglidaem exben att fallenbe Erbjdaft ent iprechenbe Ántornbung Der fristus hat bas Ber. mogen thunltaft in einex ben Broder bes Bercintes entipredenten Beife au vertuenben

B. 347

f̧ăl bas Bereinşber mögen nidgt att bett fiss. bation ftattfinbent. hus, fo mus cine Qiqui- 
I $\$ 50$.

Die \&iquibation geídiegt burd ben Borftanb.

8u Qiquibatoren Iönnen aum anbere Berjonen beftellt werben. Tie Beftellung ber lesteren erfolgt nad Maf́gabe ber firr bic $\mathfrak{B c}=$ ftellung bes Boritanbe马 geltenben Borfariftent.

Ginb Siquibatoren nidt ober nidht in ber erforberliden $\mathrm{Bahl}$ vorhanbert, [o hat bas Amtsge= ridt, in befien \$ezirte bie Pörper= fめaft ifren Sig hatte, auf Antrag eines Betheifigten, joweit nothig, für bie Zeit bis zur Bejeitigung bes Mlangels an Stelle ber feh: lenben qerfoul eine anbere als Qiquibator zu beftellen.

Die Diquibatoren haben, fo= weit nidgt aus bem 3roefe ber Qiquibation ein Anberes fí ers

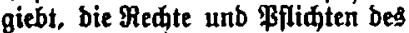
Borftandes. $\mathscr{Q}$ ud findef bie $\mathfrak{B o r}=$ fđriftent bes $\S 44$ Ubj. 6 Sab 1 , bes $\$ 4.5$ Sas 2 unb bes $\$ 46$ entjpređenbe Âwenbung.

Motive
II $\$ 43$.

Die Riquibation gejaieht burd ben Boritanb, wenn nidt anbere Riquibatoren beftellt werben. FIur bie Beftellung ber lebteren finb bie für bie Beftellung bes $\mathfrak{B o r}=$ itanbes geltenden Borjariften mit Ein[कluß bes $\$ 28$ maß́gebenb.

Tie Riquibatoren haben, potweit fím nidt aus bem Broefie ber $\mathrm{Li}=$ quibation ein Anberes ergiebt, bie rehtliahe Stellung bez Bortanbes. Sinb mehrere \&iquibatoren vorbanben, fo ift zur gejoluk $=$ faffung llebereinftimmung fâmmt: lider Liquibatoren exforberlid, fo= fern nidt ein Unberes bejtimmt ift.

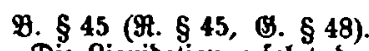

Die Siquibation exfolgt burd ben Borftanb. Bu Riquibatoren Pönnen and anbere \$erfonen be: ftellt toerden; fifr bie Beftellung finb bie für bie Pejtellung bes Boritanbes geltenbent Borjariften majgebend.

Die হiquibatoren haben bie redtlide Stellung bes Borftanbes, foweit fí niđt aus bem Bmede ber Riquibation ein Anbereg ers giebt.

Ginb mehrere Qiquibatoren vorfanben, fo ift für ihre \$ejdlüfle Uebereinftimmung aller erforber: lid, fojern nimt ein Anberes be= ftimmt ift.
$1 \S 51$.

Die Riquibatoren haben bie laujenben Brejăfte ber : erlojđjenen förperjaaft ou beenbigen, bie Gläbiger; zll befriebigen, bie forberungen ber Rörperfकaft einzuziehen, bas abrige Bermögen in

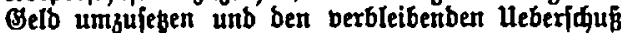
unter bie Mitglieber gu vertheilen. Zur Beenbigung

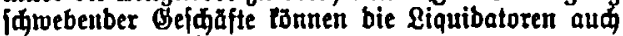
neue Geiळăfte eingehen.

Pis zur Beenbigung ber Siquibation ift bie Törperjळaft nod injoweit als fortbeftehenb anzus jehen, als es ber Brwed ber Riquibation zuläst uno erforbert.

Motive 416, Brotololle 633, Denlfinrift 826 ff.

Die Riquibatoren haben bie laufenben (Se) zu beentigen, bie forberungen eingugiefen, bas tbrige Bermögen in Gelb umzulęen, bie \&läubtger

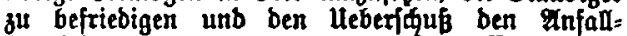
beredtigten auszuantworten. \$ur Beenbigumg ¡đwebenber Gcjめäfte tönten bie \&iquibatoren and

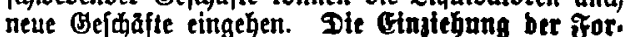
berungen fowit bie llmfegung bes übrigen $\mathrm{B}_{\text {tr. }}$ midgens in Gelb barf unferbictben, fowett biele 9RafregeIn niळt jur Befriebigung ber Blāublger ober jur Bertheilumg bes leberfinufes unter bie Infallbereditgten erforberith finb.

Der Berein gilt biß zur Beendigung ber $\mathbf{Q i}$. quibation als fortbeftehenb, forweit ber Broed ber Qiquibation es erforbert.

I $\$ 52$.

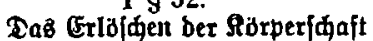
ift burd bie Qiquibatoren offentlia belantnt zu maden. In ber $\mathfrak{B e}=$ tanntmađung fiub bie Blăubiger zur 9nmelbung igrer Injprtide aufzuforbern. Tie Belasmtmadung erfolgt bura cinradung in bas Blatt, reldes zur Beroffentliđung amtlider Belanutmađungen bes Amts̈geriateş, in befien Bezirfe bie Rỏrperidait ihren Sib batte, beftimmt ift. Sie gilt ald bervirlt

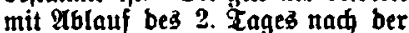
Einrüduttg ober ber 1. Cintlidung.

Befante Bläubiger finb burd befonbere Dhittbeilung zur $\mathfrak{A n}_{n}=$ melbuig aufzuforbern.
II $\$ 45(\mathfrak{O} . \S 47, \mathfrak{R} . \S 4 \overline{)})$.

Tie Auflojung bes Bereines ift burd bie Liquibatoren offentfich betannt zu maden. İ ber $\mathfrak{B} t=$ fanntmađung finb bie Bläubiger zur Anmelbung ihrer Injprifie aufbuforbern. Tie Befanntmadung erfolgt burd bas in ber Eajurt für Beröfientlidungent beftimmte Blatt, in Crmangeluutg eines folden burd Dadjenige Blatt, weldeg für Belanntmałungen bes 1 mtş= geridtes beftimmt ift, in beffen Begitle ber Berein peinen Sib Gatte. Die Befanntmadung gill mit bem Mblaufe bes 2. Tages nad ber Einrildung ober ber 1. Einniturutg als bervirlt.

Befannte Blăubiger fino bura befonbere Mittheilung zur $\mathfrak{A n}=$ meloung aufzuforbern.
B. $\$ 50$.

Die Uuflöjung beș Bereintes ober ble Cnijtehung ber Redts. fäbiglett ift bura bie \&iquibatoren offentlid befannt zu madyen. $3 \mathfrak{n}$ ber Belamtmáang finb bie Oläubiger zur Âumelbung ifrer Anjpringe aufzuforbern. Die $\mathfrak{B e}$ fanrtmadung exfolgt burd, baš in ber Sabung für Beroffentlidungen beftimmte Blatt, in Ermangelung eines̉ foløen burథ başjentige Blatt,

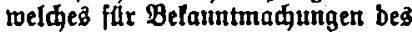
Amtgeriahtes beftimmt ift, in beffer Pezirle ber Derein feinten Sib hatte. Die Belanntmadung gilt mit bem $\mathfrak{A b l a u f e}$ bes 2 . Tages nad ber Ginntidung ober ber 1. Einrildung als betwirlt.

Oelannte BIăubiger find burd bejonbere Dhittheilung zur थีn. melbung aufzuforbern.

Motive 416 f., Brotololle 633 f., Dentidrift 826 ff. 
I $\$ 33$. Bermongers unter bie glieber barf erft nad ablauf eines 3ahres feit ber im $\$ 52$ vorge/djries benen Betanntmadung vollzogen werben.
II $\$ 46$. Die Yus an twortung bes Bermögens an bie $\mathfrak{A n}=$ fallbereffigten barf erft nad 9blauf eines Jahres reit ber im $\$ 45$ vor= gejuriebenen Belannt: mahung bollzogen werben.
9. $\S 48(\Re . \S 48)$. Tas Bermảgeri barf ber थnjallberedtigten nidt vor bem Giblaufe eines Эahres nad ber Đelannts madung bet Ruflofung besి Beteines auşgeant= wortet werben.
3. 551. Das Betmogen barfoen Infallberedtigten nidt vor bem Golaufe cines Fabres nađ ber Pelannt. madung bet $\mathfrak{A} u$ fldiung Dess Bereines ober ber Cntitehung ber Medits. fäbtgieit ausgeanttoortet twerben.

\section{Motive 416 f., Protololle 634, Dentfdrift 826 ff.}

I 554.

Sat ein belannter orlaubiget fid nidt gemelbet unb ift bie \$es rehtigung zur off. Sinterlegung vorbanben, to mus bie legtere exfolgen.

P̃ann bie Befriebigung eines

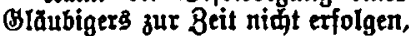
fo barf bie Bertheilung bes ger= mögens unter bie Mitglieber erit vollzogen werber, nadibem bem Brlăubiger Siderbeit geleiftet toorber if́t; es gilt bieg itşbej. in Anjegung nod jurwebenber ober ftreitiger Betbinblidpletter ber ภ̄örpería

\section{II $\S 47$.}

Sal ein betanter Blănbiger fi⿱屮 nidst gemelbet, jo ift ber $€$ dulbs betrag, twenn bie \$ereळtigung zur Finterlegung vorbanben ift, ju hinterleger.

Sft bie Befriebigung eines B̂lăubigers zur Beit nidjt auß̧s fâhrbar, fo barf bas Bermögert ben Anfallbereditigten nut augs geantwortet werben, weul bem (s) Iaubiger Eimerheit geleiftet worben ift; bies gilt ingbef. in Inffehung fumebentber ober ftreitiger Betbindlidjleiten.

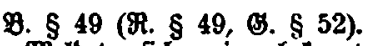
Delbet fid ein befannter Gläubiger nidit, io ift ber geo ¡nulbete Petrag, wenn bie Be. redtigung zur Ginterlegung bors Ganben ift, für ben Clâubtger zu Ginterlegen.

अft bie Berloftigung etnet Berbinbltbltit zur Beit nidt auss. filfrbar ober ift eire Berbindlidleit ftreitig, fo barf bas Bermágen bert Infalliberedtigter nur augeants twortet werben, twenn bem (SIăubiger Eiderbeit geleiftet ift.

glotive 416 f., Frotololle 634 fi., Dentidifift 826 fi.

$$
I \S 55(\Pi-, B .-, \text {. }-, G .-) \text {. }
$$

Ergiebt sich, dass das Vermögen überschuldet ist, so sind die Liquidatoren verpfichtet, unverzüglich die Eröffinug des Konkurses zu beantragen.

Mlotibe -, Brotololle 636, Dentihìift 826 fi.

I $\S 56$.

Siquibatoren, welde bie nam ben $\$ \$ \$ 2$ bis 55 ifnen obliegenben Betpflidturgen verlepen ober aus Borfaß ober fahrláfígleit Bermögelt unter bie Mitglieber vor Pefriebigung ber Gläubiger ber= theilen, haften ben Blăubigetr für ben Exją bes

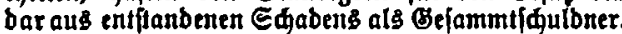

Dotive 417, Frotololle 636 f., Dentfdrift 826 ff.

$$
I \& 57(I I-, B .-, B .-, \theta .-) \text {. }
$$

In Ansehung des Konkurses über das Vermögen einer Körperschaft finden die Vorschriften der $\$ \$ 193,191$ der KonkO. entsprechende Anwendung.

\section{Motive 417.}

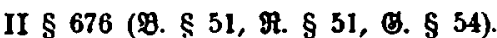

[I lehit].

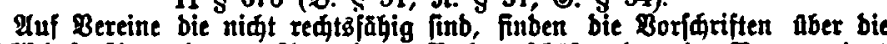

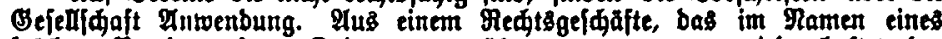
polden Bereines einem Dritten Begenuber borgenommen toirb, haftet ber Sanbelnbe perfönlid; Ganbeln Mebrete, fo haften fie als Brefammifidulbner. Motibe -, Prototolle 637 fi.

\section{Cingetragene Bereine.}

II $\$ 40$ ( $(8 . \$ 52, \Re$. § $52, \bigotimes . \$ 55)$

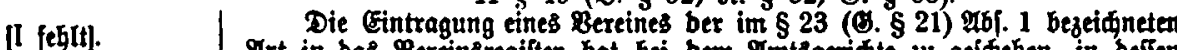

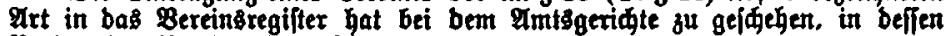
Bezitte bet Berein feinen Silb hat.

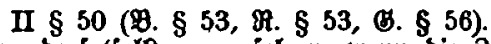

[I feglit]. minbejtens 7 betråg.

$$
\text { Potibe -, Protololfe 6+3. }
$$


[I feğ[t].

II $\S 51$ (B. § $54, \Re . \S 54$, (s. § 57).

Das Statut (bie Sałung) muß́ ben 马wed, (ben Namen) und (ben Sis bes Bereines enthalten unb ergeben. baß ber Perein eingetragen werden joll. Der game foll fín von ben Namen ber an bemfelben Drte ober in ber: pelben Bemeinbe beftehenben eingetragenen Bereine beutlid unterfdeiben. Diotibe -, Brototolle 644 f.

II $\$ 52$.

Tas Єtatut foll Beftimmungen ent= halten:

1 aber ben Cintritt und Austritt ber Mritglieber;

2. Daritber, ob unb toelde Beitrăge bon ben Mitgliebern zu Ieiften fittb;

[I feglt].

II fegltt].

[I feglt].
3. Itber die Bilbung bes Boritanbes;

4. Ither bie Borausjebungen, unter welden eine Berufung ber Mtit= glieberberiammlung ju erfolgen hat, über bie Form ber Perufung fowie fiber bie Beurfundung ber in ber Beriammlung gefaß̄ten Befdlüfle.

Motive -, Brototolle 645 .
II $\$ 53$.

Der Borftand hat ben Berein bei bem Amtछ̊ge= ridte zur Gintragıng ant= zumelben.

Der Anmeloung find beizuffuggen:

1. Das von minbeftens 7 Dritgliebent unter: zeidnete Statut unb eine थbiarift bes= jelben:

2. ein Berzeinnif ber Mitglieber:

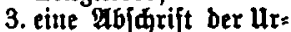
humben uber bie Beftel= lung bes Boritanbes.

$$
\text { Protive -, Protololle } 645 \mathrm{f} \text {. }
$$
antzumelbett. beizufügen: (EQDD. itatt.
タ. § 55 (9. §55, \&. § 58). Die کaßzung foll Beftimmungen enthalten:

1. Aber ben Eintritt und Austritt ber Mitglieber;

2. Darilber, ob und weldje Beitrăge von ben Mritgliebern gu leiften fint;

3. Aber bie Bilbung bes Borítandes;

4. uber bie Borausjesungen, unter benten bie Mitglieberber\{ammlung zu berufen ift, über bic frorm ber Betufung und über bie $\mathfrak{B e}$ urtunbung ber $\mathfrak{B}$ ejaliuffe.
II \& 54 .

Die Anmelbung ift. twenn ben Erjorbermifient ber $\$ \S 50$ bis 53 nidt gentügt ift, bou bem $\mathfrak{R m t g .}$ geriate unter Angabe ber Granbe zurüdzitweilent ;

anberenfalls ift fie ber nad ben Lanbesgefesen zuftänoigen Berwaltungs: behörbe mitzutheilent.

II $\$ \mathbf{5 5}$.

Die Berwaltungsbe= hörbe lann gegen bie Ein= tragung Einjprud erbe

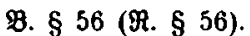

Der Borftalt hat ben Berein zur Fintragutg

Der Onmelbung finb

1. Die Eakung in $\mathbf{u} \boldsymbol{r}$

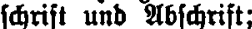

2. ein Verzeichniss der Mitglieder,

3. eine $\mathfrak{A b j} \dot{\text { rift }}$ ber $\mathfrak{U} \mathrm{r}=$ tunben uber bie Beftel= lung bess Borftanbes.

Die Sabung foll von minbeftens 7 İitgliebern unterzeidnet fein utto bie Angabe des Tages bet Frrifiturg entbalten.

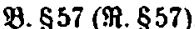

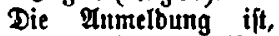
wenn Den Erforberniffen ber $\$ \$ 53$ bis 56 nidgt genügt ift, bon bem $\mathcal{A m t}=$ geridite unter Angabe ber Orranbe jurildguveifen.

Begest einent gurüd. weifenben ஒejaluß finbet bie fofortige Befdwerbe nad Den Borfariften ber

æ. $\$ 58$.

\$irb bie Anmelbung zugelaffett, fo hat bas Amtgigeridit fie ber zus

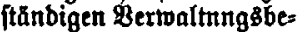
hörbe mitzutheilen.

Die Berwaltungşbe= Görbe tann gegen bie Cin= tragung Ginipruf erhe ben, wenit bet Berein
(3. § 59.

Der Boritanb hat ben Berein Jur Eintragung anzumelben.

Der Anmelbung finb beizufügen:

1. bie 巨agunth in $\mathfrak{u} r$ farift unb शrbiarift;

2. eine $\mathfrak{A} 6 f \dot{b r i f t}$ ber $\mathfrak{u} r$ tunben aber bie Bejtel= lung bes Borftanbes.

Die Sabung foll bon minbeftens 7 Mitgliebern untersetinnet fein unb bie Angabe bes Tages ber Erriatung enthalten.

\section{c). $\& 60$}

Die Anmelbung ift wenn ben Eriorberniffen ber $\$ \$ 56$ bi 59 nidt gentugt ift, bon bem $\mathfrak{A m t s}=$ geriate unter Angabe ber Srinbe zurüdumeijen.

Begen einen zurtid. weifenden Befdlus findet bie fojortige Mejulwerbe nad bert Boridriften ber (EQD. itatt.

9. \$58 (अ. § 61). Mirb bie 2 nmelbung zugelaffen, fo hat bas umtşgeriळt fie ber $\mathfrak{d u}$ ftandigen Berwaltungs: beb̆brbe mitzutheilen

Die Berwaltungsbes hörbe tann gegen bic Ein. tragung Einiprud erbeben. wenn ber Berein nad bem 
ben, went ber Bereint nad bem off. Bereinstreate unerlaubt ift ober berboten twerben tann ober went

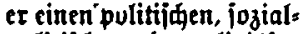
politiijhen ober religiojen Biwed veriolgt.

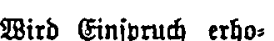
ben, jo hat inn oas Amtsgeriat unter $\mathfrak{A} u s=$ jebung ber Gintragung Dem Borftanbe mitzu= theilett.

Der Cintprum tann im Wege bes Bermaltung: itreitoerfahrens, too ein joldes nidt beftebt, im wege deș Rehurjeŝ nă Máigabe ber $\$ \S 20$, 21 Der BD. angefodtent werbell.

Motive -, Brotololle 646 fi., Sten
II $\$ 56$. bung an bie Bertualtungşbehörbe 6 Woळen abgelaujen unb ift (Fin/prud nidt ergoben, ober twirb ber ergobene Einiprua enbgültig aufgehoben, jo ijt ber Berein tu bas Bereinstregifter einzutragen. Bei ber Eintragung finb ber Rante unt ber Cis bes Bereines. bas Datum beş Statuteş, porvie bie Ditglieber bes Borjtanbes anjugeben. Beftimmungen, welde ben llmiang ber Bertreturtgosmant bes Boritanbes be 低ränien ober bie Beidlubfaffum beflelben abweigenb von ber Boriarift bes $\$ 27$ AbF. 1 regelu, finb glei $4=$ falls einzutragen.

Motive -, Brotololle 646 fi., EtcnYcriate 999
Sind nad Mittheilung ber Pumel=

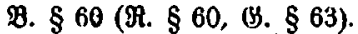

Tie Cintragung barf, lofern ntdt bte Berwaltung Bbehörbe bem Mints. geridte mitthetlt, bas (Einfprud nidit erboben wetbe, erft erfolgen, wenn feit ber Mittheilung ber : Anmelbung an bie Berwaltungşbehörbe 6 Moden verftriagu find unb Einfprud nidt erhoben ober wentl ber erhobente Fin. iprum enbgultig aufgeboben ift.

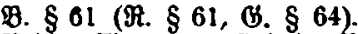

Bei ber Gintragung finb ber Rame unb ber Sib bes Bereines, ber $\mathcal{I a B}$ bet Erridtung ber Satung, jowie bie Dritglieber bes Borjtanbes im Bereinzregíter anzugeben. Bejtim. mungen, bie ben lumfang ber $\mathfrak{B e r}$ tretuingsinnaht bes Borftanbes bes 低răuter ober bie Bejdlubiaffung bes Boritanbes abtoeinend von ber Borfarift beş $\$ 25$ घbj. 1 regeln, finb gleidfalls einzutragen.

\section{II $\$ 57$.}

Nad ber Eintragung ift bas Statut, mit ber Dejueinigung ber= felben berfegen, zurdizugeben. Die Abjarift bes Statutes wirb nah bor: gangiger Beglaubigung fammt ben âbrigen Squiftituden bei Beriat auf: betoahrt.

[I fehlt].
Mit ber Fintragung erbălt ber Name beş Bereineş bie zujăblífe Bezeidnung "eingetragener Berein".

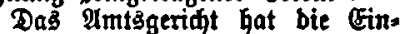
tragung burd bas far feine Belannts madungen beftimmte Blatt ou bers offentlidien.
B. $\$ 63(\Re . \$ 63$, (马. $\$ 66)$.

Das Amtsgerint bat bie Eintra. gung burd bas far feine Betannt madungen beftimmte Platt ou ber iffentlipen.

Die urfarift ber Eaguutg ift mit ber Bejdeinigung ber Cintragung zu beriegen unb zurfidzugeber. Die $\mathfrak{a b}$. ifrift wirb von bem Amtsgeriate beglaubigt unb mit ben abrigen Edriftftuden aufbetoahrt.

B. 562 (M. \& 62, (3. 565$)$.

Mit ber Eintragung erhalt bex Rame bes Bereints ber Bujak neint getragener Berein*.

Mrotibe -, Brotololle 651. 
II $\$ 59$ (श. §64, भ. §64, B. §67).

[I feblit].

[I feglt].

[I feglt].

Motive -, Prototolle 652.

II $\S 61$.

Renberungen bes Statutes bebar: fert zu $^{4}$ ihrer Wixtfamteit ber Cintras gung in bas Bereinsregifter. Die Fenberung ift bon bem Borftanbe an= zumelben. Der anmelbung ift ber bie Fenberung enthaltenbe Beldilus und eine $\mathfrak{A b}$ [drift belíltben beizufügen.

Die 20 orfuriften ber $\$ \$ 54$ bis 57 finber entipreळenbe Irnventoung.

glotive - , Brotololle 652 f.

2. §65 (भ. §65, (3. § 68).

Birb zrijhen ben bişberigent Mtitgliebern bes Yorftandeș unb einem Dritten ein Ređtşgejめăft vorgenom= men, fo tann bie Renberung bez Bors Ptanbes bem Dritter nur entgegenge: febt werben, wenn fie zur Beit ber

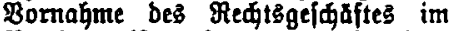
Bereinşregifter eingetragen ober bem Dritten befant ift. Sitt bie $\mathfrak{A}$ enbe: rung eingetragen, fo braudt ber Dritte fie nidt gegen fid gelten zu lafier, menn er fie nidt fennt, jeire untenuts niß aud niaht auf Frahrláffigleit berugt.

2. $\S 66$ (M. $\S 66$, (S) $\S 69)$.

Der Rađmeis, bá́ ber Bortanb aนs bert in Megitter eingetragenen Perfonen befteht, wiro gegorben gegentiber burh eit Beugnip bes

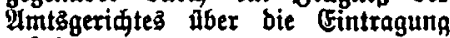
gefulfrt.

P. $\S 67$ (M. $\S 67$, (B). $\S 70$ ).

Die Boridriften bes $\$ 65$ gelten aud fâr Beftimmungen, bie ben $\mathfrak{u m}=$ fang ber Bertretung Bamant bes Bor:

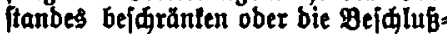
faffung bes Boritanbes abroeidenb bon ber Borfinrift bes $\& 25$ Abf. 1 regeln.

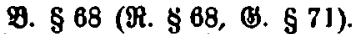

Menberungen ber Satumg bebürfen zu ihrer Birflamleit ber Cintragung in bas Bereingregifter. Die Menbes rung ift von bem Borftanbe zur Ein: tragung anzumelben. Der Anmelbung ift ber bie Menberung enthaltenbe Bejकlus in urf beizufiggetr.

Die Boridriften ber $\$ \$ 57$ bis 61

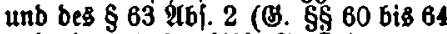
unb bes $\$ 66$ भbf. 2) finben ent. [prediente $\mathfrak{A}$ nwwertoung.

II $\S 62(\mathfrak{O} . \S 69, \mathfrak{R}$. 89 , (B. \& 72$)$.

[I fehtu]. Der Boritanb hat bem Imtsgeridte auf befien Berlangen jeberzeit ein Berzeiđnic ber Bereingిmitglieber einzureiden.

Potibe -, Brotololle 651.

II $\S 63$ (B. $\$ 70, \Re . \S 70)$.

Sintt bie 8 ahl ber Bereinsimit. alieber unter 3 herab, fo hat bas AmtB gerict auf Intrag bes Borftarbes unb, meen ber Antrag nidt binuen 3 Monaten geftellit wirb, von 9 imt:
(8). 573.

Sinlt bie 8ahl ber Bereinsmit. gliteber unter 3 herab, io hat bas Quntşgeriatt auf Antrag bes Borftanbes unb, went ber Antrag nift binnen 3 פonater geftellt wirb, volt 2 mts 
wegen naळ Anhỏnung bes Bortanbes

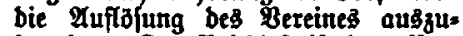

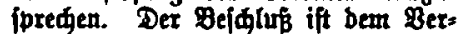
eine zuzultellen. Gogen ben Bejळluß finbet bie jojortige Befdwerbe nad ben Borjuriften ber C\&D. ftatt.

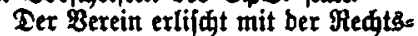
fraft beș Bejăluffes.

Dotibe -, Protololle $653 \mathrm{f}$.

II $\S 64$ (P. § 71, M. § 71).

Die $\mathfrak{A}$ uftofung bes Bereines ift in bas Bereinsregifter einzutragen, fofern fie nidht in Yolge ber Cröfintung bes Tonturfes eintritt

\$itrb ber Perein burd Beílu ber Mitglieberberfammlung ober burh ben Ablauf ber für die sauer bes Bereines beftimmten Beit aufgeloft, jo Gat ber Borftand bie $\mathfrak{A}$ fflojung zur Eintragung anzumelden. Der $\mathfrak{A} n=$ melbung ift im erfterent falle eine

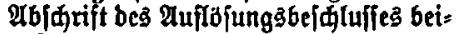
zufanen.

girb ber Berein auf Brumb bes $\$ 40$ ober auf Branb beg off. Bereing: redi)tes aufgeloft, fo erfolgt bie (Fin: tragung auf Angeige ber zuitanbigen Beförbe.

Motive -, Protololle $656 \mathrm{f}$.

II $\S 65$

Die Eröffnung bes Ronturies utfer bas Permiögen bes Bereines ift bon Amtsిwegen einzutragen. Das Oleiळe gilt von ber $\mathcal{A}$ ufhebung bes $\mathfrak{E}_{\text {r: }}$ dffnungsoejuluifes fowie von ber Gunftellung unb Âfbebung beș Pon= turies.

Motive -, Protololle $656 \mathrm{f}$.

II $\S 66$.

Die Riquibatoren find in bas Bereinstregifter einzutragen. Das Bleide gill bon Beltintnungen, welde

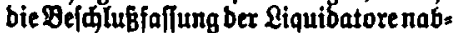
weidenb bon ber Boridrift bes \$ $4390 \%$. 3 regeltr.

Die Anmeloung fat bura ben Borftanb, bei fpateren Nenberungen burf bie Riquibatoren zu. exfolgen Die Cintragung geridgtlid beftellter Ltquibatoren ge 向ieht bon Amtsmegen.

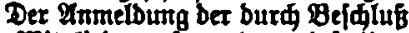
ber Mitglieberberfammlung beftellten Liquibatorent ift eine 26 fifrift bes

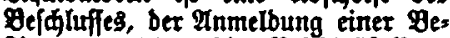
fimmung tber bie Bejulusfaffung

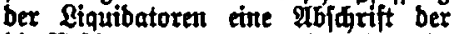
bie Beftimmung enthaltenben urfunto beizufifgen.

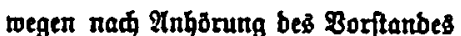

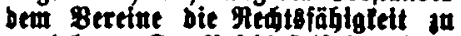
entateben. Der Beidlus ift bem $B$ er: eine zuzuftelfen. Bsegen ben Bef hlü finbet bie fofortige \$ejanerbe na ben Boridriften ber CQD. ftatt.

Der Berein berltert bie Medt8. fähiglett mit ber Med̆tötraft bes $\mathfrak{B}_{e}=$ ¡ંluffes.

\section{(3. $\$ 74$}

Tie Ruflofung bes Bereines fowie bie Cntjiebung ber Redtafäh tofeit ift in bas Bereinsoregifter einjutragent. Im falle ber Eröfnung bes \$onturię unterbleibt bie cintragung.

Mirb ber Berein bura Đejめlū ber PRitglieberberfammlung voer burf bet Rblauf ber für bie Dauer be Bereines beftimmten Beit aufgeloft, fo hat ber Borftand bie

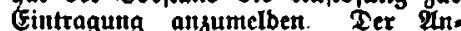
melbung ift im eriteren fralle eine

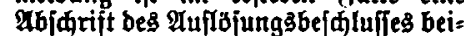
zufulgen.

खirb Dem Bereine auf Brund bes $\$ 40$ bte Reatsfäbtgleit entzogen ober wirb ber Berein auf Grunb bes off. Bereinsirechtesె aufgelöft, fo erfolgt bie Eintragung auf Ângeige ber zuftảnbigen Befojoe.

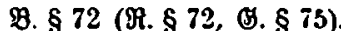

Die Eroffinung bes Ronfuries it von Amtsinegent cinsutragen. Das Bleide gill bon ber Aufbebung beš Croffmungsbefकlu|fes.

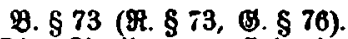

Die Qiquibatoren finb in bas Bereingregifter einzutragen. Das Bleide gill bon Beftimmungen, welde bie Befălufffaffung ber Liquibatoren abreidenb bon ber Borfdrift bes $\$ 45$ abf. 3 (\$ 48 थ6F. 3) regeln.

Die Anmelbung hat burd ben Borftanb, bet ipdteren Menbenungen burd bie \&iquibatoren zu erfolgent. Der Anmelbung ber bura Befğlnf ber Mitglteberberjamming bejtellten Liquibatoren ift eine $\mathfrak{A b}$ intift bes Befoluffes, ber Inmelbung einet Beftimmung aber bie Bejळlubfafiung ber Siquibatoren eine 96 fartift ber bie $\mathfrak{B e f t i m m u n g}$ enthaltenben litumbe beigufingen.

Die Gintragung getioftlic beftetlter Liquibatoren gefdicht bon Sintsivegen.

Rotibe -, Protofolle 656 f. 
II $\$ 67$.

[I feglt].

[1. fefili].

[I feglti].

I 58.

Bur Crrifitung einer mit jur. Gerjönlidiltit veriegenent Stiftung burd Pechtogeidaft unter $\mathcal{L C}_{\mathrm{e}}$ benben ift erforberlid, baß Der Etifter ben auf Er: ridiung ber Stiftung ge rioteten Billen in geri出ts liaer ober notariellerfform ertlått. Der Stifter ift an bas bit Erridtumg bezwedenbe Meditsgeidadft gebumber, aú wettr mur feine cinjeitige, nidt an= genommene Willensertlă: rung vorliegt. Er if berpflidtet, ber Stifturg bas in bem Medits gefdafte zugefíterte Bermögen zu ubertragen; Bermögens: refte, zu beren lueber: tragung ber Yjotretungs: bertrag gentagenb ift, geben mit Erridtung ber Stif= tung auf bie lestere aber, wenn ber Gierauf geridtete gBille aus bem bie Erridtung ber Stiftung bes bodenber Rechtogejuafte fin ergiebt. Anuf bie Be:

II $\$ 69$. $\$ 66$ angehalten werber.

II $\S 69$.

II $\$ 70$ (9. 77).
II \& 71 .

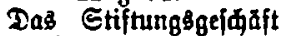
unter Rebenden bedarj ber geridtliden ober notaris eDen Beurtunbung.

Solange bie ftatlide Benehmigung nidtertheilt ift, fteht bem Etifter ber Padutritt offer. Sit bie Benelgmigung bei ber $34=$

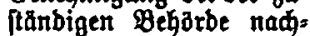
gefudt. fo tanu ber Radd= tritt nur biejer gegenüber extlart werben. Stirbt ber Stifter nad Ginreidung bes Befunes, fo lömnent bie Erben niकt zurads treten.

Die Anmelbungen zum Bereins: regifter fint bon ben MRitgliebern bes Borftantoes forwie von ber \&iquibatoren perjonlich ober mittels öfientlid bes glaubigter Ertlănung zu betwirten.

Motibe -, Protololle $656 \mathrm{j}$.

Daş Amtsgeriaht tann bie Mits glieber bes Poritanbes zur Befolgung Der Borjuriften beż $\S 59$ $\mathfrak{A b}$. 1, beş $\$ 61$ थb 1 , beg $\$ 62$, beg $\$ 64$ Ab $\{.2$ und bes $\$ 66$ butc Dronungs: fitrajen biş zu 300 . MR. anhalten. $3 n$ gleiđer $\mathfrak{B e i j e}$ tönnen bie \&iquibatoren jur Befolgung ber Borfintifter bes

Motive -, Prototolle $656 \mathrm{i}$

Das Bereinsregifter ifit affentlim.

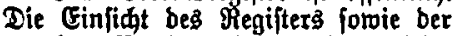
von bem Bereine bei bem 21 mägeriøte eingereidften Sadriftitade ift mäbrenb ber gewoabulliden Dienftítunden Jebem gef́tattet. Bout ben Eintragungen fann geger Erlegung ber ßoften eine $\mathfrak{A b j a r i f t ~ g e f o r b e r t ~ w e r b e n ; ~ b i c ~} \mathfrak{A b}_{3}$ ifrift ift auf Berlangen zu beglaubigen.

Motibe -, Protololle $656 \mathrm{f}$.

\section{Etfitungen.}

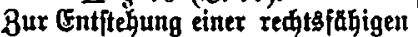
Stiftung ift aufer bem Stiftung

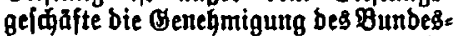
itaates erforberlia, in befien Bebiet Die Stiftung ifren Eis haben foll. Als Sib einer Stiftung gilt, went nidit ein Inberes erhellt, ber Drt, an weldem bie Berwaltung gefubrt roirb.

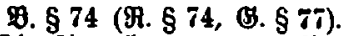

Die Anmelbungen zum Bereing regifter find bon ben Mnitgliebern bes Borftanbes forwie von ben siquibatoren mittels offentlid beglaubigter $E_{x}$ : tlărung zu bewirtent.

9. $\$ 75(\Re . \$ 75$, (3. $\$ 78)$

Tas Mmtsgeridtt tann bie Mit= glieber bes \$orftandes zur Befolgutg Der Boridriften bez $\$ 64$ Ibf. 1. bes $\$ 68 \mathfrak{A b}$. 1 , bes s 69 , bez \& 71

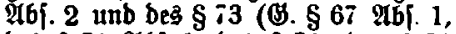
bez $\$ 71$ थ6 1 , bes $\$ 72$, bes $\$ 74$ Ab .2 und bes $\$ 76$ ) burd Dromung fitrafen angalten. Die einzeltre Strafe barf ben Betrag von 300 M. niđt atberiteigen.

Jn gleider $\mathfrak{B e i j e}$ tönnen bie Rtquiba: toren zur Bejolgung ber Bor[driften bes $\S 73(\$ 3 . \S 76)$ angetgalten werben.

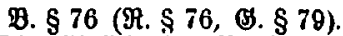

Die (Einfint bes Bereinsregifters jorvie ber bon bem Bereine bet bem Amtageriate eingereiditen Shriftitude ift Jebem geftattet. Bon ben (Ein= tragungen fann eine 206 jकrift geforbert werben; bie פabjarift ift auf Ber= langen zu beglaubigert.

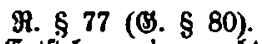

Bur Entftehung einer redtsfähtgen Stifung ift auber bem Stiftung: geidăfte bie Benehmigung bes Bunbes: paates eriorberlia, in befien Bebiet bie Stiftung ithren Sib haben foll. Soll bie Stifung thren Sip ntwt in cinem Punbegftate baben, fo ift bie Genehmigung bes Bunbegrathe ex. forberlth. भifs Sib ber Stiftung gilt. wenn nidht ein भinberes beftimmt ift, ber Ort, an weldem bie Bentwaltung gejabst mirb.

9. $\S 78(\Re . \& 78)$

Das Stiftungasgef unter \&ebenben bebarf ber geriditifien ober notaris ellen Beurturibung.

Bis zur Ertheilung Der ftaatfiden Bentehmigung ift ber Etijter zum 28 ibers rufe beredtigt. צif bie Bentegmigung bei ber zus ftånbigen 9 equrbe nad: gefudt, fo tann ber 2 iber: nuf nur biejer gegenaber ertlärt merbett. Der Crbe beż Stiftergె ift zum giberrufe nidt beredtigt, wenn ber Stifter bas Befú bei ber zuftändigen
ब. 581 .

Das Stiftungsgeiđafft unter Lebenben bebarf ber Ifrtiftltaen frorm.

Bis zur Ertheitung ber OSenebmigung ift ber Stifter Jum Wibernife berewtigt. Fit bie Bs: nefmigung bei ber zu= itänbigen Begarbe nad. gefunt, fo tann ber 29 iber= ruf nur biejer gegentaber ertlart werben. Der Erbe bes Stifters if zum gibernufe nidt beredigt, went ber Stifter $b a \delta$ Befud bei ber zuftantigigen Behobrbe eingereidat ober 
wobrrleiftungspfliqht bes Stifters finben bie Bor: \{Griftert aber bie Berolat:

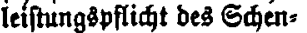
ters entipredienbe $\mathfrak{A n}^{\mathrm{n}}$ : wenbung. extheilt, 10 ift ber Stifter berpflidtet, ber Stiftung bas in bem Stifungs: gejđăfifte zugejiđerte Ber= mögen zu fibertragen. Feate, zu beren lueber= tragung ber $\mathfrak{A}$ btretungs: bertrag gentigt, gehent mit ber Benebmigung auf bie Stiftung aber, fofern fi千 niđt aus bem Stiftungs: gejajafte ein anberer 281 Ile bes Stijters ergiebt.
Bef̧rotbe eingereidgt ober bei ober nad ber Beur= hunbung bes Stiftungs: geldaftes bas (seriat ober ben Notar mit ber Ein= reidung betraut hat.

円. \$79 (円. \$79).

\$irb bie Stiftung ge= nehmigt, fo ift ber Stifter verpfliutet, bas in bem Stiftungszgejađafte zuge: fiderte Bermőgelt auf bie Stijtung zu übertragen. Pedite, zu beren lueber tragung ber abtretung vertrag gentagt, gehen mit ber Benehmigung auf bie Etiftung laber, fofern niat aus̄ bemstiftungşgejăăfte fid ein anberer $\mathfrak{B i l l e}$ bes Stifters ergiebt. im Gralle ber geriflliden ober natariellen Beut: tunbung bes Stiftungs: gejđăffteş bas Heriđt ober ben Rotar bet ober naf ber Beurtumoung mit ber ( Einreiăung betraut băt. B. $\$ 82$.

WBitb bie Stiftung ge: nehmigt, fo ift ber Stifter verpfliatet. bas in bem Etiftungägejđāfte zuge: fínerte Bermögen auf bie Stiftung zu übertragen. Reatte, zu beren lleber: tragung ber Abtretungs: bertrag genligt, gehen mit ber Genehmigung auf bie Etiftung uber, fofern nid, aus bem Stiftungsige= fadjite fí ein anberer I æille bes Stifters eraiebt.

Mlotive 417 f., Protololle 657 ff., Dentfdrift 831 f., RumBeridt 861 f., StenBeridte 1023.

I $\$ 59$.

Cine Stiftung fann aud buxณ eine Berfügung bon Tobeşwegen, in welder bet Grblaffer ben auf Errítung ber Stiftung geribteten פBilfent erllårt, erridtet werben.
II $\$ 72$.

Befteht bas Stiftungsgeidăaft in eiter Berfugung von Tobes= wagen, fo ift bie Benehmigumg. fojern fie niaht bon ben Erben ober

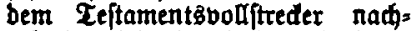
gefunt wirb, bura bas Mađlaf: geriat einguholen.
B. $\$ 80$ ( 9.880 , (5. $\$ 83$ ).

Beîteht bas Stiftungảgejđäft in einer Berflaung bon Zobes megen, fo hat bas Rahlapigeridt bie B̀enehmigung einzuholen, fofern fie nidht bon bem Erben ober bem

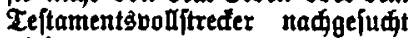
roirs.

Motibe 418 f., Protololle 657 ff., Dentf

I $\$ 60$.

Die Berfaffung einer Єtiftung wirb, jomeit fie

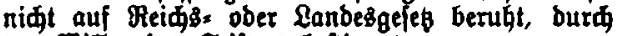

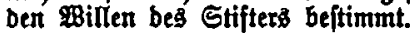

Mtotive 419, Brotololle $664 \mathrm{f}$., Denlidrift $831 \mathrm{f}$.
I $\$ 61$.

Die Boridriften bes $\S 44$ abf. $1,2,4$ bis 7, beg $\$ 45$ Sas 1 , bet $\$ \$ 46,47$, be $\$ 49$ शb. 1 , פbf. 2 Sał 1,2 unb bes $\$ 57$ finben ouf Etiftungen entpredyenbe Antwentung.

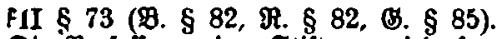

Die Berfaffung eitter Stiftung wirb, foweit fie nidt auf Fteiфż= ober Ranbesgejes beruht, burd bas Gtiftungsgef Gäft beftimmt.
II $\S 74(\mathfrak{B} . \S 83, \mathfrak{R} . \S 83$, B. $\S 86)$.

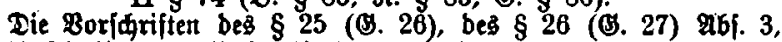

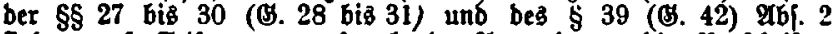
finben auf Stiftungen entipredenbe Pnwenbung, bie Borfariften bes $\$ 26$ (B. 27) 96j. 3 unb bes $\$ 27$ (B. 28) $\mathfrak{4 6 f} 1$ jebod mur infoweit, als fín ridt aus ber Berfaffung. insbef. baraus, baß bie Berwaltung ber Stiftung von einer öf. Bebärbe geflugt wirb, ein Q⿴囗十) unb be\$ $\$ 28$ (\$. 29) finben auf Stiftungen, beren Berwaltung von eiter off. פeförbe gefuhrt wirb, teine Antenbung.
II \$ 75.

Mit bem Gilofipen ber Stif: tung fallt bas Bermỏgen an bies jertigen, welde burd bie Bexfaffung als anfallberedigt beftimm fins.

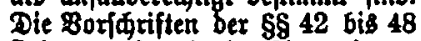
finber entprediente Intwenbung.

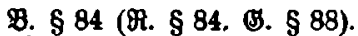

Mit bem Erlöhen ber Stiftung fallt bas Bermögent an bie in ber Bexfafiung beftimmtert Berfoner. Die Borfutriften ber $\$ \S 43$ bi $\$ 50$ (B. 46 bis 53) findent entfpredenbe Inwenbung.
Mrotive 419, Protololle 666f., Denthdrift 831 f., Romberiđt 962 f.

PomBorlage $\$ 83$ a (B. $\$ 87$ ).

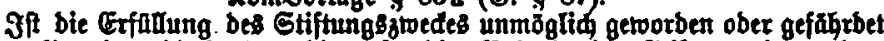
fie bas Semeinwohl, fo lann bie zuftanbige Behörbe ber Stiftung eine anbere

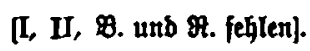
Brwedbelimmung geben ober fie autheben.

Bei ber umbanblung bes Brvedes if bie Mbfidt bes Etifters thunliqf zu berldfidhtigen, inbofef. bafar Sorge zu tragen, baß bie Ertrăge bes Stiftungobermbgents bem Berfonentreife, bem fie zu Statten tommen lollen, im Sinne bes Stifters thunliagt ergalten bleiben. Die Bebörbe tann bie 
$I \$ 62$.

Die Ianbeşgeleblithen Bor: (đ̈riften, nad welden bie Erridtung einer Stiftung bon nod anberen Erjorberniffen als bem im \& 58 Sas 1 und im \$ 59 bezeidneten Erforberniffe abblangt, forvie bie: ienigen, welde fin auf bie $E_{x}=$ ridtung einer Stiftung mittels Staatsalted unb auf bas Erlöfden bet Stiftungen bejiehen, bleiben unberubrt.

Sft zur Erridtung einer Stif:

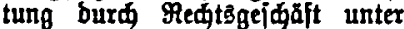
Rebenben ftaatlide Genehmigung exforberlid, po it ber Stifter an Das bie Errifturg ber Stiftung bezrodenbe Red,tsgefad exit von bem 3eitpuntte an gebunben, in weldem ex bie ftantlide (S) enehmis gung nadjudt; mit Berjagung ber Benehmigung hört bie Be= Gunbentheit auf.

Sit sur Enridung einer Stif= tung burd Berfigung von Tobes: wegen ftantlide Genthmigung ex= forberlia, to wirb bie Berfllgung bon Tobestwegen burd Berjagung ber Benefgmigung untwirtfam; toirb bie Benehmigung ertheilt, fo gilt fte in 2njehung bes 2 Infalles als f́on vor bern Exbfalle extheilt.

Motive 419 ff., \$rotololle 658 ff.. PomPeriate 961 f.

I $\$ 63$.

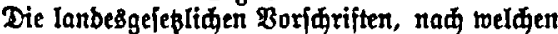

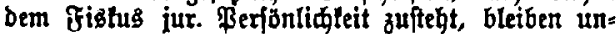
berabrt.

(Sieh̆e zu I § 58).

II $\S 72 \mathrm{a}$.

Pirb bie Etifturg exft nah Dem Tobe bes Stifters genchmigt, io gilt fie in Anjegung ber $84=$ wenburgen bes Stifters als füon vor beffer Tobe entfitanber.
[BgI. EFG. B. Qtrt. 60, ร. XIX].

D. § 81 ( $\Re . \S 81$, (G. $\$ 84)$

2girb bie Ettiftung ext naw bem Tobe bes Stifters genehmigt, jo gilt fie für bie Buwenbungen bes Etifters als fidon vor beffen Tobe entftander.

Dotive 421, Prototolle 670 fi., Denllidrift 832 , Stemberidte 982 ff.

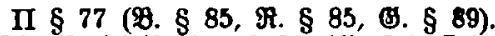

Die Borfuxift bes \&30 (\$. 31) finbet allf

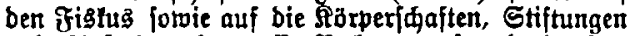

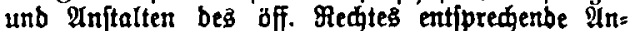
twenbung.

Das Blcidbe gilt, forweit bei Äörperídaften, Stiftungen unb anftalten bes iff. Rewtes ber

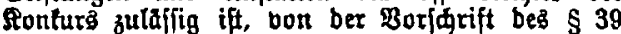

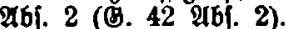

\section{Rechtsge[dafte. Gefăäftsfähigzeit.}

I $\S 64$.

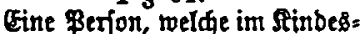
alter ftebt, tht gefifaftsunjabig.

Daffelbe gilt von einer Peton, welde bes Sernunftgebraudes, wenn and sur vorabergeheno, beraubt ift, filt bie Dauer biefes Buftanbes, ingleiden bon einer Berfon, welde wegen Beiftes: trantheit entmandigt ift, folange bie Crimandigung befteht.

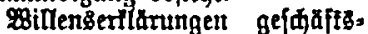
unfabiger Berfonen fins niditig.
II $\$ 78$.

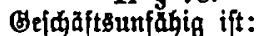

1. wer bag 7. Lebengjagr niđt vollenbet hat;

2. wer fin in einem Buftanbe trankafter Stönurg ber Beiftestba tigfeit befinbet, burm

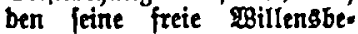
ftimmung auşge

3. wer wegen Ëeiftestrantyeit entruanorgt ift.

\section{879.}

Die æillensertlărung eines

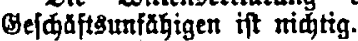

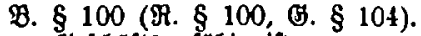
Breidaftsunfăgig ift:

1. wer nidt bas 7. Lebensjabr vollendet hat;

2. wer fin in einem bie freite

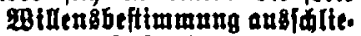
Eenben $\mathbf{3}$ uftanbe franthafter Stonung ber Beiftestadtigteit befinbet, fofert nidit ber Buftaub feiner gratur nad etit voribbergehenber if ;

3. wer wegert Eseiftestantheit entmanbigt iff.

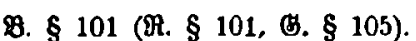

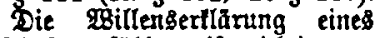
Bejđăftøunfăhigen ift niळtig. 
Ridjtig ift aud eine Moillens: extlănurg bie in guftambe ber Bewufitlofigiteit abgegeben wirb.
Ptidtig ift aud einte $\mathfrak{B}$ illengs: extranung, bie im Buftanbe ber Oetoufitlofigieit ober borüber. gehenber Etörung ber Beiftes. thätiglett abgegeben wirb.

SRotive 423 f., Brototolle 673 f., Somberidt 963.

$I \& 65$.

Ein MRinberiastriger, welder bag̊ 7. Lebenşiahr zunưfgelegt

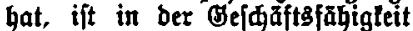
bejuräntt.

Er ijt făhig zur Bornahme

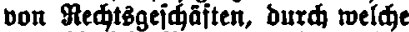
tr Iesiglid Medite erwirbt obex lebiglid von Berbindlidteiten be= freit twitb.

Bur Bormabme von Medts= geidăften anberer Prt bebarf er ber Eintwilligung bes gelęfidien Bertreters. Feglt biefes Er: forberni $\bar{\beta}_{\text {, }}$ fo ift bas einfeitige

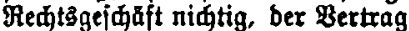
zwar galtig, bie witffamteit bes: felbett aber von ber Coenefmigung Des gejęliduen Bertreters ab̧ängig; bie Bsenebmigung forvie beren $\mathrm{ger}=$ weigerung lant nur gegentuber Dem amberen Bertragidlitentiben erflärt merben.

Solange bie Brenehmigung niळt berweigert ift, tann ber anbere Bertragídiȩ́enbe aud mit $\mathbf{B}^{\mathfrak{u}}=$ ftimmung bes Minberiăhrigen bon bem Bertrage nift juriadtreten.

IIS Berweigentmg ber Bese nehmigung gilt es, wesn bem anberen Bertragldiliefiendert un. geadtet einet von ifm an ben gefeslidien Bertreter exlafienen Áffiorberung innergalb einer vom Cmpfange berfelbent zu beredgnenten Frift bon 2 פoden eine beftimmte

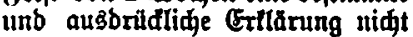
zutommt.

Sat ber Minberiåtrige bie un,

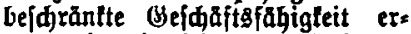
langt, io tritt feine Genehmigung an bie Stelle ber Benehmigung bes gejesliden Bertreters.

II $\S 80$ (P. § $102, \Re . \S 102$, (O) § 106).

Gin Minderjăbriger, welder bas 7. Reberesjaht vollendet Gat, ift naw 9 Rafgabe ber $\$ \$ 81$ bis 87 (3. 107 bis 113 ) in ber ses

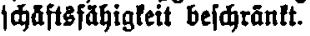

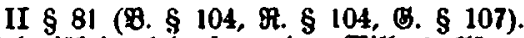

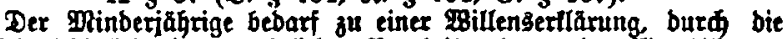
er nidit lebiglid einen redtliden Bortheil exlangt, ber Einmilligung cirtes géfeglidien Bertreters. 5

$$
\text { II } \S 82 \text {. }
$$

Sat ber Minberjăhrige einen Bertrag ofne bie etforberlide Einnilligung bes gefebliden Ber, treters geidiloffen, fo hăngt bie פsirtjamieit Des Bertrages von ber Bentefmigung bes Bextretersె ab. Tie Benegmigung fotwie berent Berweigenung tant nur bem anberen Theile gegenaber ertlătt werben. Der Berroeigenung fteht es gleid, went ber Bertreter ná (Empiang einer Afuforberung besె anberen Theiles nidt binnen 2 פoden bie Ëenehmigung extrart. Yjt ber Minberjagrige in= zroifं getworber, fo tritt feine Bes nebmigung an bie Stelle ber Be= nehmigung beb Bertreters?

II $\$ 83$.

Solange ber gejeglide Ber: treter ben Bertrag niđt genehmigt hat, lann ber anbere Theil zurild: treten, es lei benn, bā̄ er bie Minberiăbrigleit ober ben Mangel ber bon bem Minberjahrigen bes haupteten Einwilligung bes Bers treters bei bem Mbidiluffe bes Bertrages gelannt bat. Der Rutdtritt fann aux bem Mtinberjăhrigen gegenáber extlart werben.

II $\& 85$.

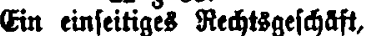
weldes ber Pinberiafrige ohne bie erforberlidge Einvilligung bes gejestidien Betreters vomumt, ift untwirtiam. Minmt ber Minbers iăhrige mit biefer Eintwilligung ein poldes Pledtsgejwaft einem Anberen gegenaber vor, fo ift bass
9. § 104 (R. § 104, (8. § 108). Éfliest bet Mpinderiădrige einen Bertrag ohnte bie erforder= lide Einwilligung bes gejeslidien Bertreters, fo băngt bie \$irtiam= leit bes Bertrages von ber Bes nehmigung bes Bertreters $\mathfrak{a b}$.

Forbert ber andere Ibell ben Bertreter jur Crilarang über bie Betrebmigung auf, fo tann bie Ertlănang nur igm gegenaber er: folgen; eine vor ber gufforberung bem gininberjä́grtger segenüber ettlätte Genebmtguag ober Bet. welgerung ber Genelgmigung witb unwirffan. Die Eienehmigung farm mur bis zum Mblaufe bon 2 28oder naw bem Empjange ber भufforberung extlărt werben; wirb fie nidit entlatst, fo gill fie ats verweigert.

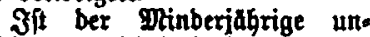

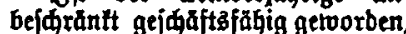
io tritt jeine Benehmigung an bie Etelle bet Benehmigung beß Bet* treters.

श. § 105 (भ. § 105, (5. § 109) Bis zur Benehmigung bes $\$$ trages ijt ber anbere Theil jum

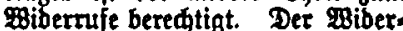
ruf Iarn oud bem פinberjăgrigen gegenlber ertlart werben.

Jat ber anbere Theil bie Minberiảbrigleit gefannt, fo tann ex nut wiberrulen, wern ber gitinbet. iơbrige ber \&afrbett juwiber bie Etamintgung bes Pertreters be. Gouptet hat; er tann aú in biefem falle nidt wibernufen, wern ihm bas Fehlen ber Einwilligung

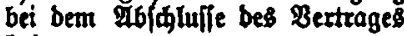
betannt war.

9. \& 107 (श. § 107, (9. \& 111). Ein cirleitiges Preditsgefdaft, bas ber MRinberjobrige ohne bie exforberlide Ginwilligung bes ges feblifien Bertreters bortimmt, if unwirtiam. glimmt ber Minber. jabrige mit biejer Ginwilligumg

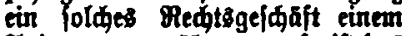
anberen gegeruber vor, fo ift bas 


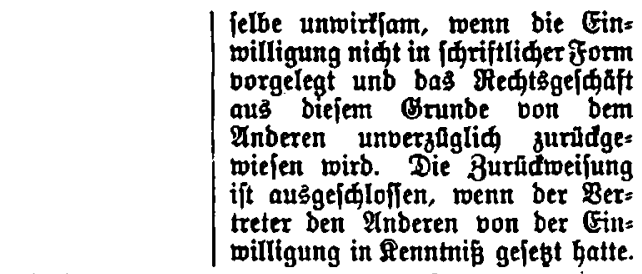

Me丸tsిgejळăfit untwirflam, wenn ber Minberiăbrige bie Cinwilligung nidt in furtifliager form borlegt

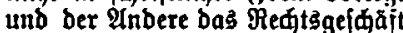
auș biejem (Grunbe unverjüglia) zuradweift. Die Buriftweipung ift auşgeidlofien, went ber $\mathfrak{B e r}=$ treter ben Anberen von ber Ein= willigung in Penntni gejest hatte.

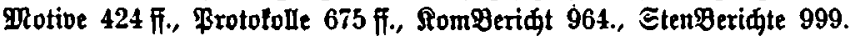

I $\$ 66$ (fiéfe II $107 \mathfrak{A b}$. 3 bei I $\$ 74$ ).

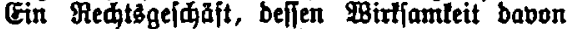
abhångt, baf es gegentiber einem Betheiligten bor= genommen wirb, ift unwirlfam, wenn bie \$ormahme gegenftber einer gejめăftşunfähigen Berjon exfolgt.

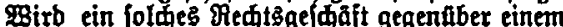

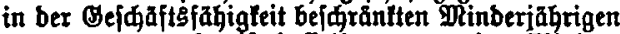
vorgenommen, jo ift baffelbe, wern ber phinber:

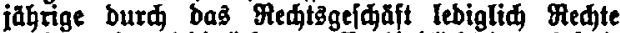
ervirbt ober Iebiglid bon Berbinblidteiten befreit wirb. wirtiam, anberenfalls untwirlfam. Bertrags:

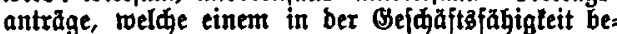
fătăntten Minberjăgrigen gemađ̆t merben, finb binbenb.

Mrotive 428 fi., Brototolle $680 \mathrm{f}$.

I \& 67.

Ein Pinberjăhriger, weløem ber gejeglidie Bertreter unter Be: nehmigung bes Botmßeridtes bie Ermåntigung ertheilt hat, eit Er= werbsigeidaft jelbjtänig zu be=

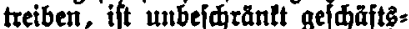
făbig in Anfehung folder Redts. geiduafte, welde ber gejtattete Eef dätşbetrieb mit fid bringt. Eg finben jebod, ungeadtet ber ertheilten (5rmähtigung, bie Bors |ariften ber $\$ \S 1511,1513,1674$ bis 1676 mit ber MRaßigabe ent= ipreduenbe Antwenbutg, ba ber Benehmigung besె Borm心e: riđtes au山 bie Einnollligung ober Benehmigung bes gejesliden $B_{\text {ers }}$ treters erforberliq ift, unb baś bie nah ben $\$ \S 1513,1675$ zu: Iaffige allgemeine Ermådigung aum bem Minberjăhrigen allein extheill werben tann.

Der gejeblide Bertreter tann bie Ermăhtigung zum felbfänbigen Sefdxaftsbetriebe mur mit ses nehmigung besె Bormßeriates zurlidnegmer.

\section{8.}

Ein शRimberjăgrigex, weldem ber gejeslidge Bertreter geftattet bat, in Dienit ober Arbeit gu treten, bebarf ber Gin: willigung bes gelestidien Bertreters niøit jux Ein. gehung bon Dienf́tber. Gălnifîn ober Arbettöver. Gáltuilien ber geftatteten

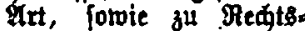

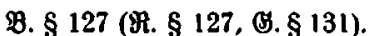

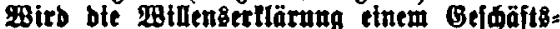
unfäbigen gegentiber abgegeben, fo wtrb fie nitht

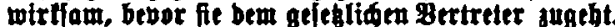

Daś Bleide gilt, wenn bie 2 Billengertlänung

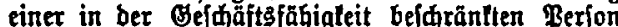
gegenüber abgegeben wirs. Bringt bie Crtlänung jebođ ber in ber Gejđăftäfăhigleit bejđrăntten Berfon Iebiglid einent redtliden Bortheil vber hat ber gejeslide Bertretez feine Filtwilligung ertheilt jo roirb bie Crtlärung in bem Beitpuntte toirtiam. in weldem fie ihr sugeht.

$$
\text { II } \S 86 \text {. }
$$

Sat ber geleslidie Bertreter unter B̈enehmigung bes BormBse: riates ben Dinberjăhrigen zum felbitänbigen Betriebe eines $6 r$

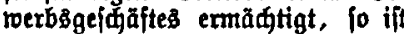
ber Mintberiăhrige in Mnfehung

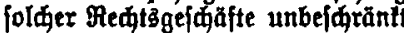

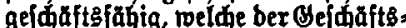
betrieb mit fid bringt. Iuşge nommen finb biejenigen Redtšs geidăfte, zu weldien ber Bertreter ber Bentehmigung bes \$ormBe: riates bebarf.

Die Ermăhtigung tann von bem Bertreter nur mit ofestehmigung beş Bormßseridtes zurladgenommen werben.

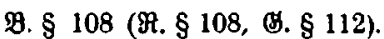

Ermäntigt ber gefebliđe Ber. treter mit Benehmigung bes Borm Beridgtes ben $M$ inberiăbrigen zum lelbftāntbigen Betriebe einte

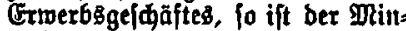

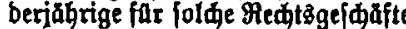

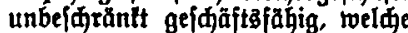

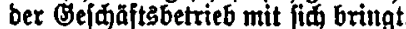

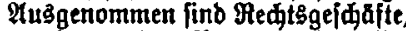
zu benen ber Bertreter ber Senehmigung bes Borm(seriates bebarf.

Die Crmădtigung lann bon bem Bertreter nur mit ש̈enehmigung

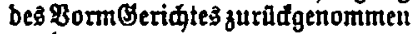
werben.

Mrotibe 430 f., Brotololle 682, Pom Oeridit 964.

II $\$ 87$. Sat ber gejeblide Ber, treter bem 9 tinberjubrigen bie Erlaubnib ertheilt, in Dienft ober Arbeit zu treten, jo bebarf ber Din. berjahrige niat ber $\mathbb{B u}$. ftimmung bes Bertreters

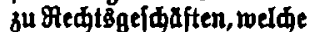

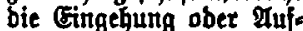
hebung eines Dienit= ober Irbeitsperhaltniffes ber
Ermántigt ber gejeb= lide Bertreter ben Min= Deriăbrigen, in Dienfit ober in Arbeit ju tretert, fo ift ber MRinberjăbrige far folde Pedtagejdafte unbefकränlt gefd)afts . fahig, weldae bie Ein: gehung ober $\mathfrak{A} u f$ gebung eines Dienft o ober Arbeits: berhăltniffes ber geitattetert

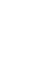




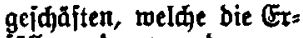
filfung ber bon bem an: beren Theile abernomme: uten Berpflidtungen oder bie $\mathfrak{A}$ fhebung bes Dienjt= berhältmiffes ober भrbeits: berhältnifîtes betrễien.

Ter gejebliqe $\dot{B e r}=$ treter fann bie Crmädti= gung zunidnehmen ober einịahräntent.

Tie für cinen eiızelnen j̧all ertheilte Ermädti= gung gilt im Btweifel ale allgemeine Ermådtigung jur Eingehung einę $\mathfrak{B e r}=$ hältniffes berielben $\mathfrak{A r t}$. geitatteten 2 rt ober bie Exfülung ber mus einem foldhen Berbåltnilfe fid er: gebenten Berpflidturgen betreffen. Durd bie Cr= laubnis wirb ber MRinber: jăhrige für bie aus biejent

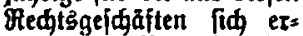
geberben Rechtsftreitig = teiten niळt prozep̧fătg.

Tie Erlaubnis tann bon bem gelestifien $\mathfrak{B e r}=$ treter zurüfgentommen ober eingeidräntt werben.

Die fur einen einzelnen fall ertheilte Erlaubnis gilt im Brweifel als all= gemeine Crlaubniö zur Eingehung eines $\mathfrak{B e r}=$ Găltmiffes berfelben Art.
Art ober bie Erfüllung ber fín aus eirem folden Berbältuitie ergebenton Berpflidtungen betreffert. Qusgenonumen find $\mathfrak{B e r}=$ träge, zu benen ber $\mathfrak{B e r}=$ treter ber Sentebmigung bes $80 r m$ (Beriates bebarf.

Die (rmádigung fann von bem Bertreter zurita = genommen ober einge= idråntt roetbert.

Tie für einen einzelnen Fall ertheilte Emåditi= gung gilt im Broeifel alsె allgemeine Ermähtigung zur Eingehung von $\mathfrak{B e r}=$ hăltutifien berfelben 2 rt. bit Crfillung ber fta aus einem jolden Berhälniffe ergebenben Berpfliaturt= get betreffet. $\mathcal{A}_{\mathrm{u}} \mathrm{ge}=$ nommen find Bertråge, zu bener ber Bertreter ber Benthmigung bez Borm(Geriates bebarf.

Die Ermādtigung fann bon bem Bertreter zurü genommen ober einges fंŭăntt roerbelt.

Ift ber gefeglidie Ber. treter ein פormunb, fo Iann bie Crmädtigung. went fie von thm ber. welgert wirb, auf Intrag bes I I tinberjäbrigen burd bas BormGertit erfest werben. Das BormGe. ridt bat bte Grmähtigung ou eriegert, wenn fie tin Intereffe bes oniunbels litegt.

Diefar einert einzelnen Fall ertbeilte Grmădi= gung gilt im Brweifel als allgemeine Erma̋htigung zur Eingehung von Ber= hăltniffen berjelben Art.

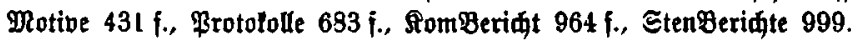

I $\$ 69$.

Ter von einem Minberjăhrigen gejdlofjene Bertrag gilt als von VInjang an wirtian, went ber Mittberiahrige bie barin äber= nommesten Berpfliøtungen aus Bermögens̊gegenitănben erfillt, roeldje ingm vout bem gefeslidgen Bertreter zul foldem Brwede ober zu freier Berfilgung redtigltitig uberlaffett warest.

\section{I \$ 70.}

Ein Dolljăhriger, weløer wegen Berfamenbung entmilnbigt ift, fteht in Qnjehung ber Gejadts: făbigleit washrent ber Dauer ber Entmandigung cinem Minberjahrigent gleid, weldjer baš 7. Qebens. jabr zuridgelegt bat.

\section{I \& 71}

Cin Boljăbriger, welder nad Mab́gabe bes \$ 1727 beg bormunbiaaftlifien Équbes far bes birftig erflät ift, ober iber welden nad Maßsgabe bes \$1737 eite borlăufige 80 ormunb/daft angeoronet iit. fteht bis fur Peenbigung ber Bormunb/4aft in

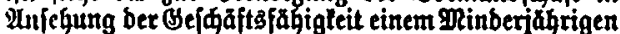
gleid, weld̄er bas̄ 7. Lebensjahr zurildgelegt Gat.

girb in Falle bes $\$ 1737$ ber Intrag auf Cntminbigung redtstraftig zuradgeniefen ober bie Entmünbigung in folge ber Anfedgtungällage red,ts: frảftig aufgehoben, fo finben bie Borjurnften beş $\$ 613 \mathfrak{A 6 f} 2$ ber CRD. entipredienbe Rnwenbung.
If $\$ 84$.

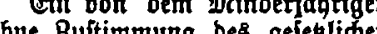
Mritteln betwirtt, bie ihm zu iugung oon bem ritten berlaffen fiito.

Motive 4.32 ff., Prototolle 684.
B. § $106(\Re . \S 106$, B. $\$ 110)$ Gin von bem Minberjăhrigen ofne Buftimmung bes géfebliden Bertreters gejaloffenter Bertrag gill alsి von Ünfang an wirtiam, toenn ber Mlinberjäbrige bie ber

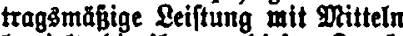
bewirt, bie ifm zu biefem Broede ober zu freier Berfingung bon bem Bertreter ober mit befjen $\mathfrak{B} \mathfrak{u}$ ftimmung bou einem Dritten abers laffen morben fino.

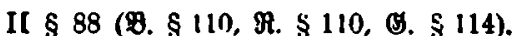

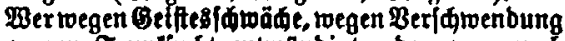
ober wegen Euntiudt entmunbigt ober wer nad $\$ 1783$ (B) 1882) unter vorlaufige Bormunbidaft

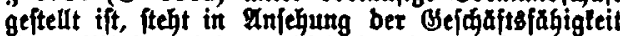
eiuem Minberaharigen gleid, ber bas 7. Lebensjabr bollenbet bat.

II $\$ 89$ (B. $\$ 111$, F. $\$ 111$, \&. $\S 113)$.

\$irb cin bie Entmanbigung ausipredenber Peílus in Folge einer Finfefitungstlage aufgeboben, fo tann bie 2 Birtjanteit ber von ober gegenaber bem

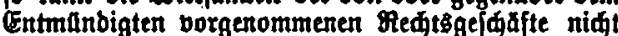
auf Srunb bes Beføluffes in Frage gefteult werben. Tuf bie Birtfamteit ber von ober gegentiber bem gelegliden Dertreter vorgentommenten Pedtsgejăbfte hat bie Tufhebung teinen Ginflüb.

Diefe Borfuriften finben entipredenbe $\mathfrak{Y}$. renbung, went im Falle eitter vorlăfigen Bor. munbjaft ber Intrag auf Entmunbigung zurtid: genommen ober redtstraftig abgewiejen ober ber bie

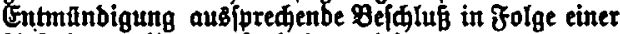
Înfeळtungstlage aufgehoben wirb.

Rotive 434 ff., Prototolle $684 \mathrm{f}$., CtenBerifte 1000 . 
Miđenęerltārung.

Die Willenserklärung kann ausdricklich oder stillschwoigend erfolgen. Potibe $436 \mathrm{f}$., Prototolie 685.

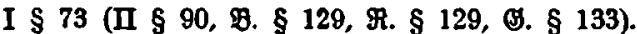

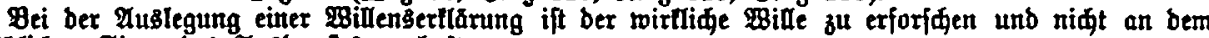
budftăbliden Girne bes Tusbrudes zu haften.

Motive 437 f., Protololle 685.

\section{874.}

Yit bie

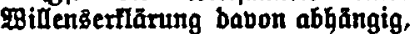
bas fie gegenaber einem Betheiligten abgegeber mirb (Empfanger ber פsillenşerthănug), unb rfolgt bie

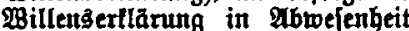
beffelben, fo wirb zur 28 ixtfamleit

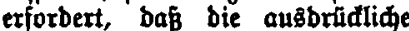
Billensertlånung ihm zutommt,

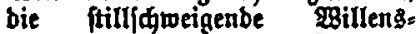
ettlănug zu feirer Rerntnió gelangt.

Die gillentsettlănung gilt alä nimit erfolgt, wenn eine ben 2 iber= ruj enthaltende 2 Billensertlătung nad ben Boridriften bes 1. 266 ;. vorher ober gleidzectig zur 20 famleit gelangt.

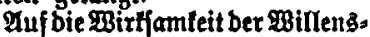
erflãrung ift es ogne Einflus, twenn ber urgeber ftirbt ober ges f呫ft bie ausbriưtlide Ertlărung behufs ber Abjenbung abgegeben ober bebor ber Betheiligte von ber fitils

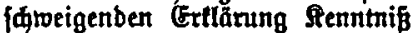
erlangt hat.

Iit bie Birfiamileit einer

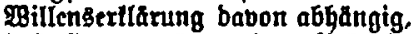
baß́ fie gegenuber einer Pelörbe abgegeben roirb, fo finben die Borjidiften bes 2. unb 3. A6f. entiprechenbe Antoendung.

\section{I $\S 75$.}

Ift Temand zur Entgegentabme einer $\mathfrak{B i l l}$ ens: exllärung berpflifitet, fo lann bie Mrittheilung ber

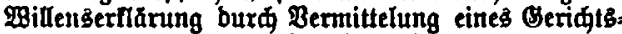
boldziehers geldehen. Die Dhittheilunt exjolgt nad ben far bie Buftellung in bitrgerliden Bedftsftreitig leiten gelterben Borjantiften.

\section{I $\S 76$.}

Befinbet fid berienige, welder eine grillens: erllăruug mittheiten will, in einter nidt auf frahr Iáffigleit berubenben Lultenntniß̄ Hber bie Berion besjenigen, welder zur Entgegennahme ber 2oillens erthărung verpflidgtet ift, ober ift ber 2lufenthalt biefer Ferion unbelannt, io Pann bie glittheilung nad ben für bie off. Buftellutg einer gaoung in

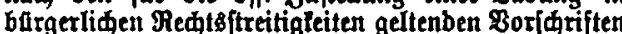

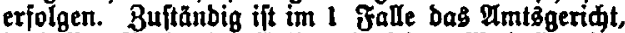
in beffen Bejirl ber Entlarente feinen $2 B$ ohnitis ober in Crmangelung eines folden feinen IUufenthalt

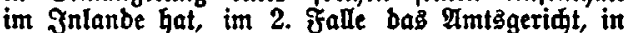
beffen $B_{e}$ irt bie Berjon, welder zuzulteller ift, Delt lester 900 hmi jold)en ben leksten 2 ufenthalt im Snlanbe hatte.
II $\$ 10 i$.

Cine gsilfens̄ettlătung, bie

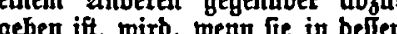

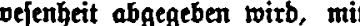
iie ifm zugeht. Sie wirb roitian, went bor ober gleid ig mit ihr ein 28 iberruf zugeht. ber rsillentertlañng ift es okne Einfluts, went ber Ertlârende nath unfäig wirb.

ein, twenn ber anbere Theil 31 ber Beit geidaftşumăhig ift, in Delaer ihm bie Erflärung zugeht bringt ober bas ber gejeglide II $\$ 109$.

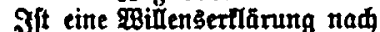
(3) Borfdrift an eine $\mathfrak{B}_{e}=$ gorbe zu ridten, fo finben bie ßoridriften bes $\S 107$ abf. 1, 2 entipredenbe Inwenbung.

Motive 438 fi., Brotolulle 685 ff.

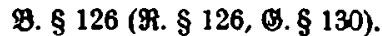

(Eine eirem 2 lnberen gegenaber $a b z u-$ geben ift, wirb, went fie in befien Q⿱a bumelenteit abgegeben wirb, in bem Beitpurlte wirtiam, in weldem fie ihm zugeht, fie wirb nidit wirfiam, twent bem ânberen vorker ober gleidzeitig mit ihr ein 20 iber= nuf zugeht.

Ouf bie Mirffamteit ber extlănung ift es obute finflus, wenn ber Cetlärenbe na屯 ber $\mathfrak{A b}$ : gabe ftirbt ober gejăfaftsunfahig tritb.

Tieje Borjariften finten aud barn Inwentung, wern bie פBillensertanaug einer Beharbe gegenilber abzugeben ift. 


\section{Berttagidifiefinug.}

$I \S 77(I I-$, B.,- R. - , G. -$)$.

Zur Schliessung eines Vertrages wird erfordét, dass die Vertragschliessenden ihren übereinstimmenden Willen sich gegenseitig erklären.

Motibe 441, Prototolle 688.

I \$ 78.

Solange bie Bertragfbliefen: ben Ibex bie nad bem Befege

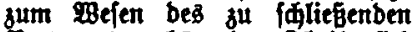
Bertrages gehorenben Theile fí nidt geetnigt baben, ift ber Ber: trag nidt gejaloffer.

Das Bleide gilt in 8tweifer aud bann, wenn bie nah ber Er: Ilårung aud mur eines ber Ber= traglaliefienben auberbem ou ber= einbarenben Beftimmungen nod nidt vereinbart finb, ohne Inter= fajied, ob eine 9 uffeiqnung ber bereitş verein6arten Đeftimmungen ftattgefunber hat ober nidt.
II $\$ 116$.

Solange bie Parteien fid nidht aber alle Buntte eines Bettrages gecinigt haben, uber welde nam ber Erflanumg aud nur einer \$artei einte Bereinbatung getroffen werben foll, ift im 3tweifel ber Bertrag nift gejळloffen. Die aber eingelne Buntte exfolgte Bers ftanbigung ift in einem folnen Falle aud bann nidt binbenb, went eine Aufzeidnung ftattge= funben bat.

3it eine Beurfunbung beg be= abfintigten Bertrages verabrebet worben, fo ift im Btweifel ber Bertrag nidit gefálolien, folange bie Beurfunbung nidht erfolgt ift.

Rotive 441 f., Brotololle 688, Denth
B. § 150 (भ. $\$ 150$, (3. \$ 154). Eolange nidit bie \$arteien fí uber alle \$untte eines Bertrages getinigt haben. aber bie nad ber Etllanung aú nur einer \$artei eine Bereinbarung getroffer wer. ben foll, ift im Broeifel ber Ber. trag nidt gefolloffen. Die Bers ftanbigung fiber eingelne \$untte if aú bam niat binbenb, wenn einefafzeidnung fattgefunben hat.

Jit eine Beurfundung bes be abfiøtigter Bertrages verabrebet toorben, fo ift im Breifel bet Bertrag niat gefaloffen, bis bie seurtunbung erjolgt ift.

$$
I \S 29(I I-, \text { B. }-, \boldsymbol{R} .-, \text { G. } \rightarrow) \text {. }
$$

Ein gegenseitiger Vertrag, tcelcher mit der Bestimmung geschlossen uird, dass der eine Vertragschliessende an denselben nur dann gebunden sei, wenn er woulle, ist für den Vertragschliessenden bindend.

Erlalärt der Erstere, dass er nicht wolle, so hört der Andere auf, gebunden su sein.

Motive 442 f., Brotololle $688 \mathrm{f}$.

I $\$ 80$.

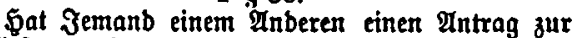
Salieburg cines Dertrages gemaht, fo ift er an ben Intrag gebunben, wenn biejer bie zum 2 Bejent bes beantragten Bertrages gehörenden Theile ents hălt, ohne bie Beteinbarung toeiterer Beftimmungen borzubehalten.

I $\S 81$.

Der Antragende ift nidit gebunben, wenn bie Bebunbentheit ausbrudlia ober ftilf hroeigenb von ifm ausgefdloffen ift.

\section{Mlotive 443 f., Brotololle 689 f., Denl゙かrift 836 ff.}

I \$ 92 (fiche aú zu I \$ 88).

Ift fur bie Annahme bes Antrages eine Frift bon bem Antragenben beftimmt, fo bleibt biefer bis fum Ablaufe ber frift gebunben. Pommt bie $\mathscr{A n}=$ nahmeerflarutg bem Antragenben vor Ablauf ber Fraft niळt zu, fo erlifft ber Ântrag.

\section{Motive 445 f., Brototolle 690}

I $\$ 83$.

2Birb ber Bertraģantrag ofne Beftimmung einet Annahmejrift einem Anwejenben gemaht unb von biejem nifit fofort angenommen, fo exlifít ber Intrag.

I $\$ 84$.

\$Bitb bet Bextragsantrag obne Beftimmung einer Innahmefrift einem Gbrvejenben gemaht, io ijt ber Orntragenbe bis zu bem Beitpuntte gebunben, in weldem er bei unterftellung ber redtzeitigen Intunft bes $\mathfrak{A n t r a g e s}$ und ber nad ber Berlehrs. fitte als rehtzeitig zu betrahtenben gbjenbung ber
II $\$ 121(\mathfrak{O} . \$ 144, \Re . \$ 144$, (S. $\$ 148)$.

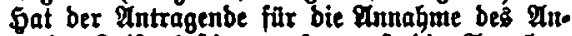
trages eine frrift beftimmt, io mus bie Annabme imethalb ber Frift exfolgen.

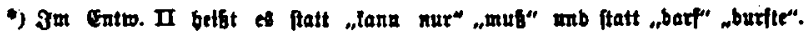


Intwort ben Fingang ber lebteren ertwartent barf. Pommt die Ertlănung ber Mnnahme nidh bis zu biefem Beitpuntte bem Intragenben zu, fo erlifift ber Antrag.

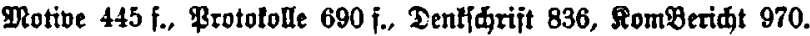

I \$ 85. (Siehe aud zu I \$ 88.)

Jit bie nad Ablauf ber Annahmeftifi bem Intragenben zugefommene Annahmeertlänung eines abwejertben bon biefem bergeitalt abgejanbt worben,

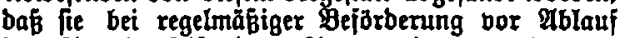
ber Arnahmejrift bem Anitagenben zugelommen fein warbe, fo bat biejer ben Anberen nah Ein: gang ber Certlarung unverzäglich von ber Ber =

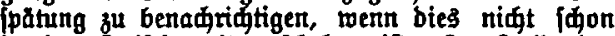
in ber 3wijhenzeit gejdehen ift. $3 \mathrm{~m}$ folle ber Berfăumung ber reătzeitigen 2Tbjenbung ber Ânzeige gill bie Annahmeertlărung als niaht beripătet.

Motibe 446, Brotololle 692, Dentidurift 896 fr.

I $\$ 86$.

Die ftruffineigende Annabme bes einem abrelenben gemahten Bertragsantrages ift zuläfíg, wenn ber Antragenbe fie geftattet hat. In einem folden Jalle ift zur isirffamteit ber Unmahme nint erforberlid, bas bie Innahme zur Renutnis beş QAntragenben gelangt.

Die ftilladmeigende 2untahme ift inşbef. alş bon bem Antragen= bert gejtattet anzuleben, wenn er iit bem Intrage pofortige Deijtung verlangt, ober toenn aus bem $21 n=$ trage erhellt, baß ber Intragente leine $\mathfrak{A n t w o r t}$, fonbern nur $2 \mathrm{in}$. nahme erroartet.

Bie lange ber Antragenbe ges Gunben ift, beftimmt fid nad feinem it bem Intrage ausobrüalid $e x=$ tlärtest ober aus bet lumftánben Des falles zu entnehmenben æillen.

Sat ber Intragenbe fofortige Seifting berlangt, fo ift er im Broeifel to lange gebunber, als zur Bewirfung ber Reiftung er: forberlic ift. $\mathfrak{W i r b}$ bie \&eiftung berjögert, fo exlifðt ber Intrag. Db eine Berzogerung vorliegt, ift nad bert llmitanben unb ber Bers tebrgfitte su beurtheilen. 2 Birb bura Bufan bie Prtunft bes $\mathfrak{M n}$. trages beripaltet ober bie fofortige seiftung verhinbert, jo iftim 8 weifel ber Antrag als erlo/dyen anjulehen.
II $\$ 122(\mathfrak{B} . \$ 145, \Re . \S 145, \leftrightarrow$ \& $\$ 149)$. Эît eine bem Ântragenben veripătet zugegangene Annahmeertlanng bergeftalt abgejendet worben, ba

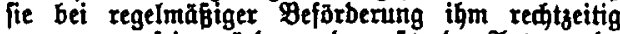
zugegangen fein wäbe, unb muste ber Antragenbe bies externen, fo Gat er bie Berfpätung bem $911=$ nefmenben unverjäglia na屯 bem Empfange ber Ertlărung anzuzeigen, fofern es niøt if on vorber

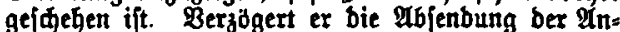
zeige, fo gilt bie $\mathscr{A}$ nnahme alz niđgt beripătet.

Drotibe 447 f., Brotololle 692 ff., Denllidrift 836 ff.

Bum Buttanbelommen bes Ber= trages gentigt bie Plnuahme bes Antrageș, ohne bas̆ eş einer $C_{r}=$ Ilărung bem Intragenben gegen: äber bebarf, renn biefer auf eine foldye Erflaruug vergidjtet hat ober toenn bas unterbleiben ber= felben ber Bertehrsfitte entipriat. Der Beitpunlt, it weldiem ber Antrag erlilut, beltimmt fid in einem foldien fralle naw bem aus bem Antrage ober ben llmftănben zu entnegmenben $\mathfrak{W i l l e n}$ bes $\mathfrak{A n}=$ tragenber.
B. \& 147 (R. \& 147, B. \& $\$ 151)$ Der Bertrag lommt burd bie Antahme bes antrages zu @iande,

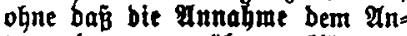
tragenber gegenilber erllät at werben braudit, roenn eine foldie Erllărung nad ber Berlehrsofitte niat zu erwarten ift ober ber $\mathcal{A} \mathrm{n}$ = tragenbe auf fie berzidtet Gat. Der Beitpunlt, in weldem ber Antrag exlif币t, beftimunt fí tad bem aus bem Attrage ober ben umitanben zu entnehmenben bes Qntragenben.

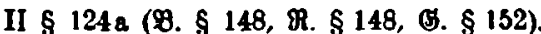

2Birb ein Bertrag geriahtidi ober notariell beurtunbet, ohne baf beibe Theile gleidseitig antwejenb finb, fo fommt ber Bertrag mit ber nad \& 106 . (ß. \& 128) erfolgten Beurtunbung ber Ennahme zu Stanbe, wern nidit cin Inberes beftumt ift. Die Boriqrift bes

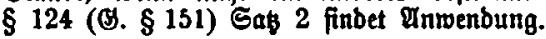

$I \& 87\left(I I-B .-, R .-, G_{.}-\right)$.

Mit dem Zeitpunkte der Annahme des Vertragsantrages ist der Vertrag geschlossen. 
I \& 88.

Die veripatete Annalime bes Bextragsantrages gillt als eir neuter \&utrag.

Der Bettragsantrag exlijळt burd bie פablegrung.

Gine Anuahme unter Erweite: rungen ober Einiärănthungen gill als ablebnung verbunben mit einem neuen Elntrage.

II §123 (B. § 146, भ. §146, O. § 150).

Die veripătete Annahme eires थ̇ntrages gilt als neutr Intrag.

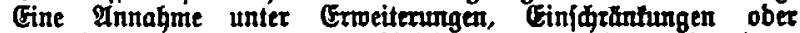

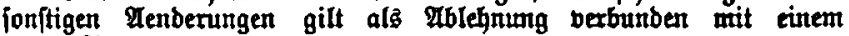
neuen $\mathfrak{A n t r a g e .}$

II \& 119 (B. § 142, Я. § 142).

Der Antrag exlifit, wenn er

bem Artragenden gegenúber ab= gelegnt ober nidit ram ben $\$ \$ 120$ bis 1:2 (ş 14:3 bis 145) redt= seitig angenommen wirb.

\section{B. $\S 146$.}

Der Intrag exlifhit, wenn et Dem Antragenben gegentiber $a b=$ gelebnt ober wenn ex nimt biciem gegenaber nad ben $\$ \$ 147$ bis 149 redtzeitig angenommen wirb.

Mtotive 448 f., Frotololle 695 , Dentidrift $8: 36 \mathrm{f}$.

I 889 .

Inf bie $\mathfrak{B}$ irtffanteit bes Bex= tragsantrages ift $e^{3}$, fofert ni⿱中⿰㇀丶㇀

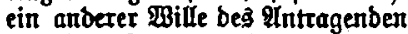
aus bem Intrage ober ben $\mathfrak{H m}=$ ftänbert bes đ̧alleż herborgeht. ohne Einflǘ, roern ber 21ttragende ober beriertige, weldem ber भ̂ntrag gemadt worben ift, nad $\mathfrak{Q}$ G fenbuug

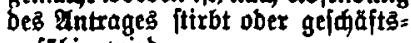
unfähig wirb.

\section{II $\$ 125$.}

Das Buftanbelommen bes Ber= trages wirb nidt baburd, gehindert, Daß ber $\mathscr{A n t r a g e n b e}$ bor ber $\mathfrak{A n}=$ nahme ftirbt ober geiđäftsunfähig wirb, é jei benn, bas aus bem Untrage ober ben umítänben bes falles ein anderer $\mathfrak{W i l l e}$ beą $\mathfrak{A} \mathfrak{n}=$ tragenben hervorgeht.
P. \& 149 (9. \&149, B. \& 153).

Das Butanbefonumen bes Ber= trages wixb niat baburd gefimbert, baß ber Intragenbe bor ber $\mathfrak{U n}_{n}=$ nahme ftirbt ober gefífăftšurfä̆hig wirb, es fei benn, bas ein anberer gille bes 2 ntragenben anzu= nehmen ift.

\section{Motibe 449, Brototolle 695, Dentfdrift 838 ff.}

\section{$1 \S 90$.}

Bei einer Berfteigerung an ben Meiftbietenben vber Benigftforbernben ift im Breifel ber Bertrag erft bant gejhlofien, went auf ein Bebot ber $B u=$ idflag erfolgt ift, tunb ber Bietende an fein Bebot fo lange gebunden, als er niळt aberboten roorben

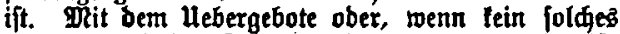
gemadt unb ber Buldlag nidt vorher erfolgt ift, mit bem ablaufe bes Berfteigerungstermines if bas Gebot im Brweifel erlolden.

\section{Drotibe 449 f., Brotololle 695, Denlfirift 836 ff.}

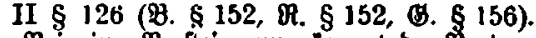

Bei eirer Berfteigerung tommt ber Bertrag erft Durd ben Bufdlag zu Stanbe. Ein Giebot exlifit, wert ein Mebergebot abgegeben ober bie Berittigenung ohne Ertbeilung bes Buldilages geidloifen wirb.
I § 91.

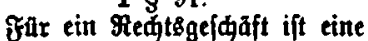
bejonbere frorm nur bann erforber. lid, wertn eitre joldie burd Gejets Dber Redtşgejdaft bejtimmt ift.

3ft burh Gejes eine bejondere form vorgefdrieben, fo ift bas Redt Der Form nidtig, fofern nidt ein Anberes vorgeidrieben ift. Tas: felbe gill im grweifel im falle bes

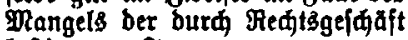
befimmten form.

Dlotibe 450 ff., Brotololle 695 f., Dentldrift 835, RomBeridgt 965.
I\$92.

Oft burd Befes bie fdriftlide Form vorgejdrieben, fo mú bie ulrtumbe von bem Uliheber ber gillensertlarung etigentandig un= teridrieben ober mittels geridittid ober notariell beglaubigten \$anb: zeifens unterzeidnet feir.

Bei telegraphififer Ulebermitte= lung ber $\mathfrak{W i d e n g e r t l a ̆ r u n g ~ g e n u ̈ g t ~}$ es, wenn bie $\mathfrak{A}$ ufgabelfifitt na山

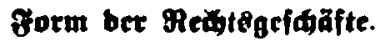

\section{II $\S 104$.}

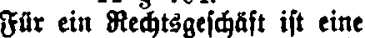
bejonbere form nur erforberlid, went eine folde burdi befes ober Ređtşgefidäft beftimmt ift.

Gii भeedt burd Bejes vorpejqriebenten frorm ermangelt, ift nidtig. Der Mangel Der burm Redts geida fo beftimmten Form hat im Brweifel gleidfalls Ri山tigleit zur folge.
B. § 121 (R. § 121, \&. § 125).

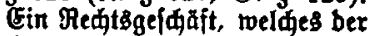
Durd Brejes vorgeidriebenen Form ermangelt, ift nidhtig. Der Mangel ber burd Redisgejdiaft bejtimmten Form hat im Broeifel gleidfalls Nidgtigleit jut

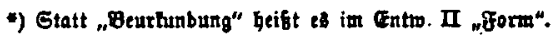

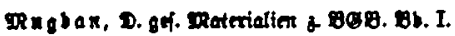

II $\S 105(8 . \leqslant 122, \Re . \S 122$, (3. $\S 126)$.

3it burd Befes ifriftlide Form vorgef

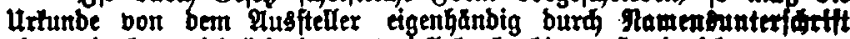
ober mittels geridutlid ober notariell beglaubigten \$anbzeidents unters geidinet lein.

Bei einem Bertrage mus bie unterzeidnung ber \$arteien auf berfelfen urfunbe erfolgen. Sind itber ben Bertrag mebrete gletid: lautenbe urtunben aufgenommen, jo genugt es, went jebe \$artei bie filt bie anbere Bartei beftimmte Hrtumbe unterjeimnet.

Die ffriftlide Form wirb burd bie geriftllife ober notarialle Bearthunbung ${ }^{*}$ ) eriegt. 
9labigabe bes 1. 24b unterid ober unterzeidinet ift.

Die geriatlide ober notarielle form exist bie fartiftlide form.

I $\$ 83$.

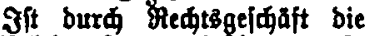
f friftlitie form beftimmt, io finbet bie Borfurift bes 892 Q161. 3 unb in 8weifel aud bie Borfariften beb \$ 92 बbj. 1, 2 Antwentung.

\section{I $\$ 94$.}

Bei einem Bertrage if zur Bolletbung ber burd Geles vor:

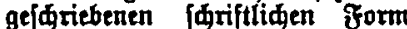
bie Unterfarift fâmmtlider Ber. tragiditiefenben auf berjelben $\mathfrak{U}_{\mathrm{r}}=$ hunbe erforberlid. Ift bie Bers traggurfunbe in mebreren gleid: Iautenben Etemplaren aufgenoms men, fo gentigt es, wern jeber ber Bertraglahliefendent ein von ben abrigen Bertragjळliefenben unter: fdriebents Eremplar empjangen

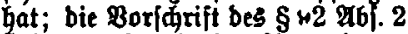
finbet entprechenbe anwenbung.

Die Borfqriften bez 1. $\mathfrak{A b}$. gelten im Btweifel aú bann, toent naळ ber Bereinbarung ber

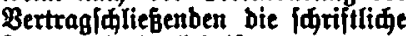
form erforberlid ift.

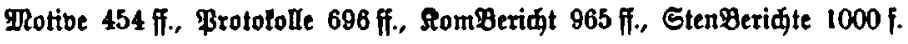

II $\$ 106(\Re . \S 123, \Re . \S 123)$

Dic Boridriften bes $\$ 105$ gelten im Brveifel oud fiur bie burळ Mectsggeiळaft beftimmte

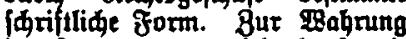
ber frorm genagt jebod, foreit nidit ein anberer $28 i f l e$ anz nehmen ift, $)$ telegraphijhe Heber: mittelung. gairb biefe gerodhlt, fo lann ber anbere Theil nadtrăg: lix eine bem \$ 105 entjpredente Beurfundung verlanger.

\section{๑. $\$ 127$.}

Die Borfdxiften bes $\widehat{\delta} 126$ gelten im Brweifel aud fir bie

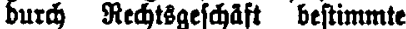
jळriftlide form. 3ur ber from genlat jebod, poweit niфt ein anberer $\mathfrak{g}$ ille anjunehmen ift, telegraphijae llebermittelung unb bet einem Bertrage Orief wedffel; wirb eine folde frorm

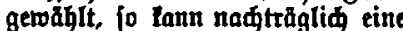
bem \& 126 entipredienbe Beurtun* bung verlangt werben.

[I feglt]

II $\$ 1116$ a (9. $\S 124, \Re$. $\$ 124$, (3. \& i28).

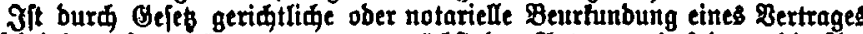

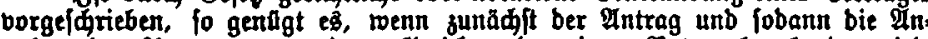
nabme bes antrages bon einem Berifte ober einem Rotate beurhunbet wirb. Motive -, Protololle 701 ff.

B. $\$ 12 \checkmark(\Re . \S 125$, (3. \$129).

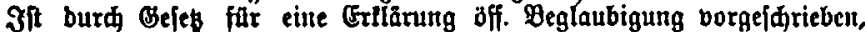

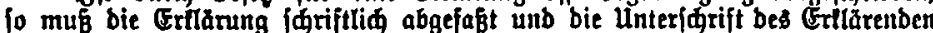
bon ber zuftänbigen Mehörbe ober eillem zuftantigen Beamten ober Potare

[I, II feblert]. beglaubigt werben. Wirb bie Ertlarung bon bem Eusfteller mittels \$and:

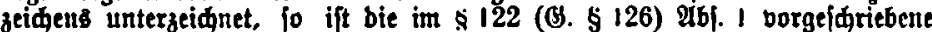
Đeglaubigung bes \$anbzeidens erforberlid unb gentigent.

Die off. Beglaubigurg wirb burd bie geriळtlide ober notarielle Beur. tunbung ber Ertlarung exjeşt.

Motive -, Brotololle $701 \mathrm{ff}$.

I \& 95.

צIt ber Urbeber einer $\mathfrak{B i l l e n s :}$ erllårung, bei welder ber wirtlide Bille mit bem erllărten $\mathfrak{B i}$ liten nidht abercinftimmt, besి mangelg ber Ulebereinftimmung fid betwust, fo ift bie 28 illenserflarung gillig, foferm ber Urheber ben Mangel berhehlt Gat. Die 28 illentserllanng ift jebod nidtig, wenn ber Em: pfänger berfelben bent Mlangel ges fannt gat.

\section{EBiปtenยmängel.}

II 891 .

Gine aú wern ber Ertlärenbe fid inss. gebeim borbebalten hat, bas Ers llarte niat zu roollen. Dic Er: Ilarung ift jeboh nidtig, wenth fie einem anberen gegenüber abzus geben war untb biejer ben Borbe: balt tannte.

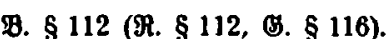
Fine Millentertlarung ift nlot beghalb nidtis, wetl fin ber $E_{r}$. tlarenbe insigebeim vorbebalt, bas Exflarte nift zu wollen. Die Er. flănang ift niळtig, wenn fie einem Anberen gegenuber abjugeben if unb biejer ben Borbebalt tennt.

MRotibe 458, Protololle 710, Dent|ळrift 832.

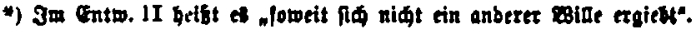


I $\$ 96$.

Cin zum Sh̆eine vorgenonme

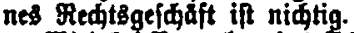

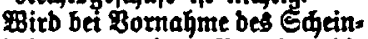
geinăftes bor ben Marteian bie Erridturts einteg anderen Mechtşs gejäb̆ftes beablidtigt, fo beftimmt

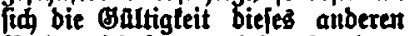

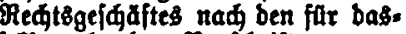
felbe geltenben Borfdriften.
II 892.

Cine gegenuiber einem 2unberen abjugebenbe \$sillenserflarung, bie mit befien Ginverfánbnis mur zum Sdieine abgegeben wirb, ift niditig.

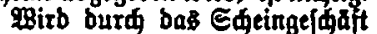
ein anberes Medtsgejdaft verbedt. 10 beftimmt fí bie Eultigleit nah ben fat bas berbedte Pleditsge idäft geltenben Bor [uriften.
จ. §113 (भ. \& 113, O. \& 11i). Bito cine pillenseriturung bie cinem Anberen gegentaber abs: bugeben ift, mit beffen Eimberfánd. nib nuт zum Sdjeine abgegeben, io ift fie niditig.

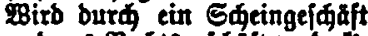
ein anberes Redtsgejdafft verbedt, jo finben die für bas berbedte

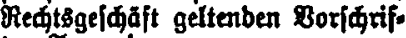
ten Antwenbung.

grotive 458 f., Protololle 710 f., Dentidifift 832.

I $\$ 97$.

5at bei einer Esillensertlănung ber Uurbeber, welder bes פlangels bet Ulebereinftimmung bes roirts liđen $\mathfrak{B i t h e n s}$ mit bem extlătten

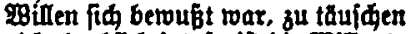
nidht beablintigt, fo ift bie 28illents: ertlärung nimtig.

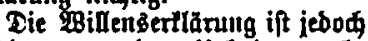
gultig, wenn bem utrbeber grobe

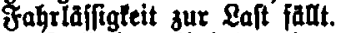

frăut bem $\mathfrak{H}$ theber eine frahrz: lasfiggteit zur $\mathfrak{L a f t}$, welde leine grobe ift, fo haftet Derfelbe bem cmplänger fir Edabenserjap. jeboh in teinem fralle aber ben Bettag ginaus, weldent er bei Borausiésung ber Bultigleit ber

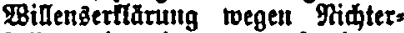
füllunt ber baraus entifanbenen Berpfliditurg zu exteben gegabt hătte.

Die Boridriftert bes 2. und 3. $\mathfrak{A b}$. Finben teine भrwenbung, wetun ber Empfänger ber æBillengs. erthårung ben glangel ber Hebers

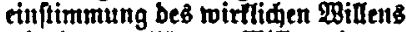
mit bem ertlătten $\mathfrak{g i l l}$ en tante oder lennen mufte.

II $\$ 93(8 . \& 114,9 \& 114,05 . \$ 118)$.

Cine nidit ermftlid gemeinte 28 illengertlänung, bie in ber Et. bartung abgegeben witb, bet IRargel ber Emftltuteit werbe nidit vertanut verben, ift niftig.

II $\S 97$ (P. 118, भ. 118).

3ft eine פBillenserflarung nad \$ 93 nimitig ober auf Grunb ber $\$ 894,85$ angefodten, fo hat bet Ertlärenbe, wenn bie Extlånung einem Inberen gegentuber abjus geben war, biejem, anderenfalls jebem Dritten ben Shaben zu ers iesen, welden berfelbe") baburd erleibet, bas er auf bie Bsaltigleit ber Exflarumg vertraut hat, jebod nidet abet ben Betrag bes Snter: effes hinaus, wel'des berfelbe") an ber Búttigleit ber Extlănung hat.

Die @áabenserfakpflidt tritt nidt ein, weenn ber Befmabigte ben Grumb ber Ptidtigleit ober Intfedtbarteit lannte ober in Folge bon f̧ahrlåffigleit nidit fannte (fentern murBte). Sm Falle Des $\$ 95$ ift bie Eqabenserfappflidt aub bann ausgetinlofien, wein bie Untiditigleit ber Uebermittelung igren (Grutb in bơherer Betwalt hat.

\section{898 .}

Beruht ber Manget ber Uebereinftimmung bes

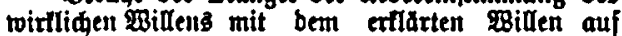
cinem 3rthume bes urbebers, fo ift bie $2 B$ illens: ertlăruug niøtig, wenn ansunehment ift, $\mathrm{ba}_{\mathrm{B}}$ ber

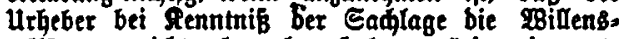
ertlărutig nidit abgegeben haben würbe; im ents gegengefebten ifalle ît bie willensertlartung gưltig. Jm Bweifel ift anzunehmen, bie \$illensertlărung

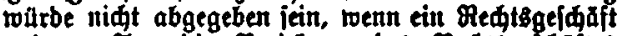

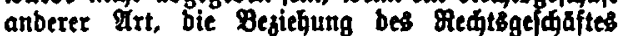
auf einen anberen Begcuitand ober bie Birlfamleit bes $\mathrm{F}$ chts fidtigt tourbe.

I s 89.

Die nah ben Borfariften bes $\$ 98$ fur niftig 3u etadtenbe 28 iffensertlarumg ift gưftig, wenn bem

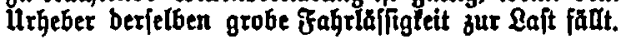

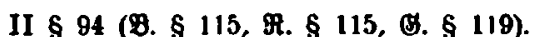

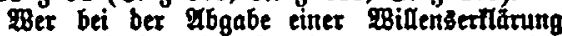
über beret guhalt to grthume war ober etre Crtlörung biefes Jubalteg überhaupt nidat abgeben wollte, tann bie Ertlárumg anfenten, wenn anzus nehmer ift, baś ex lie bei genntnis ber Sam:

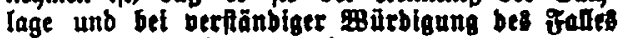
niक abgegebent habent toúrbe.

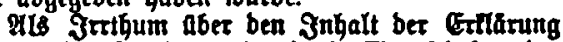

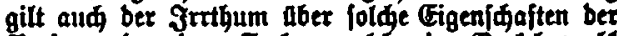
Berion ober ber Sade, weldie im Bertebre als wefentlid angefégen werben. 


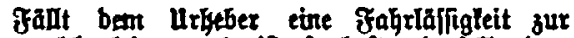
Saft, welne leine grobe if, fo haftet beriefbe betn

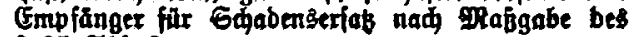
$\$ 97$ शื 3.

Die Borigriften bes 1. und 2. A95. finben teire Mnwernbung, wenn ber Emplänger ben Jrathum tamite ober tenaen marbte.

Motibe 459 f., Brotololle 712 ff., Dentfifrift 833 f., Somberidt 965.

I $\$ 100$.

F̌ehlt bei ber Sdfiefung eines Bertrages in Injiehurg eines Theiles bes Bertrages bie Uleber= einftimmung bes $\mathfrak{B i l l e n t}$ ber Ber=

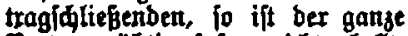

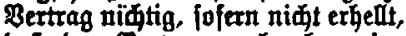
ba巨́ Der Bertrag aud ohne eine Beftimmung fiber jenten Theil ge= idloffer fein wärbe.
II $\$ 117$.

Saben bie \$arteien bei einem Bertrage, ben fie als gefdilofien anjegen, fin über einen ßuntt, aber bert eine Bereinbarung es=

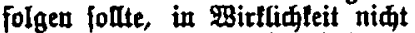
geeutigt, fo gill bás Bereinbarte, pofern fin ergiebt, baß ber Ber= trag aud ofne cine Beftimmung taber biejen Buntt gejwloffen fein würbe.

Motive 464, Brototolle 721.
9. § 151 (9. \& 131, (5. \& 155). Saber fin bie Barteien bei eirrem Bertrage, ben fie als ge=

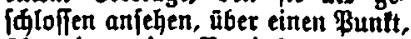
über ben eine Bereinbarumg ge troffer werber jollte, in 98 irtlingeit nidit getinigt, to gift bas $\mathrm{Ber}_{\mathrm{er}}$ einbarte, fojern anjunebratn ift, Da B ber Bertrag aud ohme cine Beftimmung äber biefen Bunth gefílohen jein watbe.
1 \$ 101 (Fiege aud zu I § 97).

Die Borfäriften ber $\$ \$ 98$ bis 100 finben ent= ipredenbe 2uttwendung, wean ber urbeber ber Widfentsertlärung zur luebeimittelung berjelben an ben Empfänger fid einer Mittelaperion bedient hat, burd welde ber 28 ifle unridtig mitgetgeilt ift.
II $\S 95(98 . \S 116, \Re . \S 116, \mathfrak{g} . \S 120)$.

Fine $\$$

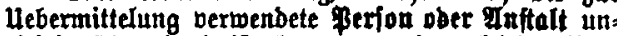
ridjig übermittelt iff, taun unter ber gleidgen Bor=

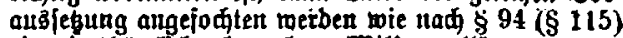
eine irrthümlía abgegebene Bilfensertlărung.

Motive 464, Brototolle 713 ff., Pomperidt 965.

$$
\text { I } \$ 102\left(I I-, B_{.}-, \text {R. }-, \text { G. } \rightarrow\right) \text {. }
$$

Ein Irrthum in den Beweggründen ist, sofern nicht das Gesetz ein anderes bestimmt, auf die Gültigkeit eines Rechtsgeschäfles ohne Einfluss.

$$
\text { grotive 465, Brotozolie } 721 \mathrm{f} \text {. }
$$

I 8103.

3ft Semanb 3ur $\mathfrak{A b}$ gabe : eimet willensertlas: rung wiberredttlic burd Drohung voer burd Bes trug beftimmt poorben, fo tann ex bie Gillillenterc tlärung anfedten.

Jit bei einer פoillens:

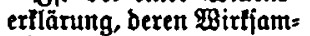
feit babon ab̧ängt, $b a \beta^{2}$ fie gegendber eirem $\mathfrak{B}_{\ell}=$ theiligten abgegeben roirb, Der Betritg bon einem Dritten Derabt, fo ift bie Biflensertlatung nur bann anfedtbar. roenn ber Gmpfänger ber

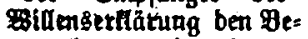
trug tarnte ober fermen muste.
II $\$ 98$.

Wer zux abgabe einer 2Bidlensertlignang burd argliftige ₹ăuldung ober burd Drogung wiberrecht= lid bejtimmint worbed ift, tarn bie Erttănung an: fechter.

Sit bie Tăuldung von einem Dritten veribt, fo ift eine Ettlänung, bie cinem Inberen gegentiber abzugeben war, nur barn aifeditbar, wenn biefer bie Tảufăung fannte ober tennen mafte.
タ. $\$ 119(\Re . \S 119)$. Ber zur $\mathfrak{A b g a b e}$ einer millenesertlănang burd argliftige $\mathfrak{x a u} u$ [dung ober Durd Drohung miberrents lid befitimmt morben ift, tana bie Ertlärung anfed ten 5 at tin Britter bie Täufoung verübt, io ift tine Crtlärung, bie einem Anberen gegenuber abzu= geben war, nur bann an= fewtbar, wenn biejer bie Täufuñ fante ober ternen mufgte. \$at ein Anberer als berjerige, weldem gegendubet bie Ertläzung abaugeben roar, aus ber Ertlärung un: mittelbar eir Medt er= worben, fo ift bie $E_{T}=$ tlantng, forveit burd fie

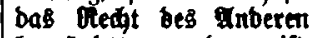
begralnbet toorber ift, bicem gegentuber ans fedftbar, weim et bie Tăuíung fannte ober tennen mußte.
\$. 128.

Ber zur $\mathfrak{A l}_{\mathrm{gab}}$ etner Willensertläruug butd arglifitige Tăuidung ober wiberredtlid burd Dros gung bejtimmt worben ift, tann bie Ertlărunt an: jedtert.

Sat ein Dritter bie Tăuffunt veribt, io ift eite Ertlănung, bie cinem Inderen gegentuber $\mathfrak{a b}_{\mathfrak{z}} \mathrm{u}=$ gebent rar, nur bann an= fedtbar, wenn biefer bie Tzuldutung fannte ober tenner maste. Eomeit ein $\mathfrak{A}$ inberer afs berienige. weldem gegetüber bie Grflarung ab zugebell mar. alis ber Ertlärung un= mittelbar ein Redit ex. roorbent hat, ift be cr= flärung ihm gegentuber anfechibar, wern er bie Tauifung lannte ober ternen mufte.

\section{Motive 465 fi., Prototolle 722 ff., Dentj巾rift 834, RomBeridit 965.}

I $\S 104$.

II $\$ 99$.

Die Anfehtung mus binnen Die Anfechtung muß $\mathrm{fm}$ Falle
D. $\leqslant 120$ ( $\Re .8120$, (\$. § 124).

Die Infedturig einer ná \$ 119 (\$) \$ 123) arfedtbaren 
beginnt mit bem Bettpunte, in nachom bie 3wangslage nuige= weldyem bie 3 mangslage aufachort Gat voer ber betrug entbeft ift.

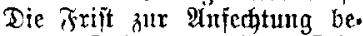
trägt 30 Эałre bou bem Beit=

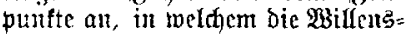
crfliturng abgegeben worben ift. wenn nicht bie \&ufechturg in (b)= määhèt des 1. 2tbi bereiț frither ausgejdolofien ijt.

Tie Sorjariften bes $\$ 166$

finben entfpredinde ?hucndutg. hört hat ober bie räufaitutg bun ben धufedtung sberechtigten er=

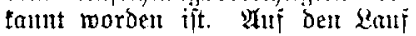
Der Frift fillon die für bie ver: iährutig geltenden $\mathfrak{B}$ oridtriftest

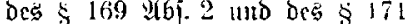
cutjpredhende Antwendung.

Die $\operatorname{Anfchtung}$ ift atsae= id loficn, menn jett dex llogabe ber Wilfensertlärung 30 Jahre abgelantent fitto.

Motive 468 , Frotofolle 723 f., Dentfdirit 834.

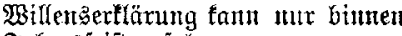
Falbresfrift erfolgert.

Sie Fript beginnt int fralle ber arglititigen Täuịung mit bem Bcitpuntte, in welchem ber $2 i n=$ fed)tutugsberechtigte die Tüntidutitg entorct, in Falle ber Irohumg mit bern Beitpulute, in welchem bie 3twangalage authört. Tha belt Qauf ber Trrift futoen die für Die Berjähruı geltendent $\mathfrak{B o r}=$ fduriften bes $\$ 198$ Ubj. 2 ut ber $\leqslant \$ 201,202$ ((3). $\$ 203$ Abj. 2 und ber $\$ \$ 206,207$ ) cutiprediende Huventintg.

Die unfechtung ift ausges ichlofien, toem icit ber Whagabe ber Willensertlörtug 30 Sabre verftrichen find.

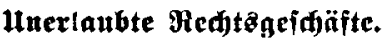

I \& 105.

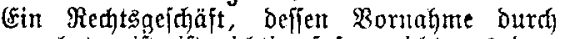
(Gejes verboten ift, ift tidtig, fofern nid) ants bem (bejese cin 2lubere jith ergiebt.

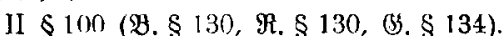

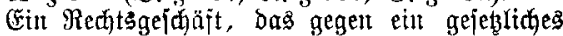
Berbot veritöbt, ift nichtig, fofern fich niwt aus bent bsejeze eitt 2 tnderes ergiebt.

Motive 468 f., Frototolle 724 ., Fumberint 969.

I \& 96.

Sie Ulufectung muź in ben

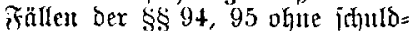
hafte Bögern (umberzüglich) er= folgen, nawbem Der Parfedtungs= berechtigte bon bem aftifentuntg: grumbe fetutuifá erlantght hat. Die

[I feglt ]. einem $\mathfrak{x b}$ wejenden gegetlüber $\mathrm{er}=$ folghte 2utfechtuntg gilt als redit= zeitig, remn bie Grtlämeng ber $\mathfrak{Y l}_{n}=$ fechturtg unberzitglich abgejentet ift.

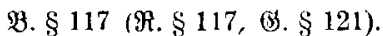
Tie anfedtumg mús in ben Fïllent ber $\$ \$ 115,116$ (\$) $\$ \$ 119$ 12(1) ohne idulbhaites Bögern (muverjitgria) erfolgen, nathent

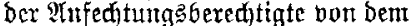

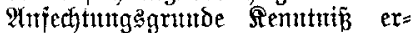
Ianat hat. Die einem abtoejeltbent gegenüber erfolgte afnjechturtg gilt al: rechtzeitig erfolgt, werut Die Anfechturgserllärung แnver züglid abgejentot worbent tît.

Die Hufedtung ift ausge. ichloffen, wertt feit bex abgabe ber $\mathfrak{W i f l l e n t s e r f l a ̈ r u n g ~} 30$ Jabre veritrichen futo.

\footnotetext{
Potibe -, Protolulle -, Denfidurift 833 .
}

I $\$ 100$.

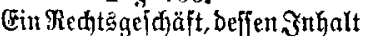
gegent bie guten Sittent ober Die dffi. Oronung verftibipt, ift nidutig.
II $\S 103(\mathfrak{B} . \S 134, \Re$. \& 134). (Ein Medjtsgejäät, Das gegen Die guten હitten veritúb́t, ift utichtig.

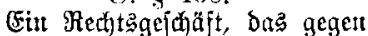

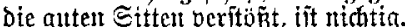

Shidtig ift itzbef. eitt Redits:

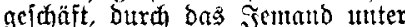
2tuzbeututg der Mlothlage, des Qeidytimus ober ber Unerfahrettheit eimes Intoerent fid oder einem Dritten für cine Seiftung $\mathfrak{B}$ er= mügensvortheile veriprecten oder gewähren läp̧t, weldhe Den $\mathfrak{B e r t h}$ Der Seifttutg Dergeftalt îberfteigeth,

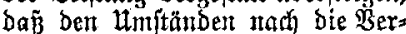
mögenşoortheile in anffälligem Mithoergăltniffe zu der Reiftutg itehett.

Photive 469, Brututolle 725, fium Beridgt 969, StenPeridte $1004 \mathrm{f}$.

I \& 107 .

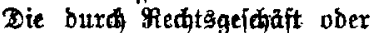
Durn artheil ober im 23 ege bex

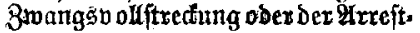

II $\$ 101$.

Beritübst bie Berfügung liber

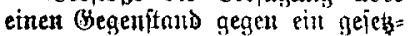

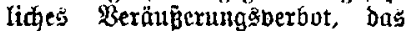

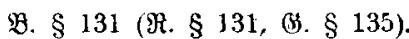
Beritöß̧̧ bie Berfügutug über einest Begentutono gegent eint geiegs

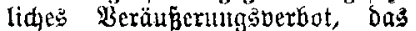




\section{LXXXVI}

nollgiehung afolgenbe Utebertra: gung ober 9ufbebung eines Fedftes unb Belaftung einex Sade ober eines Fedtes, burd welde gegen ein nur gum Squpe bes Intereffes beftimmter Berfonen bienenbes ge= leblides ober geridutlides $B e r=$ duberungsberbot berftofen wirb, ift gegendber bielen \$erjonen uns roirtjam. Die Borfariften zu Bunften berjenigen, well'se Medite bon cinem Ridgtberedtigten bers Ieiten, finben entiprectenbe $\mathfrak{A n}_{\mathrm{n}}$ wentoung.

AI berbot gilt aud bie in einem Predtsegeidäfte fíd granbenbe, naळ gejeslider Boridrift gegen Dritte wirffame Berfigungsbe= |ळ̆rănhung.

Das nux jum Ełubse bes Interefies beftimmter Berfonen bienenbe Beräuberungsoerbot bers liert burd bie Erófinung bes Ponturfes aber bas Bermögen besienigen, welder bem Berbote unterliegt, gegentaber ben Ponlurg.

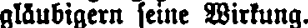

Solange bas Berbot befteht, bar ber segenftand, auf weldert es fid begieht, im 2 sege ber 8mangsoolltredung wegen eines perlönliden $\mathfrak{A}$ nipruhes ober auf Grunb eines Rextes, weldyes in Folge beş Berboteş unwint]am fein toirbe, nidt berăubert ober fiber. wiejen werben.
Exgemeinex Theil.

Iur ben Squp bes Intereffes be: finumier \$erjonen begloedt, fo if fie mur biefen \$erjonen gegentiber unvirffam. Der redisgej adftliden Berfilgung fteht eitte Berfigung gleid, bie burd urtheil ober im \$ege ber Broangsoullitredung obet ber 9urreftoolgiehung exfolgt.

Die Borídriften zu Guniten berienigen, welde Pedte bon einem Ristbereditigten Gerieiten, finben entipredenbe 9inwenbung.

\section{II $\S 102$.}

Dem geiesliden Berăubenungs: berbote in Ginne bes $\$ 101$ fteht gleid eit von einem Beriate ober einer anberen Bebjobe innerhalb ihrer Buftănoigfeit exlaffente $\mathfrak{B e r}$ auferungsberbot.

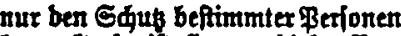
begweat, fo ift fie nux biefen \$er: fonen gegeniber univirtiam. Der rectşgej eine Berfígung gleia, bie im ærege ber 8wangsbollitredung ober ber Arreitooljielung erfolgt.

Die Borjdriften zu Bunften berienigen, welde Pefte bon einem gid entipredenbe Envenbung.

B. § 132 (Я. § 132, (B. § 136). Ein Bexăuberungşoerbot, bas bon einem Gerigte ober bon einer anberen \$ehorbe innerhalb inter Buftändigleut exlaffen toirb, fteht

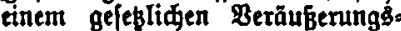
Derbote ber im $\$ 131$ (B. $\$ 134)$ bezeidneten Fitt gleid.

Plotive 169 ff.; Protololle 725 f.

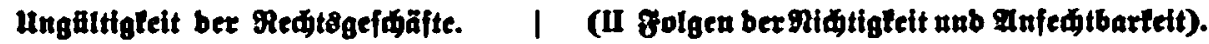
I \$ $108(I I-, B .-$ R. -, G. - ).

Ein nichtiges Rechtsgeschäft wird in Ansehung der gewollten rechtlichen Wirkungen so angesehen, als ob es nicht vorgenommen wäre.

Motide 472 f., Brotololle 726 f.

I $8109(\Pi-B .-R .-G .-)$. wegfallen.

Ein nichtiges Rechtsgeschäft wird nicht dadurch gïltig, dass die Gründe der Nichtigkeit später

Mrotive $472 \mathrm{f}$, Brotololle $726 \mathrm{f}$.

I $\$ 110$.

Mirb bas nidtige Redtsge (ळăft bon bem lurbeber beftatigt, 10 ift bie \$eftattigung als eine et: neuete Bortahme bes Pechts̊ge: fóbftes zu beurtheilen.

Bito ein nidtiger Bertrag bes ftattigt, fo finb bie Bertragldlieben: ben im Bmeifel unter einanber fo beredtigt unb verpfliatet, wie toenn ber Bertrag von Enfang ant gultig gewejen wåre.

\section{I \$111.}

Entlpriat bas beablintigte, aber als loldes nibtige Rents: gefdaft allen Exforbertiffen eines

\section{II $\$ 110$.}

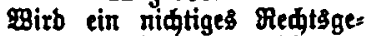
[đuăft bon bemientgen, welder es borgenommen bat, beftartigt, lo ift bie Beftatigung als emeute $\mathbb{B o r}$ nabme zu beurtheilen.

פBirb ein nimtiger Bertrag von ben Parteien beftatigt, fo [ind fie im groiffel unter einanber fo bers pfliditet, wie wenn ber Bertrag bon Enfang an gultig semefen watre.

Motive $472 \mathrm{f} .$, Protololle 727.

II $\$ 111$.

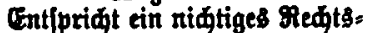
gejobaft bent Exforbernifer eines anberen Bedtşgef daftess, fo gill
D. $\$ 137$ (Я. § 137, (3. \$141). goirb ein niфtiges Medtşge= idaft von bemientgen, weldjer es vorgenommen hat, beftătigt, fo if bie Beftatigung als erneute 80 \% nabme gu beurtheilen.

\$Birb ein nidtiger Bertrag von ben Barteien beftatigt, fo jinb biefe in groeifel verpfliatet, cin. anber an gewähren, was fie haben witrben, wenn ber Bertrag bon Qunfang an galtig gewefen walte.

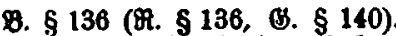

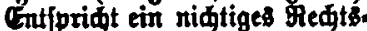
geiduft ben Erforberniffen eines antoren Bedtsge/कaftess, fo gil 
anberen Pledtsgeldaftes, fo if es als bas \&egitere aufrewt zu er= balten, toenn bies bem aus ber Bomagme bes niditigen Pedtg: gejäjutes fí exgebenber Billen gemås ift.

I $\$ 112$

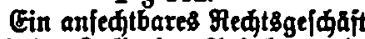
wirb im falle Der Anfectung in Infehung ber getwoultent redtlidien \$ithungen fo attgelehen, als ob es niat vorgenommen wäre, $t^{8}$

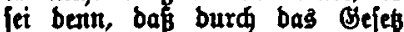
geringere 20 ithungen ber $\mathfrak{A n f e d}$ : tung vorge/

\section{I $\S 113$.}

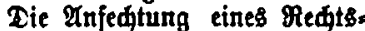
geídăftes erfolgt burd cine bon bem \&nfectung şberedtigten gegent: aber bem $\mathfrak{A n}$ fe山tungsgegner $\mathfrak{a b}=$ zugebenbe Billenserllărung

Unfectungß̊gegner ift bei einem Bertrage ber anbere Bertrag= |c̆liefenbe, bei einem einjeitigen

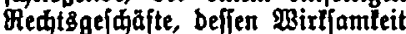
babon abhängt, ba $\bar{\beta}$ es gegenulber einem Betherligten vorgenommen wirb, ber Petheiligte, bei einem

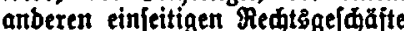

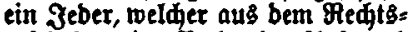
gejळafte ein Pedt in Arfprus nimmt, beffen भuffebung burq bie $\mathfrak{A}$ nfedtung beztoedt twirb.

Dură bie Benehmigung bes Infechtungbbereळtigten wirb bas

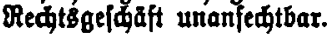

I $\$ 114$

Irift bet Grunb ber ungaltig:

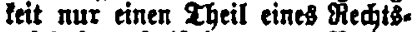
bejadftes, fo ift bas ganze Bedts:

bas Regtere, wenn anzunehmen ift, | bas Rebtere, wein anjunehmen ift, baß bies bei Tentutnif bet Rid"= bas beffen Beltung bei Penntnió tigfeit gewollt fein tourbe. ber Siditigleit getoollt fein wirrbe.

\section{Motibe 473, Protololle 727.}

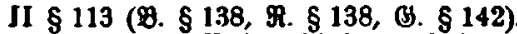

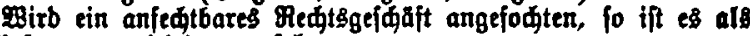
bon Infang on uthttg onjufeben.

Ber bie Aufechtbarteit lennte ober tennen mufte, wirb, wenn bie श्Anfedtung erfolgt, fo behanbelt, wie menn er bie Riatigleit bes

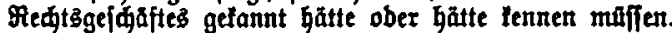

Motive 473 f., Brotololle $727 \mathrm{f}$.

II $\$ 114$.

Die Infechtung erfolgt butw Crtlărung gegenuber bem $\mathscr{A n}=$ feळhungsgegner.

Arfedtung\$gegner ift bei einem Bertrage ber anbere Theil, bei

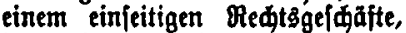
bas einem \&nberen gegenfiber vorgunehmen war, biejer, bei einem

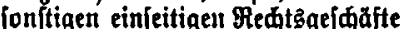

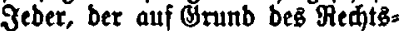
gejđăftes unmittelbar einen ređt= lident Bortheil erlangt hat.

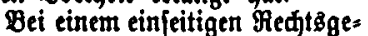
füafte, bas einem quberen ober

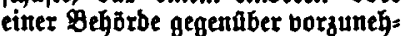
men toar, ift, aud wenn es ber Bebätbe gegendber borgenommen worben ift, ber Anbere ber Ans= fechtungsgegner.

Die OAnfedtung einer einfeitigen millenserllatung, bie bor ciner Bebärbe abzugeben ober an eine folde zu riften mar, tann burd Ertlarung an bie Behörbe erfol: gen. Die Bebörbe foll bie Cr: llărung bemienigen mittheilen, ber

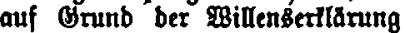
unmittelbar cinten redtliøen Bor= theil exlangt hat.

\section{8115 .}

Tie Trifectung ift ausge= falofien, went bas anfedtbare

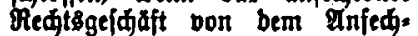
tungsherentigten beftatigt wirb.

Motive $474 \mathrm{f}$., Brotololle $728 \mathrm{ff}$.

II \& 112 Үit ein Theil cines Meats: gefdafftes nidatig, fo ift bas garge gechtigeidaft niळtig, wenn niळt
9. § 139 (9. § 139, B. § 113 ). Tie थrifedtung exfolgt burw Ertlărung gegenaber bem Anfect: tungsigegner.

onfechtungsgegner ift bei einem Bertrage ber anbere Ifeil im Falle bes $\$ 119$ (\$. \$ 123) $\mathscr{U} 6$;. 2 Sab 2 berjenige, welner aus bem Bertrage unmittelbar ein Redt errorben bat.

Bei eintem einjeitigen Redts. gefăåte, baş einem anberen gegenúber borgunegmen war, ift

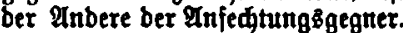

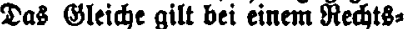
gejăffte, bas einem Anberen ober einer Befjorbe gegendiber borzus nehmen twar, aud bann, twenn

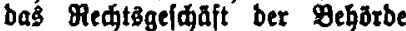
gegenuber borgenommen toorben ift.

Bei einem einfeitigen Pedts. gef tungsigegner Jeber, ber auf ostunb

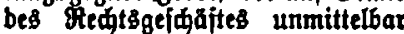
eiten reatliden Bortheil erlant hat. Die Anfechtung Iann jeboh, wenn bie 2 illendertlărung einer Bejörbe gegentaber abjugebent war, burd extlanng gegenuber ber Dehörbe etfolgen; bie פehöbe foll bie Enfedtung bemienigen mit. theilen, welder burd bas Meळts. gef worben ift.

タ. § 140 (भ. § 140, (H. § 144). Die Anfedtung ift ausge: idloffen, went bas anfedtbare

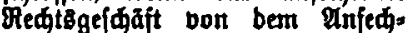
tungsberedtigten beftătigt wirb.

Die Beftatigung bebarf niøt ber falt bas Medte̊geidaft be. fimmten form.

\$. § 135 (भ. § 135, (9. § 139). . Jft ein Xheil eines Rechto. gejdaftes niditg, fo ift bas garge

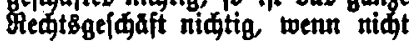


gejobitt ungaltig, fofern nidt w: belli; baf balfelfe and ofre bie unfiltige Deffimong getooll fein tourbe. anjunebmen ift, bof es mú ogne ben nidtigen gigall gewollt fein willoe.

Dotive 475, Brototolle 735. angunebmen if, buf es and. obne ben nidtiger Theil oungetunmen fin tortibe.

\section{Bextretumg (unb) Bofluad.}

$I \S 115(I I-, B .-, R .-, G .-)$.

Bin Rechtogeonhäft hann, sofan micht das Gesetz oder die Natur des Rechtegenchäfles entgegensteht, auch durch einen Vertreter und gegenïber einem Vertreter vorgenommen woerden.

Intotibe $475 f$., Protololle 735 f.

I\$116.

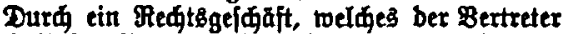
innerhalb ber Grenzen feiner Bertretungämaht vor= nimmt, wirb ber Bertretente ummittelbar beredgtigt und verpfliatet. $\mathcal{E}_{8}$ madt teinen Unterjodieb, ob

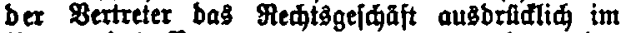
Mamen bes Bertretenen vorgertommen hat, ober ob: bie lunftantbe ergeben, bas baffelbe naf bem wiflen bet Sanbelnbent in Manten bes Betretenter borgenommen werben foute.

It bex 2 Bitle, in frembem Namen zu banbeln,

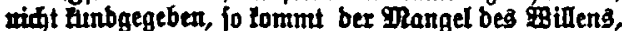
in aipenem Mamen zu hambeln, timt in Betradt.

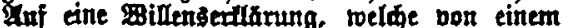
Dritten gegentlber bem Bertreter abgegeben wirb, finben bie Boridriften be\$ 1. Q 6 f. entipredenbe Arroenbung.

Motive 477, Prototolle 736f., Denlidift $837 f$.
II \$134 (\$. \& $160, \Re . \$ 160$, (3. \$ 164).

Cine Millengerilatuag, bie Semant innerbalb ber inm zuftebenten Betretunggmadt im gramen bes Bertretenen abgiebt, wirtt unmittelbar far unb gegen ben Bertretenen. (E) maht feinen unter=

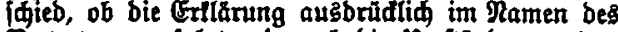
Bertretenen erfolgt, ober ob bie lumftande ergeben. baf fie in beffen Ramen exfolgen foll.

Iritt ber $\mathfrak{B i l l e , ~ i n ~ f r e m b e m ~ R a m e n ~ z u ~ G o n b e l n , ~}$ nidt erfennbar heroor, fo lowumt ber gRangel bes æillens, im eigenen $\mathfrak{N a m e n ~ z u ~ b a n b e l n , ~ t i m t ~ i n ~}$ Betraht.

Die Dordariften bes $20 ; .1$ finben antfpreduenbe Intoniturg, wern eitre gegenitber einam Finberen abjugebenbe satllensertlänung befien Bertreter gegent. itber etfolgt.

II 8135 (9. \& 161, F. \& 16L, (\$. \& 165):

[I féfilt].

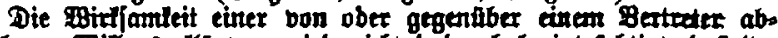

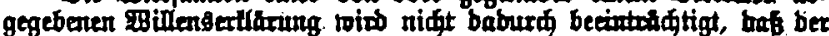

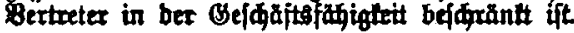

Mtotibe -, Protoblle $737 \mathrm{f}$.

18117 .

Das Cuforberni ber Hebercinftinumung ba whatiduet gleidjen bie Erbeblidghit bon Drobung, Betrug,

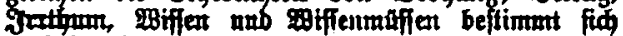
nad ber Perfon bes Bertreters.

I 8118.

Sit bie Crmulfotigung jur Bertretury bon bem

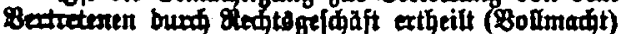
unb betingt fin bit Craringtigung auf ein beftimmtes

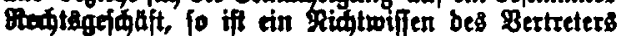
medid, toem ber sentretere touste ober, fofern

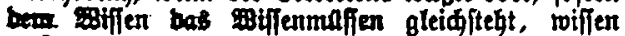
mupite.
9. $8162(\Re . \$ 162$, \&. \$ 166).

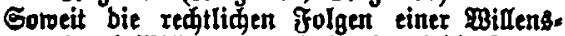
etrânmg burd \$illensmängel ober burd bie fenut: nifi") ober bas Rennenmilffen gemiffer umftanbe

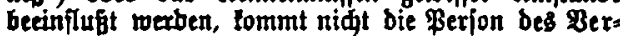
tretenen, fonbern bie bes Bertreters in Betradt.

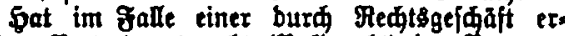
theilten Bertraungsmaht (Bollmaht) ber Bertreter nad beftimmten Beifungen bes Bollmadtgebers gehanbelt, io tunn fin biefer in Anfegung lolder

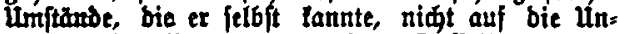
tenntnis bes Bertreters berufert. Daffelbe gilt bon um[tanben, bie bet Bollmahtgeber fennen mubte,

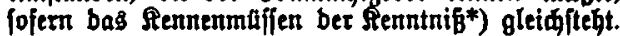

Mlotibe 477 f., Protololle 738 ff., Denl|

\section{II \& 137.}

Die Entheitung ber Bollmadt epolgt bura Ertharung gegentlber Dem zu Bebollmảdtigenber obet bem Dritten, weldem gegenaber bie Bertretung ftattfinben foll.
円. \$163 (भ. \& 163, G. \& 167). Die Crtbeilung ber Botmatit erjolgt burd Ertanung gegentaber bem zu Bebollmăhtigenben ober bem Dritten, bem gegenflber bie Bertretung ftattfinben poll.

Dte Erifürung bebarf nibt ber Form, welne fir bas Medts. Beloüft beftimmt tA, auf bas fit bie Bollmade bejtebt.

DRotibe -, Protatolle -, Detrifdrift 837 if. 
$1 \& 119$.

Die Bollmadt ift miberruflich. Üıf Die Wiberruflidyteit fann midt verziditet weroen.

Auth im llebrigen gelten für bas Erlojidyen Der Bollmadyt Die Borjuriften iiber bas Erlofwen Des Auitrages, foweit ntidit auts Dem Berhältıifie beș Sollmachs= gebers zu ein anderes fid ergiebt.
II $\$ 138$.

Das Cribichen ber Bollmadit beftimmt ith nad bem threr Er= theilung zul Grande litegenden भed toverhältniffe. Sofern fich aus Diejem Berhältnifje nidht ein Anderes ergiebt, ift die Bollmadit auch bet bem Frortbejtehen des Berhältniffes wiberrufflich. QUนf bic Extlärung bes Widerrutes finbet bie $\mathfrak{B o r j d x i f t}$ des $\$ 137$ entipredfende $\mathfrak{A n w e n d u n g . ~}$

Sumeit nad den $\$ \$ 605,666$

bie exlojujente $\mathfrak{B o l l m a}$ aht eines $\mathfrak{B e}$ aujtragten ober eines geifiäfts: fübrestben (sejellichafters als forts beftehend gilt, wirlt fie nidht $z^{u}$ Guuften eine Dritten, Der bei ber

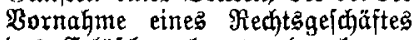
bas Cribionen fante ober tennen muste.

Mrotive 478 ff., Brotololle 740 fi., Dentidyrift 837 if
B. \& 164 (R. \& 164, (S) \& 168). Dad Erlojich Der Bollmacht beitimmt fich nar. Dem ihrer Er: thethung $z^{\mathrm{H}}$ (Srumbe liegendett Rerhtşerhältnifie. Die Bollmadit ift aud bet Dem Fortbeftehen bes Rechtse verhältniffes toidoerruftich, jofern fich nicht aus biejent ein Anberes ergiebt. $\mathscr{A} u$ fie $\mathbb{E r}$ -

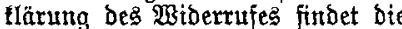
Woridhrift bes $\$ 163$ (\$. § 167)

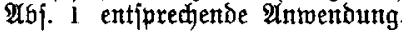

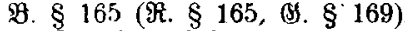
Someit nach ben $8 \$ 661,716$ (B. 674, 792) bie erlojdene $\mathfrak{B o r}=$ maht eines Beauftragter ober eines geichäftsfüfrenden Befell fóafters als fortbeftehend gillt wirft fie nicht zu (Suniten eines Dritten, ber bei ber Bornahme

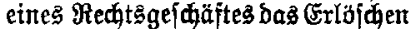
tennt ober fentuent mús.

II $\$ 139(\mathfrak{B} . \$ 166, \Re$. $\$ 166, \mathfrak{S} . \S 170)$.

[I fehlt].

I $\$ 120$

Sat ber : Bebollmähtigung Durh befonbere Mittheilung ober bura ïff. Be= lanntma hung Dritten fulogegeben, fo gilt bie flunbgefung im 1. Falfe gegenüber bent bejonters be= naüridutigten Dritten, im lesteren Falle gegentifer jeden sritten, welher ein Rechtagejchäft mit bem Bebollmảdtigtent gejhlofien ober gegenüber Demielben borgenommen ober toeldyem gegenuber ber $\mathfrak{B e}=$

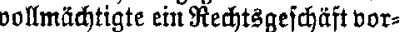
genlomment hat, als jelbftäntoige Bebollmädtigung

Das Erlöiden ber Bollmadt

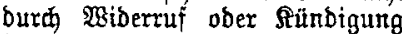
ijt gegentuber bem Dritten mur bann wirfiam, wenn bag Erlofichen

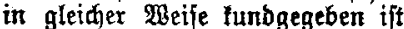
ober wemt der Dritte baffelbe tannte ober temen muphte.

\section{I \& 121}

Die Boridriften bes $\$ 120$ ab). 1 inben entiprechende $\mathfrak{A n}=$ combung, wern ber Bebollmädtigte zum gradreile ber Bebolf= mothtigung bon bem Bolmacht: geber eine Bollnahtsurtunde er Galten unb biefelbe Dem Dritten borgelegt hat.

Der Bebollmảntigte mub bie

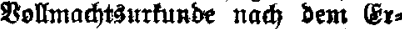
löjuen ber Bollmăt bem Borto machtgeber zuriatgeben.

Wird die Bollmadit Duth Erlärung gegenüber einem Dritten extheilt, fo bleibt fie biejem gegenüber in \$raft, bis ihm Das (Erlojiden bon bem Bollmadtgeber angezeigt wirb.

II $\$ 140$.

Sat Jemant burd bejondere Mittheilung an einen Dritten oder Durch biff. Belanutmaduung funto=

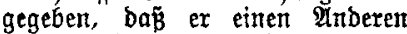
beoollmächtigt habe, jo ijt biefer auf Grutto ber futnogebung im 1. Falle gegenitber bem Drtten, im lebteren ifalle gegenüber jedem Dritter an Bertretung befugt.

Die Bertretungsmadht bleibt beitehert, bis bie funbgebuts in entipredienter Beife zurtictge $=$ nommen ift.

\section{II $\$ 142$}

Die Boridriftert bes $\$ 139$ bes \& 140 भbj. 2 und des \& 141

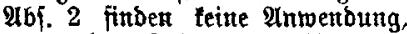
wenn Der Dritte Das Erldjohen ber Bertretunggimad bei ber

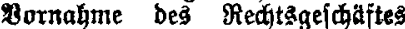
tamute ober fennen múpte.

II $\$ 141(\mathfrak{B} . \$ 168, \Re . \S 168,(S) \S 172)$.

Der befonberen $\mathfrak{D}$ tittheilutg einer Bebolmáditigung burd ben Bollma htgeber iteht es glei urfunbe argigehänoigt und ber Bertreter fie bem Dritten borgelegt hat.

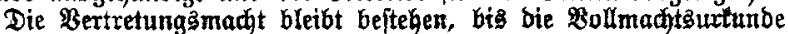

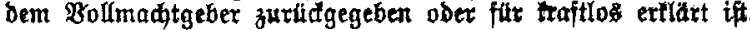

II $\& 144$

Rad Dem Erlojiden ber Boll= madit hat ber Bebollmäntiate bie

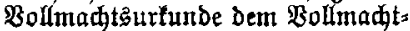

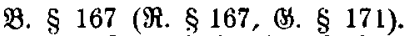
Shat Jemant burch bejondere Mittheilung an einen Dritten ober Durch biff. Befanttmadung fund =

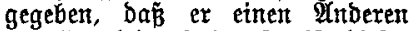
bevollmähtigt habe, fo ift biejer auf (Stunb ber Punogebung tm 1. Falle Dem Dritten gegeniuber, im Iepteren Falle jeom Drittent gegentiber zur Bertretung berugt. Die Bertretungsmadt Gleibt beitehen, bis bie Funbgebung tn

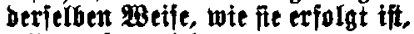
wibertuien twird

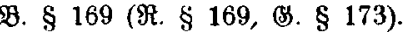
Die Borifrifter bes \& 166 , Des $\$ 167$ थb 1.2 unb des $\$ 168$ Ab 2 (G. \& 170 , be马 \& 171

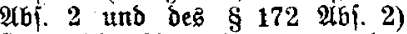
finoen feine $\mathfrak{A n}$ wentung, wenn ber Dritte bas Ertiöfthen ber $\mathfrak{B e r}=$ treturgsmadyt bei bet Botnahme bes Rechtzgeidiätes lennt ober tentmen mug.

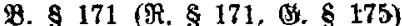

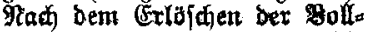
madit Gat ber Bebollmathtigte bie

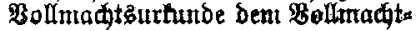


Fuf Intrag bes Bollmadt= gebers hat bas Geridt, bei weldem biejer feiner allgemeinen Beridtss ftanb hat, ober nad feinter $\mathfrak{B a h l}$ bas Geriat, welnes für bie Qlage auf Burlidgabe ber Bollmahts: urtunbe zuftånbig ift, bie luttunbe

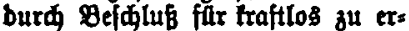

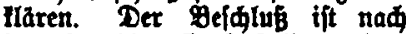
ben far bie öff. Buftellung einer Labung in bargerliajen Feats s: freitigieiten geltenber Boridriften befannt gu maden. Die Araftlos: ertlänung wirb mit Q Iblauf 1 Dto= rates feit ber Iesten Cinrildung beş Bejđluffes in bie aff. Blătter wirtiam.

Golange die Bolmantsిuttunbe weber jurlatgegeben nod far traftlos ertlärt ift, ift bas Ex= Iofífen ber Bollmadt burd $\mathfrak{W i b e r : ~}$ nuf ober fallbigung gegentiber bem Dritten nur bann wirfjam, wenn berjelbe bas (Exlajogen tannte ober fertien muste. geber jurildzugeben; tin Burthd: behaltungsiredst fteght igm nidgt zus.

Fuf Intrag bes Bollmaht: gebers gat bas Geriat bie Boll. madtsurhunbe burd Befकlus fir Iraftlos zu extlären, went bas Exlofhen ber Bollmadt glaubhaft gemaht twirb. Bor ber Ent.

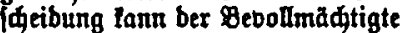
gehort werben. Der Bejqlus if rá ben Borjariften ber $\mathbf{E} \mathfrak{B O}$. fïr bie off. Buftellung ciner \&abung befarnt zu maner. Ilit bem Gblauje 1 Dlonates nad ber lesten Einrldung bes Befdluffes in bie off. Blatter twitb bie eraftlos: ertlärung wirffam.

Buftănbig far bie Rraftlos ertlünung if fotwohl bas

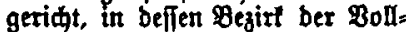
mahtgeber feinen allgemeinen

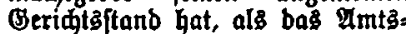
geriat, weldes für bie §lage auf Radgabe ber urtunbe, abgejehen vom 28 erthe bcs Streitgegenjtanbes, zuftänbig fein rourbe. geber zuridgugeben; ein Buruld bebaltungsredft fteht igm nidgt zu.

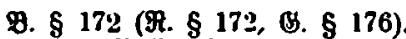
Der Bollnadgeber lana bie Bollmadtintunbe burd etue off. Betanntmadung fït Iraftios et. Hären; bie Araftlosertlảnung mus nad ben für bie off. Buftellung

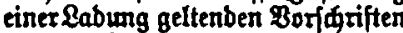
ber (EBD. veroffentliagt werber. Mit bem Ablaufe 1 Monates nad ber legten Cinrilung in bie off. Blätter wirb bie Araftlosertlänth toirtiam.

Buftănoig für bie Betolutgung ber Beröfentlibung ift jowohl bas Umtgegeriat, in beffen Begirfe ber Bollmadtgeber feinen allgemeinen Beriatsitanb hat, als bas $21 \mathrm{mts}$. geridt, weldes für bie Plage auf 9̈üdgabe bet Urtunbe, abgejehen von bem 2 Berthe bes Étreitgegett= ftanbes, suftănbig fein warbe.

Die Araftlosertlärang tft un. mirffam, wenn ber golmant. gefer bie Bolluadt nibt wiber. ruifen lann.

Motibe 483 ff., Protololle 740 ff., Ienthdrift 837 ff.

\section{I $\$ 122$.}

EBirb bun einem Sebollmån.

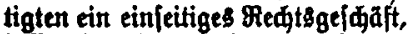
beflen \$irfjamlett babon abhangt, baf es gegenuber einem Betbeiligten borgenommen wirb, ohne Bors legung titter Bollmađtsిurlunbe vorgenommen, fo ift bas Medts:

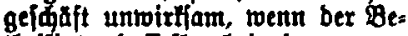
theiligte baffelbe bei ober unver = zinglin nał ber Bormahme wegen Mangels ber Borlegung einer

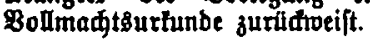

II $\S 143$.

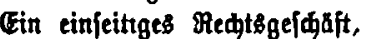
bas ein Bebollmäatigter einem Anberen gegenaber bornimmt, ift untwirfiam, wenn eine Bollmadts: urhunbe nidit borgelegt unb bas

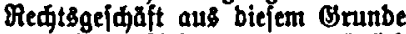
bon bem anberen unvergalialid gurdagemiejer wirb. Die Burtad: toeifung ift ausgefdlofien, toenn ber Bollmadtgeber ben Anberen von ber Bevollmảntigung in Stenntnib gefest batte.

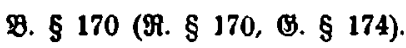

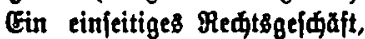
bas ein Bebollmăatigter cinem श्mberen gegentber bornimmt, ift untwirlfam, twenn ber Beboll= mähtigte eine Bolmantsurfunbe niaft vorlegt unb ber शnoere bas Redtsgejabft aus biefemt Grumbe unberzuglid zurithoeift. Die Burüdweijung ift ausigeidlolfen. ment ber Bollmadtgeber ben Anberen von ber Bevollmåhtigung in Senutnis gelest Gatte. Drotide 485, Brotololle 747 f., Tent/dyrift 837 ff.

\section{I $\$ 123$}

Sat Jemanb im Ramen eines Snberen, ogne Bertretungsmant zu haben, einen Bettrag gefíloffen, to ift bie Birflamleit bes Lesteren fur ben Bertretenett von beffen Benehmigung abhangig.

Co lange bie Senebmigung nidt verweigert ift, tant ber ans bere Bertragifliebenbe aư mit Buftimunung bes Bertreters bout bem Bertrage nidit zuritatreten.

als Bertoeigerung ber Beneh: migung gilt es, wenn bem anberen

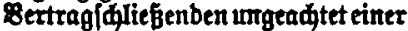
bon ihm an ben Bertretenen er: Iaffenen Tufforberung innerhalb einer vom cmpfange berjelben fut beredrenber Irift bon 2 Boden cine beftimmte unb arboridalide Extlarung nidt jutommt. Die
II $\S 145$.

Sat Jemant ohtte Bertretungs: madit im Ramen eines Unberen einen Bertrag gejdlolfen, fo hängt bie 28 irflamleit beş Bertrages für unb gegen ben Bertretenen von beffen Bsentebmigung $\mathrm{ab}$. Die Be= nehmigung fowie beren Bertwei: gerung farm mur bem anberen Theile gegentaber erflart werben. Der Berweigerung ftebt es gleid, wenn ber Bertretene ná Empfang einer Eufforberung bes anberen Theiles niфt binnen 2 פoden bie Bemefmignth ettart.
\$. $§ 173$ (F. § 173, \&. § 177).

Salieft Semanb ohne Ber. tretungsmant im Namen eines Enberen eiren Bertrag, 10 bangt bie Mirtfamleit bes Bertrages für unb gegen ben Bertretenen von beffen Eenebmigung $a b$.

Forbert ber anbere Ibell ben Bertretenen aur Crfläruttg ïber bit Cenebutgung auf, fo tann bie Ertlărung nur ihm gegentuber exfolgen; cine bar ber fufforbe rung bem Bertreter getgenüber etllärte Genchmtgung obet Bet metgetwing bet Benebmigung wir unmtrifam. Die Benebmigung lann nut bis jum Mblaufe von 2 \$oden nad bem cmpfange ber Tufforberung ertlart werben; wirb fie nidit extlart, fo gilt fie als ver. weigert. 
Benehmigung forie beren Ber: toeigerung tann naథ Deginn ber frijt nur gegentiber bem anberen Bertragidliejenben erflärt werben.

Etirbt bex Bertretene, obne genehmigt zu haben, fo wirb Gier: burd in ben Rechts̄bergaltniffen niøts geånbert.

\section{I $\S 124$.}

Sat ber Bertreter bei Shliebung bes Bertrages niфt hunbgegeben, $\mathrm{ba}$ B er ohne Bertretungsma tantn ber anbere Bertragidliesenbe, fo Iange ber Bertretene bie $\mathrm{Bl}_{\mathrm{e}}=$ nehmigung nidt ertheilt hat, von bem Bertrage zurudtreter, es fei bern, baß $\mathrm{B}$ er ben Ptangel ber $\mathfrak{B e r}$ tretungsmadyt gelannt hat.

Potive 485ff., Protololle 748f., Dentfdrift

I $\$ 125$.

Der Bertreter, welder bei

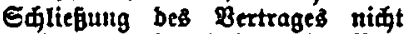
hunbgegeben hat, baf er ohne Ber. tretungsmadt fei, ift, wenn bie Benehmigung bes Bertrages verweigent wito, bem anberen Bet: tragjळliebenben perfönlid verhaftet. Der änbere lann nad leiner ææabl Exfallung ober Eqabenserfabivegen Niaterfaulutg forbern.

Die \$aftung bes Bertreters tritt niat ein, wenn ber Inbere bett Mrangel ber Dertretungsmadt gelannt hat.
So Iange ber Bertrag nidt genehmigt ift, lann ber umbere Theil juridtreten, es lei bent, DaE er ben MRangel ber Bextres tungsimadt bei bem 96idluffe bes Bertrages getannt bat. Der Mads tritt lant aud bem Bertreter gegendiber extlăt werben.
D. 5174 (9. \$ 174, (3. \$ 178). Oits aur ङenthmigurg bes Bertrages ift ber anbere Iheil gum gibernule beredtigt, es fei benn, baf ex ben Mlangel ber $\$ e x$. tretungsmaht bei bem 96\{ळlufie bes Bertrages gelannt hat. Der Miberruf tann aud bem Bertreter gegertiber etllăt toerben.

II $\$ 146$.

Ber als Bertreter einen Bers trag gefdloffen Gat, ift bem arberen Theile nad beffen gabl sur $C_{T:}$ faItung ober zum Edabenserjafe berpflitited, toenn er feine Ber. tretungsmałt niđt nađjurveifen vermag unb ber Bettretene bie Benehmigung bes Bertrages ber: tweigert.

Sat ber Bertreter bent Mrangel ber Bertretungsmađt niळt ge: lannt, fo ift er nur sum Erfake besienigen Salabens berpflidtet, weløen ber anbere Theil babura exleibet, baß er auf bie Bertretung\$: mad, vertraut bat, jebod nidt aber ben Betrag bes 3ntereffes hinaus, toeldes berfelbe att ber Sirfiamleit bes Bertrages hat.

Der Bertreter baftet nimt, toenn ber anbere Theil ben Mlangel ber Bertretungsmadt fannte ober ientren mubte. Der 2 ertreter baftet aú bann nidft, wenn er in ber

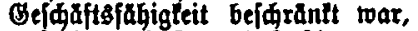
es fer bent, baf er mit Buftimmung feines gejeglidinen Bertreters ge: Ganbelt hat.

Motibe 485 ff., Brotololle 749ff., Destifdrift 837 ff.

$I I \$ 147$ (tgl. II \& 113 Abs. 2 , bei I \& 112.).

Die Kenntrios der Anfechtbarkeit einer Vollmacht steht in den Fällen der $\$ 145,146$, wenn die Anfechtung erfolgt, der Kenntniss der Nichtigkeit gleich.

Dan Gleiche gilt im Falle des $\$ 146$ eon dem Kennenmüssen der Anfechtbarkeit der Vollmacht.

Brotololle 744.

I 6126.

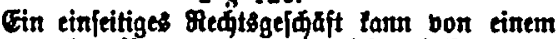
Inberen ohne Bettretungsmadt nidt wirtiam oor: genommen werben. Ift jebod bie \$ixtfamiteit bes efnieitigen Medtsgefádtes bavon abbangig, baß bafielbe gegentiber einem Betheiligten vorgenommen toirb, fo finben, went ber Betheiligte mit ber Bor: nabme fin einberftanben extht, bie far Bertăge geltenben Borfめriften entipredenbe antwentung.
II $\$ 148$ (P. $\$ 176$, H. $\$ 176$, (3) $\$ 180)$.

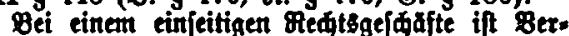
tretung ohne Bectretungsmaht ungulafing. Sat je: bod berienige, weløem gegentaber ein foldes Fedts: geldaft vorjunthmen war, bie bon bem Bertreter behauptete Bertreturgsmadt bei ber Bormabme nidt beanflanbet ober ift ex bauit cinberfanben getwejen, bab ber Bertreter obne Bertretung\$madt hanble, fo finben bie Borforiften aber Bertăge entpredenbe 
Shuvendung. Ins (sleidje gilt, wenn ein cinjeitigeós

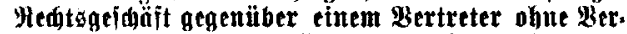
tretungsmadt mit beffen Ginveritänonin̄e vor. genoumen wirb.

Mative 488, Brotufolle 754 fi., Tenfichrift $8: 37$ fif.

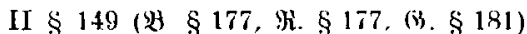

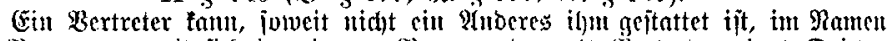
[I jehlt]. Des Bertretenen nit fith in eigenen Mamen oder als Sertreter eines Dritten

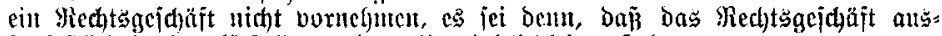

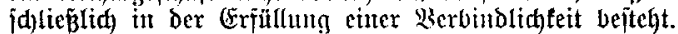

Mrotive -, Brotofulle $759 \mathrm{j}$.

\section{Cinwilligung (unb) Conehmigung.}

I $\$ 127$

Эit bie Birtianteit eine Red)tsgejhäftes babon ab̧ängig, ba $\tilde{B}$ ein Pinderer im Boralta in Die Wortahme Defielben eintwilligt voer bas borgentommene ஒieffits= gejdäft gentebnigt, jo fann die ciutwilligung ober Genefhnigung fowte bie Berwetgenung ber (\$) nehmigung, wenn bas Reát: gejめäft ein Bertrag ift, gegeníber bent eiten voer auberen $\mathfrak{B e r t r a g}=$ (đ) liế̄enden, wenn es cur einteitiges Recht

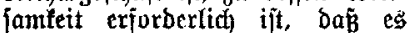
gegenüber eimem Betheiligten vor= gentommett twird, gegentüber bem

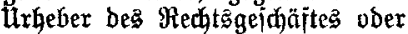
bem anderen Betheiligten erflärt werbent.

Die Erflärung fanı ausbrïdlich

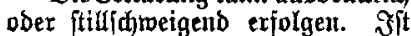

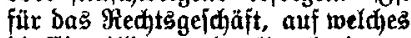
bie Eitnilligung ober(Senehntigung fich beziegt, eine form erforberlid, fo ijt bie Étzlärung an bieje Fornt utaht gebunden.

Tui bas Erlojid)en ber Witt= jamfeit ber in Boraus ertheilten Cinvilligutg finben bie Borjegriften entiprecfonbe $\mathfrak{A}$ itwentung.

Die Bentehnigutg wirłt, fofern nidht ein Anberes beitimmt iit, auf bie Beit zurita, in meld)er bas genehmigte Reditsgejđäjt vorge= nommen toordent ift. Durd bieje Rüdbeztehung werben Rechte nidht berithrt, weldye Dritte bor ber Senehmigung Durch Beriügungen bes Benehtnigenten ober in Wege einer gegen biejen erwirtten 3 wang volfitrectultg ober 21rrejtbolziehung an bent Segenftande des Rergts= ge/däates extworben haber. äber Das Erlïjden ber Bollmadt

\author{
II $\& 150$
}

5ूängt bie $\mathfrak{B i r t j a n t e i t ~ c i n c s ~}$ Bertrages oder eintes einfeitigen, einem Anberelt gegenüber vor= zunelumenden Rectisgeidintes bun ber 3 untimmung eines Irittell ab, jo faum bie (Ertheilung jorvie bie Berweigerung ber Buittinmung jotwuhl bem etnent als bent antberen Theile gegenüber errolgen.

Die Zuftimmung beourj nidyt ber für das heditsgeidäft be= ftinunten form.

Mirb eil cinjeitiges Red) $t=$ gejdjäft, Defifen Wirfjamteit von der 3uit imumung étıes Dritten abhäıgt, mit Sintwifligung bes Drttent vor= gentontment, jo finben bie Bor=

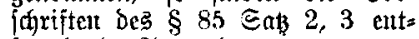
fpredgentoe Anwentung. ton

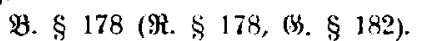
ড̣ätg̣t Die "Wirfjamteit cines Bertrages ober eines einjeitigen

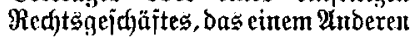
geqenüber borzumefmen iit, vou ber 3uftimmung eiutes Dritten ab, jo fant bie (Ertheilung folvie dic Bertveigenutg ber Buftimumutg jotwuhl $\mathrm{bem}$ eitten als bcm anderen Theile gegenüber erflärt twerben.

Sie Butintmung bebarf that ber jüx bas ?hedjtogejoăft be= ftimmiten fourm.

Wirb cit einjeitigc Jed $t s=$ geịdjäit, beffen isinfiumfeit von ber 811ftimmung eines Dritten $a b=$ Gängt, mit Ginwilligututg bes Sritten borgetiomntelt, fo finden bie Bur= idyriften des $\$ 107$ (\$) $\$ 111$ ) こats 2,3 entiprechende Anvendintg.

\section{II $\$ 151$}

Die vorberige 3uftimmung (Cintwilligung) ift bis zur Bormahne

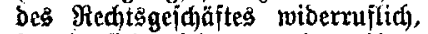
jotweit fid nicht alts bem igrer Ertheilung za (Brunde liegenden Redhtsperhăltniffe eitt Ultberes ergiebt. Pluf bie Exflärumg bes Wiberrujes findet bie Boridnrift bes $\$ 150$ 2lb. 1 cutipredjettbe มีtmentulttg.

II $\S 152$.

Die nađtrögliche Bujtimmunt (Genehmigung) wirlt anf ben 3eit= puttf ber Bornahme bes Sehts= gefdadites zurita, foweit nidat ein innderes bejtimmt ift.

Durd) bieje Rfiftwitung werben Berfiligungen nicht untuirịam. weldue bor ber benelymigung itber

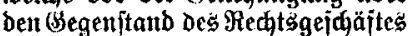
von bem (Sentehmigenber getroffen ober gegen ifit bured Irtheil obex in Wege ber 3roungsbolfitrectung vber bes Arreftwollziehung erjolgt funo.

Motibe $488 \dot{\mathrm{j}}$., Protololfe $760 \mathrm{j}$.

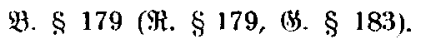
Dic vorherige Buftimmung (Eintwifligung) ift bis zur Bor= tahme bes Rechtśgefääjes wiber= rufflid, fomeit nid)t aus bem ifrer Ertheilumg an (brumbe liegenden

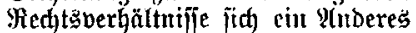
ergiebt. Der Miberruj fan jowohl bem einen als Dem anberen Theile gegenuber erflätt werden.

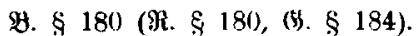
Die nadträgliche 311 timmung (Benefmigung) wirft auj ben Beit= punft ber Buornafme bes Rechts= gejœäjtes zurürf, foweit nicht ein Sitocres beftimmt ift.

Durd bie Müdwirtutg werben Berïugumgen niøt untwirfian, bie vor ber (Benefmigung liber bell (Segentitanto Des YRed)tsgejd)äftes bon bem Benehnigenden getroffen

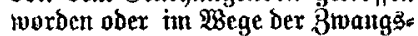
bolfitreding ober ber Arrejtooll= ziehung ober burd bea Ronfuxs. vecwalter exjolgt fins. 
II $\S 153$.

Birb aber einen Segenitanb vor einem Rid tberedtigten berfifgt, fo iff bie Berfügung wittiam, wenn fiemit Cinwilligung beşgeredtigten erjolgt.

Die Berfügung wirb wirtfam, wenn ber Beredtigte fie genehmigt ober renn ber Berfügende ben Begenftanb erroirbt ober wenin ex bon bem Perechtigten beerbt roirb und biejer für bie. Radlafberbinb: lidfeiten uinbeidrānlt haftet. Sinb in ben beiben leb̧teren făllen aber bent Segatitand mefrere mit ein= anber niqt vereinbare Berïgungen getroffen, fo wirb nur bie frühere Berfügung roitfiam.

Motibe -, Brotololle 761.

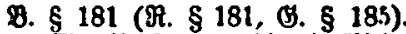
Eine Beriugung, bie cin gidgt: beredtigter aber etren Begentanto trifft, itt wixtiam, wenn fie mit Cinwilligung bes Beredtigten efolgt.

Die Bexfilgung wirb wirtfam,

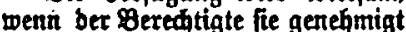
ober went ber Beriügente ben Begenftanb exroirbt ober went ex bon bem Beredigten beerbt wirb unb biejer für bie Radlajperbinb. lidfeiten unbejdräntt haftet. Эn ben beiben lekteren făllen mirb. went laber ben Olegenitanb megrete mit einamber nidht in Fintlarg ftehenbe Berfügungen getroffen worben finb, nur bie frokete Ber= fügurng wirffam.

\section{Bebingung unb Befriftung.}

I \& 128.

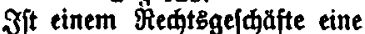
aufiditebenbe Bebingung beige= fifgt, io tritt bie bon ber $8 e^{2}=$ bingung abjängig gemadte redit. lide sgirtung mit bem Beitpuntte ein, in weldhem bie Bedingung erfüllt ift.

$1 \S 129$.

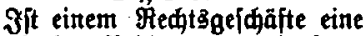
auflajenbe Bebingung beigefügt, fo entigt bie burd baffelbe er= geugte redtllide BBirturtg mit bem Beitpuntte, in weldem bie Bes bingung erfillt ift, bergeftalt, baß ber frahere guftand von Piedts = wegent wieberbergeftellt wirb.

\section{I \& 130.}

Ergiebt fid aus bem Jinhalte

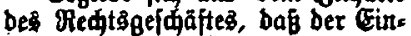
tritt ober bie Beensigung ber reditliden fralberen Beitpuntt zuratäbejogen werben foll, io find im falle ber Erfallung ber Bebingung bie $B_{e}=$ theiligten unter einanber fo be redgtigt und verpflidtet, wie werm bie redtlide $\mathfrak{B i r h u m g}$ bes. Peedta.

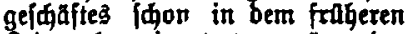
Beitpunfte eitngetteten wăte ober geendigt jätte.

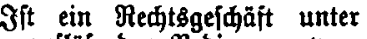
eimer auflöjenben gebingung vor: getommen, jo enbigt mit bem Eintritte Der Bebingung bie 2 Bir:

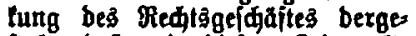
ftalt, bas mit biefem Beitbuntte ber frilhere Medistoftand wieber. eintritt.

grotive 491 fi., Brotololle 762.

$$
\text { II } \S 129 .
$$

Gollen nad bem 3ngalte bes Medtsgeffäftes bie an ben Cin. tritt ber Bebinguting getnüpiten Folgen auf einen fruberen Beito vuntt juriddgezagen werdent, fo finb, went ble gesingung eintritt bie Barteier unter tinander 10 berpflidtet, wie wenn bie Folgen in bem iraheren Beitpuntte ein. getreten wären.

Eltotive 493, Protololfe 762 f.
Wirb ein. Mechtşgeidaf́t unter einer auflibienten gebingung bor genommen, fo endigt mit bem Eintritte ber Bebingung bie 28 ir

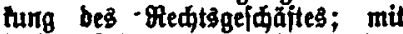
Diefem Beitpuntte tritt ber frahere Reedtşzuftanb wieber ein.

P. \& 155 (भ. \& 155, B. \& 159).

Sollen nad bem 3nhalte bes

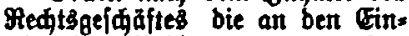
tritt ber Pebingung gethapften Folgen auf einen frúbeten Beits punit zurildbezogen toerben, 10 find, in Zralle bes Eintrittes ber Febingung bie Betbetligten bes: pfligtet, einamber in detwábtrim. was fie baben toitrben, wenn bie Folgen in Dem friberen Beitpuntte eingetreten toăren.

$$
I \S 131 \cdot(I I-, B .-, R .-, G .-) \text {. }
$$

Fällt die aufschiebende Bedingung aus, so ist der Eintritt der von der Bedingung abhängig gemachten rechttichen Wirkung ausgeschlossen.

Fällt die auflösende Bedingung aus, so ist das Rechtogeschäft als unbedingt errichtet aneusehen.

Motive 494, Brototolle 763.

$I \& 132(I I-, B .,, R .-, G .-)$.

Das bedingte Recht und die bedingte Verpfichtung sind nach den for das unbedingte Recht und die unbedingte Verpflichtung geltenden Vorschriften vererblich.

Slotive 194 fi., Prototolle 763. 
$I \& 133(I I-$, B.,- R.,- G. - -)

Der bedingt Berechtigte kann Sicherheitsleistung fordern, wenn die Voraussetzungen vorhanden sind, unter welchen nach den $\$ 8796,797$ der CPO. Arrest stattfindet.

Wird über das Vermögen des unter einer aufschiebenden Bedingung Verpflichteten der Konkurs eröffnet, so hat der bedingt Berechtigte diejenigen Rechte, welche die Konko. demselben für den Fall beilegt, dass der Gemeinschuldner zur Sicherheitsleistung verpflichtet ist (\$\$ 142,158 der tionk0.). Die Vorschriften des 1. und 2. Abs. finden keine Anwendung, ucenn das bedingte Recht wegen der entfernten Möglichkeit der Erfüllung der Bedingung als ein gegenvärtiger Vermögensbestandtheil sich nicht betrachten lässt.

Die Zulässigkeit einer einstweiligen Verfügung bestimmt sich aueh bei einem bedingten Rechte nach den Vorschriften der $\$ 814$ bis 822 der CFO.

\section{Mrotive $40 \pm$ fi.}

I \$134.

Gat ber bebittgt Derpflidtete wăhrent bes Edwebens ber Ples bingung burd borlăglide ober fahrláfíge Sanblungen bas bon ber Bebingung abjångige Pledt vereifelt ober beeinträhtigt, 10 haftet er im Falle ber crifllurg ber Pebingung für ben Erfak bes bem Beredtigten baraus entftan: Denen Єđabens. Die Žahrláffig. leit, fát welde ber Berpflidutete einzuftehen hat, wirb burch bas

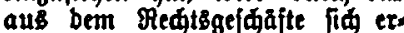
geberbe Reditsverhaltni仿 beftimmt.

I $\$ 135$.

Sit unter einer Bebingung ein Fecht abertragen ober aufgehoben ober ein Redt ober eine Eade belaftet unb wirb wăhrens bes SAmpebens ber Bebingurg aber bas Redit ober bie Eahe bon bem bebiutgt Berpflidteten ober im 2 bege einter gegen biejen er. wirtten 8roangsboultredung ober Irtefftoollyiegung verfigt, fo witb bie Perfutgung, poweit fie bie mit Crfallung ber Bebingung eintretenbe rectliche \$sirtung vereitelt ober becintrăhtigt, im folle ber $C_{\text {tr. }}$ fallung ber Bebingung unwirtfam. Die Sorfarifien us Eumfen ber. jeniger, toeldhe redite von eirem Fidiberedtigten Gerleiten, finben entlpredenbe Antenbung.

\section{I \& 136.}

Benn ber bedingt Betpflidtete bie Erjutlluth ber Bebingung in eirex bem Jnkalte bes Medit3. gefdả áftes zumiberlaufenben 23 eife verginbert, fo gill bie Bebingurng als exiüllt.

II $\$ 130$.

gBer unter einer auffidiebenben Pebingung beredtigt if, farn im fille bes cintrittes ber Mebingung Edabenserfab bon bem anberen Theile berlangen, twenn biefer währent 晌webender Bebingung bas von ber Betingung abbantigige Redt burd fein Berinulben vereitelt ober beeintrāntigt hat

Den gleiden Aniprua hat unter benjeJben Borauşíesuntatn bei einem unter einer auflöfenben Bebingung vorgenommenen Ped ts. geidáfite berjentige, zu befien Bunfter ber frubere Reditşuftario wiebereintritt.

Dotive 494 ff., Brototolle 763.

II \& 131.

Gat Jemant unter einer aufs ifieberben Bebingung uber einen Begenftartb berfingt, to ift jebe

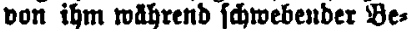
bingung uber ben Eegeriftand ge troffent weitere Berfagung im galle bes Cintrittes ber Pebingung injoweit untwirtfam. als fie bit von ber Bebiugung abbãugige פBithung vereiteln ober beeintrảas

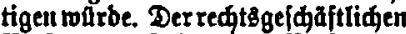
Berfagung fteht eine Berfügurt gleid, bie burd untheil ober im BSege ber \$roang soodf ftrectung ober bet Arreftooflziehung erfolgt.

Daffelbe gilt bei einer aufs lolenben Bebingung von ben Bet. fagurtgen beşjenigen. Deffen Redt mit bem Cintritte ber Bebingung enbigt.

Bie Borfdriften 3u Gunften Derjentigen, welde Redte bon einem Nidtberedtigten berleiten, finben entipredenbe Anwenbung.

Motive 494 fi., Protololle 763 f.

II $\S 132$.

3ft ber Gintritt Der 9 ebingung von ber \$artei, zu beren Padatheil ex geteiden wâtbe, wiber Treu und Slauben berhinbert worber, to gill bie Bebingung als eins getreter.
タ. § $156, \Re . \$ 156$, (s. \$ 160 ). ger unter etuer aufidiebentben Bebingung beredtigt ift, lanll im Ffalle bes cintrittes ber Bedingung Sqabenserfas von bem anberen Theile berlangen, went biejer währenb ber SApoebezeit bas bon Det Bebingung ab̆āngige Medt burd leint Ber[dulbert vereitelt ober beeinträatigt.

Den gleiden anfprum hat unter benlelben Borausiegungen bei einem unter einer auflbjenben Bebingung vorgenommenen Peef 15 . gejuaffte berjentige, zu befient

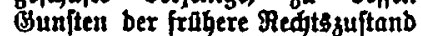
toiebereintritt.

9. § 157 (भ. \& 157, (5. \& 161). Sat Semano unter einer auf. [ajiebenden gebingung aber einen Begenftant berifigt, fo if jebe weitere Berfingung, bie er währent Der Edwebezeit âber ben Begen. flanb trifft, im Fialle bes Eintrittes ber Bebingung inforotit untwirffam, als fie bie voll ber Bedingung abłantigige Wirhung vereitelr ober beeintråntigen wourbe. Giner fol hen Perfügung fteht eine Beriagung gleid, bie währenb ber Sdwebe. Jeit in 2Bege ber 8wangdvoll. ftrecturg ober ber Arreftrollziehung ober burd bea fonfurberwaltet exfolat.

Daffelbe gilt bei einer aufIolender gebingung von ben Bero fïgungen besjenigen, beffen Miedt mit bem Eintritte ber Bebingung enbigt.

Die Boridriften zu Buniten berjentigen, welde Redite von einem gintberedtigten herleiten, finber entfpredgentibe Annenbung.

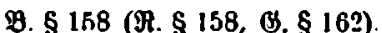

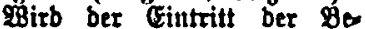
bingung von ber Bartei, zu beren Raditgeil er gertiden muirbe, miber Ireu unb Slauben berbinbert, fo gilt bie Bebingung als eingetreten. Wiro ber Eintritt ber Be. birgung bon ber \$artei, zu beren 
Potive $498 \mathrm{f} .$, Protololle 764.

Bortgeil at gereidt, toiber Treu unb STauben betbeigefágrt, jo gilt bet cintritt als nigt exfolgt.

$I \$ 137(\boldsymbol{I}-, \boldsymbol{B}-, \boldsymbol{R} .-$ G. -$)$.

Ist die Bedingung zur Zeit der Fornahme des Rechtsgeschäfles bereits erfillh so ist das Rechtsgrschäft, wenn die Bedingung eine aufschiebende ist, als unbedingt errichtet, wenn sie eine auflösende ist, als unwirksam ansuselien. Die entgegngesetzte Folge tritt ein, wenn die Bedingung zur Zeit der Vornahme des Rechtsg ochäftes bereils auggefallen ist.

Solange die Hirfüllung oder der Ausfall der Bedingung nicht bekannt ist, finden die Vorschriften des $\$ 13.3$ entoprochende Anwendung.

Int bei einem Rechtsgeschäfte die Beifügung einer Bedingung nicht sulässig, so ist auch dio Beifügung einer Bedingung der im 1. Abs. bezeichneten Art uneulässig, sofern nicht das Gesets ein Anderes bestimmt.

Motibe $499 \mathrm{f} .$, Brotololle $764 \mathrm{f}$.

$\S 138(I-, B .-, R . \rightarrow$, G. -$)$.

Die Bedingung kann in einer Bardlung bestehen, derm Fornahme von der Willkür des Verpflichteten abhängt. Besteht die aufschiebende Bedingung in dem blossen Wollen des Ferpfichteten, so ist die Ferpflichtung unwirksam.

Motive 500, Brotololle $764 \mathrm{f}$.

$I \$ 139(\boldsymbol{I}-, B .-, \boldsymbol{R} .-$, G. -$)$.

Ist einem Rechtsgeschäfte eine unverständliche oder eine woidersinnige Bedingung beigefügt, so ist dasselbe nichtig.

Motive 500 f., Protololle $764 \mathrm{f}$.

$I \$ 110(I I-$, B.,- R. - , G. - ).

Durch Beifügung einer Bedingung, wellhe die rechtliche Wirkung von einem Dmstande abhängig macht von ucelchem diexelbe auch ohne den Willen des Erklärenden abhängig ist, wird an der rechtlichen Bestimmtheit des Verhältnisses nich's geändert.

Potive $501 \mathrm{f} .$, Protololle $764 \mathrm{f}$.

I $51+1$.

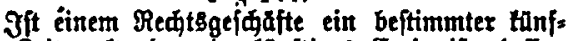
tiger Beitpuntt ober ein tâftiges Ereigniß, beflen (E) intritt gemif ift, als infangstermin beigefagt, io

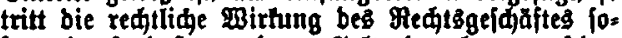
fort ein, fo baf nur beren oeltenbmadung auf ben Anfangstermin hituas gejđoben ift, jojern nidgt aus bem 3nhalte bes Rectsgejăfftes erhellt, bas bie redtlide Birtung er/t mit bem Anfangstermine eintretent foll. $3 \mathrm{~m}$ legteren Falle finben bie Bor: ítriften bes 5 13:, bes $\$ 13$ 1 $961.1,4$ unb ber S马 134, 133 entfprediende Inwenbung.

Mrotive $501 \mathrm{f}$., Brotololle 765.

16148 .

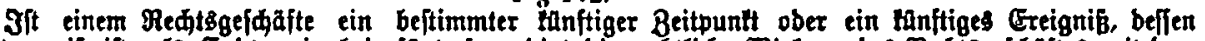

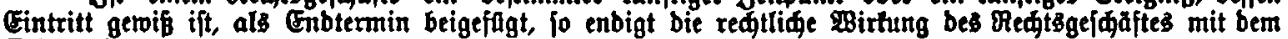
Enbtermille Fnmenbung.

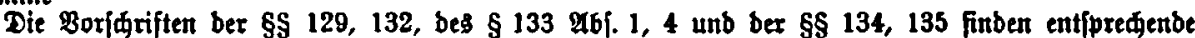
grotibe $501 \mathrm{f} .$, Brototolle 765.

$I \$ 143(I I-, B .-, R .-,-)$.

Der einem Rechtsgeschäfte beigefügte Termin, ion weichem ungewiss ist, ob or eintreten werdes ist als Bedingung anzusehen.

Motive 502 fi., Protololle 765.

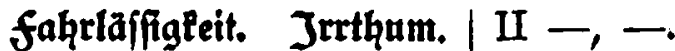

I \& 144 (fiebe gu I \& 227).

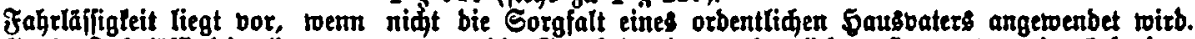

Grobe Jahrlăffigleit liegt vor, went die Sorgfalt eines orbentfident saugbaters in befonbers

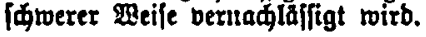

Motive $507 \mathrm{f}$., Protololle $765 \mathrm{f}$. 
I $\$ 145$ (fiele zu I $\$ 224$ ).

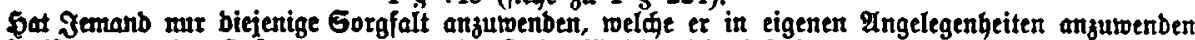

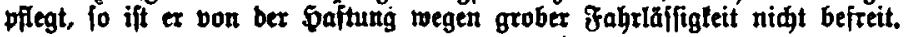

glotibe 307 f., Brotololle -

Im Sinne des Gesetzes ist

$I \S 146$ (siche $24 I, \$ 75,76,97$ ).

unter Irrthum sowohl der Irrthum über Thatsachen als auch der Rechtsirrthum, unter entschuldbarem Irrthume ein nicht auf Fahrlässigkeit beruhender Irithum unter Kennenmüssen oder Wissenmüzen ein auf Fahrlässigkeit beruhendes Nichtkennen oder Nichtwoissen

zu verstehen.

Motive 508, Brotololle 766 .

\section{Zeitbeftimmangetr.}

griften. Termine.

I $\$ 147$.

3n Arjehung ber in Bejeben, geridutliden

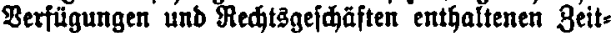
beftimmungen gelten bie Ans̄legungsiregelı ber $\$ \S 148$ bis 153 .

\section{Mrotive 508, Brotololle 766.}

I $\S 148$.

Sft fiur ben Anfang eitter nadh Tagen bes ftimmtert Frift ein Ereignis ober ein in ben Rauf eines Tages fallenber geitpuntt maßsgebend, fo wirb bei Berednung ber Frift ber Tag nidt mitgerednet, auf welden bas Ereignif ober ber geitpunlt falt.

Fine nam Tagen beftimmte frift endigt mit AGlauf bes lepten Tages ber Frift.

I $\$ 149$.

Gine frift, welde nad 28 oden, Monaten ober einem mehrere Tonate umfaffenben Beitraume - Jahr, halbes Yahr, Biertels iahr - bejtimmt ift, enbigt, wenn fär ben \&nfang berielben ein $(\mathrm{r}$ : eignib ober ein in bett Lauf eines Tages falfenber Beitpunft mas= gebenb ift, mit ablauf besjenigen Zages ber Iesten 280 de ober bes Iesten Monates, welder bura feine Bentennung ober $\mathrm{Bahl}$ bem Iage entipridt, an welliem bie Frift begonnen hat; fehlt bet einer Monatsifrift biejer zag in bem Ieteten Mronate, fo enbigt bie frrift mit Rblauf bes lesten Tages bieles gionateä.

Bilbet ber Beginn eines Tages Den firr ben 2Infang ber Frift mabgebenben infaugapuntt, fo enbigt bie Frift mit qublauf bes= jenigen Tages ber lesten Mode ober bes lebten Mtonates, reldher bem Tage porhergeht, ber burd feine Benennung ober $3 a b l$ bem Arfangstage ent|priat; feblt bei einer Monatsfrift biefer Tag in bem Iebten Mronate, fo eribigi bie frift mit RGlauf bes Ieșten Sages biejes Monates.

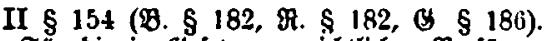

Fir bie in Bejepen, geridtliden Berfagungen

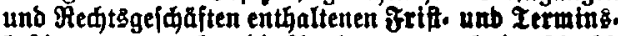
beftimmungen gelten oie Auslegungżregeln ber $\$ \$ 15.5$

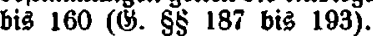

II $\& 155$ (B. $\S 183, \Re . \S 183$, \$. \& 187). उft futr ben $\mathfrak{U}$ nang einer Frift ein Ereignib ober ein in ben Lauf eines Iages fallenber Beit= puntt maßgebenb, fo wirb bei ber Berednung ber Frift ber $\mathbf{z a g}$ nidht mitgerednet, in welaen bas Creignif ober ber Beitpunft fallt.

3it ber Beginn eines Zages ber für ben $11 n=$ fang einer frrift maßggebenbe Beitpunit, 10 twirb biefer $\operatorname{Tag}$ bei ber Beredunung ber Frift mit= gerednet. $\mathfrak{D a s}$ Sleidje gill von bem Iage ber Geburt bei ber Berefinung Des Lebenga alters.

II $\$ 156$.

Cine Had Tagen beftimmte Frift endigt mit bem Hblaufe bes lestent Tages ber Frift.

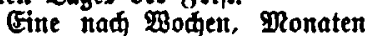
ober cinem mehrere Donate ums faffenben Beitraume - Jaht, halbes 3ahr, Bierteljahr - be. ftimmte frrift enbigt mit bem $B_{e}$ ginute besjentigen Tages ber lestent Wode pber bes lebien Monates, welder burh feine Benenuming ober Bahl bem Zage entpridt, bon weldem an bie Frifí naq $\$ 155$ zu beredinen ift; fehlt bei einer naf Monaten beítimmten Frift biefer Zag in bem legten Mronate, to estbigt bie frrift mit bem Rblaufe bes leghten rages bieles Monates.
9. \$ 184 (भ. § 184, B. \$ 188). Cine nad Tagen beftinmte Irift enbigt mit bem Qtblaufe bes lesten Tages ber ơrift.

Gine Fttit, bie nad ஐodnen, nad Mtonaten ober nad einem mebrexe Monate umfaffenben Beit: raume - Sahr, halbes Sahr, Bierteljaht - beftimmt ift, enbigt im Falle bes 8183 (ब. \$ 187) भbf. 1 mit bem Ablauje besjenigen Tages ber lebten Bodie ober bes les: tent Ponates, welder burd ieine $\mathfrak{B} e=$ nennung ober feine 3 ahl bem Tage entipriat, in ben bas cer: eigniis ober ber Beitpuntt fallt, im folle bes 8 183 (B. 8 187) qbi. 2 mit bem Ablauie bes. jentgen Tages ber Iebten 90 odt ober bes Ieften Mlonates, welloer bem Iage vorhergeht, Der burd fetne Peatumung ober fetne $3 a \mathfrak{l}$ bem Infangstage ber Zrift ent. fprigt.

Fehlt bei einer nad 9lonatent beftinmten Frift in bem lebten Morate ber für ibren Qublauf mafgefenbe $\mathfrak{T a g}$, jo endigt bie Frrift mit bem Ablaufe bes leb̧ten qages biejes monates. 
I $\$ 150$ (II § 157, B. § 185, भ. § 185, \&. \& 189).

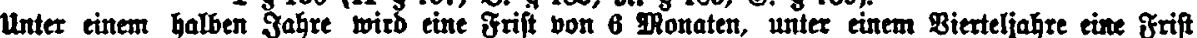
von 3 Pronaten, unter einem halben Monate tine Frift bon 15 Tagen berftarben.

Ift eine \&rift mif einen ober megrese ganze QRonate und einen halben MRonat geftellt, fo find bie

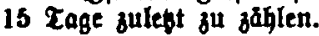

Motive 510, Brotololle 767.

I \& 151.

צit far bie Berefonung einer צahresfrift ober

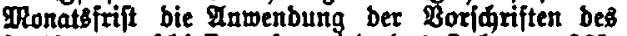

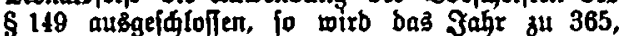
ber Monat zu 30 Tagen gerehnet.

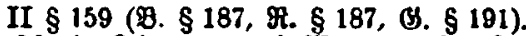

Үit ein Beitraum nad 9lonatert ober Yahren in bem Einne beftimms, bas ex nidgt zufammens băngend zu verlaufen braudt, fo wirb ber Monat zu 30, bas Jahr zu 365 Tagen gerednet.

Rotive 510, Brotofolle 767.

I $\S 152$ (II $\S 158, \mathscr{B} . \S 186, \Re$. § 186, (G. $\S 190$ ).

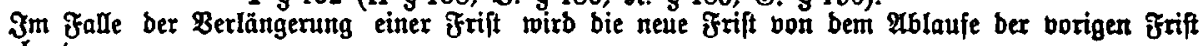
an berednet.

Motive 510.

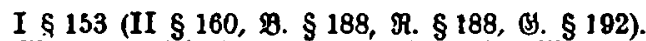

Unter Infang bes gionates wirb ber 1., unter Miitte bes Mionates ber 15., unter Enbe bes

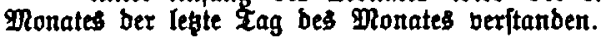

Mlotive 511.

SomBorlage \& 188a (B. \& 193).

Sift an einem beftimmten Tage ober innerhalb einer frift eine 28 illens:

[I, II, B., $\mathfrak{R}$. feh̆[en].

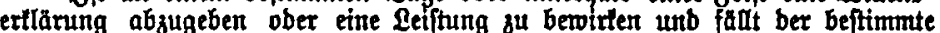
Tag ober ber legte $\mathcal{T a g}$ ber frift auf einen Sonntag ober eitren am Er:

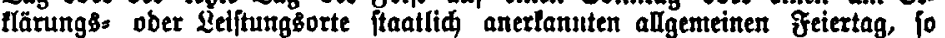
tritt an bie Etelle bes Gonntages ober beş Feiertages ber nădiffolgenbe Berttag

Prototolle 767, StomBeridite 971.

\section{Unกprudsver\}ährang.}

$$
\text { I } \$ 154 .
$$

Das Beft einer Betjon, von einem Anberen eine Leiftung zu berlangen (Infprud)), unterliegt

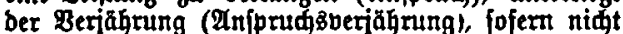
bas Gejes cin Inderes beftimmt. Es madt leinen

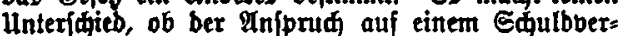
Gadtutife ober auf einem anberen Meditsgnumbe beruft.

Der auf einem familienredtliden Bergăltniffe beruhenbe 2unfprứ unterliegt nidt ber Berjảhrung. forveit er auf berftellung beş bem Berhăltnifie ent= ipredenben 8uftanbes fiur bie Butunft geriatet ift.

\section{Motibe 313 ff., Protololle 770 ff., Denlldrift 840 ff.}

I 5155.

Die Berjăhnungsfrij betrăgt 30 3ahre (orbent=

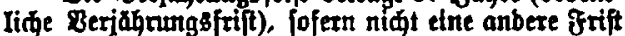
beftimint ift.
II $\S 162(98 . \S 190, \Re . \S 190$, \$. § 195).

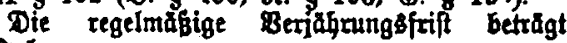
30 צahre.

Mlotive 515, Brototolle 770 ff., Denkfrift 840 ff.

I $\S 156$.

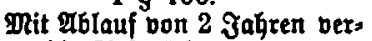
jăgren bie Anfprathe:

1. ber Plaufleute, ber Fabrifanten, ber Santwerter fortie bers jenigen, welde ein frunft: geverbe betreiben, für Lie= fertung bou $\$$ Seifturtg vott Irbeitett ein:

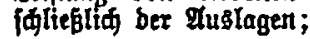

II $\$ 163$. Thit bem $\mathfrak{A b l a u f e}$ bon $2 \mathfrak{J a h r e n}$ veriăhren bie $\mathfrak{A n}\{$ prähe:

1. ber Rauflette, Fabritanten, Sanbwerler und berjenigen, tweldie eir funftgetwerbe bes treiben, fur Liejerung bon Baaren, Reifturtg bon $\mathfrak{A} r=$ beiten uth Beforgutug frember

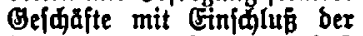
Aluglagen, es fei benn, baß bie Riefertitg, Reiftung ober Beforgung für ber Bewerbe: betrieb bes Gaulbners et: forgt ift;
9. § 191 (92. \& 191, §. § 196). In 2 Jahrest berjăhren bie An iprldie:

1. ber Staufleute, Frabrilanten, Sambtoetler utrb betienigen, weldibe ein funftgetwerbe bes treiben, für siejerung bon Maaren, Kusfabtung bon Frbeiten unb Belorgung frember Bsejuăfâte mit Eins

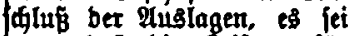
betn, baß bie Reiftung fítr ben Serverbebetrieb bes Shulbners erfolgt; 
2. berjeniget, twelde \&anbroirth: fdaft betreiben, fär Rieferung bon lanbwirtbínaftliqen E: zeugniffen, insbej. bon \&ebenz: mitteln unb grenumaterialien. fofern bie Erzeugniffe zur Bermentoung im \$aushalte geliejert roorben finb;

3. ber (3ajtwirthe unt berienigen, welde Epeijen ober Betränle irgend einer Art gerverbs: mäsig verabreiden, für Be rodhrung von TBognung unb Befojtigung forvie für fonftige ben Bâften zur Bepriebigung bon Beburfuiffen gemährte Reiftungen einjめlieşlid ber भuslagen ;

4. Der öfi. und niđtöf Antalten, pelae bem Unterriate, Der Erziefung, ber Berpilegung ober ber Seilung bienten, für Bemährung von llnterriat, Berpflegung, weilung, ionte für jebent Damit in Berbinbung ftefuben Aujwanb, ingleiden berientigen, weldie Berjonen zur Berpflegutg vber Fr $_{5}$ fiehung aufgestommen haben. für Leiftungen unb 2 uj $=$ tonbungen ber bezeidnetelt Qrt:

5. ber öfi. Rebrer unb ber \$rivat= lehrer wegeti ihrer Sontorare, jufern biele niqt bei bff. Eehranitalten naw beftehenbent befunberen Eiutridtungen ge= ftundet fints :

6. Der Lebrherrent unb \&ebrmeifter megen bes gehrgeldes unto anberer im Legroertrage be= Dutugener Reiftungen forvie ber fut bie Sebrlinge bejtrittentent Anġlanen;

7. Der Яied) šantwälte, Notare unto (Serid)ts̄oollzieber, potwie aller Rerjouth, welde zitr Beforgung getrifjer Gejuăite Bffentlia bejtell ober zugelafjen fiit), ingleidten ber Beugen unb Eadjveritändigent toegett ibrer Hebübren unb $\mathfrak{A}$ uslagen. unbeidjabet ber Boridrift bes $\$ 16 \approx a \beta$ ㄴ ber BebührenD. v. :10. Juni 1878 (요. ร. $17 \%$

8. ber Rerzte, insbei. aú ber खumbärgte, Geburtshelfer. Bahnärzte unb r bierārzte,forte ber פebantmelt, ingleiđen ber= jentigen, weldye Eiente ber Aerzte oder \$ebammetl, ohne approbirt zu iein, geleiftet haben, fürihre Lienftleiftungest einf
2. bezienigen, roelde Sarb= ober forftwirthidajt betreiben, für bie zur Bermenbung im \$auss. balte gelieferten lanb: ober forftivirtbidaftligen (Erzeug: niffe;

3. Dex Eifenbahnunternefmungen, Fradtuhrleute, 厄aiffer, Sohnhutjaser unb Boten wegen beş Frahrgelbea, ber frraut, besీ Fuhr: unb Botenlohnes

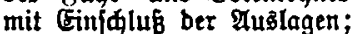
[1. 1 Nr. 10]

4. Der Braitwirthe unb berienigen, welde ¿opeifen ober Getrănte geroprbimå̉̄ig verabreiфen, für Betwährumg von Bobnung und Belöftigung fowie für fonftige best Gäften zur $\mathfrak{B e}=$ friebigung von Bebürfuiffen getwährte \&eiftungen mit Ein: ईॅIus ber Ruslagen;

$$
\text { [i. I } \Re x \text {. 3]. }
$$

5 berienigen, welde Rotterie: Iooje vertreiber, aus bem Ber: triebe ber Looje, es jei bent, baß bie Looje fum bertriebe geliefert finb;

$$
\text { [I jeblt]. }
$$

6. berjenigen, weldae betweglide Eaden getwerbŝmäвtg ver= mietgen, wegen bess Mieth= zimles;

$$
\text { if. I Nr. 11|. }
$$

7. berjenigen, weløe, ohnezu ben unter $\mathfrak{R \tau}$. I bezeidneten $\mathfrak{B e r}=$ fonen zu gehören, aus ber Beeforgung frember (Heja)äfte ober ber Qeif́tung vou Tieniten sill Getwerbe niadjen, fofern bie Pulprdide aus ihrem Bes werbebetriebe herrühret;

$$
\text { [i. } 1 \text { 凡r. 9]. }
$$

8. berjentigen, toeldie im Brivat= bienite fteben, wegen bes (be= halteş Rohnes ober an: Derer Tientibezûge mit Fin=

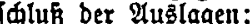

2. berienigen, welde Lanb $=$ ober Foritmirtbf价位 betreiben, für Rieferung bon lanb= ober forft wirthidaftliden Ergeugnifen, fofern bie Qieferung our $\mathfrak{B e r}=$ mentung in 5aush halte bes Edulbners erfolgt;*)

3. ber cifenbafnunternehmun gen, Fradtfuhrleute, હڤiffer. Qohntutjłer und Botent wegett besె Ffahrgelbes, ber fraht. bes \{fuhr unb Sotenlohne?

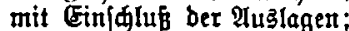

4. bet Gaftwirthe unb berjentgen, melae ङpeijen oder Getränte gewerb五äbig berabreidjen, filr Geroăhrung von Bohnung und Befojtigung forvie für anbere ben Gäften zur $\mathcal{B} e$ friebigung threr Bedürinifie geroäbrte Qeiftungen, mit Ein=

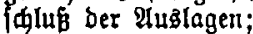

5. berienigen, welde Lottexie= looje vertreiben, aus bem $\mathfrak{B e r}$ triebe ber Roofe, es fei beut bas bie Loole zum Weiter = vertriebe geliejert toerden;

6. berjentigen, welthe beroeglithe Sahes getoerbamäвig ver miethen, wegen bes ghtietf zinjes;

7. Derjenigen, welde, obne 34 ben in Rr. 1 bezcifineten Perjonen zu gehören, bie $\mathfrak{B} e=$ joryung frember Gejajäjte ober bie Reijtung bon Itcuiten gewerbämās̆ megen ber thnen aus bem Gemerbebetriebegebübrenben Bergütungen, mit Ginidlub ber Muslagen;

8. berjenigen, welde im Brivat= bienfle ftehen, wegen bes OSe haltes, Rohnes ober anberer

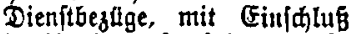
ber $\mathfrak{A} u s$ lagen, fowieber Ditenft. berehtigten megen ber auf folde İpiprü̈e gemährten Borf由üfle;**) 
9. Derjenigen, trellfe aus ber Leiftung von Dienten ober ber Belorgung bon Puftrăgen ein Bewerbe madien, jofern bie Anipride aus bem bes triebe ihres Serwerbes ber: rabren;

10. ber Eifenbahnberwaltungen fradtfuhrleute, Ediffer, $\mathbb{L}$ hn: futidier unt Boten wegen Fahrgelb, \{ิuhrlohnunb@oten:

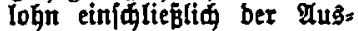
lagetr;

11. berjenigen, meldye berweglide Caden gewerbsmåßjig ver: miethen, wegen bes Mieth= zinịes;

12. berjenigert, weldhe im Bribat: bienfte ftehen, wegen bes Be: Galtes, Sohnes ober anberer Dienjtbezulge einfdick Aușlagen;

13. ber gewerbliđen Arbeiter Befellen, Gehullen, Lehrlinge, Fabritarbeiter -, Der Tages Iohner unb \$anbarbeiter ves gent bes Lohnes unb jonftiger an Etelle ober als 2heil bes \&ohnes zugefagter Qeiftungen

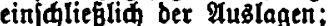

14. der Arbeitgeber wo gen der den gewerblichen Arbeitern auf Lohn oder Auxlagen gewährten Vorschiusse;
9. ber gewerbliden Arbeiter Bejellen, Gehalien, Rehrlinge, Fabrifarbeiter -, ber Tage Iohner unb Ganbarbeiter toegen bes 2ohnes und fonftiger an Etelle ober als Theil bes Lohnes zugeiagter Reiftungen

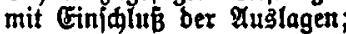

$$
\text { [i. I } \mathfrak{N r} \text {. 13]. }
$$

10. der Arbritgeber woegen der den gewerblichen Arbeitern auf Lohn oder Auslagen gewährten Vorschüsse;

$$
\text { [f. I Pr. 14]. }
$$

11. Der Rehrherren und Qegt= meifter wegen bes Rehrgelbes und anberer im Lehrbertrage bebungener Reiftungen fowie ber für bie Qehrlinge be itrittenen $\mathscr{A}$ (uslagen; [1. I $\mathfrak{N r}_{\text {. 6] }}$.

12. ber off. unb nidtoff. OXnftalten welae bem Unterriate, ber Erziehung, Berpflegung ober \$eilung bienen, für(Setoảhrung von Ulnterriat, Berpfleguщg, Seilung forvie für jeben bamit in Berbinbung ftehenben $\mathfrak{A} u f=$ wanb, ingleianen Derienigen, welde Berjonen zur $\mathfrak{B}$ er: pflegung ober Crziehung auj= genommen haben, fuir get= itungen unb Aufwenbungen ber bezeiqneten $\mathfrak{A}$ rt;

$$
\text { [1. I } \mathfrak{R r} \text {. 4]. }
$$

13. ber off. Qehrer unb ber $\mathfrak{R}_{\text {rivat: }}$ lehrer wegen ifrer Gounrare, jofern biele night bei off. Regr= anftalten nad) beftehenben be= jonberen Eintiatungen ge: itunbet find;

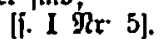

14. ber $\mathfrak{X}$ erzte, insbef. aud ber 29undargte, Beburt\$helfer, Bahnårzte unb Ihierårzle, jo= wie ber bebammen far ifre Dien[tleiftungen mit Ginidlus ber Tualagen

$$
\text { [1. I } \mathfrak{M r} .8] \text {. }
$$

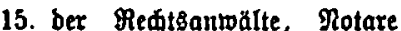
unb Geriftzbolzieher. fotwie aller Berionen, weldie zur Beforgung gewiffer Bejळăfite off. beftellt ober jugelafien finb, toegent ifrer Bebahren unb Auslagen, folvest lolde nidit zur @taatslaffe fließen. ingleiden ber Beugen unb Sadjverftäntbigen toegen igret Bebübren unb Ituslagen;

$$
\text { [f. } 1 \text { Rr. 7]. }
$$

9. ber getwerbliðen $\mathfrak{A r b e i t e r}-$ Bejellen, Bebulien, Sehrlinge, Iabrilarbeiter -, Der Tage: Iohner unb \$anbarbeiter wegen bes Lohnes unb anderer an Etelle ober als Theil bez Lobnes vertinfarter Leis fungen, mit Eitijhlus ber Tuğlagen, fowie ber Mrbett. geter wegen ber auf lolde Iniprübe gemährten Bor. (西苚保)

10. der Arbeitgeber ucegen der den gezoerblichen Arbeitern auf Lohn oder Auslag n gecährten Vorschü $-8 e_{\text {,**) }}$

11. (G. 10) ber Lehrherrent unb Lehrmeifter toegen bez $\mathfrak{L e h t}$ gelbes und anderer im Qehrber: trage vereinbarter Reijtungen foroie wegen ber für bie $\mathfrak{Q e h s}$ linge bejtrittenen Utuslagen;

12. (अ.11) ber off. ÂItalten, weldge bem Unterridte, bet Erziehung. Berpflegung ober Seilung bienten, fowie ber Juhaber von Brivatanftalten folder IIt für Betoăbrung von unterridt, Berpflegung ober Geilung und für bie bamlt jufammentängenben ॠuf. wenbungen;

13. (G. 12) berienigen, welde Perionen zur Berpflegung ober zur Erziehung auf: nehmen, fûr Reiftungen unb Auptoestoungen ber in $\mathfrak{N r} .12$ bezeidueten 2 rt:

14. (अ. 13) ber off. Rehrer unb Qribatlehrer wegent ihrer $\$ 00$ norare, bie Urm|prühe ber ôf. Legrer jebod nidt, went fie auf Brunb befonberer Fin: ridutungett geftunbet finb;

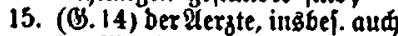

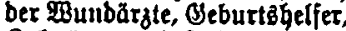
Baḩuð̋rgte unb Ihierărgte, fo: voie ber Gebammen für ibre Dienftleiftungen, mit (rinjकluß ber 9ušlagell;

16. (15. 15) bex Rébtsannwalte, Rotare und Beridts̄bollzieher. fowie aller Berfonen, bie zur Bejorgung gewiffer Bsejaăfte zif. bejtelut ober zugelaffen finb, toegen ihrer Syebühren unb Aus̆lagen, foweit nidt biefe sur Staatsiafie flieben;

-) Dal fett Gebratte if Bufab bez fomperlage

*) Fit. 10 is in bet Romborlage geftridert. 
15. ber Barteien wegen ber ibren Pedtsanwălten geleiftetent Boridutie.
16. bex Parteien toegen ber ifren Feditsanwalten geleifteten Borfduffe.

17. (G. 16) ber Parteien wegen bez ihren Medtsantiolten ge. Ieifteten Boridunfile;

18. (\$5. 17) bet Beugen unb Eaduerftänbigen wegen ihrer Bebahren und Ouslagen.

Soweit bie im $\mathfrak{A b}$. 1 IR. 1 , 2, 5 bezeidneten $\mathfrak{A}$ njprüdje nidit ber Berjabnuthg bon :2 3ahren unterliegen, beriăbren fie in 4 Jaḩren.*)

Motibe 315 fi., Brotolole 774 fi., Dentfdrift 840 ff., SomBeriat 972.

I $\$ 157$.

Mit Mblauf von 4 Jahren

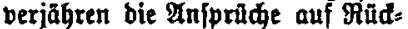

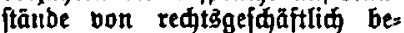
ftimmten Binjer, bon Bahtzinjen uno Miethzinjen, fomeit bieje nimt unter bie Boridtiften bes \& 150 刃t. 11 fallen, ingleiden auf $\Re$ ad: ftänbe bon Menten, Muşags= leiftungen, Befolbungen, \$arte= gelbern, Benftonen, unterhalts: = beiträgen und allen fonftigen Reiftungen, welde in regelmásig wieberfegrenben fुriften zu ent= riditen finb.
II $\$ 164$.

Mit bem ablaufe von 4 צahrent beriähren bie Anjprỉळe auf Mild: ftande von Binfen mit Einjhlu bet als Bujhlag zu ben Binjent behufz allmảhliđer fapitalstilgung ou entridtenben Oeträge, auf Hud fitunbe von Badts unb Miethzinfen, porocit bieje nimt unter bie $\$$ f西rift bes $\$ 163$ Nr. 6 fallen, ins gleidjen auf Madjitätbe von Menten, Ászuggel leiftungen, Befolbungen, Martegelbern, Fuhegehalten, lunters Galtsbeitrågen unb allen fortitigen Seiftungen, bie in regelmåpig wieberfehrenben Griften zu ent ridtert finb.

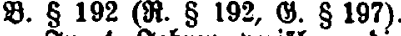
3ัt 4 Jahren berjăgren bie Inipridue auf Mudtíanbe oon

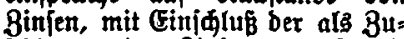
低lag zu ben Binien zum Bivede allmăblíger xilgung bes Rapitales zu entriatenden $\mathfrak{P e t r a ̆ g e , ~ b i e ~} \mathscr{I} \pi=$

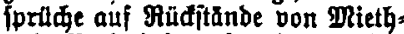
unb ßahtzinjen, forweit fie niat unter bie Borjdrift bes $\$ 191$

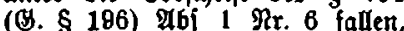
unb bie Anjprtafe auf Fatatänbe

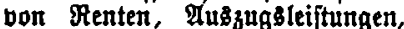
Bejolbungen, Bartegelbern, Mugegehalten, unterhaltabeitragen unb allet anberen regelmâfig roieber= lehrenben Seiftungen.

Motive 520f., Protololle 774ff., Denfifdrift 840 ff.

I $\$ 158$.

Die Berjăbrung beginnt mit bem 3eitpuntte, in wel̄em bie Befriebigung bes 2 n[pru氏es redt= liđ berlangt toerben tann (Făllig: teit).

Ynobef. beginnt bie \$erjährung eines bebingten ober betagten $\mathfrak{A} n=$ jprudies erit nad bem Cintritte Der Bebingung ober bes Iermines.

Iit bie Entiftehung eines $\mathscr{A}=$ ipxudes von bem bloben 280 llen bes Perehtigten ab̧ăngig. io bes giunt bie Berjābrang mit bem Beitpuntte, in weldem ber $\mathscr{Q}_{\mathfrak{n}=}$ (prud) zur Entftebung gebraळt werber fonnte.

Yit bie Befriebigung eines $2 \mathrm{n}=$ iprudies bon bem Berlangen ober bout ber Stinbigung bes Bered: tigten abbungig, jo beginnt bie Berjăhrung mit bem Beitpuntte, ill weldem bas Berlangen ober bie filnbigung exiolgen tonnte. Sift oon ber fiunbigung an nod eine frrift für bie Befriebigung beftimmt, fo beginnt bie Berjährung mit bem Beitpuntte, in weldem ein biefer Frift gleidtommenber Beitraum feit bem Beitpunlte $a b$ : gelaujen ift, in weldhem bie Rün= bigung erfolgen tonnte.
II $\S 165$.

Die Berjabrung bes Fniprudes beginnt mit belien Entftegung. Geht ber Qufpnud auf cin Unter Iaffen, fo beginnt bie Berjăhnang mit ber guwiberhanblung.

Pann ber Beredtigte bie Leiftung erft uă borgăngtger Planbigung berlangen, fo beginnt bie ser= jăbrung mit bem Beitpuntte, in weldem bie Panbigung zulăfig getoorben ift Jit für bie Qeiftung nod eine frrift nad ber finbigung beftimmt, fo roirb der Beginn ber Beriährung um bie Dauer ber Frift hinauşgejdoben.

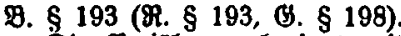
Die Berjăbrung beginnt mit ber Entftebung bes Unipruates. Beht ber Anjprud auf ein unters Iaffen, fo beginnt bie Berjabrung mit ber Buwiberhanblung.

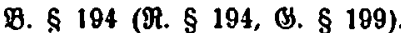
Stann ber $\$$ eredigte bie \&eiftung erit berlaugen, wenn er bem $B$ er pflichteten gelünbigt Gat, fo be ginut bie Bexiăbrung mit bem Beitpuntte, bon welom an bie filnbigung zulåfíg ifl. פat ber Berpllintete bie Deifung exit zu betwitlen, wean jeit ber frandigung eine beftimmte frift berftriden ift to witb ber $\$$ eginn ber Beriabnung un bie Dauer ber frift hinaus. gejdoben.

Motive $\$ 21$ f., Protololle 779ff., Dentiquift 840 .

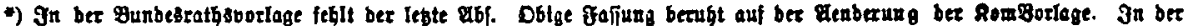

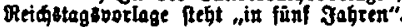




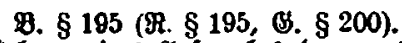

[I, II feblen].

I \& 159.

Die Beriăhrung ber in bet $\S \S 156,157$ bezeidneten $\mathfrak{A n}\{p r i d e$ beginnt mit bem Sdilufie beg Jahres, in weldem bie Befriebi= gung rechtlic berlangt werben tant.

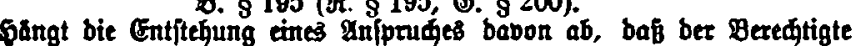
von eirtem ihm suftehenben Anfedtungşrehte Bebrauh madht, fo beginnt bie

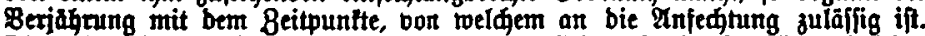

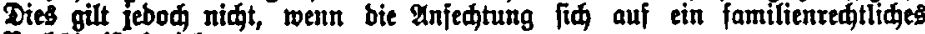
Betrăaltritis bezieht.

II $\S 166$.

Die Berjabrutng ber in ben $\S \S 163,164$ bezeidneten Injprinde beginnt mit bem Sdluाje bes 3ahres, in treldem ber nad $\$ 165$ maß̈gebende Beitpuntt eingetre= ten ift unb, wern bem Ber: oflifteten aber biejen Beitpunlt Ginaus eine Frift betwilligt ift, mit bem Edilufie bes \{̧ahres, in weldem bie frift abgelaufent ift.
\$. § 196 ( $\Re$. § 196, B. § 201). Die Beriāhrung ber in ben $\$ \S 191,192,18.196,197$, be zeidgnten $\mathfrak{A} \mathfrak{n}\{$ prilde beginnt mil bem Ediluffe bes Tahres, in weldem ber nad bent $\$ \$ 193$ bie 195 (ङ. 198 bis 2011) maß̧gebende Beitpuntt eintritt. Pann bie Leifturtg exit nad Dem 2tblaufe einer iber biefen Beiturntt hins: austreidgenben Frift verlangt wer= ben, fo begirnt bie Berjahrung mit bem Єaluffe bes łahtes, in weldem bie Ertift abläuft.

Mntibe 522 f., Protololle 781, Denlídrift 840 ff.

$1 \leqslant 160(U-, B .-R-$ G. -$)$.

Hängen wiederkehrende Leistungen von einem Hauptrechte nicht ab, so beginnt die Verjährung des Anspruches im Ganzen mit dem Zeitpunkte, in welchem die Ferjährung des Anspruches auf eine Leistung begonnen hat.

Dlotive 623, Protololle 782.

I $\$ 161$.

3it bie Berjăgrutg gehemmt, fo tann toährend ber Dauer ber Sermmung eine Berjăhrung niđt beginnen, eine begonnente Ber= iảhrung uidt fortlaufen.

Pirb bie Berjăbrutg unter= broden, fo ift bie bis $z^{4}$ ber unterbreding abgelauferte Beit in bie Berjabrungsfrift nidt eingu= redinen.
II $\S 167$.

Jit bie Beriăbrung gehemmt, fo wirb ber Beitraum, wäbrenb beffen bie Semmung befteht, in bie Beriăhrungsfrift nidt einges redinet.

TI \$ 173. Grodent fo lommt beng unter brodent, fo tommt ber bis gur Unterbrediung abgelaufere Beit= raum nidt in Betradt unb tam eine netue Berjăgrumg exft ná Beendigung ber Lnterbredung be: ginten.

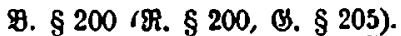
Der Beitraum, währenb beffen bie Beriăhrung gebemmt ift, wirb in bie Beriăhrunggfrift nimt ein= geredinet.

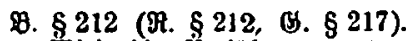
Eirb bie Beriährung unter Grodant, fo tommt bite bis zur Unterbrechung berftridere 8eit nidgt in Betradjt; eine neut $\mathfrak{B e r}$. jăbrung tann erft nah ber Be: enbigunig ber llnterbredurng bes gimner.

Motibe 323 f., Brotololle 782, Dentiditif 840 fi.

I $\$ 162$.

Die Beriąhrung roitb bura jebes reditlide binberni weldes vermoge ber Befdaffenteit Deg̉ Iniprudies ober vermiöge einer

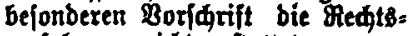
verfolgung nidit geftattet.

Die Berjărnng wirb baburd nidt gehenumt, Daß̉ bem Ariprude bie Einrebe bes niqt erfanten Bertrages, bes Burudbehaltung:s: redtes ober ber Boraustlage ober

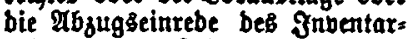
erben entgegenfiteht.

Sie mirb aud baburd nidit gehemmt, boß bem aniprude cire gur Qufredinung gecignete gorbes rung gegeniberjtegt ober bá ber Anjprud ber Infectumg unterliegt.
Il $\S 168$.

Die Berjăhrung if gégemmt, jolange bie Leiftung geftumbet ober ber Ëqulbner aub antberen (S) riln: ben vorlbergegent zur Berweiges nung ber Reifung bereditigt ift.

Diefe Boridrift finbet teine Anwenbung auf bie Cinrebe bes

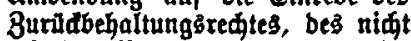
exfinter Bertrages, ber mangeln= ben Stinerheitsleifturg, ber Bors austlage unb auf bie nad \$ $\$ 10$ einem Pargen zuftegenbe Einreben.

BRotive $524 \mathrm{f}$., Protololle 282 ff., Dentidrift 840 ff.

$$
I \S 163(I I-, B .-, \boldsymbol{R} .-, \text { G. }-) \text {. }
$$

Die Verjährung des dem Eigenthümer eines Pfandes gegen den Pfandgläubiger zustehenden Anspruches auf Rückgewöhrung des Pfandes ist 80 lange gehemmt, als das Pfandrecht besteht.

Motibe 525 . 
I $\$ 164$.

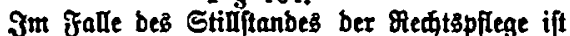
wăhrenb ber Dauer beffelter bie Beriăhrung ge: Germmt.

I $\S 165$.

Mirb ber Beredtigte burd hohere Bewalt an ber Medtsberfolgung verbinbert, fo ift bie Ber= jährung gehemmt, went unb forveit das Ginberni

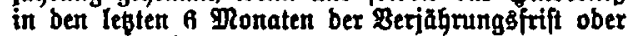
bei einer Berjåhrung bon 6 monatiger ober turzerer Daues ftattinbet.

\section{Mrotive 525 f., \$rotololle 784 f., Denlidrift 840 fi.}

I $\S 166$.

Begen eine ßerjon, weløe geidăftşunfăbig ober

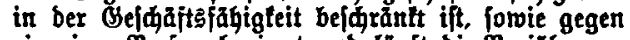
eine jur. Berion beginnt unb Iăuft bie Beriahnung, aud wenn bie Berjon teinen gejeslichen Bertreter hat.

Die Berjabnung wirb pebod in Ermangelung eirtes gefesliden Bertreters nidt bor Mblauf oon 6 Monaten nud bem Beitpuntte vollenbet, in weldiem ber Srumb ber gejegliden Bertretung weggefalfen ift ober ber Mangel Der Bertretung aufgehört hat. Sfl bie Berjăhrunggfrift turrer al 6 glonate, fo tritt an bie Etelle ber 6 monatigen Frift bie $\mathrm{Ber}=$ jährungşfrift.

Goweit bie im 1. $\mathfrak{A}$ bf. bezeidneten Berfonen prozeşfäbig find, finden bie Boridiften bes 2. $\mathfrak{A} 6$. teire Itmendung.

\section{Motive 527 ff., Brotololle 785 f., Denlidrijt 840 ff.}

I \& 167.

Durd bie Erfolge wirb bie Berjährurng ber gegen ben Madila geribteter ober zu Dem Rablaffe

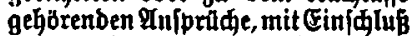
Der nam bem Erbfalle enttftanbenter, nidit gehement.

Die Beriährung eines foldhen Anipnudes wirb jebod nidht vor शtblauj bon 6 Mronater ram bem Beitpuntte vollenbet, in weldem iiber belt Radjlaß ber Ponthurg eröffnet ober ein Bertreter, gegen weldien ober bon reldem ber Anjprud gellenb gemadtt werbent fann, beftellt ober bie Erbjdaft bon bem Erben angentomment worben ift. Jft bie Beriăhnumgsfrift titrzer als 6 Dionate, io tritt an bie Etelle ber 6 monatigen Frift bie Berjăhrunggfrift

Mrotive 529 ff., Protololle 786, Dentidifift 840 ff.

I $\$ 168$.

Fär Anfprithe zwildgen bem Bormunbe unb bem grundel ift

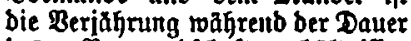

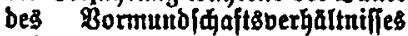
gehemmt. Daffelbe gilt bon $21 \mathrm{t}=$ ipridळert 3wijhenEItern unb Sinbern roăhrenb ber Minoerjăhrigleit ber lesteren unb bon Aullpraden 3wij内ent EGhegattent wăhrent ber Tauter ber Ehe.

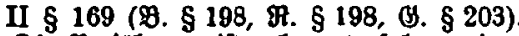

Die Beriahnung ift gehemmt, polange ber $\mathfrak{B}_{e}=$

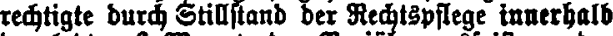
ber Iesten 6 monate ber BertäbrungBfrif an ber Fedtaperfolgung berhindert th.

Das \& leide gilt, wert eine folde Berhinderung in anberer Beife burd hohere Bewalt herbeige= filgtt wirb.

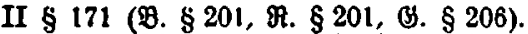

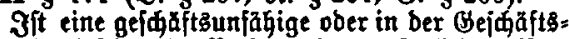
făhigleit bejătåntte Berion ogne gejegliden $\mathfrak{B e r}=$ treter, fo wird bie gegen fie laufenbe Berjäbrumg

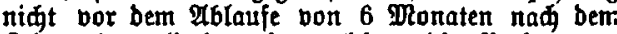
Beitpuntte vollenbet, in weldem bie Berfon un.

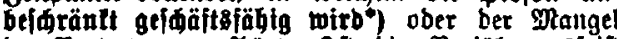
ber Bertretung aufhört $\Im$ fft bie Beriährungagirift tiltrger als 6 Mlonate, fo tritt ber für bie $\mathfrak{B e r}$. jăhnung bejtimmte Beitraum an bie Stelle ber 6 Mronate.

Dieje Boridriften firben leine Inwenburg,

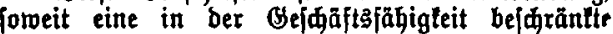
Berfon prozesfátig ift.
Gehört ein $\mathfrak{A n}\{$ prud zu einem Nadilafie ober ridjtet fid ein $\mathfrak{A n}=$ iprua gegen einen radilas, fo wirb bie Beriåhrung nimt vor gblauf von 6 Mtontaten naw bem Beitpuntte vollenbet, in weldem bie Erbjiaft bon bem Erben an= genommen ober ein Bertreter, bon weldem ober gegen weldyen ber Anfprud geltend gemadit werben tann, beftellt ober ber fionlurz aber ben Radía eröfinet roorben

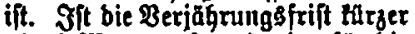
als 6 Mtonate, fo tritt ber filr bie Beriăbrung befintimte Beitraum an bie Etelle ber 6 Mronate.

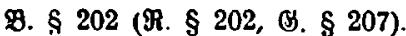
Die Betiăbruttg eines $\mathfrak{A} \mathfrak{n}=$ iprudes, ber za eitrem Radilafie gehört ober fím gegen einen Rađjlás ridtet, wiro nidit bor bem Ablaufe von 6 Monaten nadi bem geit= puntte bollenbet, in weldem bie Erbiafaft bout bem Erben ange= nommen ober ber Ronturs uber Den Radlás erōffutet wiro ober bon weldem an ber Ifulpnid bont einem Bertreter ober gegen einten Bertreter geltertb gemadt werdent lann. Yit bie Beriảhrungsfrift tarzer als 6 Monate, fo tritt ber fur bie Berjăbatng beftimmte 8eitraum an bie Stelle ber 6 Plonate.

Drotive 531 f., \$rotololle 786, Dentidift 840 fi., RomBeriat 973.

\footnotetext{
") Im Entr. II Geibt es „Dec Grunb bex Bertietung toeggefaIten ift".
} 
I $\$ 169$.

Die Berjăbrumg wirb unter= broden, wern ber Berpfliditete gegenáber bem Bereditigten ben

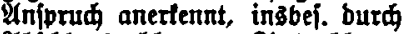
Abidlag:zaklung, Bingzahlung,

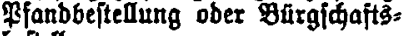
beftellung.
II $\$ 174$.

Die Berjājnung mirb unter= broden, wenn ber Berpflidtete bem Beredtigten gegenüber ben Oniprud anterfent, inģbef. buth

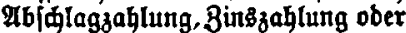
Sideritellung

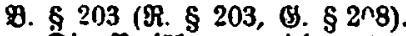
Die Beriăhrullg wiro unter broden, wenn ber Berpflidtete bem Beredtigter gegenuber ben

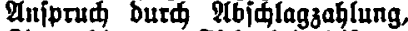
Bing̨zahlung, Siderbeitsleiftung ober in anberer 28 eile arertentst.

Motive 532, \$rototolle 786 f., Denlidrift 840 ff.

I \& $17 \mathrm{C}$.

Tie Berjăhrung wirb unterbrodjen, wenn ber Bereditigte auf Yefriebigung ober ffeffitellung bes Anjpruches, auf Ertheilung ber Bollitredungstlaujel ober auf Erlaffung bes Bodftretungsiurtheiles Slage erhebt.

Der Rlagerhebung ftehent gleiø:

1. Die Buftellung eines Bablungabbejegles im Magnberfahren;

2. Die $\mathfrak{A}$ melbung einer Ronfursiorberung im Sonturie;

3. bie Streitberfundung in bem Prosefife, bon befien 2 usgang ber 2 niprum abhångt;

4. bie Bornahme einer Bollitrectungshanblung unb, foweit bie Bwangsoollftredunt ben Seerimter ober anberen Beb̆orben jugetwiefen ift, Die Etellung bes auf bic 31wangabofl=

ftrefung geriditeten Antrages. unberifirt.

Die Borldrift bes $\S 190$ Der EqD. bleibt

Motive 532 fi. Brotofolle $787 \mathrm{f}$.

I. $\S 171$.

Die Utnternehmung mittel\$̧ Plagerhebung gilt als nidt exfolgt, wenn ber Bereditigte bie Plage zuridnimmt, ober wenn biejelbe wegen Mangel einer Brozeǵporaubjekung abgemiejen wirb.

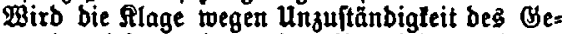
ridtes abgerviejen und von bem Beredtigten binnen 6 Monaten nađ ber Medtstraft bes urtheiles bei bem zuftäribigen Beriate neue Rlage erhoben, fo gilt bie Beriăbnung als burd bie erite Rlagethebung unterbrofem.

3it im falle bes $\S 36$ Mr. 6 ber CPO. bie exite Silage innerhalb ber Beriătungsfrift unb jebe nawfolgenbe Rlage binnen 6 Mlonaten naw ber Red tstraft bes vorausgegangenen Hrtheiles erhoben. aud binnen 3 Mronaten nađ ber Medistraft bes Ieşten Urtheiles bie geftimmurg beß zuftănbigen Beridtes nadgefudt unb bei bem beftimmten Ge= ridte fodatn binnen 3 gonaten nad ber Beftimmung befielben bie Plagergebung exfolgt, fo gilt bie Berjăhrung alg burd bie erfte Rlagerhebung unter: brodien.

פ̧irb bie Mlage wegen unzulăfifigleit ber ge= wăhlten Brozebart abgetwiefen und vor bem $\mathfrak{B}_{e}=$ reditigten biunen 6 Monaten na. ber Meditstraft beş Urtbeiles iut ber zuläffigen Brozesart treue Rlage ethoben, to gilt bie Berjabrung als butw bie erfte RIagerhebung unterbrodien.

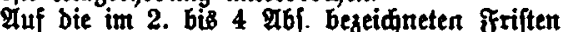
finber bie Boridziften ber $8 \$ 164,166$ entipreduente Anwenbutg.

\section{Motive 534, Brotololle 789, Dentlfifift 840.}

I \& 172.

Die Unterbrecfung mittels Buftellung eires Bablungabefebles im gihnuerfabren gilt als niht

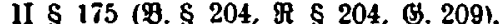

Die Berjährung wirb unterbrođen, wenn ber Bered,igte auf Befriebigung ober Feftitellung bez Anjprudes, auf Ertheilung ber Boujtredungstlaujel

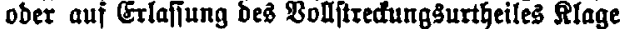
exhebt.

Ter Rlagerbebung fteben gleiळ:

1. Die $\beta$ urftellung eines 3 ablungşbefegles im Diafnuerjahren;

2. Die Anmeloung einer Ronhursjorbenung bes Ariprudes im Ronturje:

3. Die Beltenbmadung ber भujtedrung bes थriprudes im Broseffe;

4. bie Streitbertilnoung in bem Prozejie, von

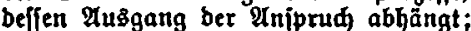

5. bie Bornahme einer Bodjtrectungş̧andlung und, forweit bie Btrangsbodftredung ben Bes rifiten ober anberen Beģ̈rben zugerwielen

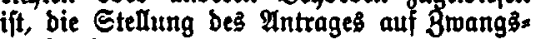
bolfitredung.

II $\S 178$ (98. § 207, 凡. § 207, G. § 212).

Die lunterbredunt buth slagerhebung gilt als nidt etfolgt, twenn bie Rlage zunütaenommen ober burd ein nidt in ber Eade felbit ent|delbenbes urtheil reditsträjtig abgetwiejen wirb.

Erhebt ber Pereditigte binnen 6 Mlonaten von Reurem Mlage, fo gilt bie Berjăbrumg als burd bie erite Plagerhebung unterbroden. IIuf biefe ortit finben bie Borfitriften ber 88169,171 (9.8 203, 206, 207) entipredjenbe भimenburg.

II $\S 176(9 . \S 205, \Re . \S 206$, B. $\S 210)$.

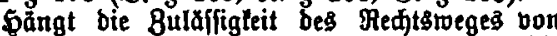
ber Borentjacibung einer Behörbe ab ober hat bie Beftimmung bes zuftänbigen Beridtes burd ein Göheres Beridt zu erfolgen, fo wirb burd bie Ein: reidung bes Befuches an bie Behorbe ober bas Göhere Beridht bie Berjährung in gleider Meife wie burd Plagerhebung unterbroden, wenn bie Plage binnen 3 Monaten naw Erlebigung bes bes \{umes exhoben wirb. Afuf biefe frift finden bie Boridriften ber $\$ \S 169$ bis 171 (\$. 203, 206, 207) entprediende Arwenburg.

II $\$ 179$ (9. § 208, भ. § 208, \$. \$ 213)

Die Unterbredung burm Buftellung eines Bablungsbejehles in Dahnberfabren gilt als nimt 
efolgt, went bie 28 irtungen ber Mecht

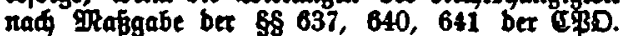
exisfiner.

Mrotive 534, \$rotololle 790, Dentfdrift 840 ff.

I $\$ 173$.

Die Unterbredung mittels Bormahme ober Be: antragung einer Bolffredungshanolung gilt als nidt erfolgt, twent bie etwirtte Boljtredungs: mafregel auf Antrag bes Beredtigten ober wegen Mangela ber geieblidien Borausjebungen auf: gehoben wirb.

Die Unterbređung mittels Peantragung eirer Bolftrectung b̆hanblung gilt als nidt exfolgt, wenn bem Intrage feitens ber Beharbe nidht ftattgegeben

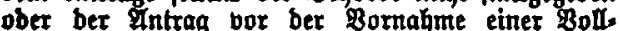
ftredungshanblung zuritgenommen twirb.

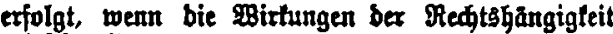
crlöpunen**)
II $\S 182 \mapsto B . \S 211, \Re . \S 211$, (g. § 216).

Die Unterbredung bura Bomahme einer Bolltredunģ̧̧andlung gilt als nidt erfolgt, wenn bie Bolftredungsmapregel auf Antrag beg $\mathfrak{B e}$ redtigten ober wegen $M$ angels ber gefekliden $\mathfrak{B o r}$ auşebungen aufgehoben wirb.

Die Unterbredung burd Stellung bes $\mathfrak{A n}$. trages auf 8wangşoulftrechung**) gilt als nidit erfolgt, wenn bem Intrage nidt ftatlgegeben ober bet $\mathfrak{A n t r a g}$ vor ber Bormahme ber Bollftredung Ganblung guradgegeben ober bie extrittte $B_{0}$

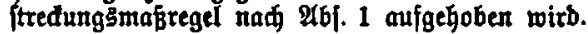

$1 \$ 174$.

Die burf Erhebung ber Alage bemirtte Unterbredfung bauert bit: zur rechtšltüftigent Entideibung ober anbentoiten Erlebigung beg Brozefies.

(Berăth ber \$rozę in Folge etner Bereinbarung ber Barteien pbet in Folge ber Unterlafiung bes Betreibens in Stilfitand, fo enbigt bie unter6refung mit bem Beitpuntte, in welhem ber Still. ftanb eintritt. Die mit Oeenbigung ber Unterbrechung beginnenbe neue Berjăbnang wirb burd bas weitere Petreiben bon Seiten ber einen ober anberen Bartei mit ber gotrthung ber Plagerbebung unter. broden.

\section{Mrotive $535 \mathrm{f} .$, Protololle $790 \mathrm{f}$., Dent/datt 840 ff.}

I $\S 175$.

Cuf bie burd Streitoertinbung beroirtte Unterbrechung finben bie Borfariften bes $\$ 174$ entipredenbe Intoenbung.

$$
\text { II } \$ 177 .
$$

Die burळ Frbebung ber Rlage betwirtte linterbredung bauert, bis ber Brozes rechtsilrăfig entjóieben ober anberweit erlebigt ift.

Berăth ber Brozef in Folge einer Bereinbarung ober in Folge Ritutbetreibens in Stillitand, io enbigt bie Unterbređung mit ber Iegten \$roze巨́ banblung ber \$arteien ober bes Bertates. Die naథ be= enbigter Unterbredung beginnenbe neue Berjăhrung roirb burd basి weitere Betreiben bon Setten ber einen ober anberen Bartei in gleiner खeife wie burn Plagers hebung unterbroden.

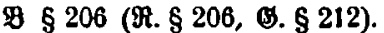

Die Unterbredung burd शlag. exhebung baltert fort, bis ber Broze巨́ redtştrăfig entfquieben ober anberweit erlebigt ijt.

Serath ber Brozes in folge einer \$ereinbanung ober baburw, bak er nidt betrieben wirb, in Stillifand, fo endigt bie llnter. bređung mit ber lesten Brozes. hanblung ber Barteien ober deg Geriđtes. Die nađ ber Beenbigung ber Interbredung beginnenbe neue Beriăhrung twir̉ baburd, ba einte ber Barteien bent Brozen weiter betreibt, in gleiner 28 eije wic burd Rlagerbebung unter. broden.
II $\$ 181$.

Iuf bie burd Beltenbmadung ber Rufredinung im \$rozeffe ober burd Streitbertunbung betwirlte unterbredung finber bie Bor fariften bes \$ 177 entipredente Intoentung. Die Unterbredung gilt als nint erfolgt, wenn ber Beredigte niwt binnen 6 glonaten nad Beenbigung bes Brozelfes Plage auf Befriebigung ober §ept= ftellung bes Iniprudes erbebt; auf bieje \&rijt finben bie Borfdriften ber $\$ \$ 169,171$ entipredenbe Inwenbung.
B. $\$ 210$ (भ. $\$ 210$, G. \$215).

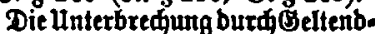
madung ber Fufredinug im Pro. seife ober burळ Streitpertinbung bauert fort, bis ber \$rozé redits: trăftig entificben ober anberweit erlebigt ift; bie Boridriften bes 8206 (S. 211) এb| 2 funbert 9 . toenbung.

Die unterbrechung gilt als nict exfolgt, wenn ntot binnen 6 glonaten ná ber Beenbigung bess Brozeffes Mlage auf Befrie bigung ober Feftitellung bes \&in: (prudjes ergoben wird. $\mathfrak{A u j}_{\text {bieje }}$ Frift finben bie Borfariften ber

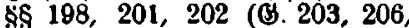
207, entiprechenbe $\mathcal{A}$ nwenbung.

Drotibe 536, Protololle 791 f., Denth

I 6176.

Die burh Anmelbung im \$ons hurfe berwitte unterbredung bauert bis jur \$cenbigung bes Stonhurfes. Die unterbredung gilt als nibt exfolgt, went bie Inmelbung juridgenommen wirb.
II $\$ 180$.

Die burd 9nmelburt im Ston: hurie betwirltellnterbredung bauert, bis ber Ponlurs beenbigt ift.

Dic unterbrefulung gilt als niळt erfolgt, wenn bie Anmelbung gurdidgertommen toirb.
9. 5209 (M. 8209, (S). 5214 ).

Die Unterbredung burs An: melbung im Ronturfe bautert fort, bis ber \&onthrs beentigt ift.

Die Utnterbređung gill als nidt exfolgt, went bie Anmelbung zurildgenommen wirb.

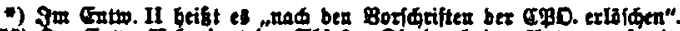

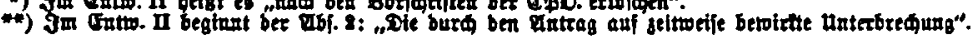


3it bei Beenbigung bes Routs lurfes fir eine forberung, welde in Eolge eines bei ber Grafung erhobenen \$oiberiprudies in \$roze befangen ift, eir Betrag surid behalten norben, fo bourent bie Unterbredung aú nah Beenbi: gung bes Sonturies fort; bas Enbe ber Unterbredung bejtimm! fiळ in biefem salle nah ben Bors 低riften bes \$174.
If bei bex Meenbigung bes Ponhuries far eine Forberung, bie in Folge eines bei ber Praffung

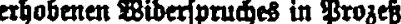
befangen ift, ein Betrag jurlids behalten toorben, fo bauert bie Unterbređung aud nađ Peenbigung bes Ponthries fort; bas Enbe ber unterbredung beftimut

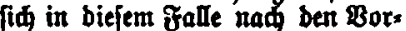
\{áriften bes $\$ 177$.
Mirb bei bex Beenbigung bes Monturies far eine Forberung, bie in folge eines bei bet Prilfung exhobenen Miberfprudes in Prozes befungen if, ein Betrag zurild behalten, fo bouat bie ilnter: bredung auめ naळ ber Beenbigung bes Ronfuries fort; bas Tnbe ber unterbredung beftimmt fid nad ben Boriariften bes $\$ 206$ (\$. 211)

Protive 536 ff., \$rotololle 792, Denildrift 840 ff.

I 8177.

Pedtatraftig feftgeftellte An: pridge berjabren, aud werm fie an fin einer tisneren Beriohrung unterliegen, mit ablauf bon 30 Gabren. Daffelbe gilt bon ans fprifden aus bollftedbaren Ber: gleiden und bollftredbaren $\mathfrak{H} r$. tumben forvie bon ginjprllgen, twelde burd bie im Ponturie er: folgte feftiftellung volftredbar ge= morben finb.

Goweit bie freftitellung fid auf regelmäfig miebertegrenbe, erft tinjtig berfallenbe Reiftungen ers ftreft, finben bie Borfariften bes 1. AbF. Teine Antwenbung.

grotive 538, Protololle 792, Denthdrift 840 ff.
Meçts̆trăftig feftgefteute $\mathbb{M}_{\mathfrak{r}}=$

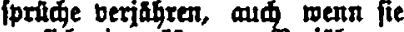
an fin einer targeren Berjobnang unterliegen, mit bem qblaufe bon 30 Jahren. Daflelbe gilt bon

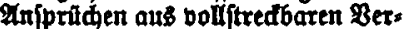
turnben fordie bon Anjpridaen, welde burd bie im Ronturfe er: folgte feftftellung volltredbar ges roorbett firtb.

Coweit fid bie Feflftellung auf regelmåfig wiebertehrenbe, exft tinftig fălig werbenbe Reifhungen erftredt, berbleibt es bei ber thit = zeren Beriahnoungsfrift. gleifen unb bollftredbaren $\mathfrak{U}=$

円. §213 (भ. ૬ 213, 6. § 218) Ein rentstraftig feftgeffellter

Aniprú vecjōtst tu 30 Jagren oud werth ex an fith einer turseren Berjănung unterliegt. Tas (Oleide gilt bon bem Injprude aub cinem bollitredbaren Bergleide ober einer volfftedbaren liftunbe fowie bon eintem Anjprude, weløer burs bie im Sonturie effolgte feftitellung volftredtbar gewor= ben ijt.

Soweit fin bie freftftellung auf regelntäitg wieberiegrenbe, erft tunjtig făhig toerbenbe Leiftungen bejieht, betwenbet es bei ber hat: zeren Beriăbungsfrif.

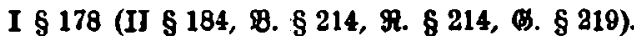

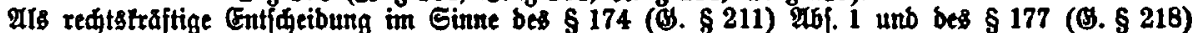

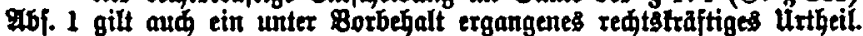

Mrotibe 538 f., Denlintift 840 ff.

I $\$ 179$.

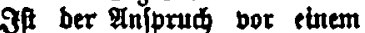
Shiebsgertate ober beforberen Geride, bor einem Bertoaltungs: geridite ober einer Bertoaltungs: bebisibe geltenb gu maden, po finben bie Boridriften ber $\$ \$ 170$ bis 175 unb ber $\$ \$ 177,178$ ent. \{prectenbe Antoenbung.

Sind in einem SGiebsbertrage bie Sqiebsriater niat emannt, ober bangt bie Inrufung eittes bereits beftebenben Caicbsage riates bon ber Exfallung befons berer Borbebingungen $a \bar{b}$, [o toirb bie Beriabrang fळon baburd

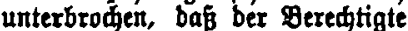
bas peinerfeits our Erlebigung bes enftanbes Erforberlice bor: nimmt.
II $\S 185$.

Yit ber $\mathfrak{A n}$ |purd vor einem Shiebsgeridjte ober bejonbeten Seriqte, vor cinem Berwaltungs: geribte ober einer Berwaltungs: beborbe geltent zu maden, fo finben bie Boridriften ber $\$ \$ 175$ bis 179, 181 biz 184 entfpredente Anwentung.

Sinb in tinem Gofiebsvertrage bie Shitebsriater nidgt ernant ober if aus einem anberen (Srunbe bie Emennung cines Squiebs: riøters ober bie Crfalung einer Fonftigen Borbebingung erforber= lid, che bas Ghiebsogeriat an: gerufen werben tann, to wirb bie Berjahnung fán baburd unter: broden, bafi ber Peredtigte bas zur Erlebigung ber Safe feiner. feits Erforberlide vortimunt.

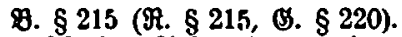
Эit ber Ariprún bor einem Sartebsgeridte ober eincm befon: beren Beriate, bor cinem Ber: waltungsigeridte ober cinte Ber. toaltungsbebörbe geltenb gu madien, fo finben bie Borfintfiten 85204 bis 208, 210, 211, 213. 214 (अ. 209 b15 213, 215, 216 , 218, 219) entipredienbe Inwen. bung.

Sinb in bem Shiebsvertrage bie Squebsiriळter nimt emant ober ift bie Ernenumang eines Săiebsrifters aus einem anberen Grunbe erforberlin ober lann bas

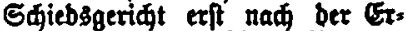
fillung einer fonftigen Boraus: lebunt angertifen werben, fo wirb

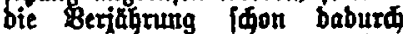
unterbrohen, bab ber Beredtigle bas zur Erlebigung ber Eade feinerfeits Erforberliafe bornimmt. Dotive 539, \$rotololle 792 f., Denifdift $840 \mathrm{ff}$.

I \$ 180 (fiege zu I \$171).

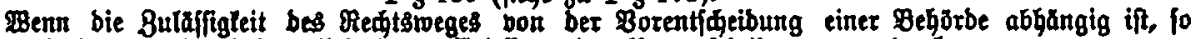
wirb bie Berjabrung burq bas Bejú um Grlaffung ber Borentífibung unterbroden.

Die unterbrechung bauert bisె zur ErIebigung bes befudjes.

Motibe 539, Brototolle 789, Dentifrift 840 ff. 
I \& 181.

Belongt eine Gade, in 2rrehung beren ein ouf einem Redte an berjelber beruberber थriprud begrambet ift, burd Redtenadfolge in ben gefib eines Dritten, 10 wiro bie wätrenb bes Befibes bes

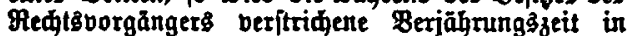
bie Berjäbrungsfrift eingeređnet.

Motive 539 f., Brotololle 793, Denffintift 840 ff.

\section{I \& $15 \dot{2}$}

Rad Bollerbung ber Berjăh= rung fitegt bem Infprudje eire Eintebe entgegen, butw welde bie (selterbmadurg bes Anjprudes Dauemb ausgeffloffen wirb.

Das zur Befriebigung eines veriăbrter Iniprumes̆ Geleiftete farn aud bant nidt zuriad= geforbert werben, wenn in $\mathfrak{u n}=$

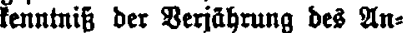
fprudes geteiftet ift.

\section{II $\$ 187$.}

Nad Bollerbung ber Berjahs rung fteht bern antiprude cine Einrebe entgegen, burd welde bie Geltenbmadurg bes Mriprudes bauent ausgeld hlofien ift.

Tas zur Pefriebigung eines beriāhnten Iripruties B́eleiftete fann nidit zurudgeforbert werber, aud wertr bie Leifturtg in $\mathfrak{U n}=$ ferntritis ber Berjăhrung berwirtit ift. Tas Bteide gilt bon einem

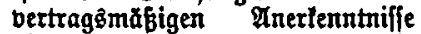
ober Erfüllungß̋̄neripredent, fomie einer Eidherheitsleiftung bes Ber= pilintelen.

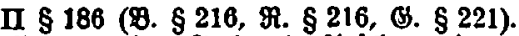
(elangt eine Eahe, in Injebung beren ein in ben Befis tines Tritten, fo lommt bie mährend

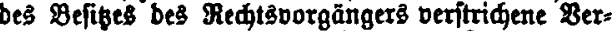

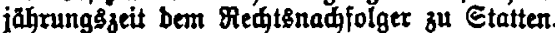

Motive 540f., Brotololle 793 ff., Dentifirift $840 \mathrm{ff}$.

\section{I $\$ 183$.}

Die Beriăhrung eimeş burđ Piandredt ges fiderten $\mathscr{2}$ niprumes hinbert bent Beredtigten nidit, feine Befriebigung au\& bem Banbe zu berlanger. Bei ber Berjăbnumg von $\mathfrak{A}$ (nfpridden auf rild ftănbige Binjer ober anbere mieberlebrenbe Reiftungen

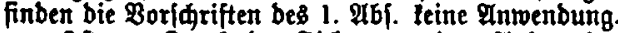

3it zum Brwede ber Siderung eines Anjprudes eir Rectit tibertrager, to finbet bie Radforberung auf Grumb ber Beriahrung bes $\mathfrak{A}$ nfpruhes nidit ftatt.

\section{Motibe 542, Brototolle}

II $\S 188$ (B. $\S 218, \Re . \S 218$, b. $\S 223)$.

Die Berjâhrung eines 2friprudes, für ben tine Eypothel ober ein Pfanbredt befteht, hinbert ben Beredtigten nidt, feine \$efriebigung aus bem bet. bafteten Begenttanbe zu fuher.

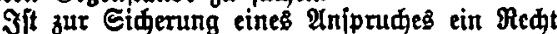
Hbertragen worben, fo tann bie Rüdübertragung

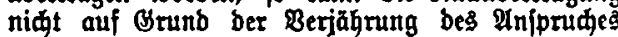
gefordert werber.

Diefe Borfintiften finben Itime Inwenbung bet ber Berjährung von ginfprüben auf Rüdtänbe von ginien ober arberen toitberlebrenben \&eiftungen.

I \& 184 .

3it ber Sauptanfprud berjähth, fo ift aud ber Iniprú auf bie bon bemielben ab̧ängenben Reben= Ieiftungen beriăhrt, felbit wenn bie für ben lezteren Infprut geltentbe befonbere Berjährung nod) nidjt nolfenbet itt.

Bei selbständigen toiederkehrenden Leistungen ist mit der Verjährung des Anspruches im Ganzen auch der Anspruch auf die bis dahin verfallenen Leistungen verjährt.

Motive 542, Prototolle 796, Denlidrift 840 ff.

\section{I \& 18E.}

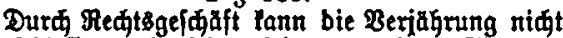
ausgefidlofjen und nidt erjfbert werben. Sie tann

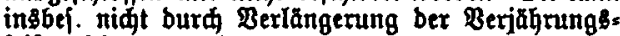
frift eridmest werber.

Die Erleifterung Der Berjăhnung, inşbel. Die

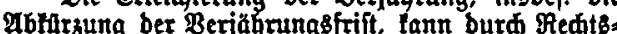
gejadift beftimmt werben.

Mrotibe 542 f, Protololle 796, Dentffrift 840ff.

\section{Selbftwertheibigung (und) Selbfhatilfe. I (II, $\mathfrak{B})$.}

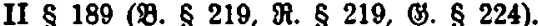

MRit bem \$auptaniprude beriăbrt aud ber

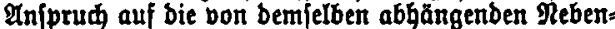
Ieiftungen, felbft wenn bie far biejen $\mathfrak{A}$ nfprud geltenbe bejon bere Berjăhang nod nidt vollenbet ift.
II \& 190 (B). \& 220, R. \& 220, (3) \& 225).

Die Betiăhrung tann burd Mechtsgefdaft weber

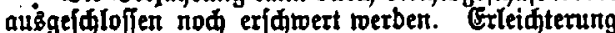
ber Berjăbrung, insbej. A6turzung ber Berjabrung frift, ift zulafifg.
[I, II 9., M. feb̆[en].

\section{Jusübung Der Rechte. Selbftoertheidigung, Selbfhalfe.}

BomBorlage \& 220 a (B. \& 226).

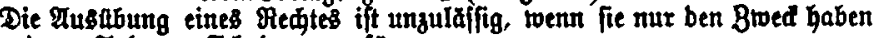
lann, einem Inberen Sमjaben zuzufügen. Potibe -, Brototolle 796 f., Somberidgt 973. 
I \& 186.

Eine unerloubte Şanblung ift niwt vorhanden, wenn bie \$arblung burd Mothwehr geboten war.

Rotbrweht ift biejenige Bertheibigung, welde exforberlit ift, um einen gegentwärtigen, redts=

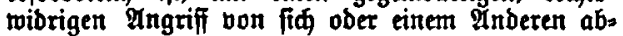
sumenber.

glotive $543 \mathrm{f}$. , Grotololle $797 \mathrm{f}$., Dentfintift $843 \mathrm{f}$.

$1 \S 187$.

Gine unerlaubte Sandlung ift nidt vorhanben, wenn Jemanb eine frembe Eadje befouäbigt ober zerftört, um eine von biejer Eade brohenbe Gejabr

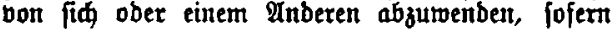
bie Sanblung zur Abtoenbung ber Ssefahr eriorberlic

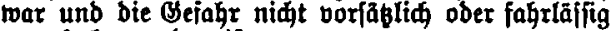
verurfact toorben ift. uidut wiberredttiof. zumentben.

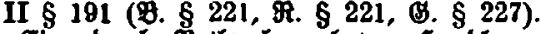

Gine burd Nothwehr gebotene Sanblung if

Rothwebr if biejentige Bertheibigung, weldie exforberliđ ift, um einen gegenwärtigen redits:

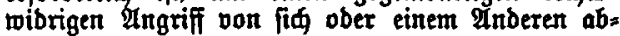

II $\S 192$ (B. § $222, \Re . \S 222$, B. $\S 228$ ).

Ber eine frembe Sade befäabigt ober zertiont, um eine burd fite brobentbe Bejahr vont fid ober einem Anberen abjumenden, Ganbelt nidit wiber.

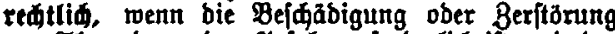
zur Mbtwentung ber Gefahr erjorberlid ift anb ber

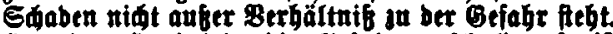
Wat ber Sandelnbe bie Gefagr beridulbet, fo ift er zum Edabentierjage verpfliditet.

Motive 544 fi., Prototolle 798, Denfidrift 843 f.

$I \S 188(I I-, B .-, R .-, R .-)$.

Selbsthülfe mittels Handlungen, welche an sich unerlaubt sind, ist unerlaubt, soweit nicht das Gesetz ein Anderes bestimmt.

I $\$ 189$.

Selbithâlfe mittelä \$egrahme, Berftörung ober Bejä̆bigung von Sadjen ober mittels Nosthigung beB Berpflidteten zur Erfaulumg feiner Berpflidturtg ift erlaubt, went obrigfeitlide Sulfe niaft redizeitig za erlangen ift unb ber Bereditigte ofne fofortiges (Fin= greifent Befahr lăuft, baß̄ bie Berwirtliđung bes $2 \ln _{\text {rpruches }}$ berciteft ober wejentlid erfidwert werbe.

Ter Beredtigte barf bei $\mathfrak{A}$ as= abuntg ber SelGithalle nidgt weiter gehen, als zur Ulbmentung ber Gefahr nothwelloig ift.

Jm Falle ber feftnahme bes Berpilidtetent ift berjelbe, pofert er nidft wieber in freibeit gefest

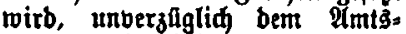
geridte, int beffent Dezint bie Feftrahme erjolgt ift, vorgufuhren, zugleid ift bei biefem Beriate bie Inorbnum bes perjönliden

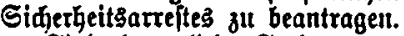

Einb berweglide Saden zum Brode ber Sidertung eines $\mathfrak{A n}^{n}=$ fprudes weggenommen, jo ift, fojerm niat 8rwantgsoolfitredung

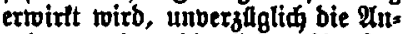
orbnung bes binglident भirreftes ou beantragen; wirb bie Stellung bes Intrages berzögent ober ber Quntrag abgelegnt, fo find bie Saden zurildzugeben.

Motive $546 \mathrm{j}$., Brotololle 806 .

II $\S 193$.

Wer zum Brwede ber Gelfit= Gulffe eime Sadje megnimmt, zer= Itỏnt ober bejuäbigt ober wer zu biejem Brecte ben Berpilidteten feftuimmt ober bert befielbent gegen eine Sanblung, bie ex zu Dulben verpflidtet if bejeitigt, Ganbelt nidat wider redutlid, went obrigleitlide satlfe nimt rectizeitig zu exlangen if und ohre fofortiges Eingreifen Befajr vorliegt, bá bie $\mathfrak{B e r}=$

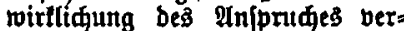
eitelt ober wejentlia eridivert werde.

\section{II $\S 184$}

Die nad $\$ 193$ zulläffige Selbittalfe bari nidt weiter gehen, als zur 2lbrentbung ber Bejahr nothmentig ift.

Im Falle ber \$egnahme von Sahen ift, fofern nidit Swangs= bolfitrednng erwirtt wirb, ber

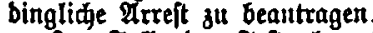

Im Falle ber foftnabme bes Berpflidteten ift berfelbe, fojern er nidjt wieder in freiheit gejest twirb, umverzulglid bem 2 imt $\delta=$ geridite, in beffen Bezirt bie fefts nahme exfolgt ift, vorguiähren; aud ift bei biefem Beridte ber perjönlide Siderbeitzarreft zu beantragen.

2 Birb ber Arreftantrag vers zögert ober abgelegnt, fo hat bie भiddgabe ber tweggentommentent Sadjer und bie freilafint bes Fefitgenontmenen unverzüglim zu exfolgen.
B. \& 223 (H. \& 223, (5) \& 229)

Ber zum grwede ber Selbit: Gulfe eine Sahe twegnimmt, zet= ftört ober bejđábigt ober wer aum Brwede ber Selbithalife ben Ber. piliditeten ${ }^{*}$ feítnimmt ober ben 2Biberitanb bes Berpflifiteten gegen eine Ganblung, bic biejer zu bulben verpfliatet ifi, Gefeetigt, hanbert nidit wiberredtltid wenn obrigs Jeitlidje Galfe nidt redtzeitig ou eriangen ift und ofne fofortiges Eingreifen bie Befajar bejteht, bas bie Bertwittlidung bes $\mathfrak{A n}$ /prudes vereitelt ober wejentlid erf [fovert werbe.

B. § 224 ( $\Re . \S 224$, B. $\S 230$ ) Die Selbithalfe barf niat weiter geben, als zur Abrwenbung Der Befahr erforderlid iff.

Im falle ber $2 B e g n a b m e$ von Eaden ift, fofern nidit Brwangs: bolftrectung erwirtt toirb. ber binglide थrreít zu beantragen.

3m Falle ber feftnagme bes Berpflidteten ift. fofern er nidt wieber in Freeiheit geiebt wirb. ber per[ätidue Sidferbeitsatreft bei bem Mmtşgeridte zu bean: tragen, in befien Bezirt bie feeft. nahme eriolgt ift; ber Berpflidtete ift unbergliglid bem Beridte bor= zufahren.

sitb ber Arteitantrag ver= zongert ober abgelehnt, fo hat bie Rudgabe ber weggenommenen Sadien unb bie Freetlaflung bes Feftgenommenen unverzägli erfolger.

Dotibe 547 f., Brotololle 806 f., Dentidrift 843f., PomBeridt 973 f.

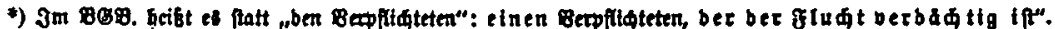


III $\S 195$.

gBex eine bex in $\$ 193$ beseid. neten 5andlungen in ber irrigen $\mathfrak{A n}_{\mathrm{n}}$ nahme vornimmt, bá bie für ben

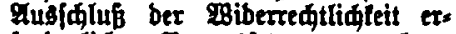
forberliden Boraug\}etungen vorban: ben feien, ift aud int Fafle entfiulb: baren Srthumes bem anberen Theile oum Sdaberserjabe berpfliditet.
D. §225 (R. § 225, 0. § 231).

$29 e r$ eine ber im $\$ 223$ (\$. \$ 229 ) begeidneten bandlungen in bet inrigen Arrahme vorminmt. báp bie für bert

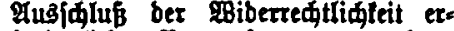

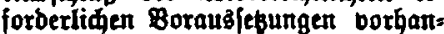
Den feien, ift bem anderen Theile zum 巨aаbenserfake verpflidtet, aud

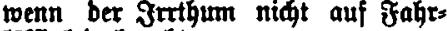
Iafifigleit berubt.

\section{Motive -, Brototolle 807 f., Som:Deridt 974.}

\section{Urtheil.}

$I \S 190(I I-$, B. - , B. -, G. - ) .

Die Verurtheilung su einer Leistung ist nur zulässig, woenn die Fälligkeit bereits eingetreten ist.

Bei voiederkehrenden Leistungen, welche nicht auf Rechtsgeschäft beruhen, kann die Verurtheilung auch für die erst später fällig werdenden Leistungen erfolgen.

Wird eine von einer Gegenleistung nicht abhängige Geldforderung erst mit Ablauf einer Frist nach der Kündigung fälig, oder endigt ein Miethverhältniss erst mit Ablauf einer Frist nach der Kündigung. so ist die Verurtheilung zur krünftigen Zaklung oder Räumung auf Grund der mit der Klage rerbundenen oder derselben voraugegangenen Ë̈̈ndigung zulässig.

Mlotive 552, Brotolle $808 \mathrm{ff}$.

$$
I \S 191\left(I I-B_{\text {. }}, R_{\text {. }}-G_{\text {. }} \rightarrow\right. \text { ). }
$$

Das rechtskräftige Ortheil ist massgebend für das Bechtsrerhältniss zwischen den Parteien. Das rechtskë̈ftig Zuerkarnte kann nicht mehr bestritten, das rechtskräftig Aberkannte nicht mehr geltend gemacht woerden.

Auf diese Wirkung des rechtokräftigen Urtheiles kann verzichtet werden. Das Gericht darf dieselbe nur beriicksichtigen, wenn sie geltend gemacht wird.

grotive 658ff., Prototolle $811 \mathrm{ff}$.

$I \S 192\left(I I-\right.$, B.,$- R_{.}-$, G. -$)$.

Das rechtskräftige Ortheil toirkt für und gegen die Parteien und diejenigen Personen, welche nach Eintritt der Rechtshängigkeit Rechtsnachfolger der Parteien oder Inhaber des in Streit befangenen Gegenstandes für eine der Parteien genoorden sind.

Die Vorschriften au Gunsten derjenigen, welche Rechte von einem Nichtberechtigten herleiten, finden entsprechende Anvendung.

Mtotive 558ff. Brototolle 814 f.

\section{Beweis.}

I $\$ 193(I I-$, B.,- R.,- G. -$)$.

Wer einen Anspruch geltend macht, hat die zur Begrindung desselben erforderlichen That sachen zu berceisen. Wer die Aufhebung eines Anspruches oder die Bemmung der Wirksamkeit desselben geltend macht, hat die Thatsachen su beweisen, welche zur Begrïndung der Aufhebung oder Hemmung erforderlich sind.

Mrotive $561 \mathrm{f} .$, Protololle $815 \mathrm{f}$.

I $\$ 194($ LI - , B. - . R. - , G. - ) .

Wer die rechtliche Wirkung eines Thatbestandes wegen besonderer, die regelmässige Wirksamkeit ausschliessender Thatsachen verneint, hat diese besonderen Thatsachen zu beweisen.

Dies gilt insbes. für Bechtsgeschaffe, wenn geltend gemacht wird der Mangel der Geschäftsfähigkeit, der Debereinstimmung des wirklichen Willens mit dem erklärten Willen, der Willensfreiheit wegen Drohung oder Betruges, oder wenn geltend gemacht wird, dass eine besondere Form rechtogeschäflich bestimmt woorden sei.

Plotive 560, Brotololle $815 \mathrm{f}$.

$I \S 195\left(I-, B .-, R .-, G_{-}-\right)$.

Wer Rechte aus einem Rechtsgenchäftè geltend macht, hat, wenn eine besondere Form zur Gilltigkeit desselben orforderlich ist, auch die Beobachtung dieser Form zu berocisen.

Mtotive 361, Protololle 815 if.

I \$ $196(I I-, B .-$, R. - , G. - $)$.

Wer Rechte aus cinem Rechtsgeschäfte geltend macht, hat zu beocisen, dass dasselbe in der von ihm behaupteten Weise zu Stande gekommen ist, auch zoenn der Gegner die Errichturg zugesteht, jedoch behauptet, dass das Rechtogeschäft tn anderer Weise, insbes. unter Beifügung einer aufschiebenden oder auflösenden Bedingung oder unter Beifügung eines Anfangstermines oder Endtermines errichtet worden sei.

Motive $361 \mathrm{f}$., Protololle 815 fi. 
I) $197(I I-$, B. - R. --, G. -)

Die Erfillung oder den Ausfall einer Bedingung hat derjenige zu beweisen, welcher aus der betreffenden Thatsache ein Recht herleitet.

Motive 561 f., \$rotofulle 815 ff.

$I \& 198(I I-, B .-, R .-, G .-)$.

Wenn das Gesetz vorschreibt, dass eine Thatsache, vermuthet werde, so gilt dieselbe für erwiesen; es ist jedoch der Beweis des Gegentheiles zulïssig, sofern nicht ein Anderes vorgeschrieben ist.

Miotibe 562 f., \$rotutolle 815 ff.

I \& 199.

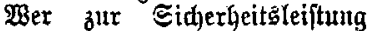
berpllidtet ift, hat biejelbe int eitrem

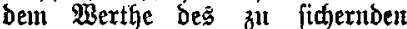
Redtes entiprechenden Detrage nach feiuer $\mathfrak{W a h l}$ zll berwirfen:

Durd bff. Sinterlegung bon Bselo ober Bertfpapieren,

Durch Berpfănbung beweglidjer Sadien,

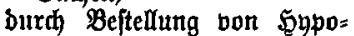
thefen an inlänbilichen Brandiftüfen,

Durd Berpfändurtg von \$npo= theten ober Brunbifulden

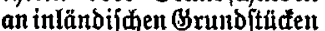

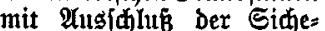
ruttgahypotheten.

Saun bon igm in biejer Meije Die Simerheit uifit geleiftet werben, fo ift bie Etellung tild tiger Butrgent zuläffig.

Die Borfariften bes 1. und 2. $\mathscr{X} 6$. Finden nur infoweit $\mathfrak{A}_{1}=$ wenburg, als nidit burch Bejes

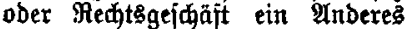
beftimmt ift.

\section{I \& 200}

Mit bex Geinterlegung erwirbt ber Beredtigte ein Branbredt an bem histerlegten Belbe ober an

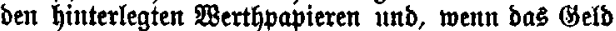
ober bie Merthpapiere Lanbesgejeblith in bas Eigen= thum bes frisfug ober einer âtiftalt atbergehen, ein Pfanbredt an ber forberung auf Müderitattung.

Motive 563 ff., Protololle 817.

\section{I $\$ 201$}

W3erthpapiere find zur Sider= heitsleiftung nur geeiguret, wenn fite auf ben Ģnthaber lauten, einen Auremerth habent unb einer (battung antgehörett, in welder Mhintbel= gelber angelegt werbett bürfett.

Mit Werthpapieren taun nur in Sobhe bon $3 \%$ bes Turswerthes Eiduerheit geleiptet werbent.
II $\$ 196$.

Ber Sidferheit zu leijten hat, fant bies nach jetner $23 a h l$ be wirfen:

Durd Sinterlegung bon Beld ober Werthpapieren

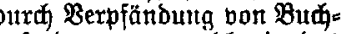
forbenutuen, welde in bas

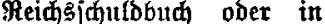

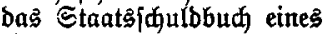
Butbešftaateśs eingetragent finto,

Durd) Berpfänoung betweglicher Saden,

Durch Bejtellung bon Sypo= the fen an inlänotidgen (Srunditüitent,

Durd \$expfändung bon For= berntaen, für bie eine Wypothet an einem in= läubifínen (S)runbitude be= fteht, ober von (Srunb=

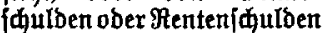

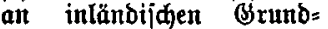
ftüfen.

fann Eidherheit niat in biejer Weife geleiftet werben, io ift bie

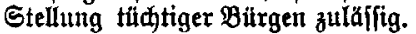

Mtotive 563 ff., ßrototolle 817.

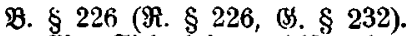
Mer Sidjerheit zu Yeifted hat fant bies Gemirfen

Durch Sinterlegung pon Brelo ober Merthpapieren,

ourch Berpfänoung von For. berungen, bie in Das Reifis: iđulbbud ober it bas Staatsidullobud eines Buntoesitaates eingetragen find,

bur๘) Berpfänoung betwegliçer Sadien,

burd Beftellung von Sppo= thefen an inlärtbijąen Brunditiifen,

burç :Berpfänoung von Fror berungen, für bie eine Sypothel an einem inlänt= bijden Granditüute beftefht, ober burdh Berpfänoung bon Bruntofdulben ober Mentenihulbert an inlän= bijđen Grunditüaten.

Raun bie Sidherbeit nidht in biejer Meife geleiftet werben, fo ift bie Steûung eines taugliden Bürgen zuläffig.

II 198 (P. $\$ 227, \Re . \$ 227$, (S. $\S 233$ ).

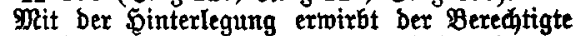
ein ßrandredit an bem hinterlegten Gelbe ober an bent hinterlegten Werthpapieren und, wenn bas Gelb ober bie Merthpapiere nad Ianbeşgefeblider $\mathfrak{B o r}=$

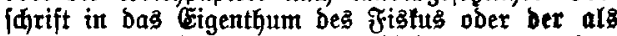
binterlegung gifelle beftimmten $\mathfrak{A}$ [talt*) übergehen,

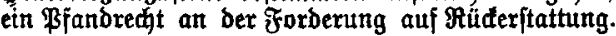

Berthpapiere fint zur Sither= Geitşleiftung nur geeiguet, went fie auf bett $3 \pi$ haber lautent ober als Ramentapiere aut Grunto etnes Blantoindoffaments umlaufen, einen Sturgtwerth haben unto einer Battung angehören, in welder Mündelgelber angelegt werbent bürfent.

Mit ben Merthpapieres futo Die zligebörenten Bing=, Renten=

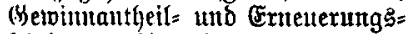
fineine zll hinterlegen.

Mit 2 gertifpapierent fant nur in ber Gible boll 3/4 bes Surs= werthes Sidyerheit gelciftet twerben.

Motive 563 ff., Brotofulle 818.
月. \& 228 (भ \& 228, (1) \& 234) 3erthpapiexe fins zur Sidex= heitşletifung nur geeignet, wenn fie auf Den Эnhaber lauten, eitten Surstwerth haben unb einer (jattung angehören, in ber $\mathfrak{M}$ änbelgelb angelegt werben fann. Den S̈nhabex= papieren ftehen Droerpapiere gleid, bie mit Blantoindoffament ber= feken futo.

Mit Den BSerthpapieren find bie Bin $3=$, Renten $=$, Sewinnantheil= unto Erneuerungsfdeine zu hituter= Ieger.

Mit Werthpapieren fann Sidher= heit nur in Sobe bon 3/4 Des Aurswerthes geleiptet werden. 
[f féflit].

ПI § 199 (․ § $229, \Re . \S 229$, (S. § 235).

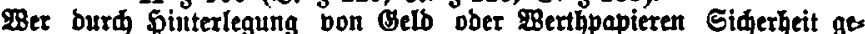
Ieiftet hat, ift beredtigt. bas Ginterlegte Belb gegen geeignete \$erthpapiere,

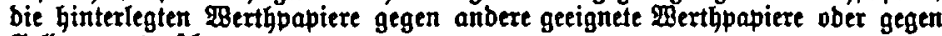
Belb umzutauidien.

Mrotive -, Protololle 819.

II § 2.0 .

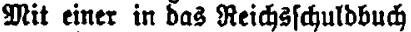

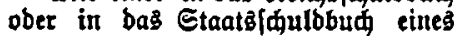
Bunbeşftaates eingetragenen Bud = forberung tann nur in ber şobe bon

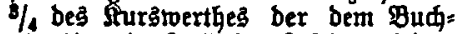
glâubiger im falle ber \&ojidung feiner Forberung auşzuliefeniben $\mathfrak{B e r t h}=$ papiere Sinerbeit geleiftet werben.

Motibe -, Prototolle 819.

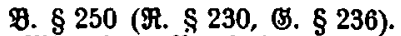

Mit einer Budforberting gegen bas Reid ober gegen einen Gunbezs: $^{2}$ ftaat fann Ciderbeit nur in Sobe

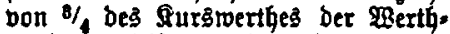
papiere geleiftet werben, beren $\mathscr{A}$ uş: hănbigung ber Blăıbiger geget \&ofinung jeiner forberung berlangen tann.
I $\$ 202$.

97it einer bervegliden Eade fann nut in \$obe

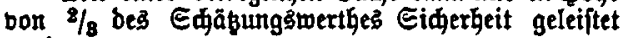
werben.
II $\S 201$ (B. $\S 231, \Re . \S 231$, (4. $\$ 237$ ).

פit einer bemegliden Eade tant હiqetheit

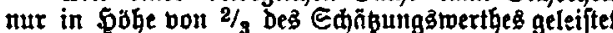
werben. Eadien, iseren Berberb zu bejorgen ober beren थuibetwahrung mit befouberen €dmiexigleiten verbunben ift, tönnen zurladgeroiejen werben.

Mrotibe 563 ff., Protololle 819.

I $\$ 203$.

Eine \$ypothel ober Brunbinulb ift zur Ciner: heitsleiftung unt geeigntet, wenn fie ben Boraus: \{egungen entipridut. unter welduen Münbelgelber in Sypotheten ober Brumbidulben algelegt werben butfert.

Mrotive 563fi., Brotololle 819.

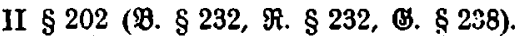

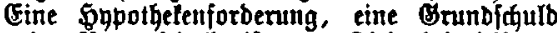

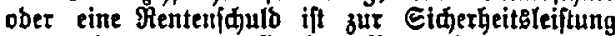
nur geeignet, wenn fie ben Borauşeßungen ent: [priat, unter benen am Drte ber SlaterbeltsIetftung*

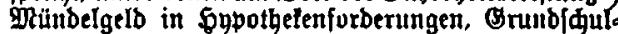
ben ober Fentenifulben angelegt werben barf.

Fine Forberung, für bie eine Eiđernungşgapo. thet befteht, ift zur éciderheitsleiftung nidht gecignet.

\section{I $\S 2 n 4$}

Ein Bürge ift tilutig, wenn er ein ber sube ber zu leiftenben Eiderheit angemeffenes Bermögent befibt und feiuent allpemeiner oseriditsftanb im Sulanbe hat.

$$
\text { II } \leqslant 203 \text {. }
$$

Ein Batrge ift thathig, wenn er ein ber sube ber zu leiftenben Eimerheit allgemefifenes Bermögen befigt und feinen ađgemeinen (s) ridisfitant im 3nlaube hat.

Die Bürglăhaftęertlärunt hat unter Berzidtt auf Die Einrebe ber Boraustlage idriftlid zu erfolgen.
B. $\$ 233$ เЯ. \& 233, (3. \& 239). Ein Bürge ift tauglid, wenn er eit ber Sobje ber zu leiftenden Eiduerbeit augemeffentes Bermogen befibt und feiuen allgemeinen Gex riatsitand im Sulanbe hat

Die Bürgiळaftsertlărung muв idriftlic abgefápt fein unb**; ben Berjidt aul bie (Fimrebe ber Bor ausitlage enthalten.

Mntive 563ff., Protolole 820, Fomperiate 975 .

I $\$ 205$.

Bird bie beftellte Siderheit ogne Beriđulden besీ Beredtigten unzureidentb, to bat ber Bets pflidtete anberweite Siderbeit . $\mathfrak{u}$ leiften.

\section{II $\S 2.4$.}

Mirb bie geleiftete Eiderheit ugne Berfdulben bes Beredtigten unzureident, fo ift fie zu ergănzen ober ift anderweit Eiderbeit $3 \mathrm{u}$ Ieiften.

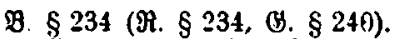
Wird bis gelsiftete Eiderbelt ohne Berjaulber bes Beredtigten unzureichend, fo ift fie zu ergänzen ober anberweitige Eifherheit zu leiften.

Drotive 565 ff. Brototolle 820.

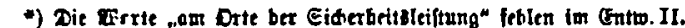

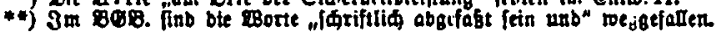

